CIRJE-F-903

\title{
Do Wild Fluctuations in Quarterly Inventory Investment Data Matter?: A Study of Japanese GDP Statistics, 1994-2010
}

\author{
Yoshiro Miwa \\ Osaka Gakuin University and The University of Tokyo
}

September 2013

CIRJE Discussion Papers can be downloaded without charge from:

http://www.cirje.e.u-tokyo.ac.jp/research/03research02dp.html

Discussion Papers are a series of manuscripts in their draft form. They are not intended for circulation or distribution except as indicated by the author. For that reason Discussion Papers may not be reproduced or distributed without the written consent of the author. 


\title{
Do Wild Fluctuations in Quarterly Inventory Investment Data Matter?: A Study of Japanese GDP Statistics, 1994-2010
}

Yoshiro Miwa $^{1}$

\begin{abstract}
For more than half a century, inventory investment has attracted wide attention as a major cause of short-term macroeconomic fluctuations, and the mechanisms involved have been the focus of many major studies. Yet microeconomists and business people familiar with corporate behavior have frequently expressed misgivings about the enterprise.
\end{abstract}

Using Japanese quarterly GDP inventory investment statistics both by commodity and by category, 1994 2010, I investigate the nature of quarterly inventory statistics and the inventory investment behavior, and draw two conclusions. First, statisticians estimate the quarterly statistics under severe time constraints, and their resulting figures incorporate seasonal variations which dominate the quarterly fluctuations. This fluctuation mostly disappears in annual data. Secondly, when I examine the inventory variation after the Lehman Shock in the autumn of 2008, I find neither a notable increase in inventory stock nor a long-run stock adjustment process. Given the size of this unforeseen exogenous shock, most observers expected a large inventory stock accumulation to follow. That the accumulation did not follow suggests that the focus on inventory variation may be misplaced.

For inventory investment data estimation, Japan is an ideal OECD country, with generous statistics availability. The conclusions of this research, drawn from the quarterly GDP inventory statistics, will stimulate the interest both in the study of inventory data in other countries focusing on its estimation process and source statistics,

1 Professor, Faculty of Economics, Osaka Gakuin University, and Professor Emeritus of the University of Tokyo. Email: miwa@e.u-tokyo.ac.jp. I gratefully acknowledge the helpful comments and suggestions of Mototsugu Fukushige, Takashi Kano, Tatsuya Kubokawa, Naoto Kunitomo, Tadashi Morita, Hiroshi Ohashi, Wataru Ohta, Yasuhiro Omori, J. Mark Ramseyer, Kaoru Sano, Sim Seung-Gyu (Andrew), Hajime Wago, Yoshihiro Yajima, and participants of workshops at Osaka University and the University of Tokyo. Also I acknowledge the helpful cooperation in providing detailed information and suggestions from Kengo Moro (Director, National Expenditure Division, Department of National Accounts, Economic and Social Research Institute, Cabinet Office) and Kazuhiko Manaka (Deputy Director, Statistics Planning Office, Research and Statistics Department, Minister's Secretariat, METI). This research was supported by MEXT Kakenhi, Grant-in-Aid for Scientific Research (C) 23530271. 
and in the great variety of inventory investment. At the same time, the conclusions pose a grave implication not only for re-evaluation of the literature in inventory investment variations but also for other research topics in macroeconomics like monetary transmission mechanisms including "financial accelerator" theory. 
[1]. Introduction

Fashions in economic research, as in other discipline, often run in cycles. Such is the case with inventories. Modern interest in inventory behavior was stimulated by Metzler's (1941) demonstration that an inventory-accelerator mechanism can produce cycle in simple Keynesian models. Empirical and theoretical aspects of inventory behavior became hot topics in the 1950s and early 1960s, a period when the U.S. economy's cyclical fluctuations looked much like Metzlerian inventory cycles. (Blinder and Maccini, 1991, p.73)

Symbolically since "Metzler's(1941) illuminating analysis of the inventory accelerator process and Abramovitz's(1950) fundamental empirical analysis of inventory behavior" (Feldstein and Auerbach, 1976, pp.351-2), inventory investment has attracted wide attention of macroeconomists as a major cause of short-term macroeconomic fluctuations, and the mechanisms involved have been the focus of many major studies. Yet microeconomists and business people familiar with corporate behavior have frequently expressed misgivings about the enterprise.

Wen [2005, p.1534] begins: "Understanding inventory fluctuations is a key step towards understanding the business cycle. Blinder and Maccini (1991) show that the drop in inventory investment accounts for $87 \%$ of the drop in total output during the average postwar recession in the U.S." 2 Also Romer [2012] in its latest edition calls attention to wild fluctuations of inventory investment. ${ }^{3}$

Studies of past quarterly data often conclude that too high or too low inventory stock took on average 8 or 12 quarters for adjustment, with which the processes and mechanisms involved have attracted wide attention. Also the financial accelerator theory emphasizes as a monetary transmission mechanism the effectiveness of transmission channel through inventory variations. ${ }^{4}$

Studies of mechanisms in inventory investment fluctuations, primarily using

\footnotetext{
2 Also see his survey article, Wen [2011], in American Economic Journal: Macroeconomics.

${ }^{3}$ Referring to Table 5.2 Behavior of the components of output in recessions (p.191), the only place he focuses on inventory, Romer (2012) writes: "even though inventory investment on average accounts for only a trivial fraction (0.6\%) of GDP, its fluctuations accounts for close to half of the shortfall in growth relative to normal in recessions: inventory accumulation is on average large and positive at peaks, and large and negative at troughs." The average share in GDP was $0.6 \%$, and the average share in fall in GDP in recessions relative to normal growth was $44.8 \%$.

${ }^{4}$ See Bernanke et al [1999]. I will discuss the "financial accelerator" theory in Section [10].
} 
quarterly GDP statistics, have been under severe constraints in data availability. Many inventory studies use another type of data set on manufacturing firms' inventory, which provide no information on inventories non-manufacturing firms hold, for example, distributors' inventory of manufactured products or non-manufacturing firms' raw material stock and goods-in-process inventory. Blinder and Maccini [1991] conclude that the size of the latter is larger than the former. ${ }^{5}$

Of their five basic characteristics of the inventory data, Feldstein and Auerbach [1976, p.356] points, "[T]he first, of particular importance, is that even major changes in inventories represent the outputs and inputs of only very short time periods", raising questions about the dominant view that the adjustment of too much (or too small) inventory stock takes eight or twelve quarters. ${ }^{6}$ Yet, no other paper than mine has asked: "what will happen if the estimation method and process is a major cause of wild inventory fluctuations in quarterly GDP statistics?"

Most studies of inventory investment use the US data. The OECD dataset suggests that the data availability condition seems basically similar everywhere. ${ }^{7}$

As an empirical micro-economist, I have long studied firm behaviors, industries and markets, primarily in Japan, feeling misgivings about the enterprise. Basically, it sharply deviates from what I have observed routinely and confirmed upon microdata about the corporate behaviors in Japan.

It is irrational and implausible to leave for no reason too much or too small inventory stock as it is. When it is too much or too small, the adjustment process will be prompt and complete in a short period. It is irrational and implausible to take a tremendously long time, 8 quarters for instance.

5 In fact, most those studies focus on finished goods inventory of the manufacturing industry. Feldstein and Auerbach [1976], however, using Survey of Current Business, focus on the finished goods, raw material, and work-in-process inventories in durable-goods manufacturing industries. The corresponding value of inventories of materials and goods in process is obtained by subtracting real finished-goods inventories from the value of total durable-goods manufacturing inventories reported in the national income accounts (p.353). Blinder and Maccini [1991, p.76] points, "retail inventories and materials and supplies held by manufacturers are by far the most volatile components of inventory investment." However, the data availability has severely constrained research.

${ }^{6}$ Even in the year of the deepest drop in stocks, "[T] he entire year's fall in the stock of finished-goods inventories was thus equal to less than one day's production! The largest one-year increase in finished-goods inventories was a $\$ 2.0$ billion rise from the end of 1966:2 to the end of 1967:2" (Feldstein and Auerbach, 1976, p.356). Nonetheless, facing with the wild fluctuations in quarterly data available for a long term (and probably because no other reliable and effective data is viable), they shift the focus to the target-adjustment model.

7 Wen [2005] uses the OECD database. 
Some rather see, "individual agents, firms in particular, may behave rationally, aiming prompt response and adjustment. Market mechanism, interaction of individual agents' choices, may not be so prompt and efficient." For some, the long duration of inventory adjustment implies that the adjustment speed of the market is not so prompt and efficient as many microeconomists assume. ${ }^{8}$

\section{The subject and method of the study, and the data}

As shown below, in addition to the data type typically used in countries like the U.S., in Japan a rich variety of other data are available for the inventory cycle studies. ${ }^{9}$ At the center of the sets of data I use in this study is the quarterly GDP inventory investment statistics both by commodity and by category, the original series of the final estimates (kakuho, detailed below in [3]), that I have an opportunity to use.

With a long time series of aggregate quarterly GDP inventory investment estimates, it is hard to draw relevant information about the causes and mechanisms of its wild fluctuations frequently observed. As a consequence, subjects of most studies are: How was the adjustment process for the consequences of variations?; What fluctuation patters and relations with other variables we observe in inventory investment? Symbolically they are: Is inventory investment fluctuation pro-cyclical or counter-cyclical?; Are they realization of single-wavelength or of synthetic form of multiple-wavelengths?

In this research, for studying an inventory stock accumulation and long-run stock adjustment process to follow, I investigate in detail an unforeseen exogenous shock (a surprise change in variables). As an experimental laboratory I choose the Japanese economy after the Lehman Shock in the autumn of 2008. At the beginning of this period, recognizing the serious financial crisis occurred in the U.S. and developed to European countries, most Japanese expected its influence to Japanese financial markets and institutions rather small, and to the Japanese economy not so serious. As shown in [2], however, in terms of the fall in GDP and export, its influence to the

8 The same holds also for many macro-economists who have little interest in short-run macroeconomic fluctuations, recognizing that it is hard to explain it or that economics have achieved little success in it.

9 OECD [2012] reports that, in addition to its availability, the estimation method of quarterly SNA (GDP) inventory investment data differs greatly across countries.

Basically it is because of the content and accuracy of the basic information available like the source statistics and the timing of their availability. At least at the kakuho stage (detailed below in [3]), the accuracy of Japanese inventory investment estimates, upon wide range of rich data, is not lower than many other OECD countries. 
Japanese economy was the severest of major developed countries. The speed and the range of fall was the severest of the depressions in Japan since the 1970s, not only than the ones in "the Financial Crisis" since 1997 and at the beginning of the 1991s after the "Bubble Burst" but also the one after the Oil Shock in 1974. Some might expect it serious, but for most economic agents in Japan such a rapid and huge fall in demand and shipment including export was an unforeseen exogenous shock (or "innovations").

Given the size of this unforeseen exogenous shock, most observers expected as "an impulse response" a large inventory stock accumulation to follow and a long-run stock adjustment process, providing solid information for studying the reality of stock accumulation and the speed and duration of adjustment process. I find, however, neither a notable increase in inventory stock nor a long-run stock adjustment process, both in aggregate and in most individual industries (to be precise, individual commodities as detailed in [3]). The same applies also to the study of the period during the "Financial Crisis" after the end of 1997.

That the accumulation did not follow suggests that the focus on inventory may be misplaced. It is consistent both with the misgivings microeconomists and business people familiar with corporate behavior have frequently expressed and observations in relevant micro data.

For inventory investment data estimation, Japan is an ideal OECD country, with generous source statistics availability. The conclusion of this research, drawn from the quarterly GDP inventory statistics, will stimulate the interest both in the study of inventory data in other countries focusing on its estimation process and basic statistics, and in the in the great variety of inventory investment. If noises, tics, or errors incorporated and mixed in through the estimation process is a major source of variations in quarterly statistics and its deviation from the reality, the long-lasting wide attention to wild fluctuations of quarterly inventory investment statistics as a major cause of short-term macroeconomic fluctuations may be adequately expressed as much ado about nothing.

\section{The two subjects of the study}

Inventory investment is the aggregate of variations in inventory stock mostly held by individual firms. Basic information for the inventory investment statistics comes from individual firm's accounting information. Firms collect information and fix figures, following both the Accounting Standards and their own rules determined taking management policies and accounting customs into consideration. Upon request, each firm, taking various factors including the timing of reports into consideration, selects 
and reports figures to statistics offices. Aggregating those figures statistics offices estimate the source statistics including inventory investment statistics, upon which quarterly GDP inventory investment statistics are estimated. Therefore, compared to other items like production, sales, and equipment investment, inventory investment statistics is more vulnerable to mixing in noises, tics, and errors. Wild fluctuations in quarterly GDP inventory investment data may not primarily reflect the violent variations of investigation object.

Many observers share a basic view that inventory investment fluctuates wildly, that forms a common basis of inventory investment behavior studies. The conclusion of the first study subject raises a grave doubt on the validity of this basic view. Long-term time series aggregate quarterly GDP statistics widely used in inventory investment studies do not easily allow investigation of specified causes and mechanisms of fluctuations. As the second study subject, focusing on the period after Lehman Shock in the fall of 2008, I investigate the consequences of a large unforeseen exogenous shock, in which most observers expected to find notable increase in inventory stock and long-run stock adjustment process. The focus of the study is the size and content of stock accumulation, and the pattern and depth of the adjustment process and its length of time.

The first subject of the study

In addition to a huge variety of rich public data, I have the opportunity to use detailed inventory investment data by commodity ( 91 commodities) and by category ( 4 categories) that are estimated on the process for quarterly GDP QE (quick estimate, on the kakuho ${ }^{10}$ stage) statistics. ${ }^{11}$ Together with detailed public information on the estimation process of quarterly data, I draw the following five conclusions from the study of quarterly GDP inventory investment statistics.

(1) Quarterly GDP inventory investment statistics shows sharp and stable regular seasonal fluctuations (hereafter, I call it M-shaped).

(2) Its investigation by category reveals more or less in inventory investment of every category regular seasonal fluctuations, of which those of goods-in-process inventory is the sharpest and most remarkably regular. The dominant portion of

10 On the sokuho and kakuho stages of quick estimates, we see in [3].

11 It is based on the international standard recommended by the UN in 1993 (93SNA). For the details, see Cabinet Office (CAO), Economic and Social Research Institute (ESRI), Department of National Accounts ed, "Transition to 93SNA in Japan" and "Technical Manuals for 93SNA Estimation" (both in Japanese) (http://www.esri.cao.go.jp/jp/sna/menu.html). 
regular seasonal fluctuations in total inventory investment is doe to those of goods-in-process inventory investment.

(3) Annual inventory investment statistics, the sum of four quarterly estimates (or their annual average), shows a dramatic decrease in the size of fluctuations.

(4) Because of sharp regular seasonal fluctuations, I classify quarterly data into four groups, from the first quarter $\left(\mathrm{q}_{1}\right)$ to the fourth quarter $\left(\mathrm{q}_{4}\right)$, and examine the fluctuations respectively. The standard deviation of inventory investment in each group is dramatically smaller everywhere than that of quarterly inventory investment throughout the period. Moreover, this standard deviation in each group is still all larger than that of the annual average.

(5) Annual statistics shows the biggest factor of total inventory investment fluctuations is the distribution inventory, where those of goods-in process become a figure in the background.

SNA (System of National Accounts) estimates, demanded "accuracy" in describing the national economy, is published annually. At the time of SNA annual estimates publication, quarterly SNA QE estimates (called sokuho, or preliminary) are revised (kakuho, or final). Census of Manufactures (kogyo tokei chosa), an annual census survey, is the most basic to the SNA in Japan, with which SNA statistics are estimated annually, and quarterly GDP inventory investment statistics are finalized. As detailed in [3], however, "adjustment" conducted on the finalizing process is just to allocate evenly to each quarterly preliminary estimate a quarter of the difference between the annual estimate and the aggregate of four quarterly preliminary estimates. As a result, regular seasonal fluctuations observed in preliminary estimates of quarterly GDP inventory investment statistics, which reflect noises, tics, and errors in estimation, remain as it is after the finalization. Conclusions from (1) to (5), together with the above story, I draw a speculation that wild fluctuations in quarterly GDP inventory investment statistics rise out of the estimation process of quarterly data.

From the study of the first subject, I draw the following conclusion. Aside from the SNA annual estimates for accurate description of the national economy, quarterly SNA (GDP) statistics are published in response to strong demand for quickness as a basis of characterizing the state of the economy. Wild fluctuations in quarterly inventory investment are observed in the quarterly estimates, and in the SNA annual estimates the inventory investment variations dramatically decrease. Studies of inventory investment variations and their mechanisms, including the studies mentioned above, with little necessity of quickness, should make the shift from the 
quarterly GDP inventory investment data to annual SNA data, also using other micro data such as IIP (Indices of Industrial Production) and Hojin kigyo tokei (Corporate Enterprise Statistics, quarterly and annual). In using quarterly GDP inventory investment statistics, we should be more careful about the regular seasonal fluctuations.

\section{The second subject of the study}

As the second subject of this study, I investigate the too much or too small inventory stock accumulation as an impulse response to a surprise change in variables and stock adjustment process that follows. Focusing on the period after Lehman Shock in the fall of 2008, I examine the impulse response in the Japanese economy to a large unforeseen exogenous shock, dramatic fall in demand and shipment. The conclusion is clear and succinct, summarized below in five points. It raises grave doubts to the basic picture and mechanisms of inventory stock accumulation and its long-run adjustment process that many researches focusing on the wild fluctuations in inventory investment assume implicitly.

(1) At the manufacturers stage, in many industries monthly data show that a dramatic fall in shipment paralleled a fall in production of an almost equal size and speed. Dramatic shipment fall observed many industries ended in a short period, and shipment made a sharp recovery that paralleled production recovery of almost an equal size and speed. During this time, the manufacturers' stock level remained almost unchanged.

(2) Examination of quarterly GDP inventory investment statistics by commodity, either by individual quarters independently or by accumulation over sequence of quarters, reveal that in or around the $4^{\text {th }}$ quarter of 2008 rarely I find large inventory stock accumulation. In the $1^{\text {st }}$ quarter of 2009 I find almost everywhere a dramatic fall in inventory investment (a huge negative investment) and huge accumulation of negative inventory investment since then.

(3) Above two points of observations, (1) and (2), apply not only to total inventory investment but also to each of four inventory category, product-, goods-in-process-, raw material-, and distribution inventory. With few exceptions this applies also to inventory investment by commodity.

(4) For comparison I also studied the Financial Crisis period of Japan, from the end of 1997 to the beginning of 1999, and draw the similar conclusion.

(5) In the first subject of the study, as a part of M-shaped regular seasonal fluctuations, I point that inventory investment is the largest in the $4^{\text {th }}$ quarter 
and the smallest in the $1^{\text {st }}$ quarter. Because of this, both the increase in inventory stock accumulation in the $4^{\text {th }}$ quarter of 2008 and its fall in the $1^{\text {st }}$ quarter of 2009 pointed in four conclusions above tend to be exaggerated.

The conclusion of the second subject of the study, focusing on the situation of Japanese economy, raises a grave doubt to the validity of the view of large unforeseen exogenous shock as a major cause of observed wild fluctuations in quarterly GDP inventory investment data.

The view that a large unforeseen exogenous shock causes wild inventory variations that accompany a long-run adjustment process has activated the study of inventory investment fluctuations, attracting the interest of macroeconomists. This conventional wisdom often leads to a claim that this slow stock adjustment process badly needs active government intervention into the market for macroeconomic stability. This conclusion raises grave doubts to the basic picture and mechanisms of inventory stock accumulation and its long-run adjustment process. ${ }^{12}$

Some argue that, although individual agents, firms in particular, may behave rationally and try prompt response and adjustment, the market, as interactions of individual agents, does not necessarily work promptly and efficiently. My conclusion raises grave doubts also to this view.

For inventory investment data estimation, Japan is an ideal OECD country, with generous statistics availability. The conclusion of this research, drawn from the quarterly GDP inventory statistics, will stimulate the interest both in the study of inventory data in other countries focusing on its estimation process and basic statistics, and in the great variety of inventory investment (see below section [10]). Few careful readers feel a sense of relief, saying, "So we use seasonally adjusted figures."13

The conclusions of this research, drawn from quarterly GDP inventory

12 "[S]ince the publication of Metzler's theoretical study of the inventory cycle", the size of sales-forecasts error has been a big concern of economists. Upon an estimate that the average absolute error of $\$ 2.01$ billion per quarter is equal to about one day's production, Feldstein and Auerbach [1976, p.363] concludes, "Forecast errors should not be a source of any substantial undesired quarterly changes in inventories". My conclusion is consistent with this view, and mutually complementary.

13 See Kunitomo [2006]. Referring to X-12-ARIMA, Kunotomo comments: "Most economists using seasonally adjusted figures in their empirical studies rarely understand how those statistics are seasonally adjusted. Yet, both in the US and Japan persons in the government statistical offices provide and use fairly complicated seasonal adjustment methods for their practical needs of estimation and publication of public time-series statistics, but often they lack professional expertise in statistical time-series analysis like those summarized in RegARIMA Model” (p.464). 
investment statistics which are commodity-based, are consistent with those drawn from other groups of statistics including hojin kigyo tokei (Corporate Enterprise Statistics) which are firm and industry based.

\section{$\underline{\text { Roadmap }}$}

I investigate the first subject of study in Sections [4] [6], and the second subject in Sections [7] [9]. Sections [2] and [3] prepare the study of those two subjects. For an aperitif for readers, Section [2] first shows that the situation of the Japanese economy after Lehman Shock was unforeseen, and with monthly IIP (Indices of Industrial Production) illustrates that shipment and production moved almost perfectly in parallel, inventory remaining unchanged. Section [3] briefly introduces the estimation methods and their source statistics of inventory investment estimates both of quarterly GDP quick estimates (QE, sokuho) and of annual SNA estimates, together with their mutual relations, the place of kakuho (final report) of quarterly QE published at the same time with annual SNA figures, and relations between sokuho and kakuho quarterly QE with method of their "coordination".

Section [4] examines the quarterly GDP inventory investment statistics, focusing on its variation patterns and their generation sources. Section [5] further studies the variation patterns and their generation sources found in [4]. In Section [6] I first focus on a likely candidate of the generation source of wild but regular seasonal fluctuations in quarterly inventory investment estimates, and then with the inventory data from the Corporation Enterprise Quarterly Statistics (CEQS) I confirm that the regular seasonal fluctuations at the center of attention do not arise on the process of converting firm-and-industry based inventory data into commodity based SNA (GDP) inventory data.

In Section [7] I investigate the corporate inventory investment by commodity around the period of Lehman Shock. Our data provides information not only by category but also by commodity. In Sections [7] and [8], using the information by commodity I study the inventory investment in eight major selected commodities. Section [7] still treats inventory investment in each quarter basically as an independent observation or decision making. Instead, viewing inventory investment to be a continuous adjustment process, Section [8] focuses on its accumulation process. Entitling 'Inventory

Adjustment Process as a Consequence of Exogenous Shock and its Adjustment: Summary and Supplement', Section [9] first summarizes [7] and [8], then like in [6] shows that the same conclusions are drawn with CEQS data, and finally presents data that suggest in detail prompt manufacturers' responses to a large unforeseen exogenous 
shock.

Section [10] discusses the implications of the conclusions of this research based on the Japanese quarterly GDP inventory investment statistics. Judging from the estimation methods and basic information involved, Japan is an ideal OECD country for quarterly inventory statistics estimation. Those conclusions about Japan suggest the similar observations to be found in other countries and will stimulate the interest both in the study of inventory data in other countries focusing on its estimation process and source statistics, and in the great variety of inventory investment. At the same time, the reality of inventory investment statistics and the conclusion that variation patterns of actual inventory investment significantly deviates from what the conventional wisdom has supposed strongly suggests the need to evaluate the basic assumptions of research and policy discussions on many fronts. Section [11] concludes briefly. Section [12] is an Appendix entitled 'Inventory Investment Decision-making Process, Inventory Investment Function, and Data Availability Constraint'.

[2]. Aperitif : The Japanese Economy around the Period of Lehman Shock

In this research, for studying an inventory stock accumulation and long-term stock adjustment process as a consequence of specific cause, I focus on the Japanese economy after Lehman Shock in the fall of 2008.

This financial instability of the US origin rapidly spread from the US to other countries, European countries in particular. Partly because of the Japanese financial institutions" small investment balance on the much-talked-about realty-related investment securities, at first most Japanese anticipated not to be affected so seriously. However, with dramatic decrease in demand, particularly export, dramatic fall in shipment, production, and GDP became reality, which was unforeseen for most Japanese, a surprise change in variables. As the second subject of the study, I investigate in Sections [7] [9] the large inventory stock accumulation and long-run stock adjustment process observers expected to find as a consequence of this exogenous shock.

In Section [2], I first show why and how the Japanese economy after Lehman Shock was in the unforeseen situation caused by a large exogenous shock. Next, referring to monthly indices on shipment, production, and inventory reflecting the accumulation of the gap between shipment and production, I show that shipment and production moved almost perfectly in parallel, and despite their dramatic movement the 
inventory remained almost unchanged. ${ }^{14}$

The Japanese Economy after Lehman Shock: Unforeseen Situation

I begin with figures of dramatic changes in the Japanese economy caused by an unforeseen situation. The first one is contributions to Japan's real GDP growth by type of demand (seasonally-adjusted quarter-to-quarter basis, \%), from White Paper on International Economy and Trade 2009 (Figure 1-1-2-13). After the collapse of Lehman Brothers Co. in September 2008, Japan's GDP fell dramatically, -3.6\% in the $4^{\text {th }}$ Quarter of 2008 (hereafter, 2008Q4) and further $-3.8 \%$ in the $1^{\text {st }}$ Quarter of 2009. The dominant factor of drastic decline in 2008Q4 is external demand (this time, export).

\section{Contributions to Japan's real GDP growth by type of demand}

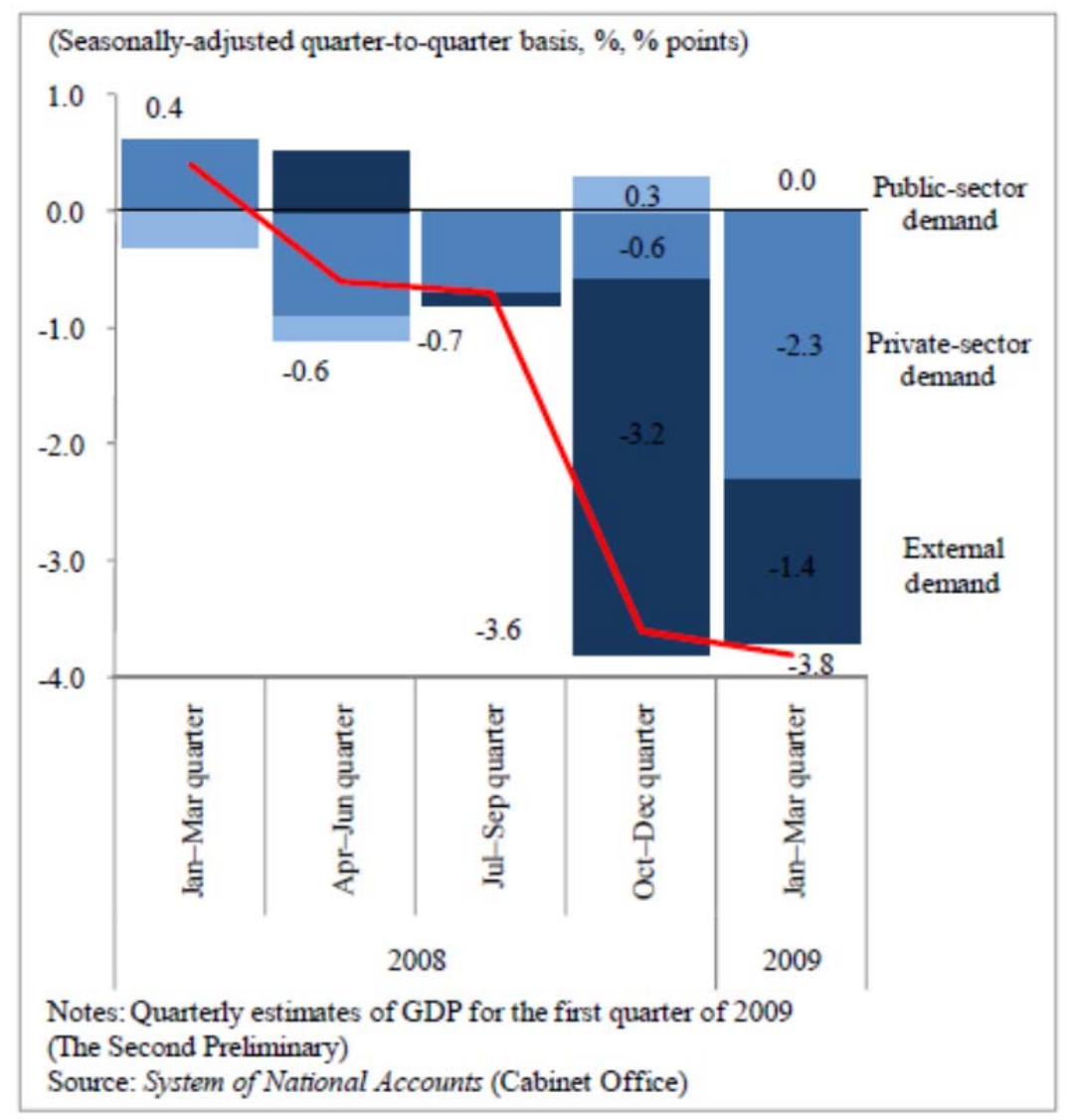

The production (also GDP) decline was record-quick speed and "deep", among

${ }^{14}$ For the Japanese economy of the time, see Annual Report of the Japanese Economy and Public Finance (CAO), and White Paper on International Economy and Trade (METI), each year, particularly 2009. 
the recessions after the 1970s including the one after the Oil Shock as shown in the next figure (from Annual Report of the Japanese Economy and Public Finance 2009).

Comparison with Recession Phase of Production (Figure 1-1-4(2))

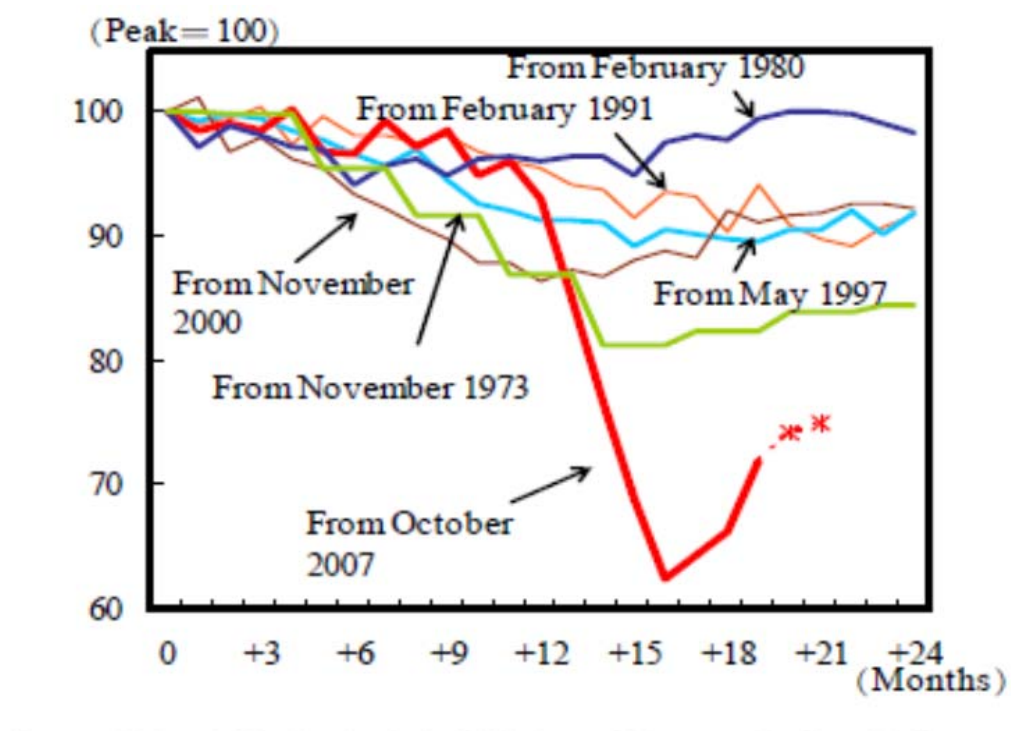

Source: "Industrial Production Index", Ministry of Economy, Trade and Industry

The figure shows the level of monthly indices of industrial production in each recession. The recession of this time started in October 2007 (=100), and began drastically declining in October $2008(+12)$. In February $2009(+16)$ it fell to the level lower than 2/3 of 100. During the recession after the Oil Shock, the level even at the bottom was higher than 80 .

The GDP decline in Japan was the severest among the major developed countries (Baldwin ed., 2009, Figure 7, p.5).

The current recession, OECD nations and G3, 2007Q1 - 2009Q2 


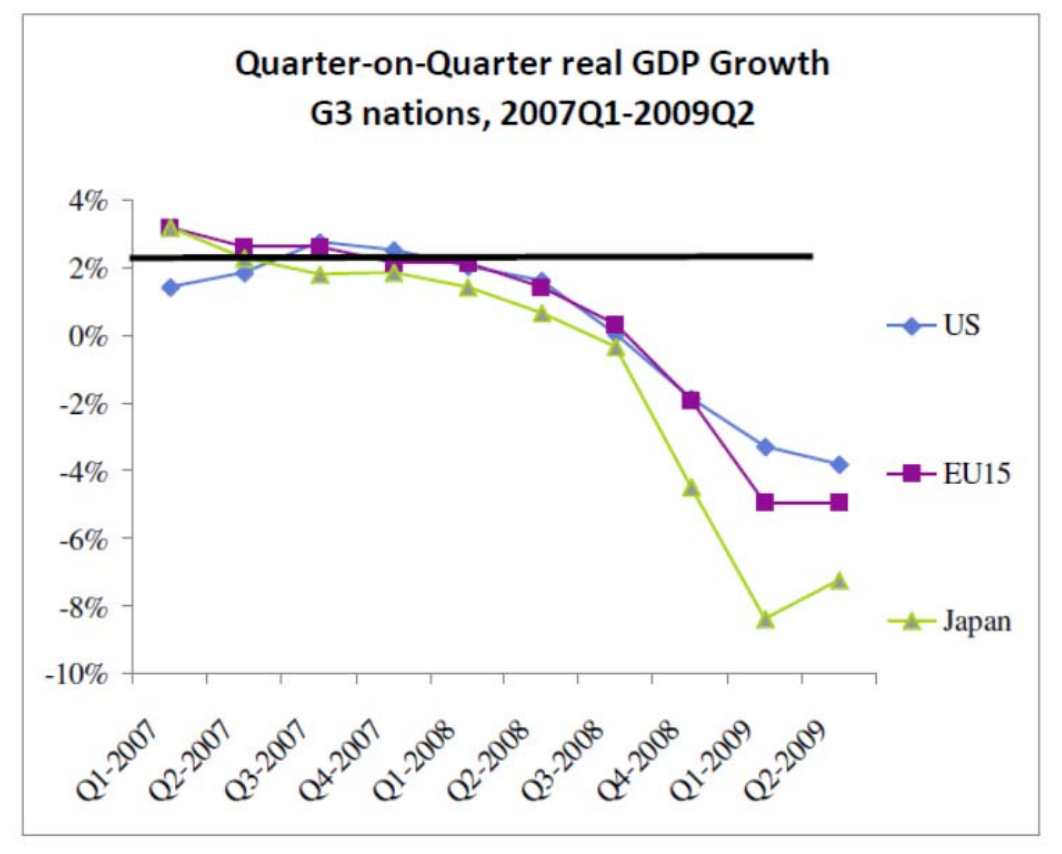

\section{Note: G3 is US, EU and Japan. Source: OECD online data base.}

\section{Indices of Industrial Production and others}

The recession began as an impulse response to a large exogenous shock to be called an unforeseen situation. Observers anticipate and expect to find phenomena as follows: Sudden and dramatic decline in shipment, particularly export, comes first, and production decrease starts a little late; At least temporarily inventory stock, both in total and in each of four inventory categories of distribution, product, goods-in-process, and raw material, accumulates as a remarkable rate, and a long and deep stock adjustment process follows. If I find neither notable increase in inventory stock nor long-run stock adjustment process even in such an extreme situation of serious decline in GDP and production generated by a large unforeseen shock of this time, where else wild fluctuations of inventory investment will occur, they would ask?

Preparatory to studies below, using IIP (Indices of Industrial Production) most frequently used in those studies in Japan, ${ }^{15}$ I show that observations almost completely

15 As in Annual Report of the Japanese Economy and Public Finance and White Paper on International Economy and Trade, it is standard in Japan to focus on IIP for studying the state of industrial production. Including METI's Analysis of All Industrial Activities, it is customary to show and emphasize the inventory ratio (=inventory/shipment) as in the next figure. As shown in the figure on the Lehman 
violate those anticipations and expectations. ${ }^{16}$ For more details see the Analysis of All Industrial Activities (quarterly and annual) by METI (Research and Statistics Department, Economic and Industrial Policy Bureau, Ministry of Economy, Trade and Industry).

First, the figure shows the industrial production, shipment, inventory, and inventory ratio (=inventory/shipment): quarterly, 2005 2011, 2005=100, and seasonally adjusted. The next table shows the relevant indices for 2008 and 2009. Both are adapted from the Review of the Year 2009, Analysis of All industrial Activities, p.3.

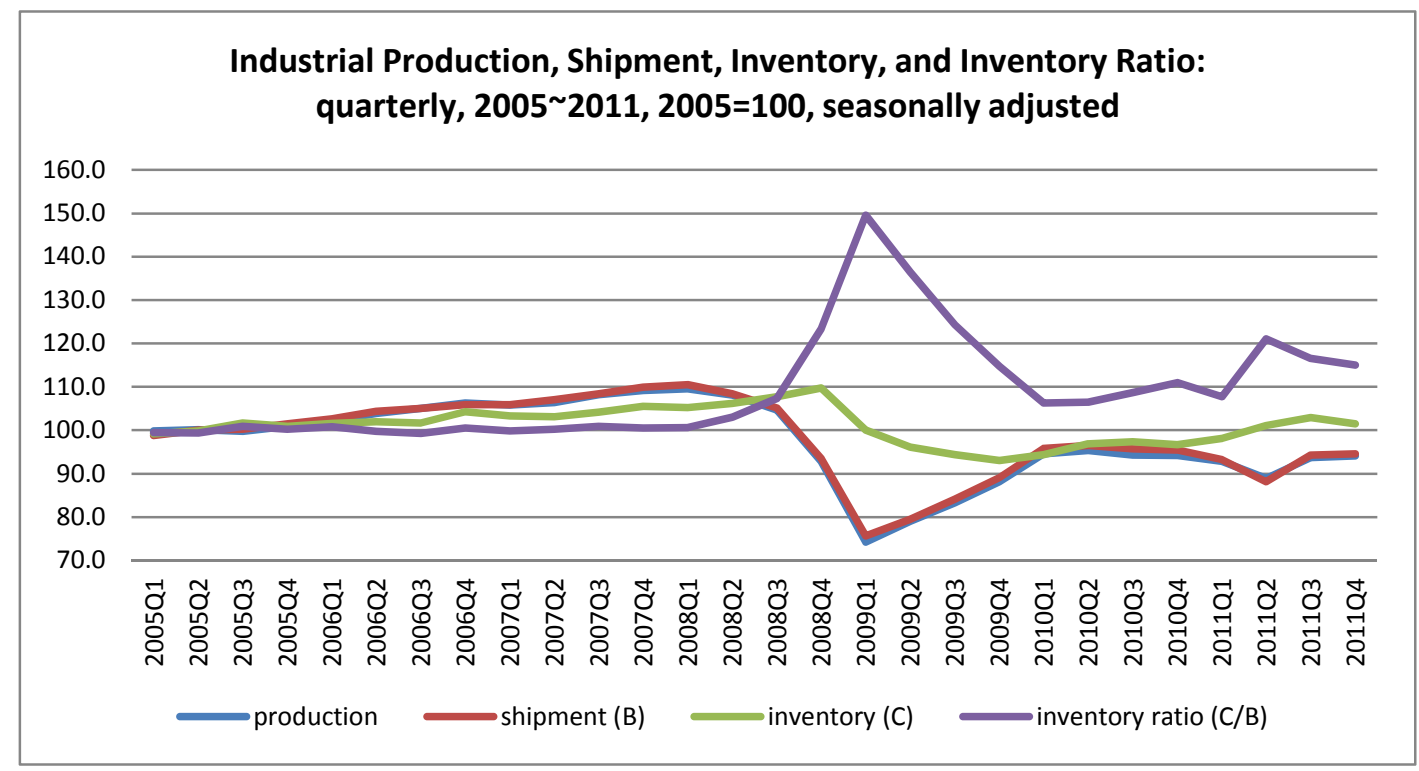

Industrial Indices: quarterly, $2008^{\sim} 2009,2005=100$, seasonally adjusted

\begin{tabular}{|c|c|c|c|c|c|c|c|c|}
\hline & $\begin{array}{l}2008 \\
\text { Q1 }\end{array}$ & Q2 & Q3 & Q4 & $\begin{array}{l}2009 \\
\text { Q1 }\end{array}$ & Q2 & Q3 & Q4 \\
\hline Production & 109.5 & 108.1 & 104.6 & 92.8 & 72.3 & 78.3 & 84.1 & 87.9 \\
\hline Shipment & 110.5 & 108.4 & 105.1 & 93.5 & 73.9 & 78.6 & 85.2 & 89.6 \\
\hline domectic & 106.8 & 104.6 & 101.8 & 92.8 & 74.1 & 77.9 & 84.3 & 87.8 \\
\hline export & 126.4 & 122.6 & 117.8 & 98.5 & 72.8 & 80.4 & 88.5 & 99.9 \\
\hline Inventory & 105.2 & 106.2 & 107.7 & 109.7 & 99.8 & 95.3 & 94.7 & 93.6 \\
\hline Inventory Ratio & 100.6 & 103.0 & 107.3 & 123.5 & 153.0 & 138.3 & 121.2 & 112.7 \\
\hline Capacity Utilization Ratio & 105.6 & 104.0 & 100.4 & 87.1 & 63.4 & 71.4 & 78.8 & 82.6 \\
\hline
\end{tabular}

adapted from Analysis of Industrial Activities, Year Book 2009, METI

Note two points. First, production moves in perfect harmony with shipment during the period. Following a gradual decline from the $1^{\text {st }}$ quarter to the $3^{\text {rd }}$ quarter of 2008 , both dramatically fell both in the $4^{\text {th }}$ quarter of 2008 and the $1^{\text {st }}$ quarter of 2009 , and then from the $2^{\text {nd }}$ quarter of 2009 and after they rapidly increased. As shown soon, this holds true also in monthly data.

Shock, however, although inventory remains stationary, the ratio moves wildly primarily because of wild variation in shipment. This ratio backs up and amplifies the conventional wisdom. So I show the inventory ratio only in the first figure.

16 In [10-2] I discuss briefly the process of firm's prompt response and adjustment. 
Second, during the period the inventory index remains almost unchanged. At the end of 2008Q4 when production and shipment fell dramatically it was 109.7, +1.9 compared with the previous quarter and +4.8 in year-over-year basis, and at the end of 2009Q1 it was 99.8, -91 compared with the previous quarter and -5,2 in year-over-year basis.

Using monthly IIP, let's see in more detail. I begin with a figure on the whole industrial sector, and then three commodity sectors to make the image more specific. ${ }^{17}$

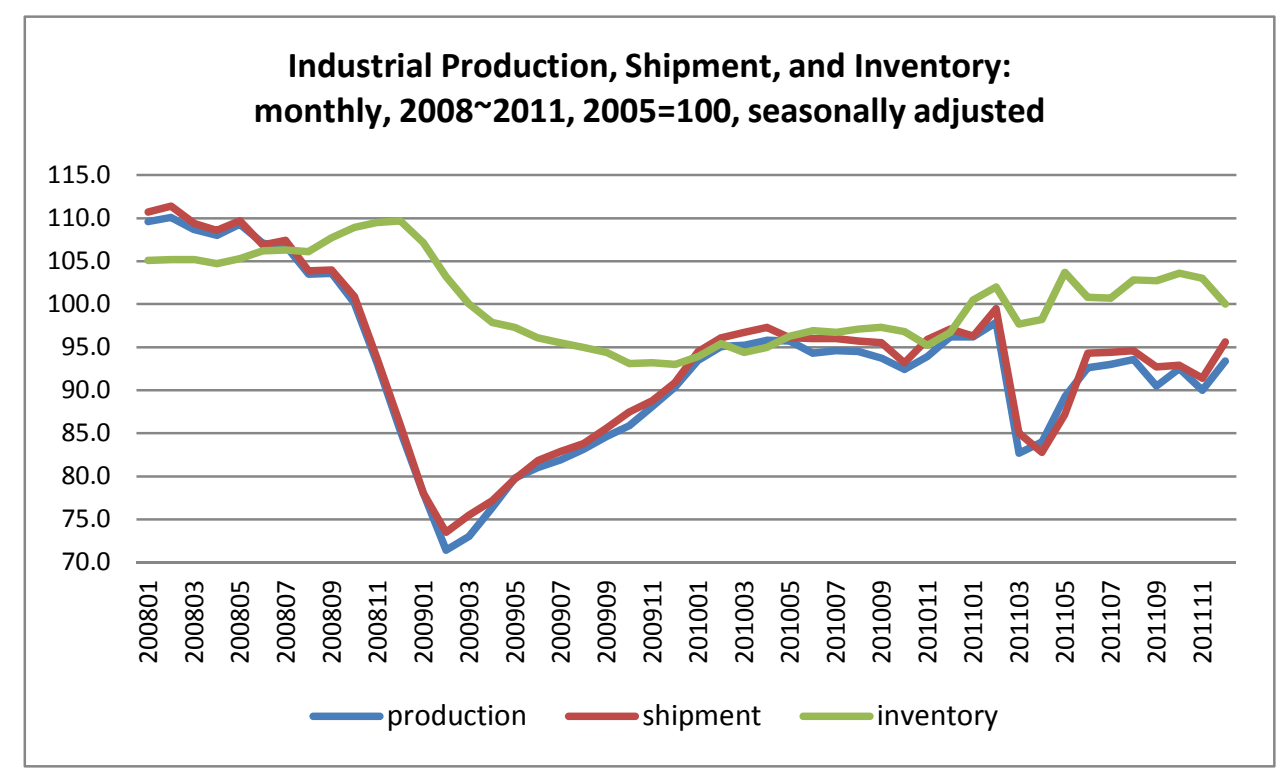

IIP is based on the Current Survey of Production (Seisan dotai tokei, monthly) of METI. Therefore, for example, steel products inventory is steel manufacturer's product inventory. It includes neither manufacturer's material inventory like iron-ore and coal nor their goods-in-process. It does not include distribution stock distributors possess or steel product stock construction companies hold as construction material, either. ${ }^{18}$

I show in turn the figures on steel products, general machinery, and passenger

17 Reader interested in other commodity sectors should see Analysis of Industrial Activities, quarterly, by METI. Like the SNA (GDP) statistics I mainly use in what follows, IIP and Current Survey of Production on which IIP depends, and therefore those estimates are all commodity-based. In contrast, Corporate Enterprise Statistics, quarterly and annual, is firm and industry based. I will discuss the details and its importance of this difference in Section [3].

18 Surveyed "commodity" is not necessarily the same in production survey and shipment survey. As a result, even when production index moves in perfect harmony with shipment index, the inventory index could move remarkably. It may be important to note that in some commodities survey item is the value rather than quantity. Also readers should note that indices define the base year level as 100 and similar movements in indices do not imply their similar movements in size. 
cars. In all three cases, monthly data show that the production index moves in perfect harmony with the shipment index. Except for passenger cars, the inventory index remains almost unchanged. ${ }^{19}$ The conclusions hold true during the period after the Great East Japan Earthquake in March 2011.
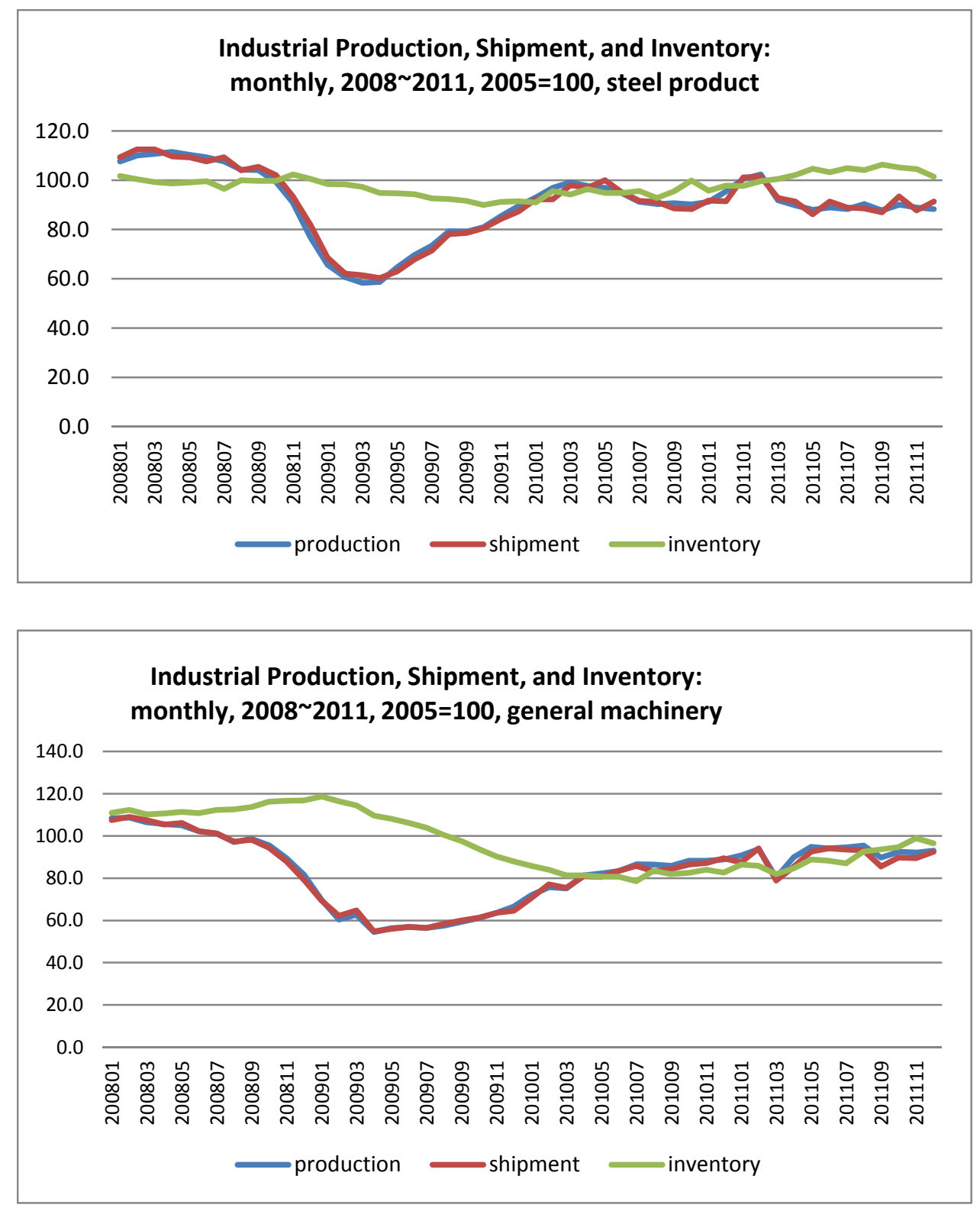

19 Assuming comments that distribution stock must have accumulated, Analysis of All Industrial Activities (the Review of the Year 2009) concludes with evidence that it did not occur. As I show below, my conclusion upon quarterly SNA statistics is consistent with this one. 


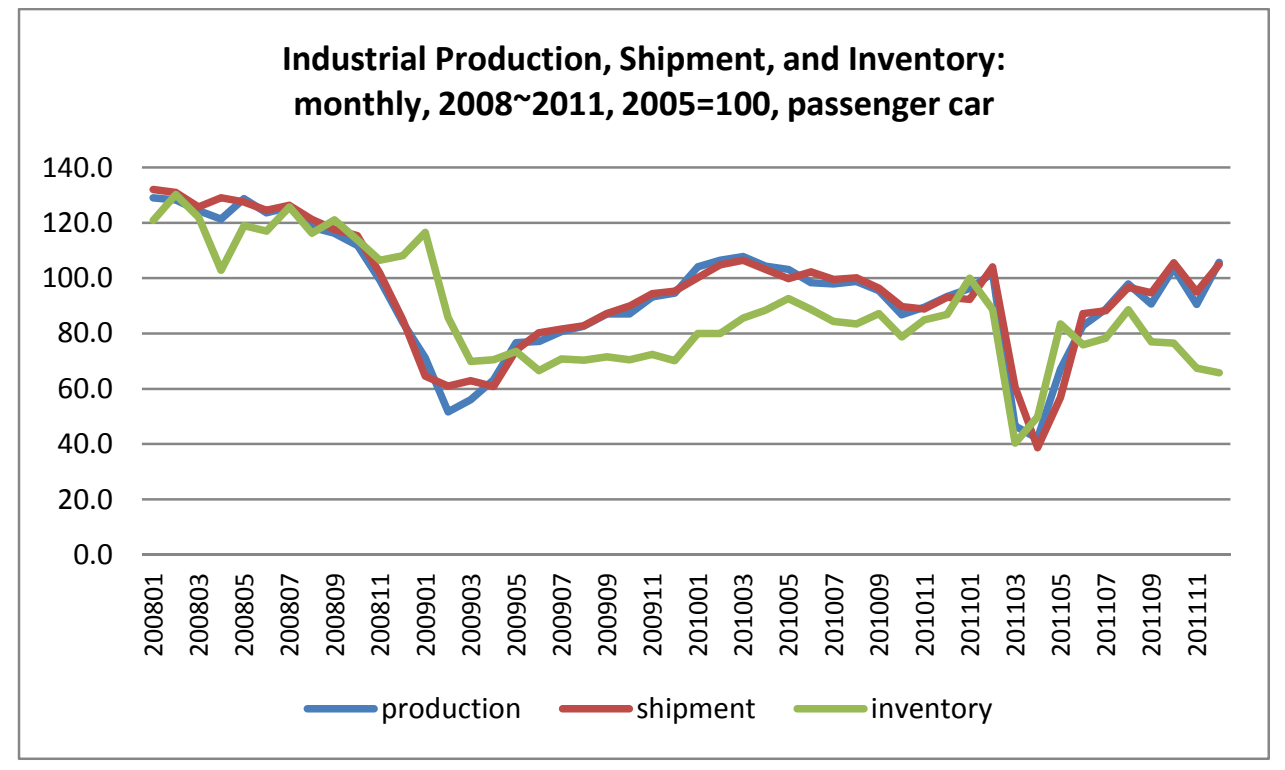

\section{Export vs. Domestic Shipment}

The quarterly SNA (GDP) statistics I primarily use in this research estimates inventory investment as changes in value of domestic inventory stock. Upon a very strong picture that the primary cause of the drastic GDP decline in Japan since 2008Q4 after the Lehman Shock is a dramatic decline in export demand, ${ }^{20}$ readers may be concerned or dissatisfied about the choice of this estimates confined to domestic inventory.

Yet, as shown below, comparison of export vs. domestic shipment in industrial products, this choice of estimates confined to domestic inventory does not greatly influence the discussion and conclusions.

The breakdown list of industrial shipment (of the base year 2005, METI) tells that, of the total industrial shipment $(=10,000), 1917.3$ is for export and 8082.7 for domestic market. In Steel product (weight, 547.4), 95.9 for export and 451.6 for domestic, in general machinery (1159.9), 286.2 and 837.7, and in transportation machinery including automobiles (2014.7), 530.9 and 1483.8. Thus, even in those three relatively export-oriented sectors, export ratio does not notably exceed the $25 \%$ level.

20 As the IIP figures shown above illustrate, decrease in shipment, both for export and domestic markets, had begun before the Lehman Shock. Drastic shipment decline in 2008Q4 and 2009Q1 began slightly earlier in export than in domestic market, and also its size a bit bigger in the former. Nonetheless, fall in domestic shipment was also dramatic during this period. The same applies also to the rapid recovery of shipment since the 2009Q2. The view is unpersuasive that dramatic decline in export shipment, by way of decrease in national income, is the primary cause of the drastic fall in domestic shipment. 
I present the figure on export vs. domestic shipment first on the whole industrial sector, and then three sectors, steel products, general machinery, and transportation machinery. All those figure show that export shipment reveals little notably peculiar movement, and that its recovery began earlier and the speed faster than the domestic shipment.
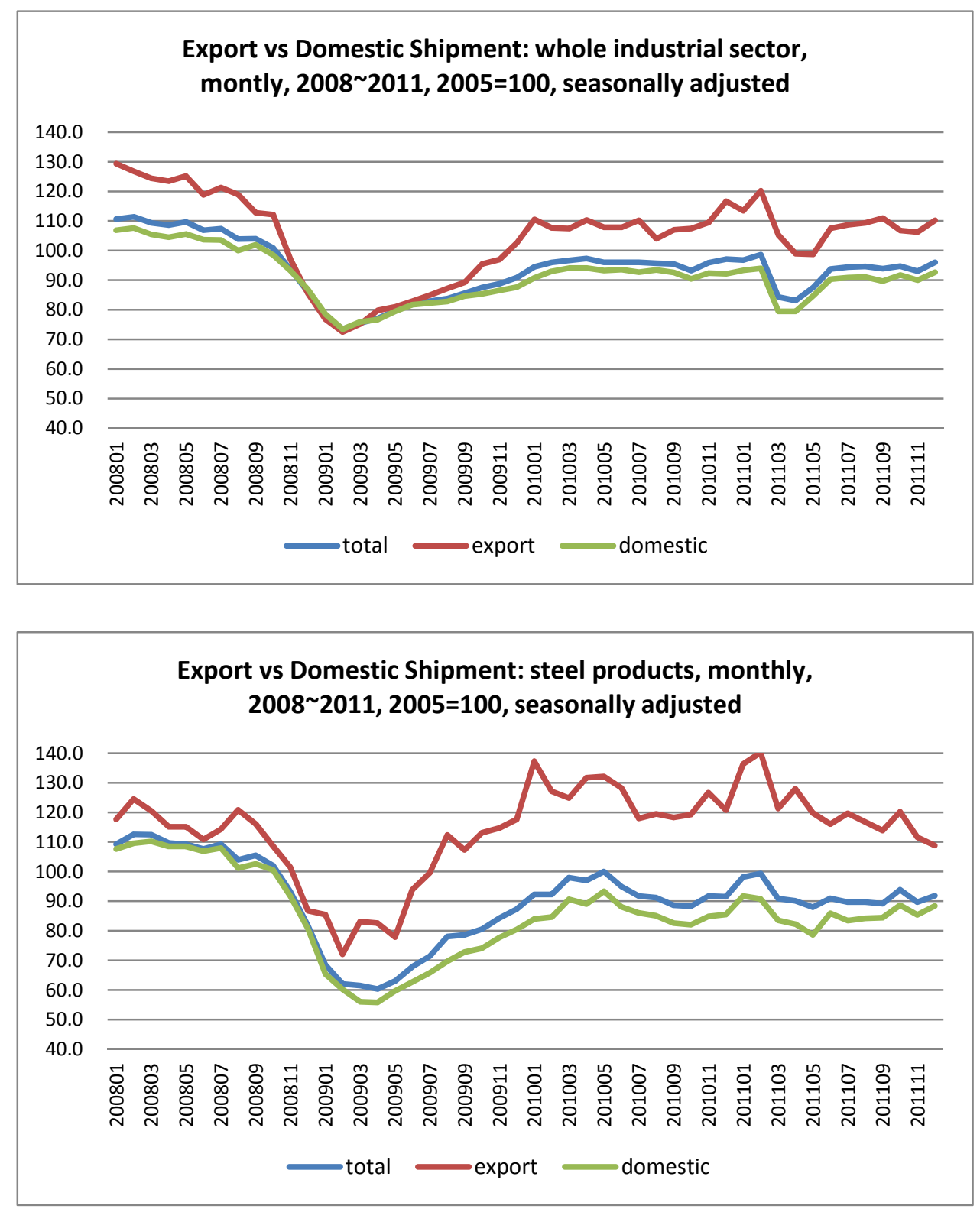

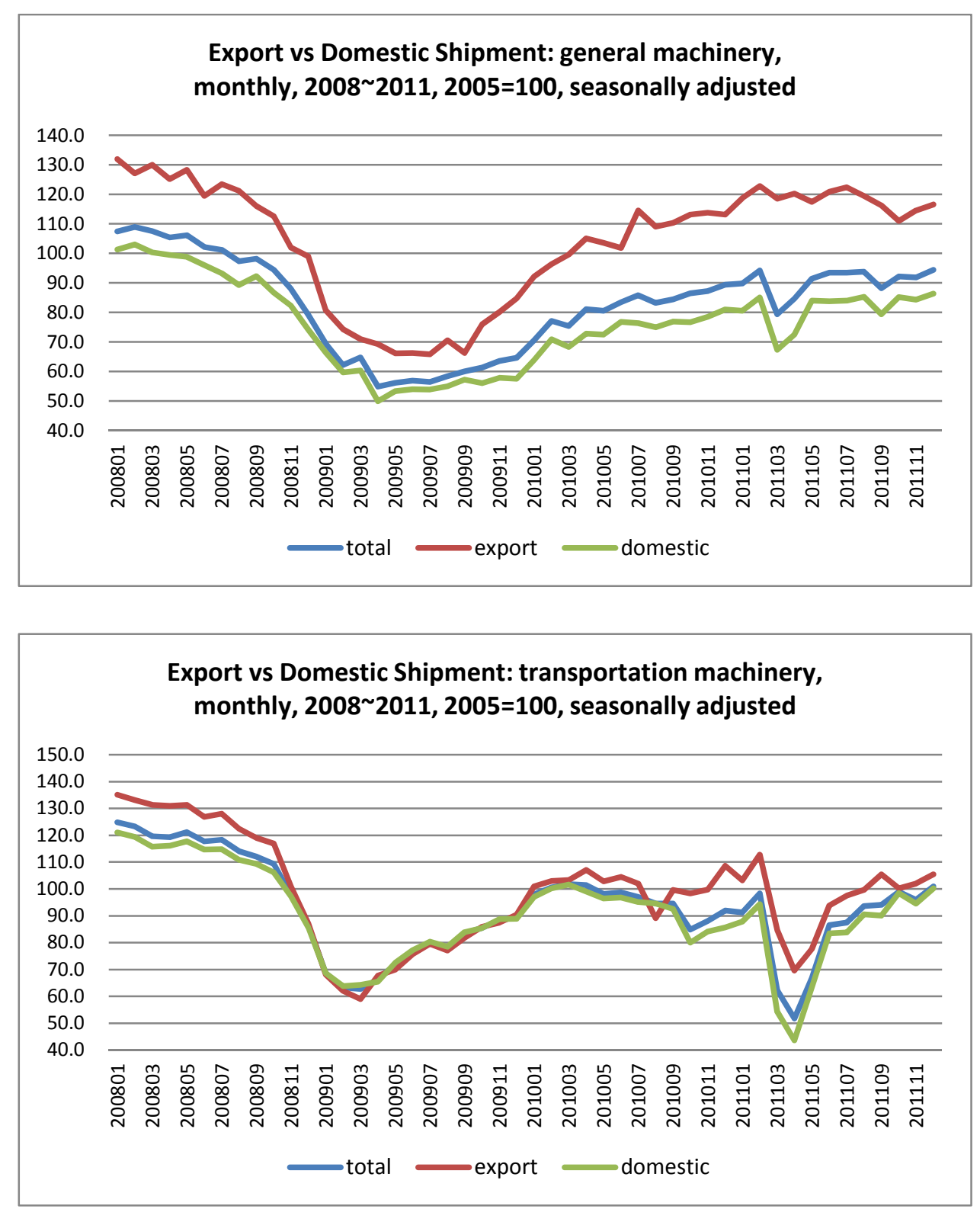

[3]. Inventory Investment Estimates in Quarterly GDP Statistics: estimation process and source statistics

In Japan, SNA (System of National Accounts) statistics is estimated for systematically reporting in an internationally comparable form the whole picture of the Japanese economy. Upon the international standards recommended by the UN, as a backbone statistics of the Statistics Act it is worked out following the SNA estimation manuals and methods.

SNA statistics is estimated as indices to see multidimensionally and 
comprehensively the activities of national economy, that is requested not only accuracy in the description of the economy but also promptness for understanding the economic outlook. In this perspective, in order to make reports on the SNA, particularly its expenditure series such as GDP (expenditure side) which is the aggregate of value added generated by domestic economic activities and private final consumption, as soon as possible, quarterly SNA statistics is estimated using source statistics available earlier and revise it step by step in response to the availability of more accurate and reliable statistics, improving the accuracy of statistics (CAO, "System of SNA Estimation").

SNA consists of Quarterly GDP Preliminary (sokuho) and SNA Final (kakuho). The former, emphasizing promptness, publishes quarterly estimates of expenditure side series including GDP eight times a year, twice for each quarter. The latter publishes one a year estimates both on flow side including production, distribution, expenditure, and capital accumulation and on stock side including assets and liabilities (CAO's Home Page).

Annual estimates is published at later than the end of the next year of the reference year as the Final, and the Second Final (kakukakuho) at the end of the following year when the Final of the next reference year is published. Those two Finals are different in source statistics available. For example, the source statistics for estimating shipments in the manufacturing sectors is for the Second Final the Census of Manufacturers: Report by Commodity (METI), but at the stage of the Final it is not available yet and instead the Census of Manufacturers: Report by Industry is used. ${ }^{21}$

As quarterly GDP statistics including inventory investment estimates that I use in this research, two Preliminaries and two Finals are published for each quarter. The First Preliminary, so-called the first QE (Quick Estimate), is published approximately one month and two weeks after the end of the reference quarter, and the Second Preliminary, the second QE, two months and 10 days after the end of the reference quarter. ${ }^{22}$ In addition, the Final- and the Second Final quarterly estimates are also published respectively at the time of the Final- and the Second Final annual estimates publication. For the quarterly inventory investment estimates in 2008Q1, the First Preliminary and the Second Preliminary are published in mid-May and mid-June, respectively, and the Final at the end of 2009 and the Second Final at the end of 2010.

When compared to the Final, Preliminaries are estimated with scarcer source

21 The Census of Manufacturers surveys once a year the activities of manufacturers during the reference year and their state at the end of the year.

22 In Japan QE stands for either "quarterly estimate" or "quick estimate", and here the latter. 
statistics, placing more emphasis on demand-side statistics from individual agents. At once, in order to improve the compatibility with the Final estimates and reduce the width of revision from the Preliminary to the Final, it also depends on supply-side statistics taking the advantage of the basic process of the Final estimates, thus integrating the demand-side and supply-side estimation. ${ }^{23}$

The commodity-flow method (hereafter, $\mathrm{CF}$ method) first estimates the whole domestic supply-side by assessing production, export and import, change in inventory stock, and so on by commodity in the reference year, and then on each stage of distribution it allocates by value among demand items like consumption and investment. The existing CF method is a core framework of Japan's SNA estimation on which about $80 \%$ of nominal GDP (expenditure side) except government's consumption and investment is determined. Understanding that the finer the commodity classification is, the more precisely it can specify the allocation destination, leading to the more accurate estimates, and the CF method adopts a commodity classification of approximately 2,100 . The accuracy of Japan's GDP estimates depends on this fineness. More than $80 \%$ of commodities are in the manufacturing sector, most of which are surveyed by the Census of Manufacturers. As production values are unavailable except on benchmark years, the existing CF method estimates the total supply values by adjusting shipment values by commodity adding export-import and change in inventory stock, on which it estimates the final values by allocating destination of each commodity on distribution channels. ${ }^{24}$

Quarterly inventory investment statistics attracts attention primarily in relation to short-term economic fluctuations, and the Second Preliminary estimates is most frequently referred to as its representative. The Census of Manufacturers which is a core framework of Japan's SNA estimation becomes partly available even at the stage of the Final, and the Second Preliminary is estimated under a grave constraint that key source statistics like the Census of Manufacturers is entirely unavailable. Japan's quarterly inventory investment statistics included in the OECD database is this Second

${ }^{23}$ Using as the benchmark the realized values of the previous year estimated by commodity-flow method adopted for the Final estimates, it conducts extrapolation estimation upon the period-to-period rates of increase both in demand-side statistics like Household Expenditure Survey and Corporate Enterprise Quarterly Statistics and in supply-side statistics like Current Survey of Production and Survey of Selected Service Industries. Upon integrating thus estimates both from demand-side and supply-side, it applies price- and seasonal adjustment. See CAO, System of SNA Estimation.

${ }^{24}$ See "Study of Annual Supply-Use Table Estimation in Japan when the Economic Census of Business Activity is Introduced" National Economy Research Quarterly (Kikan kokumin keizai kenkyu), No.142 (July 2010) p.53 (in Japanese). 
Preliminary, which is frequently used for international comparison study like Wen [2005]. ${ }^{25}$

In this research I use primarily the Final of annual and quarterly estimates of each year.

The CF method in annual accounts, upon about 2,100 commodity classification, identifies distribution channels in detail for each commodity and estimates values for each allocation destination. The supply-side estimation on quarterly accounts, in principle, adopts another classification of 91 commodities, and simplifies the distribution channels. The estimation method is as follows (CAO, 2007, p.12).

(1) Making consistent with the definition of annual shipment values in 91 commodity classification of the CF method for annual Final estimates, subsidiary series that show the movement of quarterly shipment is created from monthly or quarterly source statistics.

(2) With the quarterly ratios in this subsidiary series, the Final annual estimates are divided into the Final quarterly ones.

(3) The Preliminary values are estimated by extrapolating the last available values of the Final quarterly estimates by the quarter-over-quarter ratio of the subsidiary series. With that, we obtain the quarterly estimates of shipment values based on the 91 commodity classification of the CF method.

(4) After adding transportation cost, margins, and export-import adjustment on the shipment values, the domestic total supply values are estimated by deducting net increase both in distribution inventory and raw material inventory values which are estimated separately.

(5) Domestic household final consumption expenditure and gross fixed asset formation are estimated by multiplying to the total domestic supply values the allocation ratios among demand items obtained from the latest Final annual accounts (p.12).

As part of this estimation process, quarterly inventory investment (increase in private inventory stock) values are estimated in four categories of product-, goods-in-process-, raw material-, and distribution stock, and are calculated by adding together. For the periods the Final already exists, the quarterly Final values are estimated by adding equally to each quarterly Preliminary value a quarter of the

25 OECD [2012] points that not many OECD countries estimate quarterly inventory investment statistics from detailed supply-side information like Japan. Not a few countries make estimates as the difference between shipment and production. 
difference between the aggregate of four quarterly Preliminary values during the year and the annual Final value obtained by the CF method. For the periods the Final does not exist (QE Preliminary periods), the quarterly Final values are estimated by adding to the quarterly Preliminary values the same amount added in the periods the Final already exists (p.26). 26

What matters for this research is that the adjustment given to the quarterly Preliminary estimates at the time of the annual Final's publication, leading to the quarterly Final, is equally add to the Preliminary a quarter of the difference between two annual values. The adjustment does not affect the fluctuations within each year at all. Unless the values added at this adjustment differs greatly across years, the causes of variations in inventory investment values are either the variations in inventory investment or in the process estimating quarterly changes in inventory stock values from source statistics.

Quarterly inventory investment (increase in private inventory stock) values are estimated in four categories of product-, goods-in-process-, raw material-, and distribution stock, and are calculated by adding together. Even on the manufacturing sector, the estimation method greatly differs across categories. In addition the Census of Manufacturers, a core source statistics of the annual Final estimation, is not available at the time of the quarterly Preliminaries. ${ }^{27}$

This research uses quarterly inventory investment values for 17 years, from 1994 to 2010, separately in four categories and in 91 commodities, which is estimated as part of estimating the quarterly Final values. The data is estimated along the existing estimation method revised at the time of publishing the quarterly First Preliminary of 2002Q2. In what follows, I place special focus on real inventory investment values and nominal shipment values.

\section{Three points for avoiding confusion}

Note three points for avoiding confusion.

First, for example, the estimation method of existing quarterly GDP

Preliminaries was adopted at the time of the quarterly First Preliminary of 2002Q2, one

${ }^{26}$ For example, when the annual Final 2008 is published (December 2009), every 2008 quarter is in "the period the Final already exists", and 2009 quarters belong to "the periods the Final do not exist". The 2010 Final was published in December 2011. It is November 2012 that this research began the use of the quarterly Final inventory investment estimates for 1994 2010, and all the periods under study belong to the "the periods the Final already exist".

27 For the details of source statistics and estimation methods that differ across inventory categories, see CAO [2007, pp.27 ]. 
purpose of which is to improve the consistency with the estimation method of the annual Final. ${ }^{28}$ Despite the efforts for improving the consistency, however, the quarterly GDP Preliminaries and the annual SNA (GDP) accounts are estimated separately upon different source statistics with different methods. No change on this key point occurs with the revision from the Preliminary to the Final. The annual GDP Final using the Census of Manufacturers improves accuracy, but no additional information on the more accurate and appropriate allocation of the annual values to each quarter seems to be obtained on this estimation process. The quarterly Final values are not newly estimated by other method than the one for quarterly Preliminaries to replace the latter, but are estimated by equally added a quarter of the difference in the two annual values (explained above).

Second, upon the CF method, SNA accounts estimate the total domestic supply values by commodity, deducting export and import, and changes in inventory stock from production or shipment value. Naturally, inventory investment values (=net increase or decrease in inventory stock values) are estimated by commodity, that is, commodity-based. Neither firm nor industry is the estimation unit. Therefore, for example, raw material inventory of steel products is not iron ore and coal steel manufacturing companies possess but steel products construction companies or shipbuilders and machine makers possess as production materials. Likewise, raw material inventory of petroleum products is not crude oil manufacturers possess but petroleum products firms like power companies possess as raw fuel. ${ }^{29}$

Third, by definition inventory investment value is the change in investment stock value. It is not the change in inventory stock volume, for example the number of machines-in-process or quantity of steel product stock in tons, but the change in their value. With fair-value adjustments at the end of accounting period, for example, without any change in inventory stock volumes, the inventory stock values may decrease

28 The purposes of revision of this time were, (1) for better understanding of economic trends, in response to the environmental changes surrounding statistics, by greatly expanding the source information primarily on the supply side, (2) improving the contribution to prompter business outlook, by speeding the publication timing in no way inferior to other major developed countries, and (3) improving the consistency with the estimation method of the annual Final (p.1).

29 Although IIP and Current Survey of Production I used in [2] are commodity-based, the survey object is producer and the "inventory" is producer's product inventory. In the Corporation Enterprise Quarterly Statistics I use later, the survey object is corporation and the statistics is published on industry-base, inventory stock values by industry in three categories, raw material-, goods-in-process-, and product stock. Nonetheless, for example, some automobiles in distribution stock are included in distributors" inventory, but none appears in inventory in the automobile industry. 
dramatically, recording a huge negative value in inventory investment. As I show below, the dominant portion of wild fluctuations in quarterly GDP inventory investment could have been the result of regularly conducted fair-value adjustments. ${ }^{30}$

\section{[4]. Investigation of Quarterly GDP Inventory Investment Estimates}

[4-1]. Investigation of All Industries Inventory Investment Movement

This research uses the quarterly GDP (SNA) inventory investment estimates for 1994 2010, sixty eight quarters over seventeen years, in ninety one commodities and in four categories (to be precise, I use data on 59 commodities, excluding commodities with consistently 0 inventory investment like commodities in service sectors). Although Sections [7] [9] focus on the years after 2003 including the period around Lehman Shock, Sections [4] [6] study primarily the inventory investment movement over the whole period. In preparation for the detailed examination, this section presents its whole picture and stimulates interests on the issues in the next section and after.

Together with the estimates by category, the availability of estimates by commodity (furthermore by commodity-category) is an advantage of this research. Sections [7] [9] use the data by commodity, and sections [4] [6] confine the use to inventory investment data on all industries. Conclusions of the study in [7] [9] of inventory investment by commodity are consistent with those of all industries inventory investment in [4] [6].

Following the study of all industries inventory investment movement in [4-1], [4-2] and [4-3] investigate the quarterly and annual movement of total industries real inventory investment, respectively, of which [4-2] is central.

30 "The SNA is in principle based on an accrual basis, and change in inventory values is evaluated at the price of the time it occurs. Notwithstanding, available inventory related information is firm's accounting data on inventory stock, which is evaluated by various inventory valuation standards allowed as standard business accounting practices such as last-in first-out system and first-in last-out system. Hence, the change in inventory stock value, obtained by deducting the opening inventory value from the final inventory value, includes the changes due to the change in valuation prices." Following this commentary, CAO [2007, p.27] states, "In estimating the changes in inventory stock values upon the inventory stock information obtained from firm's accounting data, it is necessary to adjust the valuation difference between the SNA and business accounting, which we call the inventory valuation adjustment," and explains their methods. As shown below, however, the results of this research pose grave doubts on the effectiveness and validity of this "adjustment". For more details, see the opening paragraphs of Section [6]. 
First is the table of each quarter's values (unit: billion yen) of all industries: from nominal sales (nsales) and total nominal inventory investment (ntotal) to total real inventory investment (rtotal) and real inventory investment in four categories, that is, product(rfinal), good-in-process (rprocess), distribution (rdistribution), and raw material (rraw). I draw a horizontal line below the $4^{\text {th }}$ quarters, under which are values of each year's $1^{\text {st }}$ quarter.

The foci of investigation are first the size of real inventory investment values and their variation patterns, and second the size of values and variation patterns by inventory category.

\begin{tabular}{|c|c|c|c|c|c|c|c|}
\hline & nsales & ntotal & rtotal & rfinal & rprocess & rdistr $n$ & rraw \\
\hline $1994 q 1$ & 180,440 & $-3,139$ & $-2,645$ & -25 & $-1,539$ & -619 & -462 \\
\hline $1994 q 2$ & 174,646 & 775 & 879 & -83 & 910 & -40 & 92 \\
\hline $1994 q 3$ & 185,699 & -685 & -836 & -79 & -404 & -235 & -119 \\
\hline $1994 q 4$ & 184,984 & 2,104 & 1,883 & -255 & 945 & 1,232 & -39 \\
\hline $1995 q 1$ & 182,438 & $-3,250$ & $-2,937$ & 267 & $-2,034$ & -874 & -296 \\
\hline $1995 q 2$ & 176,543 & 2,015 & 1,893 & 450 & 1,206 & -47 & 284 \\
\hline $95 q^{3}$ & 183,449 & 60 & 114 & -87 & -129 & 207 & 123 \\
\hline $1995 q 4$ & 185,010 & 2,963 & 2,494 & -21 & 1,317 & 1,069 & 130 \\
\hline $1996 \mathrm{q} 1$ & 185,756 & $-3,500$ & $-3,213$ & -34 & $-2,451$ & -651 & -77 \\
\hline $1996 q 2$ & 179,935 & 2,812 & 2,476 & 426 & 1,480 & 498 & 73 \\
\hline $1996 q 3$ & 189,955 & -172 & -90 & -346 & 32 & 279 & -56 \\
\hline $1996 q 4$ & 192,184 & 3,337 & 2,874 & -12 & 1,377 & 1,376 & 134 \\
\hline $1997 q 1$ & 195,775 & $-4,129$ & $-3,794$ & -498 & $-2,180$ & -737 & -379 \\
\hline 1997q2 & 187,293 & 2,835 & 2,602 & 906 & 1,207 & 397 & 92 \\
\hline $1997 q 3$ & 194,689 & 478 & 592 & -263 & -143 & 889 & 109 \\
\hline $1997 q 4$ & 190,473 & 3,715 & 3,501 & 184 & 1,361 & 1,579 & 378 \\
\hline 1998q1 & 192,096 & $-3,227$ & $-3,007$ & -53 & $-2,317$ & -349 & -289 \\
\hline $1998 q 2$ & 180,070 & 2,516 & 2,213 & 457 & 1,326 & 380 & 51 \\
\hline $1998 q 3$ & 187,537 & -677 & -638 & -517 & -92 & 53 & -82 \\
\hline $1998 q 4$ & 184,330 & 2,913 & 2,683 & -84 & 1,236 & 1,607 & -75 \\
\hline $1999 q 1$ & 185,150 & $-4,918$ & $-4,606$ & -418 & $-2,303$ & $-1,669$ & -216 \\
\hline $1999 q 2$ & 173,601 & 1,286 & 1,100 & 324 & 1,556 & -780 & -0 \\
\hline $1999 q 3$ & 185,303 & $-1,777$ & $-1,758$ & -330 & -489 & -729 & -210 \\
\hline $1999 q 4$ & 183,988 & 1,440 & 1,224 & -75 & 1,217 & 211 & -129 \\
\hline $2000 q 1$ & 188,809 & $-4,369$ & $-4,190$ & -109 & $-2,462$ & $-1,336$ & -284 \\
\hline $2000 q 2$ & 179,661 & 2,481 & 2,355 & 343 & 1,534 & 200 & 278 \\
\hline $2000 q 3$ & 189,295 & -974 & $-1,014$ & -332 & -307 & -298 & -77 \\
\hline $2000 \mathrm{q} 4$ & 189,961 & 2,321 & 2,103 & -2 & 1,432 & 544 & 129 \\
\hline $2001 q 1$ & 189,813 & $-3,522$ & $-3,410$ & -35 & $-2,621$ & -751 & -3 \\
\hline 2001q2 & 179,907 & 2,699 & 2,719 & 685 & 1,722 & 226 & 85 \\
\hline 2001q3 & 184,472 & $-1,190$ & $-1,188$ & -377 & -910 & 35 & 65 \\
\hline $2001 q 4$ & 181,011 & 2,049 & 2,000 & -106 & 1,275 & 919 & -88 \\
\hline $2002 q 1$ & 181,995 & $-4,667$ & $-4,441$ & -485 & $-2,618$ & $-1,231$ & -106 \\
\hline $2002 q 2$ & 173,891 & 1,505 & 1,298 & 175 & 1,538 & -354 & -61 \\
\hline $2002 q 3$ & 182,875 & $-1,047$ & $-1,158$ & -222 & -725 & -170 & -41 \\
\hline $2002 q 4$ & 182,221 & 2,004 & 1,885 & 128 & 1,341 & 564 & -148 \\
\hline
\end{tabular}




\begin{tabular}{|c|c|c|c|c|c|c|c|}
\hline |2003q1 & 183,212 & $-3,919$ & $-4,000$ & -278 & $-2,510$ & $-1,125$ & -87 \\
\hline $2003 q 2$ & 173,555 & 1,891 & 1,863 & 437 & 1,527 & -233 & 131 \\
\hline $2003 q 3$ & 181,355 & -76 & -73 & -151 & -222 & 211 & 89 \\
\hline $2003 q 4$ & 183,331 & 1,601 & 1,506 & -163 & 1,181 & 622 & -134 \\
\hline $2004 q 1$ & 185,188 & $-3,106$ & $-3,102$ & -138 & $-2,097$ & -808 & -60 \\
\hline $2004 q 2$ & 177,065 & 2,297 & 2,301 & 501 & 1,261 & 397 & 142 \\
\hline $2004 q 3$ & 184,970 & 143 & 129 & -225 & -323 & 534 & 143 \\
\hline $2004 q 4$ & 186,339 & 2,315 & 2,311 & -153 & 1,156 & 1,304 & 5 \\
\hline $2005 q 1$ & 187,959 & $-3,417$ & $-3,435$ & -128 & $-2,404$ & -793 & -109 \\
\hline $2005 q 2$ & 181,339 & 2,552 & 2,563 & 549 & 1,647 & 245 & 123 \\
\hline $2005 q 3$ & 188,609 & -152 & -148 & -43 & 14 & -46 & -73 \\
\hline $2005 q 4$ & 190,805 & 1,679 & 1,693 & -47 & 1,178 & 621 & -59 \\
\hline $2006 q 1$ & 193,357 & $-3,405$ & $-3,366$ & -218 & $-1,984$ & $-1,103$ & -62 \\
\hline $2006 q 2$ & 186,388 & 1,723 & 1,708 & 369 & 1,314 & -298 & 323 \\
\hline $2006 q 3$ & 193,686 & -172 & -103 & -31 & 28 & -61 & -39 \\
\hline $2006 q 4$ & 196,950 & 1,877 & 1,832 & 146 & 1,356 & 428 & -99 \\
\hline $2007 q 1$ & 199,305 & $-2,945$ & $-2,918$ & -363 & $-2,087$ & -407 & -61 \\
\hline $2007 q 2$ & 193,171 & 2,386 & 2,382 & 357 & 1,735 & 80 & 211 \\
\hline $2007 q 3$ & 200,579 & -132 & 100 & -26 & -157 & 453 & -170 \\
\hline $2007 q 4$ & 204,034 & 2,373 & 2,383 & 235 & 982 & 1,035 & 131 \\
\hline $2008 q 1$ & 204,917 & $-2,838$ & $-2,795$ & -154 & $-2,007$ & -175 & -459 \\
\hline $2008 q 2$ & 196,305 & 2,631 & 2,642 & 626 & 1,080 & 737 & 200 \\
\hline $2008 q 3$ & 204,857 & -414 & -269 & -77 & 151 & -37 & -306 \\
\hline $2008 q 4$ & 191,144 & 3,450 & 3,216 & 35 & 726 & 1,607 & 848 \\
\hline $2009 q 1$ & 173,387 & $-4,207$ & $-4,278$ & $-1,000$ & $-2,377$ & -967 & 66 \\
\hline $2009 q 2$ & 166,360 & 265 & 332 & 53 & 577 & -123 & -176 \\
\hline $2009 q 3$ & 176,568 & $-1,769$ & $-1,752$ & -140 & -274 & -887 & -452 \\
\hline $2009 q 4$ & 179,966 & 104 & 297 & 77 & 239 & 71 & -89 \\
\hline $2010 q 1$ & 181,305 & $-4,012$ & $-4,131$ & -338 & $-2,289$ & $-1,259$ & -245 \\
\hline $2010 q 2$ & 176,356 & 1,026 & 1,338 & 457 & 1,199 & -259 & -59 \\
\hline $2010 q 3$ & 184,160 & -183 & -120 & -284 & 227 & -40 & -24 \\
\hline $2010 q 4$ & 182,870 & 1,582 & 1,760 & 225 & 779 & 593 & 164 \\
\hline
\end{tabular}

First, what is the most impressive is that rtotal repeats extremely regular seasonal fluctuations in big scale every year. It starts from a big negative value in Q1, jumping up to a big positive value in Q2, falling to a value around 0 in Q3, and again jumping up to a big positive value in $\mathrm{Q} 4$.

Second, inventory investment by category (rfinal, rprocess, rdistribution, and rraw) more or less repeats similar kinds of regular seasonal fluctuations. In strong regularity, synchronism and the size of fluctuations, the association of rprocess with rtotal stands out.

The next figure highlights these two points, and shows that the rprocess fluctuation is the dominant factor of the rtotal fluctuation. As the above table shows, both rtotal and rprocess radically fall to a big negative value in Q1, and remarkably jump up to a big positive in Q2 and Q4. 


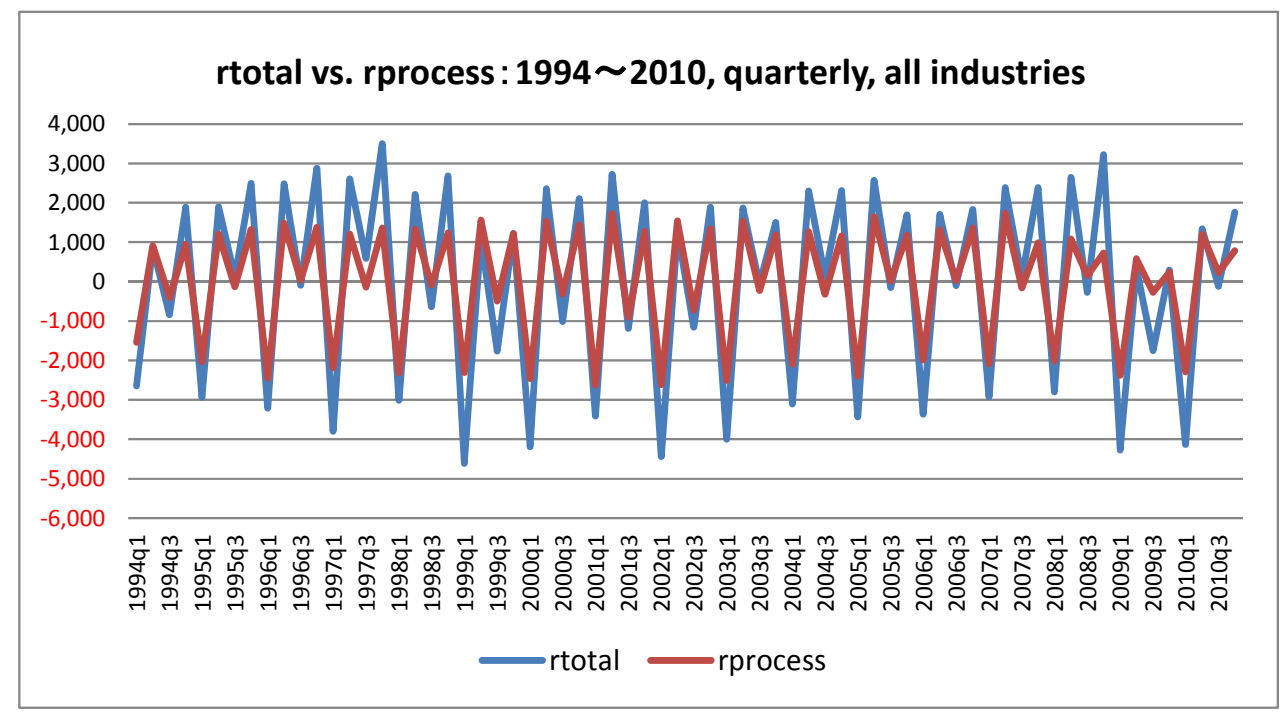

Variations in nsales and values in ntotal

As reference to studying the connection between the level of overall economic activity and the inventory investment, the next figure illustrates by quarter the quarter-over-quarter change in nominal sales (d-nsales) and the total nominal inventory investment (ntotal). ${ }^{31}$

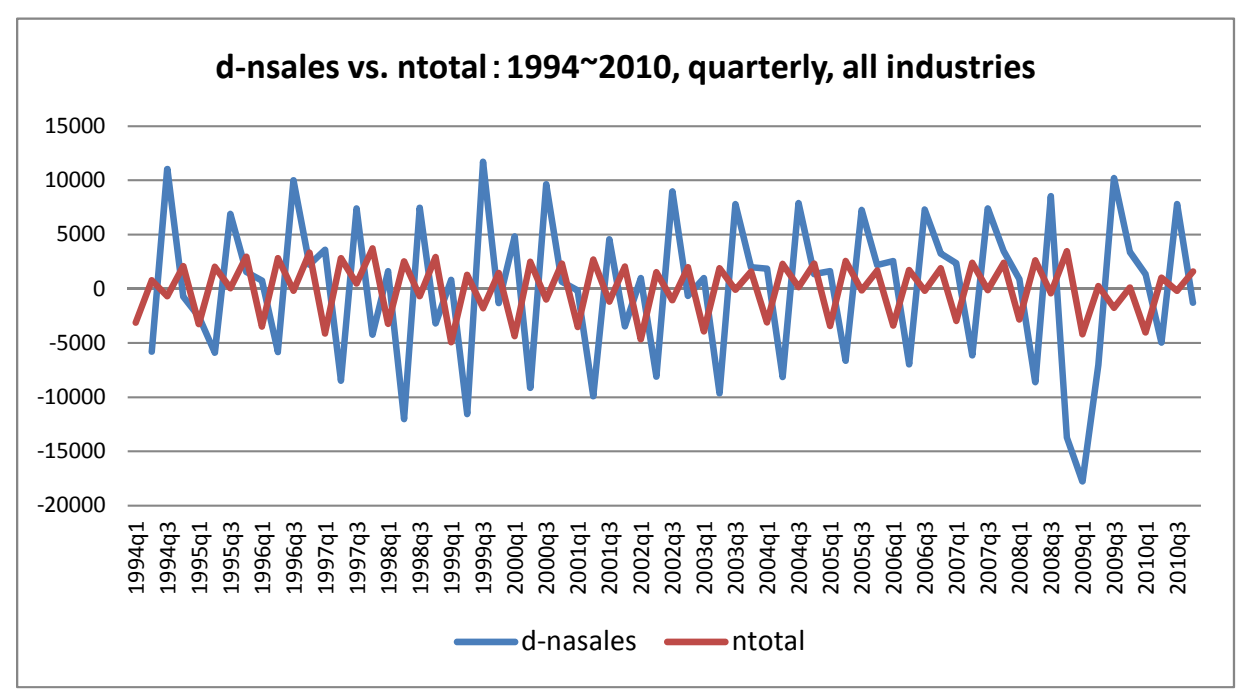

The nominal sales does not drastically decrease in the $1^{\text {st }}$ quarters, and d-nsales does not move strongly in tandem with ntotal. Ntotal exhibits far less volatility than d-nsales.

[4-2] Quarterly Real Inventory Investment Movement in All Industries

31 I use here nominal sales as real sales estimates is unavailable, and correspondingly nominal inventory investment estimates rather than real values. 
Limiting the period to eight years (32 quarters), 2003 2010, including the period around Lehman Shock, [4-2] studies in greater detail the quarterly real inventory investment movement in all industries.

The next figure illustrates the quarterly real inventory investment both in total and by category.

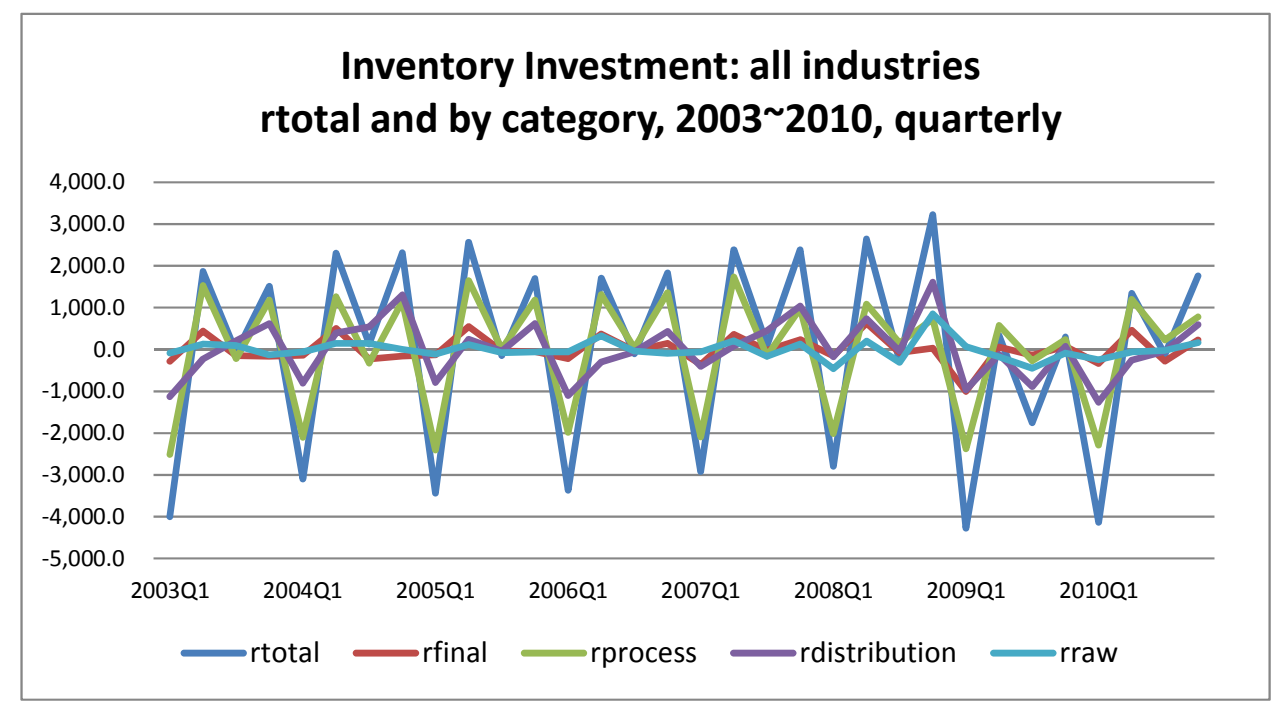

First, particularly rtotal and rprocess show in parallel stably regular seasonal fluctuations in spectacular scale. Second, nowhere I find either a notable increase in inventory stock or a long-run stock adjustment process after Lehman Shock. As consequence of the latter, the inventory investment, falling in 2009Q1 to an extremely low level, exhibited a singular pattern staying at by far lower level (not the opposite) than the previous years.

As the above figure is rather complicated, next I illustrate four figures with each of inventory investment by category together with rtotal. Comparison with the rtotal in common makes the inter-categorical inventory investment comparison easy.

\section{$\underline{\text { Rtotal vs. rprocess }}$}

First comes the comparison of rprocess with rtotal, which clearly shows that the fluctuation in rprocess overwhelms that of rtotal. This regular seasonal fluctuation, which I call M-shaped, is observed consistently without any alteration in basic pattern. Yet, not only in 2009Q1 but also in 2008Q4 rprocess's influence on rtotal decreased. 


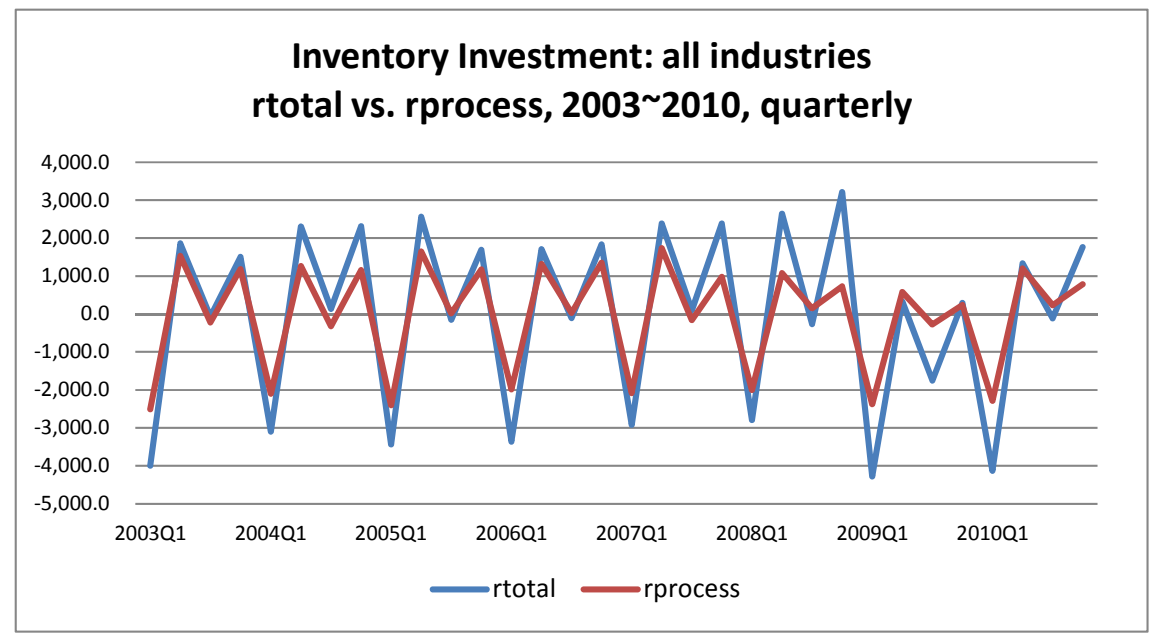

Rtotal vs. rfinal

Next comes the comparison of rfinal with rtotal. The rfinal fluctuation only slightly influences rtotal. Yet, its temporary fall (not the opposite) after the Lehman Shock is slightly eye-catching.

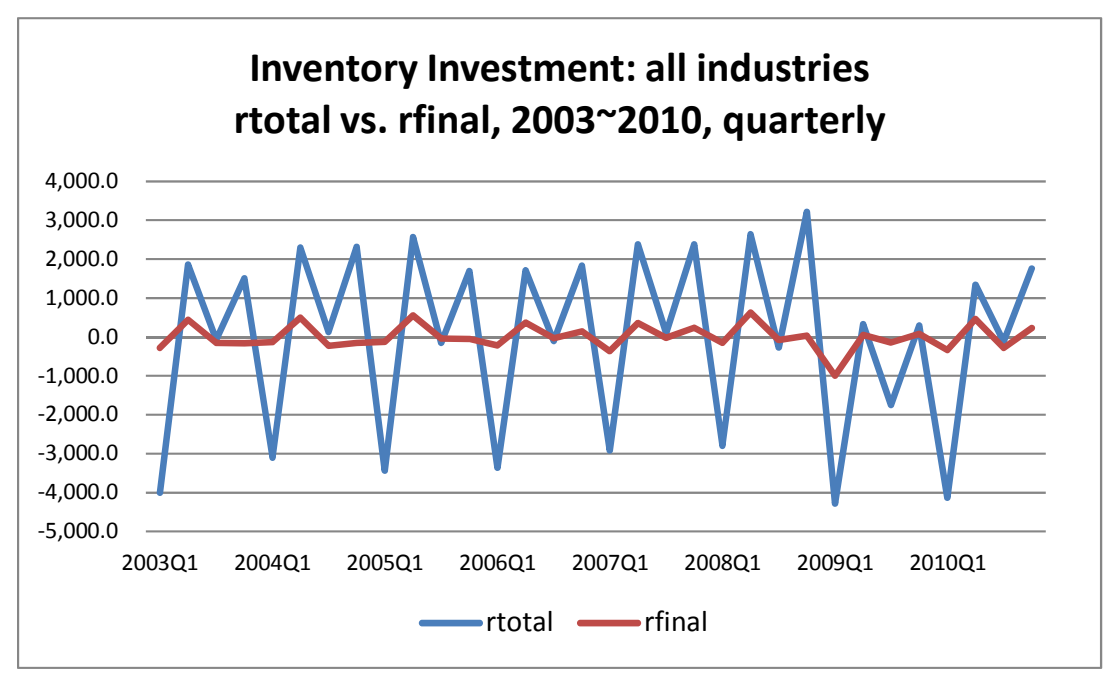

Rtotal vs. rdistribution

Next to rprocess, rdistribution fluctuation has big influence on rtotal movement. Every year rdistribution starts from the bottom of a big negative value in Q1 and ends at a big positive value in Q4, repeating a regular seasonal fluctuation. Its fluctuation range is much smaller than that of rprocess, which affects the rtotal fluctuations less strongly than rprocess.

Its increase in 2008Q4 and the size of negative values in the following quarters, together with its length, may be modestly impressive. Yet, the size of its 2008Q4 increase is not much greater than the previous Q4 values, 2004Q4 for instance. 


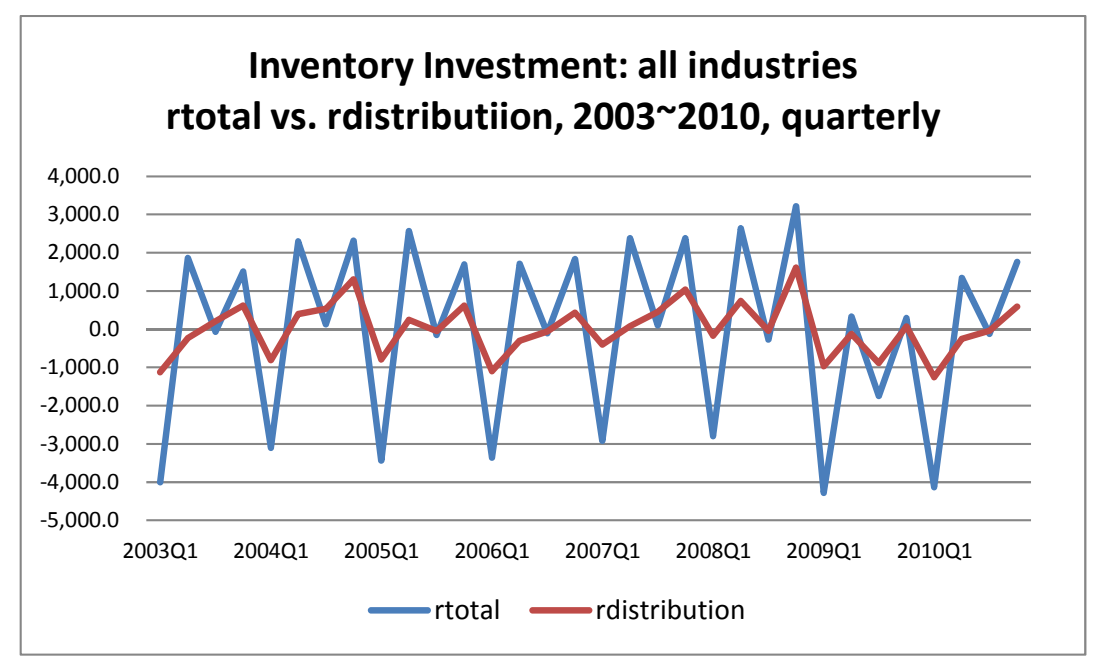

\section{$\underline{\text { Rtotal vs. rraw }}$}

Comparing with the rtotal the rraw is consistently by far smaller, the smallest among four inventory categories Its fluctuation has little influence on rtotal fluctuation, with the exception of its small increase in 2008Q4.

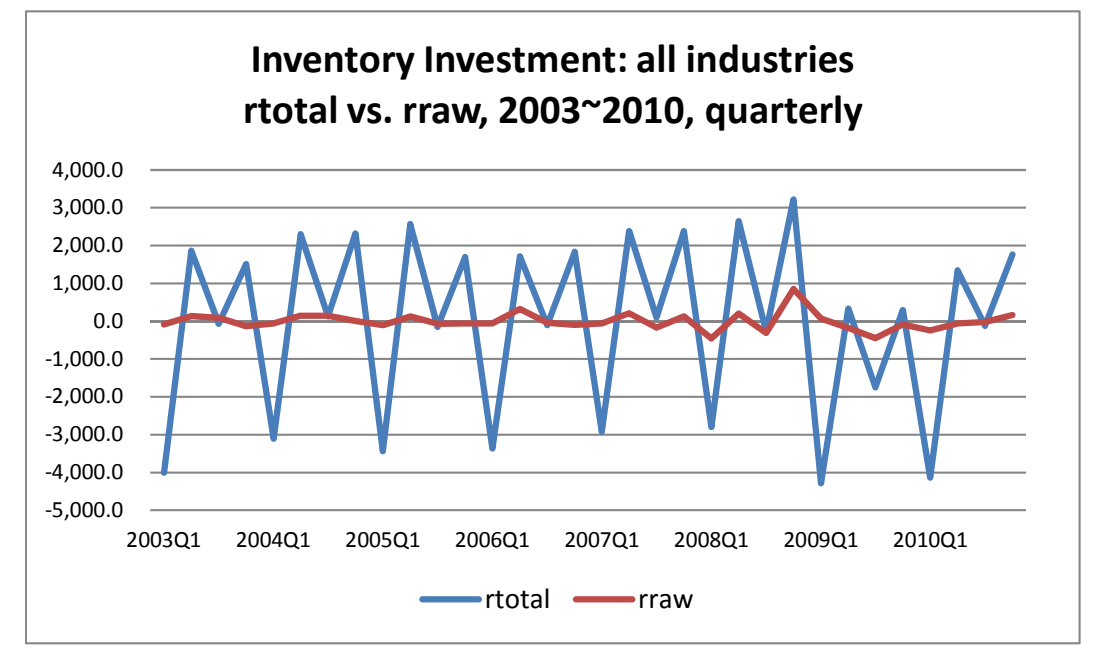

[4-3]. Annual Real Inventory Investment Movement: 1994 2010

Bearing in mind the study of the quarterly inventory investment data, from 2003Q1 to 2010Q4 in [4-2], [4-3] investigates the annual inventory investment data for the entire period of study, 1994 2010. The primary focus is placed on the relation between the regular seasonal fluctuations observed in quarterly rtotal, rprocess, and rdistribution and the annual inventory investment fluctuations.

Note that in [4-3] the study period is 1994 2010 to which that of [4-2] is the second half. The sequence of figures is the same as in [4-2]. 
As explained in [3], the quarterly GDP inventory investment Final statistics is estimated by allocating according to the predetermined rules the annual SNA inventory investment (Final) statistics obtained from the Census of Manufacturers data.

In the annual data, it is not the goods-in-process inventory but the distribution inventory whose fluctuations have overwhelming influence on the annual total inventory investment fluctuations.

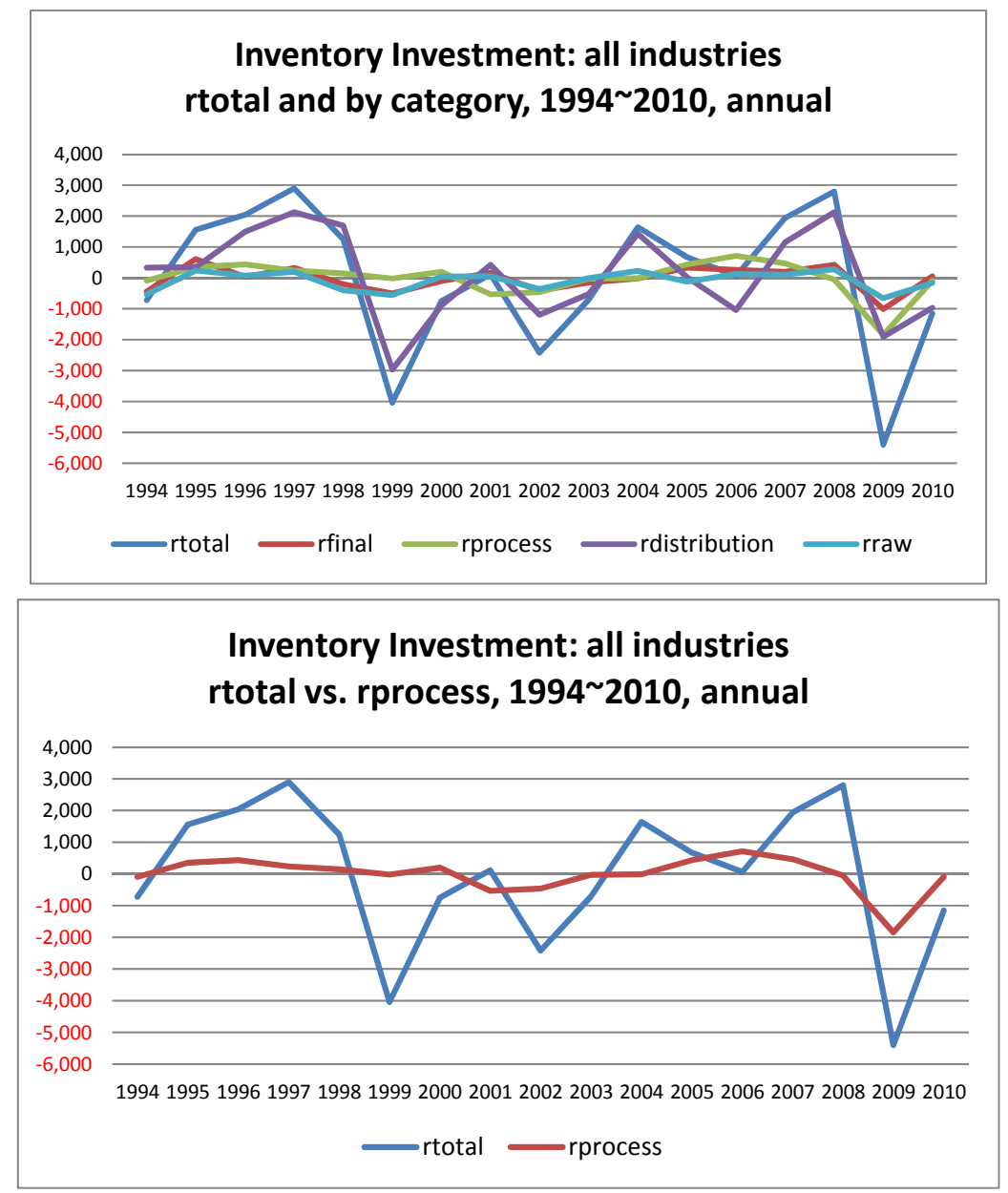



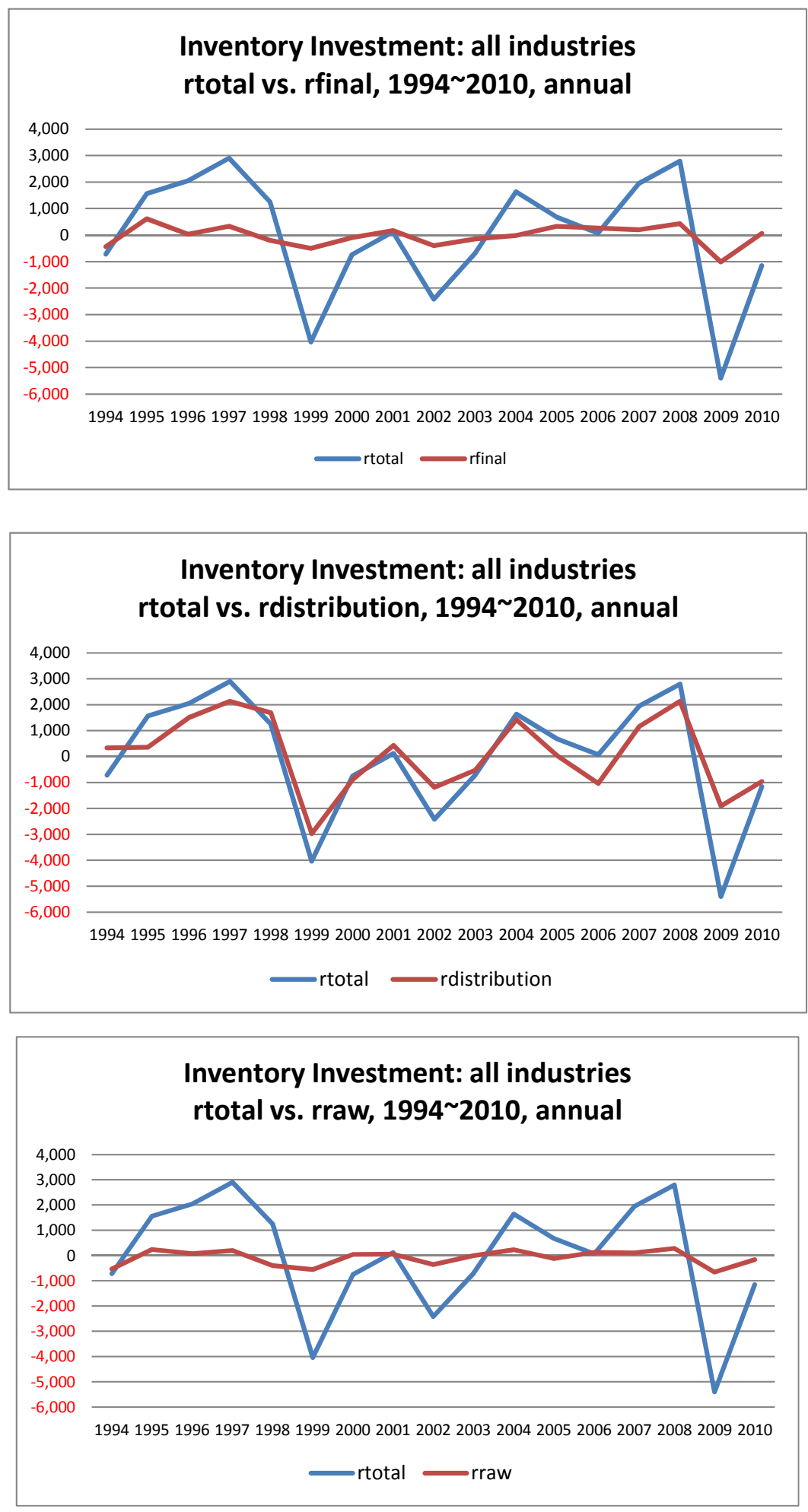
[5]. Study of Regular Seasonal Inventory Investment Fluctuations and its Interpretation

Focusing on the wild and spectacular, M-shaped, regular seasonal fluctuations in all industries quarterly inventory investment estimates observed in [4], Section [5] further investigates the quarterly inventory investment data, particularly its fluctuations, and presents its interpretation with a way on how to deal with it.

A major part of M-shaped regular seasonal fluctuations in quarterly inventory investment statistics seem to arise from its estimation process (estimation methods and source statistics). It is noteworthy particularly for the goods-in-process inventory which is the dominant factor of total inventory investment fluctuations. When the regular seasonal fluctuations are eliminated, the wild and spectacular quarterly inventory investment fluctuations decrease radically. Moreover, the fluctuations in goods-in-process inventory which is the dominant factor of quarterly total inventory investment fluctuations almost entirely disappear in annual statistics (or the annual average of four quarterly estimates of the year, which is the same thing).

Upon all these observations, I draw two conclusions. It will be an important research issue in the future to investigate the sources and generating mechanisms of the M-shaped wild inventory investment fluctuations and adopt appropriate countermeasures. ${ }^{32}$

(1) Wild fluctuations in quarterly inventory investment statistics do not accurately and appropriately reflect the economic reality of inventory investment and its fluctuations, the dominant portion of which arises on the estimation process of the quarterly GDP statistics.

(2) Aside from annual SNA accounts for accuracy demand for reporting accurately the economic reality, quarterly GDP accounts is published in response to promptness demand for diagnosing the state of the economy. Wild quarterly inventory investment fluctuations are observed in quarterly GDP accounts published for promptness demand, and inventory investment fluctuations radically decreased in annual SNA accounts for accuracy demand. Therefore, in investigating the reality of inventory investment and the fluctuation generating mechanisms where promptness is inessential, we should switch focus from the quarterly GDP estimates to the annual SNA estimates, and make active use of

32 Notwithstanding, inventory investment estimates is a part of quarterly GDP accounts, and it may not be easy to take measures to inventory investment estimates separately. 
micro-based source statistics like IIP and Corporate Enterprise Statistics. In using the quarterly GDP inventory investment statistics, we should take account of wild and spectacular regular seasonal fluctuations.

\section{Movement by quarter of all industries rtotal and inventory investment by category}

I begin with a figure that emphasizes the importance of quarterly regular seasonal fluctuations that shows the all industries rtotal by quarter, from Q1 to Q4 separately. The blue line consistently at the bottom indicates the Q1 estimates, the red line on the top the Q2, the green line at the middle the Q3, and the khaki line also at the top the $\mathrm{Q} 4$.

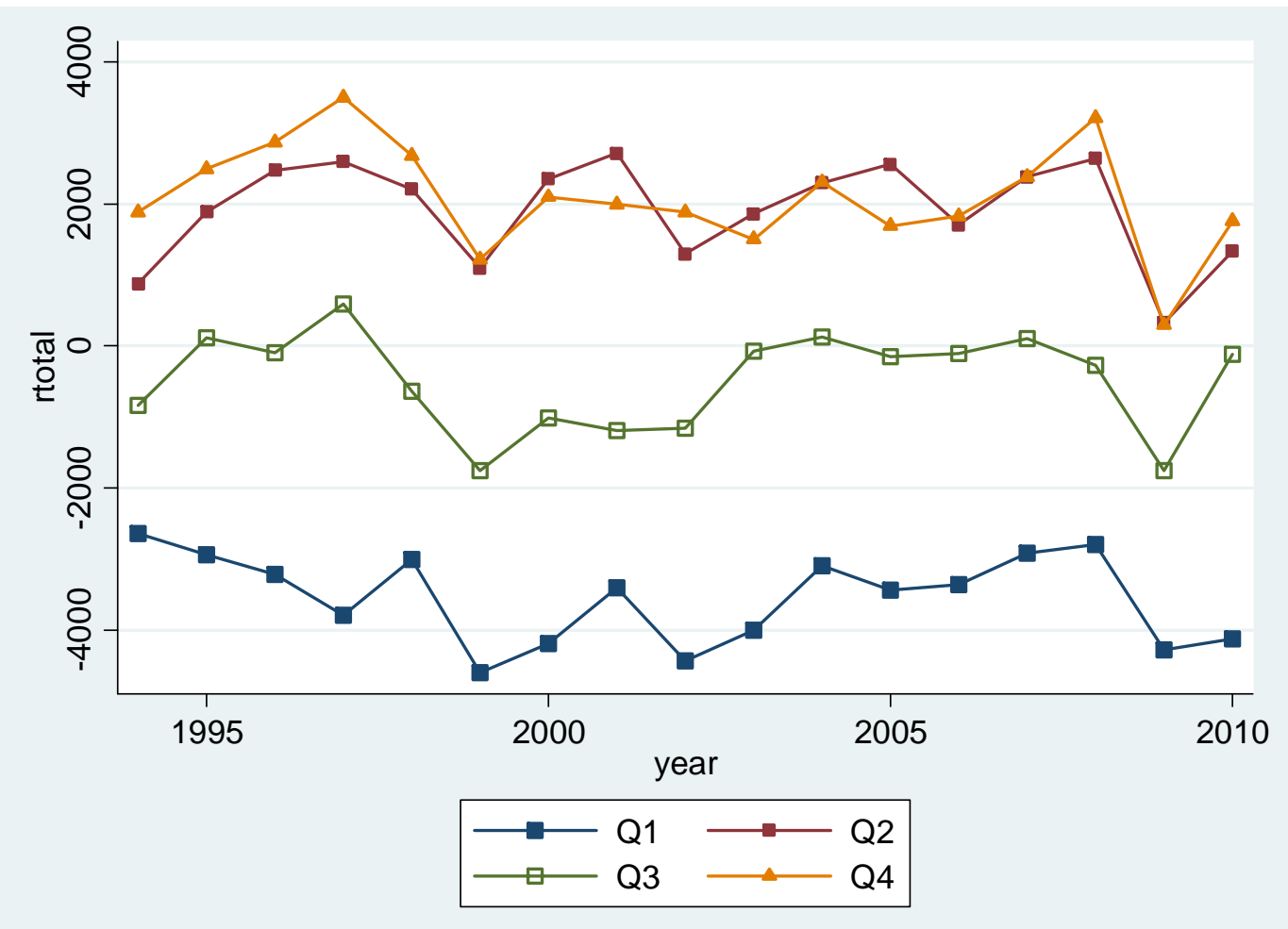

Every year all industries rtotal starts from the bottom with big negative value of Q1, jumps up to the top with big positive value of $\mathrm{Q} 2$, comes down to the middle with small absolute value of Q3, again jumps up to the top with big positive value of Q4, and then dives to the next value on the bottom line of next year's Q1. Each line never intersects with the line of neighboring quarters.

The distance from Q1 line to Q2 or Q4 line for example always by far surpasses the vertical distance of two points on the same line (year-over-year change). For example, a big decrease from the Q4 value to the next year's Q1 is almost completely offset by an increase from the $\mathrm{Q} 1$ value to the $\mathrm{Q} 2$, and similarly somewhat smaller 
decrease from the $\mathrm{Q} 2$ value to the $\mathrm{Q} 3$ is offset by an increase from the $\mathrm{Q} 3$ value to the Q4. Because of this, wherever the beginning, with few exceptions, change in the aggregates of 4 quarter values, that is change in annual values, is by far smaller than change in quarter values or year-over-year change in quarter values. Thus, the $\mathrm{M}$-shaped regular seasonal fluctuations shown in [4] dominate the fluctuations in quarterly GDP inventory investment estimates. This applies also to the years of inventory investment decrease over quarters like in 1999 and 2009.

Whatever are the causes (in my view, a major cause is due to accounting rules and firm's accounting customs ${ }^{33}$ ), it is obvious that this regular seasonal fluctuations exert a dominant influence on the fluctuations in quarterly GDP inventory investment (Final) estimates. For studying the reality and influence of other factors including stock adjustment behaviors of relevant firms, it is of definite importance to eliminate the influence of this regular seasonal fluctuation.

I find no notable time trend either in any quarter lines or in the whole picture.

Next is the summary table by quarter of inventory investment values both in total (rtotal) and by category, showing mean, sd (standard deviation), p50 (median), p25 (25 percentile) and p75 (75 percentile) over 17 years.

\begin{tabular}{|c|c|c|c|c|c|c|}
\hline & & rtotal & rfinal & rprocess & rdistribution & rraw \\
\hline & $\mathrm{N}$ & 17 & 17 & 17 & 17 & 17 \\
\hline$q=1$ & mean & $-3,545.0$ & -235.7 & $-2,251.7$ & -873.7 & $\begin{array}{l}-184.0 \\
\end{array}$ \\
\hline & $s d$ & 626.9 & 277.5 & 275.3 & 386.3 & 158.6 \\
\hline & p50 & $-3,409.7$ & -153.7 & $-2,303.1$ & -807.5 & -109.0 \\
\hline & p25 & $-4,130.9$ & -363.4 & $-2,451.0$ & $-1,124.9$ & -288.6 \\
\hline & p75 & $-3,006.8$ & -53.1 & $-2,086.9$ & -650.5 & -61.5 \\
\hline$q=2$ & mean & $1,921.5$ & 413.6 & $1,342.3$ & 60.3 & 105.2 \\
\hline & $s d$ & 708.7 & 229.8 & 303.4 & 379.8 & 132.6 \\
\hline & p50 & $2,213.4$ & 437.1 & $1,325.7$ & 79.8 & 91.8 \\
\hline & p25 & $1,337.7$ & 343.4 & $1,206.1$ & -232.8 & 51.1 \\
\hline & p75 & $2,476.4$ & 500.7 & $1,538.1$ & 379.7 & 200.1 \\
\hline$q=3$ & mean & -483.1 & -207.6 & -219.0 & 9.4 & -65.8 \\
\hline & $s d$ & 689.3 & 143.9 & 296.9 & 429.2 & 157.2 \\
\hline & p50 & -147.9 & -221.9 & -157.4 & -37.3 & -55.7 \\
\hline & p25 & $-1,013.5$ & -330.2 & -323.3 & -170.4 & -118.5 \\
\hline & p75 & -73.1 & -78.6 & 13.7 & 211.1 & 64.9 \\
\hline$q=4$ & mean & $2,096.7$ & 6.4 & $1,123.2$ & 904.9 & 62.1 \\
\hline & $\mathrm{sd}$ & 760.5 & 142.7 & 307.9 & 492.6 & 248.0 \\
\hline & p50 & $1,999.5$ & -12.4 & $1,216.6$ & 919.2 & -39.3 \\
\hline & p25 & $1,760.2$ & -84.3 & 981.5 & 563.9 & -89.0 \\
\hline & p75 & $2,494.3$ & 128.2 & $1,340.7$ & $1,304.4$ & 130.5 \\
\hline
\end{tabular}

The feature (1) suggests that the above observations on rtotal with little change apply also to all inventory investment categories.

(1) Neither p25- p75 deviation nor mean-median deviation is huge. The figures

33 On this point, see [6]. 
suggest that with few exceptions a line representing any quarter's inventory investment value either in total or in any category does not intersect with the ones on neighboring quarters. Thus, all industries quarter GDP inventory investment statistics either in total or in any category every year starts from the bottom with big negative value of $\mathrm{Q} 1$, jumps up to the top with big positive value of Q2, comes down to the middle with small absolute value of Q3, again jumps up to the top with big positive value of Q4. They repeat regular seasonal fluctuations.

(2) Share values of each category's variations to the total inventory investment variation $\{=(\mathrm{sd}$ of rprocess $) /($ sd of rtotal), for instance $\}$ in each quarter shows that it is the rdistribution rather than rprocess that has the biggest influence on the sd of rtotal. This is then followed by rprocess, rfinal, and rraw in that order. This sharply contrasts with the picture of all the quarters, shown above in [4] and again soon below.

In addition to actively using annual GDP statistics (or annual average of four quarter values) instead of quarterly GDP statistics, I suggest an alternative of using revised values to be obtained by deducting the average value from the original by category ${ }^{34}$, for example rtotal or rprocess of all industries inventory investment in Q1. In this research, particularly in [7] [9], I place enormous importance on the study of inventory investment both by category and by commodity, this choice of revision is extremely useful.

For comparison, next is the summary table for the whole study period on three series of quarterly GDP inventory investment figures: First, the original, that is the quarterly Final; Second, the revised values obtained by deducting the average value by category from the original, for example Rrtotal corresponding to rtotal of the original series; Third, year-to-year change in quarterly inventory investment series, for example L4rtotal to the rtotal, which is widely used as a seasonal adjustment method.

34 Here I use 'by category' on three dimensions, that is, quarter, commodity, and inventory category, therefore for 1,840 categories $(=4 * 92 * 5)$ I deduct average values for the original. 


\begin{tabular}{|c|c|c|c|c|c|c|}
\hline quarterly & & rtotal & rfinal & rprocess & rdistr $\tilde{n}$ & rraw \\
\hline \multirow[t]{6}{*}{ inventory investment value } & $\mathrm{N}$ & 68 & 68 & 68 & 68 & 68 \\
\hline & mean & -2.5 & -5.8 & -1.3 & 25.2 & -20.6 \\
\hline & $s d$ & $2,401.2$ & 330.5 & $1,469.6$ & 757.5 & 209.4 \\
\hline & p50 & 314.5 & -50.0 & 232.9 & -1.4 & -57.3 \\
\hline & p25 & $-2,201.3$ & -220.0 & $-1,224.4$ & -513.2 & -113.8 \\
\hline & p75 & $2,051.1$ & 204.5 & $1,267.6$ & 516.3 & 115.8 \\
\hline $\begin{array}{l}\text { revised quarterly } \\
\text { red }\end{array}$ & & Rrtotal & Rrfinal & Rrproc ${ }^{s}$ & Rrdist $\tilde{n}$ & Rrraw \\
\hline \multirow[t]{6}{*}{ inventory investment value } & N & 68 & 68 & 68 & 68 & 68 \\
\hline & mean & -0.0 & 0.0 & 0.0 & -0.0 & -0.0 \\
\hline & $s d$ & 682.2 & 202.0 & 289.4 & 414.7 & 175.5 \\
\hline & p50 & 157.1 & 15.0 & 56.3 & 16.9 & -9.0 \\
\hline & p25 & -557.1 & -107.8 & -148.2 & -300.1 & -116.6 \\
\hline & p75 & 546.6 & 130.1 & 215.8 & 294.6 & 103.6 \\
\hline year-to-year change & & L4rtotal & L4rfinal & L4rpro ̃ & L4rdis $\tilde{n}$ & L4rraw \\
\hline in quarterly inventory & $\mathrm{N}$ & 64 & 64 & 64 & 64 & 64 \\
\hline \multirow[t]{5}{*}{ investment value } & mean & -6.8 & 7.8 & 0.0 & -20.3 & 5.7 \\
\hline & sd & 910.3 & 276.2 & 303.8 & 573.0 & 244.0 \\
\hline & p50 & 142.7 & 10.8 & 8.3 & 43.3 & 7.4 \\
\hline & p25 & -383.6 & -138.8 & -185.0 & -332.4 & -129.4 \\
\hline & p75 & 650.9 & 189.6 & 223.3 & 384.8 & 165.2 \\
\hline
\end{tabular}

The sd (standard deviation) of Rrtotal is less than the $30 \%$ level of rtotal's, and that of L4rtotal is less than $40 \%$ of rtotal's. In particular, the sds of Rrprocess and L4rprocess, goods-in-process inventory investment value series, are just around $20 \%$ that of the original, rprocess whose fluctuations dominate the rtotal's fluctuations.

Next is the summary table of annual average of four quarterly GDP inventory investment estimates (quarterly Final), for example, martotal to the rtotal.

\begin{tabular}{|l|l|r|r|r|r|r|r|}
\hline annual average & & martotal & marfinal & marpro s & mardis n & marraw \\
\cline { 2 - 7 } of four quarterly GDP & $\mathrm{N}$ & 17 & 17 & 17 & 17 & 17 \\
inventory investment & mean & -2.5 & -5.8 & -1.3 & 25.2 & -20.6 \\
\hline estimates & sd & 578.3 & 100.9 & 143.3 & 368.4 & 76.2 \\
\hline & $\mathrm{p} 50$ & 30.2 & 8.5 & -1.1 & 84.5 & 11.6 \\
\hline & $\mathrm{p} 25$ & -186.6 & -49.4 & -21.2 & -241.0 & -89.1 \\
\hline
\end{tabular}

Naturally, the mean value of martotal, -2.5 , is the same as that of the rtotal in the previous table. The sd of martotal is a little over 80 percent of the Rrtotal's in the previous table, which is smaller than that of either rtotal or L4rtotal.

The next figure just adds the martotal to the previous figure. The martotal hovers around the Q3 value, with smaller sd. It is the annual average of four quarterly values, average of four values on the same vertical line. 


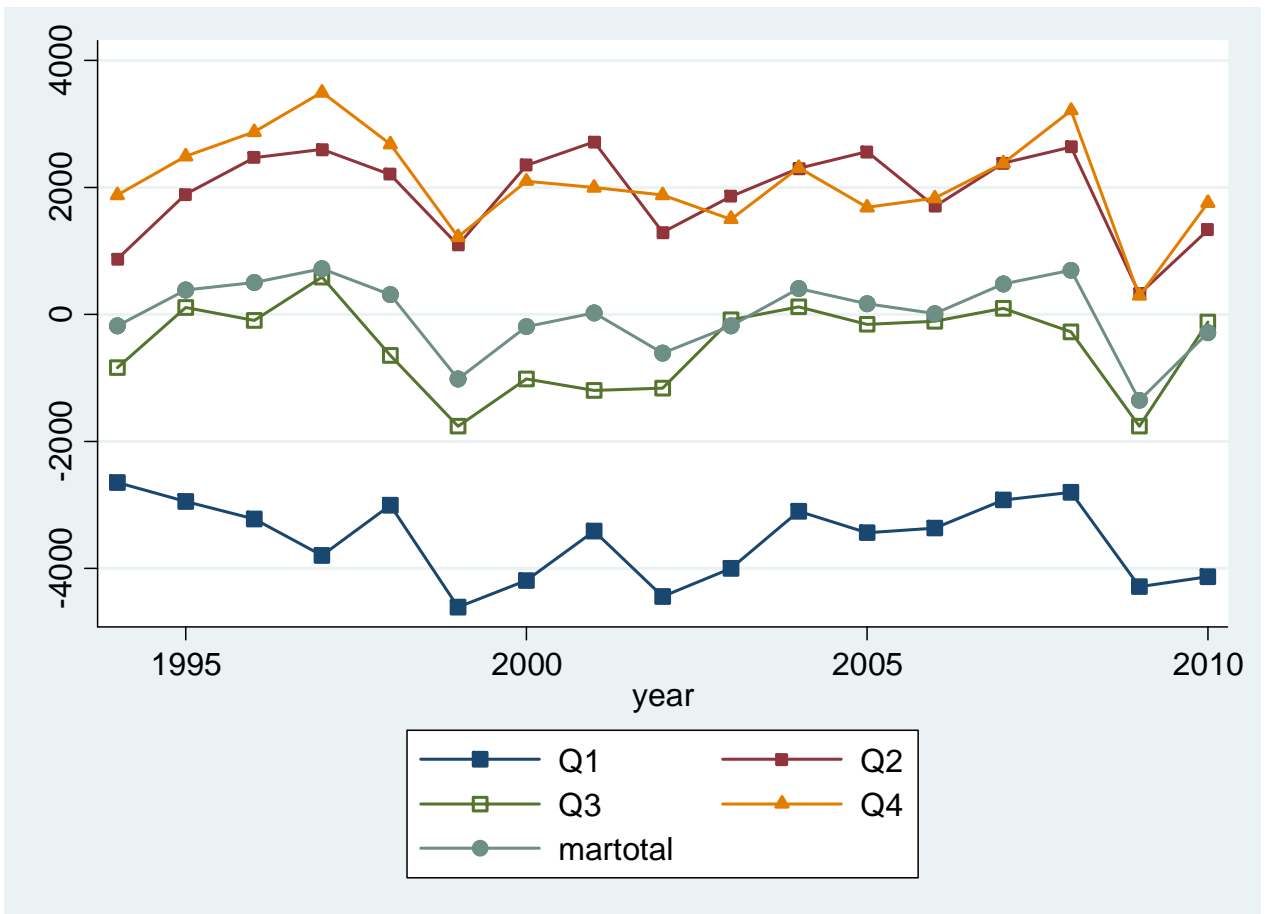

As a useful reference to confirm the preceding discussion, next I present four figures on each category of all industries inventory investment estimates by quarter, in the order corresponding to rfinal, rprocess, redistribution, and rraw. Note that the vertical scale is not always the same.

Both in the unambiguity of the patterns and in the length of vertical deviations, the regular seasonal fluctuation in quarterly inventory investment is the most spectacular in rprocess, and next in rdistribution. Although not so spectacular as in those two categories, regular seasonal fluctuations are observed also in rfinal and rraw. 

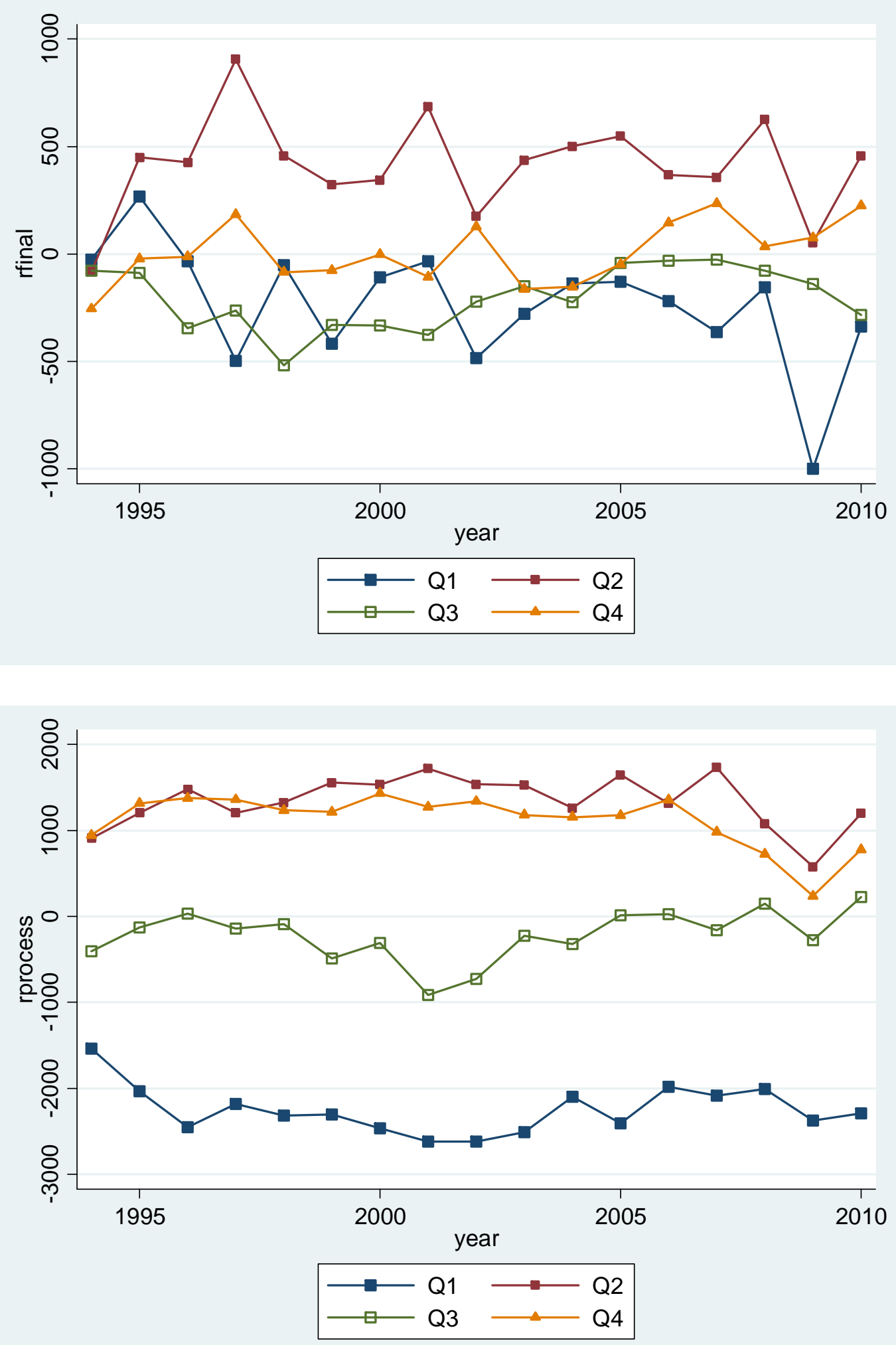

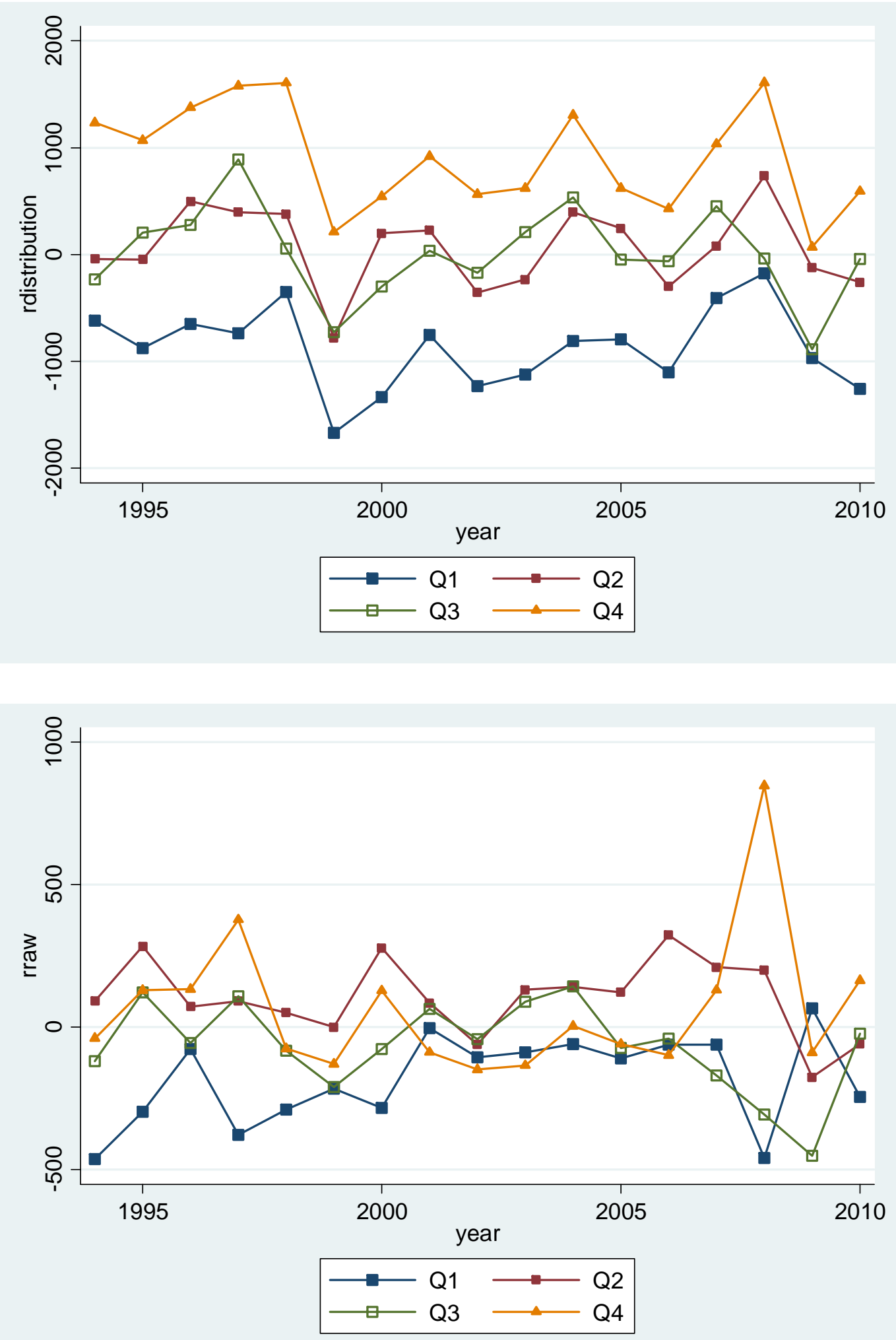

$\underline{\text { Rrtotal and others: Revised quarterly real inventory investment estimates series }}$ 
Emphasizing wild seasonal fluctuations in quarterly GDP inventory investment (Final) estimates, in this paper I think it a useful and appropriate adjustment method to deduct the average value by category from the original ones in each relevant category. As shown above in the second summary table in this section, with this method, the sd of Rrtotal, revised rtotal, over the whole period dramatically decreased to less than 30 percent of that of the original rtotal.

Here I show four figures, two for 2003 2010 studied in [4-2] Rrfinal and Rrprocess in the first and Rrdistribution and Rrraw in the second, both with Rrtotal, and two for 1994 2002 including the Financial Crisis period of 1997 1999 in a parallel manner with the first two. Readers confirm three points: first, regular seasonal fluctuations disappear almost completely; second, variations dramatically decrease; and third, distribution stock rather than goods-in-process stock becomes the dominant factor of quarterly total inventory investment fluctuations.

First comes the two figures for 2003 2010.
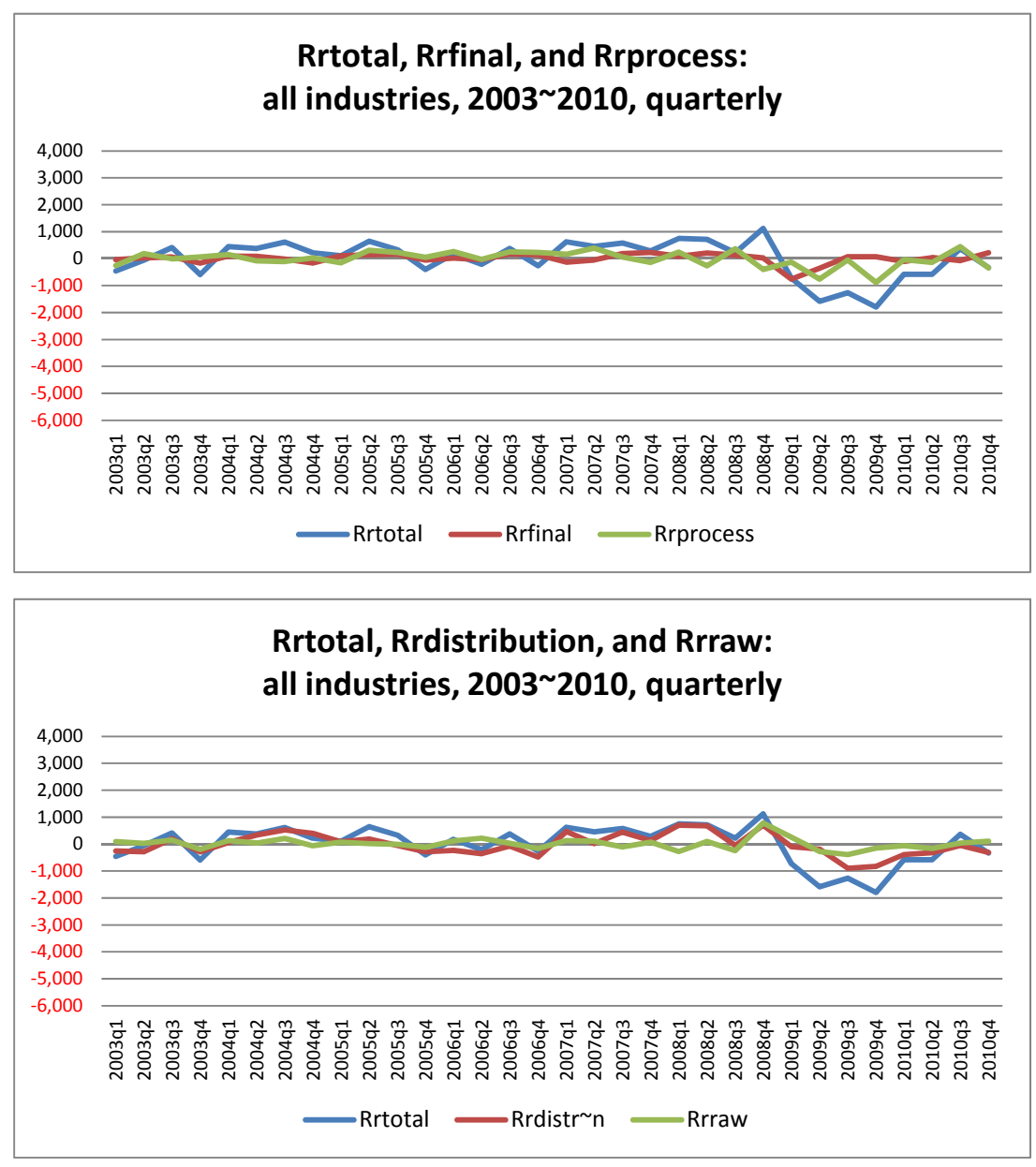

Next comes figures for 1994 2002. 


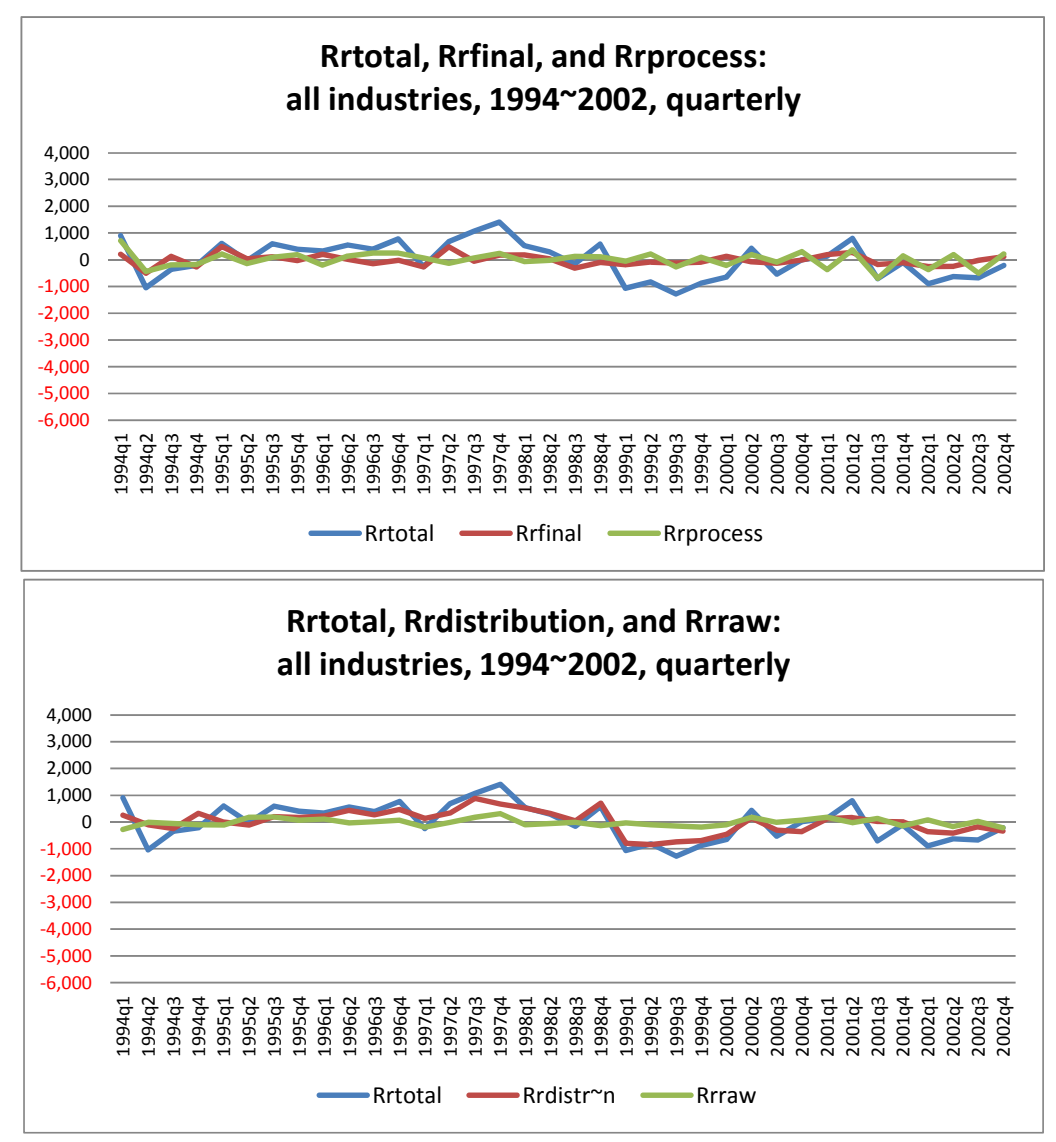

This study primarily uses the original series of the final estimates (kakuho) of quarterly GDP inventory investment statistics. As reference for comparison, the next figure shows both the original series and the seasonally adjusted series published by the Japanese government, both of which are of the quarterly GDP inventory investment statistics. rtotal stands for the original series, and AdjRrtotal the seasonally adjusted series. 35

35 No information on the objective and the method of seasonal adjustment is available. Recall the above footnote 13. 


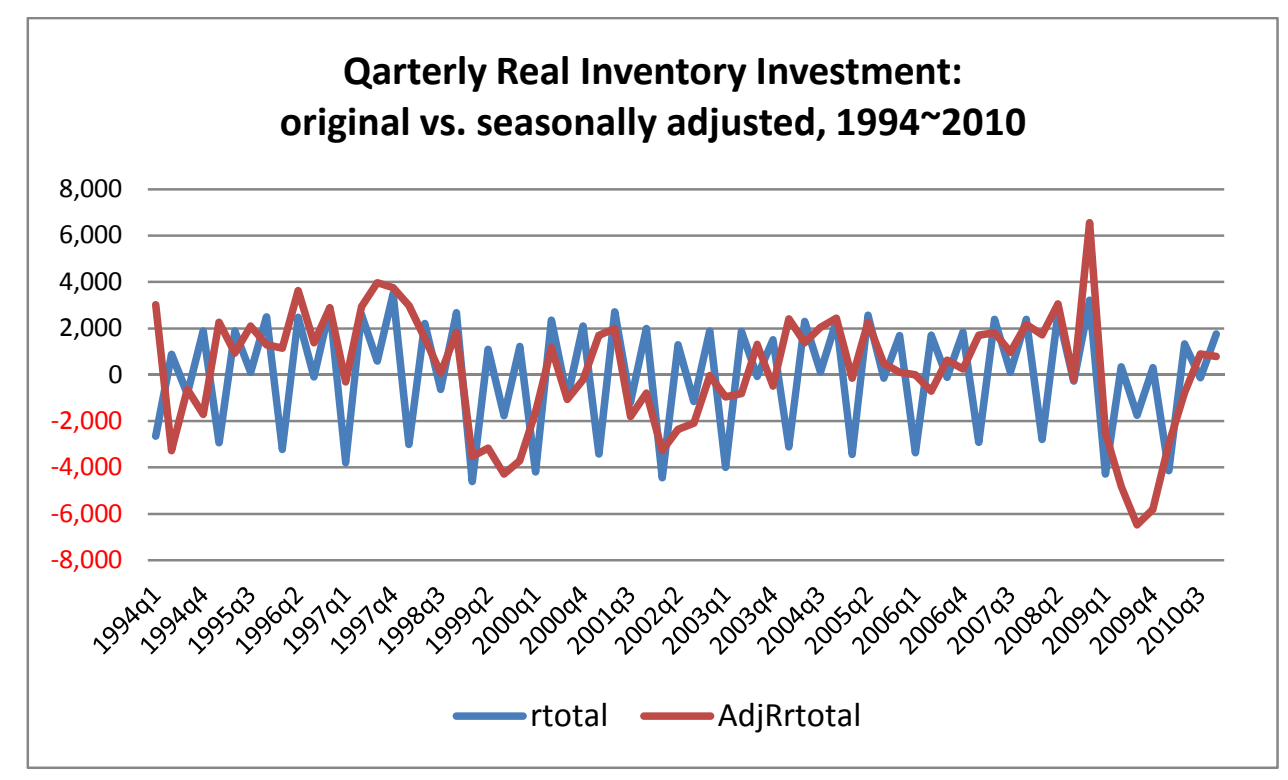

[6]. Sources of Wild Fluctuations in Quarterly GDP Inventory Investment Statistics

Wild seasonal fluctuations in quarterly GDP inventory investment statistics arise primarily from its estimation process, that is, estimation methods and source statistics. It is especially prominent in goods-in-process inventory investment that is dominant in total inventory investment fluctuations. By eliminating the influence of regular seasonal fluctuations, wild quarterly fluctuations decrease dramatically. Moreover, fluctuations in goods-in-process inventory investment, the dominant source of fluctuations in quarterly total inventory investment, disappear in annual statistics (or in annual averages of four quarterly statistics) almost entirely.

Upon all these observations, in Section [5] I drew two conclusions. It will be an important research issue in the future to investigate the sources and generating mechanisms of the M-shaped wild inventory investment fluctuations and adopt appropriate countermeasures.

(1) Wild fluctuations in quarterly inventory investment statistics do not accurately and appropriately reflect the economic reality of inventory investment and its fluctuations, the dominant portion of which arises on the estimation process of the quarterly GDP statistics.

(2) Aside from annual SNA accounts for accuracy demand for reporting accurately the economic reality, quarterly GDP accounts is published in response to promptness demand for diagnosing the state of the economy. Wild quarterly inventory investment fluctuations are observed in quarterly GDP accounts 
published for promptness demand, and inventory investment fluctuations radically decreased in annual SNA accounts for accuracy demand. Therefore, in investigating the reality of inventory investment and the fluctuation generating mechanisms where promptness is inessential, we should switch focus from the quarterly GDP estimates to the annual SNA estimates, and make active use of micro-based source statistics like IIP and Corporate Enterprise Statistics. In using the quarterly GDP inventory investment statistics, we should take account of wild and spectacular regular seasonal fluctuations.

As information for "an important research issue in the future", in [6] with background materials I suggest my basic view on a major source of wild regular seasonal fluctuations in quarterly GDP statistics.

As the third point I emphasized at the end of [3] that the inventory investment was the change in inventory stock value. Available inventory data are inventory stock values in corporate accounting, which are obtained upon inventory valuation standards. Hence, the change in inventory stock value, obtained by deducting the opening inventory value from the final inventory value, includes the changes due to the ones in valuation price. With fair-value adjustments at the end of accounting period, for example, without any change in inventory stock volumes, the inventory stock values may decrease dramatically, reporting a huge negative value in inventory investment.

In my view, a large portion of wild regular seasonal fluctuations in quarterly GDP inventory investment statistics is most likely to be due to regularly conducted fair-value adjustments. In addition, a vast majority of Japanese firms, choosing a year from April to next March as accounting period, end the accounting year at the end of March is also the end of its fourth quarter. For those firms, the end of September is the end both of midterm period and of second quarter. As a consequence, every year inventory investment starts with a big negative value in Q1 valued at the end of March, jumps up the a big positive value in $\mathrm{Q} 2$, jumps down halfway in Q3, jumps up again to the top in Q4, and then return to the level around the starting point in the next Q1, thus forming a M-shaped annual fluctuation.

\section{Explanation $^{36}$}

At the end of accounting year a firm is forced to comply with a set of accounting regulations. For example, at the end of accounting year it has to re-evaluate the current value of inventory asset when its current value falls below the fixed ratio of acquisition

${ }^{36}$ No reference with clear statements is available, however. This explanation is based on my interviews from several persons including academic experts in accounting. 
cost. The ratio was raised higher recently, which makes this regulation have a much higher impact. Under this regulation, a firm has to re-evaluate the value even when it strongly expects soon a sharp rise in market value. For instance, in industrial machinery manufacturing sector where made-to-order is dominant, some products, remain as inventory stock, goods-in-process stock in particular, due to cancellation or postponing delivery. In such cases, the current value often drastically decreases, falling below the fixed ratio of acquisition cost.

In addition to mandated regulations, as an in-house rule or custom or as a business strategy, a firm re-evaluates inventory stocks particularly at the end of accounting year, and at the end of midterm accounting year, which also have big impact. The executive branch, accounting department in particular, are not able to accurately understand the status of profits and finance by just accepting the reported figures from manufacturing and marketing divisions. For decreasing the risk of management control problems over the corporate organization and alleviating bloated inefficiency, the accounting department often appraises and evaluates the financial status of individual divisions, part of which are stock value re-adjustments at the end of accounting term. Stock value re-adjustments, reducing pre-tax profits, often reduce (or roll over) the amount of corporate income tax payment.

Inventory stock evaluation costs money. At what timing, in what rigor and coverage, and who design and implement the stock value re-evaluation differs between firms. Furthermore, when and what part of re-evaluation results obtained by accounting department is open to other in-house divisions, and further to the public also differs by firm and by information. For example, the division that reports to government statistical survey does not always possess all the re-evaluation results available to the accounting department. Relevant information the reporting division possesses may not always be reflected accurately in the report to the statistical office. Particularly, the responses to the questionnaires about quarters other than the end of accounting period and midterm period, Q2 and Q4 in the present study, may not be of the same character and quality as that of the end of the period, which is obtained primarily to make public.

The effects of the aforementioned factors greatly differ between firms making replies, however. The accounting periods may affect the firm's choices about which a firm would record existing stocks as inventory. Firms may take positive (or negative) actions for settling the enterprise's accounts. Firms often expedite or delay delivery to distributors either materially or on paper.

At the end of accounting period a firm may take other actions than fair-value adjustments. Some promote sales, often at a substantial discount, and others demand 
distributors to accept more as stocks (channel stuffing). ${ }^{37}$

The effects of those corporate accounting institutions and customs, and in-house decisions substantially differ both between firms and industries, which also depend on time. Moreover, both the type of its effects and its importance differ between Japan and the US, for instance. To my knowledge, there is little research on those points, and no relevant information is available.

\section{Seasonal Fluctuations of Inventory Investment in Corporate Enterprise Quarterly}

\section{$\underline{\text { Statistics }}$}

Quarterly SNA (GDP) accounts estimates inventory investment (change in private inventory stock) by category, in four categories of product-, goods-in-process-, raw material-, and distribution stock, and sums up. On estimating the quarterly inventory investment values, Corporate Enterprise Quarterly Statistics (CEQS) is of critical importance, which is directly used as source statistics for goods-in-process- and material stock. ${ }^{38}$ Change in inventory stock values is estimated by commodity from the inventory stock value in corporate accounting data, typically surveyed in CEQS. As I show below soon, evident regular seasonal fluctuations are observed also in the estimates of inventory stock values and changes in their values in CEQS surveyed by firm and published by industry. This suggests that regular seasonal fluctuations in quarterly GDP inventory investment statistics do not emerge primarily on the process of conversion and estimation from the source statistics. As reference material for the former, I present relevant results of my CESQ study. ${ }^{39}$

Inventory stock values (not inventory investment values) in CEQS are respectively aggregates of inventory stock values by category reported by firms, and therefore respective aggregates of raw material, goods-in-stock, and product firms possess as inventory stock both at the start and the end of the period. Thus, in industries like the automobile industry where industry classification corresponds to commodity classification, goods-in-process- and product stock data in CEQS basically corresponds to those in GDP statistics, in coverage of survey objects and stock values. As for material stock, coverage of survey objects is completely different. Distribution stock is not directly surveyed in CEQS. In CEQS distribution sector is classified and

37 Experts may illustrate this group of observations as "end-of-accounting-period adjustments". Relevant information is decisively missing, however, and no effective measure is available for identifying them and evaluating their importance.

38 CAO [2012, pp.27 29].

39 Here I present figures on all size categories. Although I studied also two size categories, from $¥ 100$ million $¥ 1$ billion and more than $¥ 1$ billion in paid-in capital, I found no noteworthy difference to report. 
surveyed in two industries, wholesaling and retailing. Any estimate corresponding to automobile distribution stock, for example, is unavailable. ${ }^{40}$

In Section [6] I show the results in the order corresponding to the manufacturing sector in total, wholesaling, and retailing. I show the results of CEQS study by industry in [9], following the examination of quarterly GDP inventory investment estimates by commodity in [7] and [8].

First comes the movement of inventory investment values (=change in stock values during the quarter) in the manufacturing sector as a whole. Two figures show the movement for 2006 2012Q3 and 1997 2002, respectively, of inventory investment values in three categories, product (final), goods-in-process (process), and material, and also inventory investment in total (total), (unit=¥million).
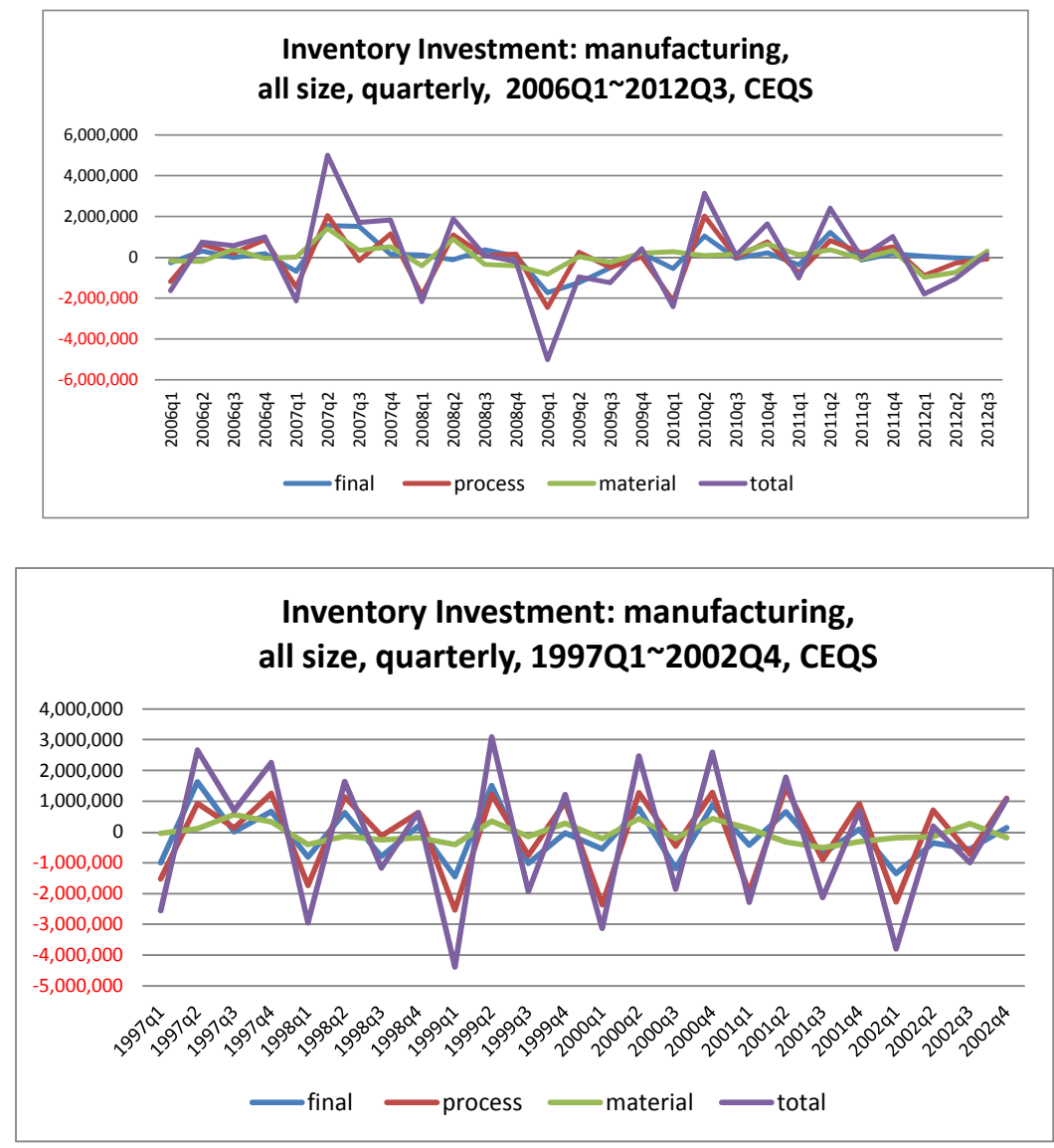

Of the total inventory stock in the manufacturing sector, product inventory occupies approximately 40 percent, and goods-in-process inventory and material inventory 35 percent and 25 percent, respectively. The ratio of total inventory to total assets is

40 Kunitomo [2001] discusses the application of seasonal adjustment methods, particularly the X-12-ARIMA method, to main items of CEQS, such as sales, profits, fixed investment, and inventory (investment), suggesting great difficulties particularly in application to inventory (investment) estimates. 
approximately 10 percent.

The total inventory stock value in the manufacturing sector is $¥ 40$ trillion, which is 30 percent larger than the value in the construction industry, $¥ 30$ trillion, in the first half of the 1990s, and also exceeds the sum of wholesaling sector’s $¥ 20$ trillion and retailing sector’s $¥ 10$ trillion.

The maximum ratio (in absolute value) of total inventory investment value to inventory stock value, $¥ 4$ billion/ $¥ 40$ billion, is 10 percent.

Both every inventory investment by category and in total shows M-shaped regular seasonal fluctuations.

During the period around Lehman Shock neither a notable increase in inventory stock nor a long-run stock adjustment process is found anywhere. Actually, over two years after the shock, the inventory investment continuously fell below the previous level, deforming temporarily the regular seasonal fluctuations.

Including the case of 2011Q2 after the Great East Japan Earthquake, in no shock periods I find a notable increase in inventory stock. The inventory investment value in $2011 \mathrm{Q} 2$ is rather lower than the previous Q2 values.

In order to confirm the existence of regular seasonal fluctuations I show the figures on movement of estimates by quarter that I used in [5], in the order corresponding to inventory investment in total, product inventory investment, and goods-in-process inventory investment. Only to the first figure I add the movement of annual average inventory investment.

Regular seasonal fluctuation is especially prominent on goods-in-process inventory investment value. As was the case in [5], the annual average inventory investment is the least volatile.

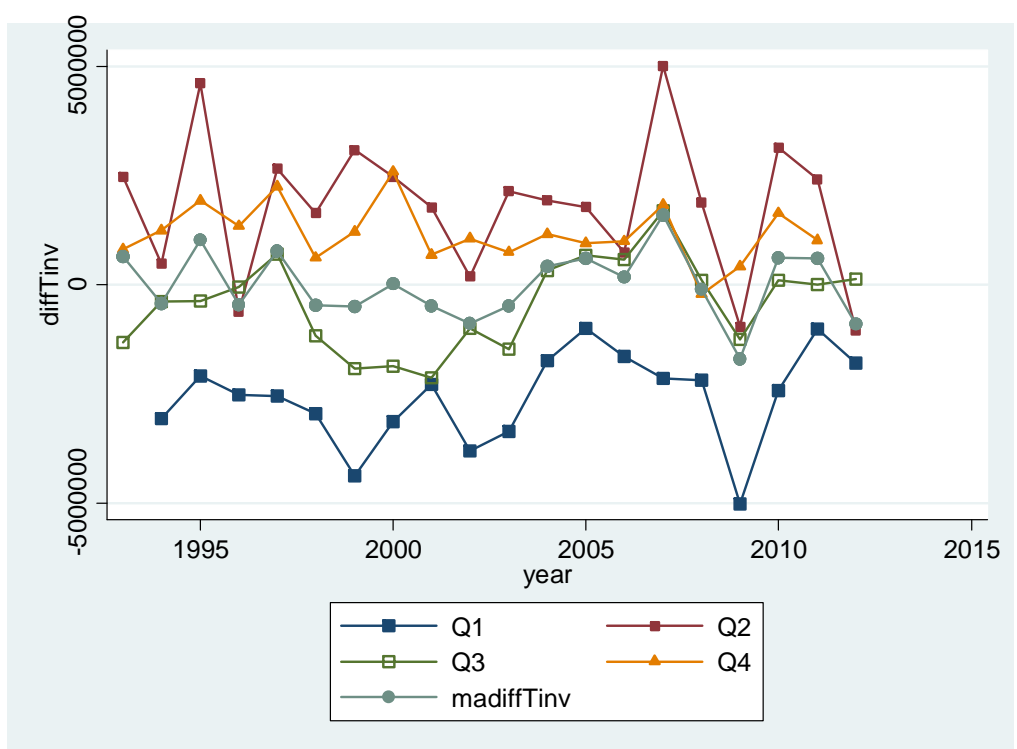



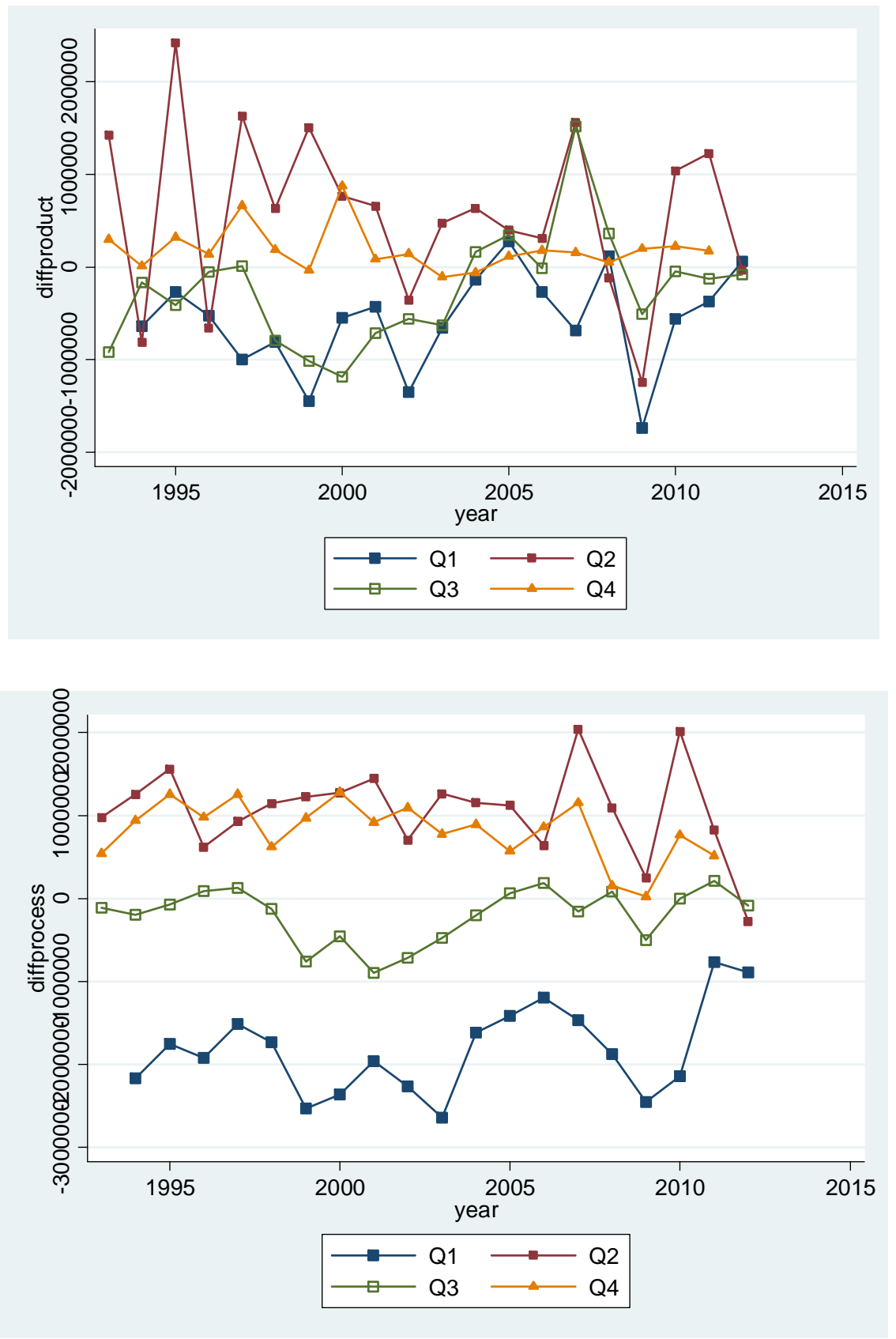

Because distribution stock is not rich in information, I show figures on inventory investment in wholesaling and retailing industries from CEQS. In both most is goods-in-process inventory stock, approximately $90 \%$ in the former and $97 \sim 98 \%$ in the latter. Naturally most variations in inventory investment value arise from goods-in-process inventory investment. In both, the ratio of total inventory stock to total assets is $10 \%$. I show figures in the same way as the case of the manufacturing sector.

First comes the wholesale industry. 

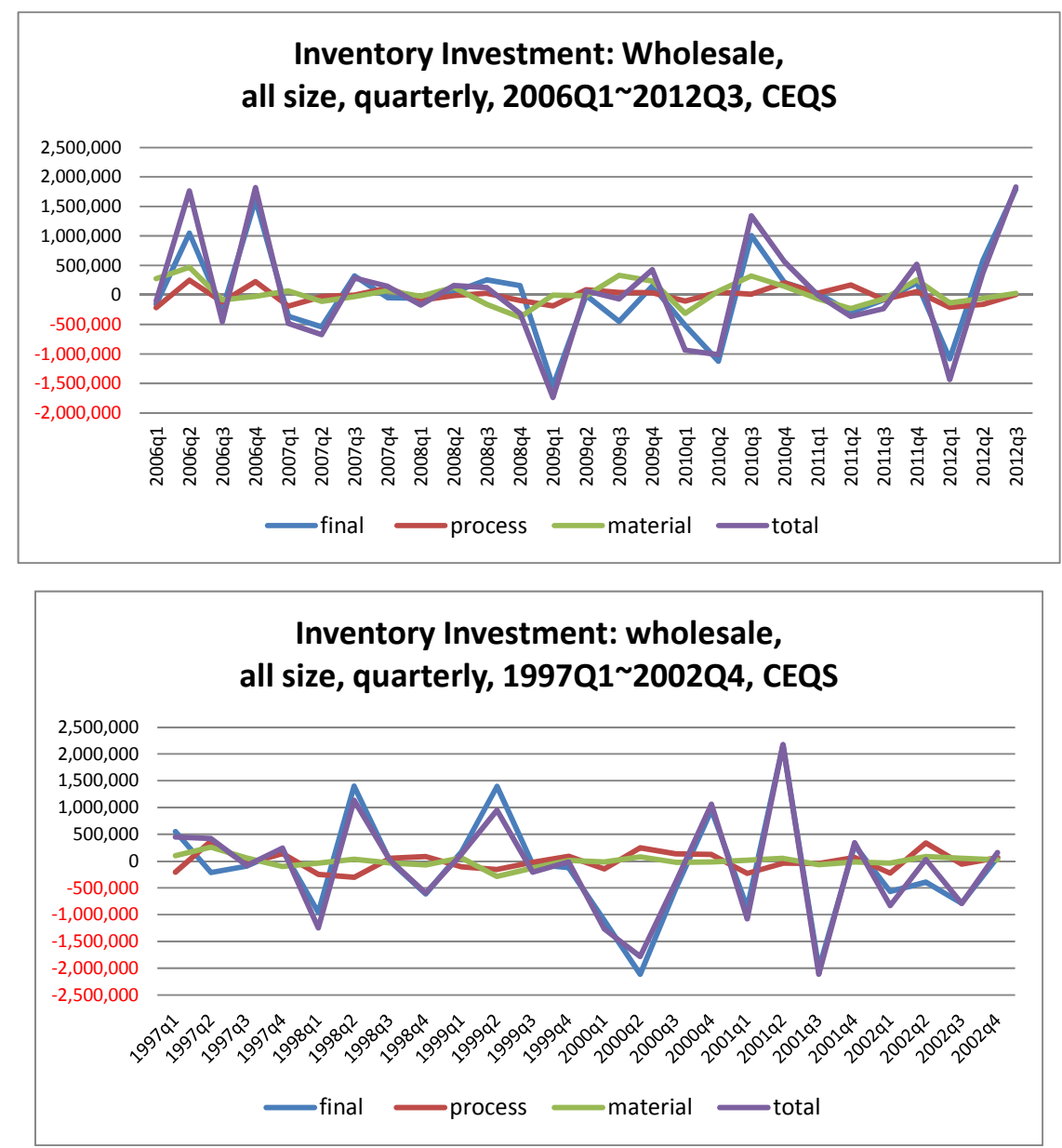

On average the total stock value is $¥ 20$ trillion, and the maximum absolute value of inventory investment, $¥ 2$ trillion, is equivalent to $10 \%$ of the total stock value.

No notable increase in inventory stock is found either in the 2008Q4 just after the Lehman Shock or in 2008Q3, and inventory investment decreased radically in the next 2009Q1. It seems that there was little increase in purchased goods that remained unsold and that due to fair-value adjustment at the end of March 2009 inventory stock value drastically decreased. I find little influence of the Earthquake in March 2011, either. The seasonal variation may offset the stock increase in 2009Q1, however.

Wholesalers' inventory investment in CEQS corresponds to part of quarterly GDP distribution stock investment. It fluctuates wildly, but like the quarterly GDP distribution stock investment, it does not show regular seasonal fluctuations.

Next comes the retail industry. 

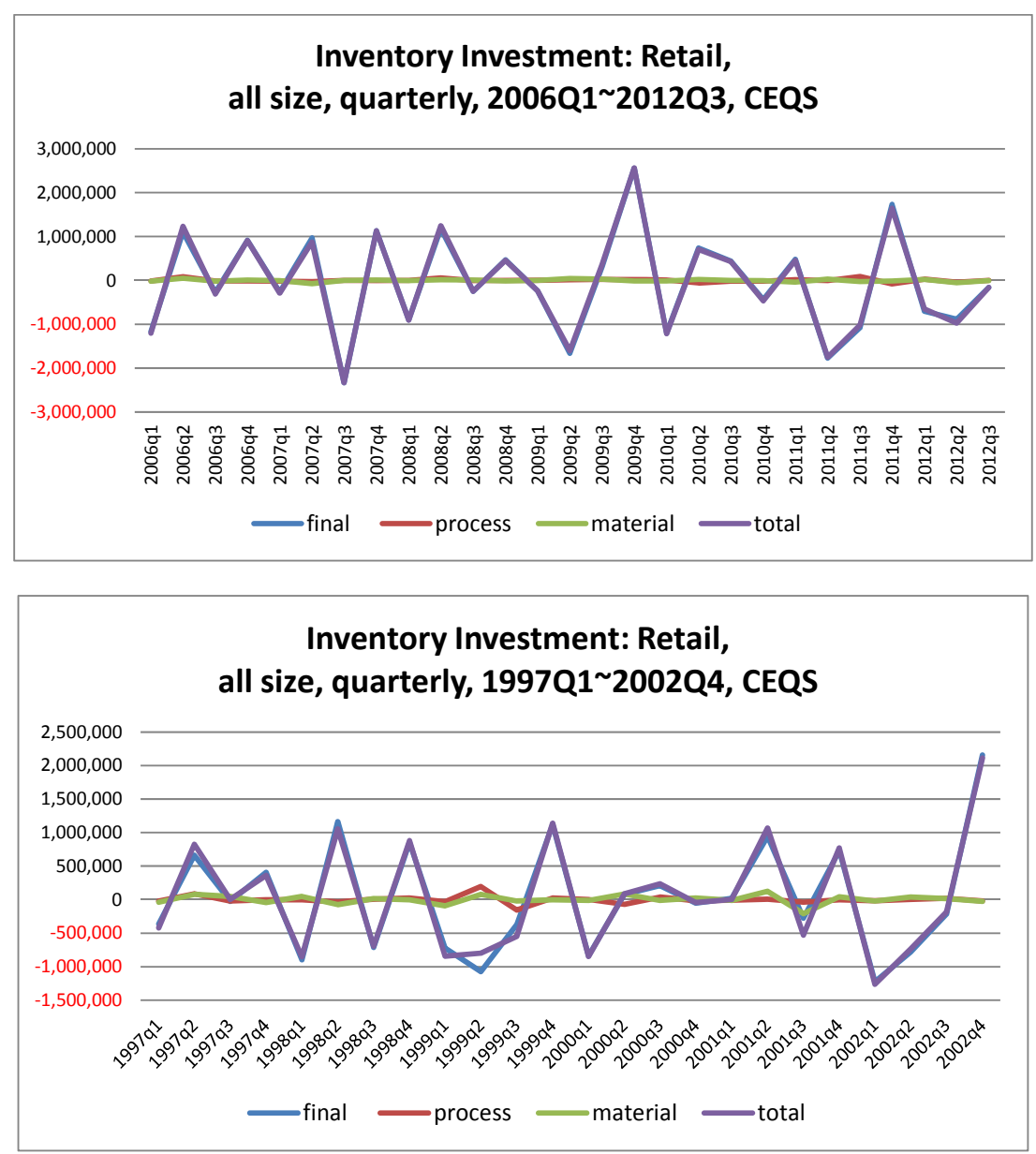

The maximum absolute value of inventory investment, $¥ 2$ trillion, is equivalent to $20 \%$ of the total tock value of the retailing sector, $¥ 10$ trillion.

Either after the Lehman Shock or after the Earthquake, no notable increase in inventory stock is observed.

Retailers' inventory investment in CEQS corresponds to part of quarterly GDP distribution stock investment. It fluctuates wildly, but like in the wholesale industry, it does not show regular seasonal fluctuations.

Unlike in the case of inventory investment estimates in quarterly GDP statistics, we can obtain from CEQS the estimates of inventory stock value.

The ratio of maximum absolute value of quarterly inventory investment to total stock value is, $10 \%$ both in the manufacturing- and wholesaling industry, and $20 \%$ in the retailing. For example, assuming the inventory investment is all due to fair value adjustments at the end of accounting period, the maximum adjustment ratio is $10 \%$ or $20 \%$. 
[7]. Investigation of Corporate Inventory Investment Behavior, Focusing on the Lehman Shock Period: By Commodity

[7-1]. Introduction

In Sections [7] [9], I investigate the corporate inventory investment behavior, focusing on the consequences of an exogenous shock, realization of unexpected situation to most firms during the period called "the Lehman Shock" and its adjustment process.

As shown in previous sections, inventory investment estimates in the Japanese quarterly GDP statistics reveal wild and regular seasonal fluctuations. Keeping this observation in mind, I use this quarterly GDP inventory investment statistics in Sections [7] [9], which do not influence greatly the conclusions. For example, 2008Q4 expected to be the peak of the inventory accumulation process due to unexpected sales decrease after the Lehman Shock would be emphasized by it because it is the $4^{\text {th }}$ quarter.

In this study I use the quarterly GDP inventory investment statistics both by inventory category and by commodity, and in the following sections I actively use the latter side. The conclusions drawn in previous sections basically hold when investigated by commodity, which I briefly mention below.

\section{Inventory investment by industry}

Recall the figures in [4-2] on the quarterly inventory investment of the all industries in 2003 2010 both on total inventory and by category, and focus on the Lehman Shock period, particularly on 2008Q4 and 2009Q1. Also recall the corresponding figures in Section [5] shown by each quarter.

Note four points from figures in [4-2]. Particularly points (1) and (3) can be more clearly confirmed with figures in [5] by each quarter. I find either little accumulation of inventory stock expected as a consequence of unexpected exogenous shock or the subsequent inventory adjustment process.

(1) The inventory investment in 2008Q4 recorded a large positive value, whose size however reached slightly more than that of previous $2^{\text {nd }}$ or $4^{\text {th }}$ quarters.

(2) As viewed by category, goods-in-process- and product inventory in 2008Q4 were slightly smaller than the previous quarters. The distribution inventory investment notably increased in 2008Q4 than in the previous $4^{\text {th }}$ quarters, which was the dominant factor of total inventory investment increase. The raw material inventory investment, almost always nearly zero, recorded a positive value, as 
well.

(3) The volume of inventory investment in the following 2009Q1 recorded a huge negative value, which however was slightly below the level of previous $1^{\text {st }}$ quarters. The absolute value of (the 2008Q4 inventory investment volume) - (its average in previous $4^{\text {th }}$ quarter values) is smaller than the absolute value of (the 2008Q4 inventory investment volume) - (its average in previous $1^{\text {st }}$ quarter values). This observation suggests that, if the former is the inventory accumulation as a consequence of unexpected shock, its resolution was completed within the next quarter.

(4) The large negative value of goods-in-process inventory investment in the 2009Q1 overwhelmed the corresponding negative values of other categories, the absolute value of which did not exceed the average value of the previous $1^{\text {st }}$ quarters. The same applies also to the distribution inventory investment. The product inventory investment recorded a slightly larger negative value, and the raw material inventory investment nearly zero.

\section{$\underline{\text { Inventory investment by commodity: eight commodities }}$}

In this study I use quarterly GDP inventory investment estimates in 4 inventory categories and in 91 commodities, which are obtained as intermediate products on the process of estimating the final aggregate data. The number of commodities whose inventory investment was not always zero was 59 , and it is impractical to study inventory investment by commodity in all individual commodities.

In Sections [7] and [8], I focus on eight commodities: automobile, electric device and electric machine (hereafter, electric-machine), special-purpose machine (special machinery), general-purpose machine (general machinery), non-ferrous metal refining and manufacturing (non-ferrous metal product), steel product, petroleum product, apparels and personal belongings (apparel). I chose eight commodities from those with large weight in all industries total inventory investment), particularly with large weight during the Lehman Shock period, with sufficient attention given to diversity and balance.

I place a special focus on 2008Q4 and 2009Q1. In the former all industries total inventory investment volume was slightly larger in absolute value than the $4^{\text {th }}$ quarter average, and the latter than the $1^{\text {st }}$ quarter average, too. From among commodities with large weight in all industries total inventory investment during these quarters, I choose four durables (automobile, electric-machine, special machinery, and general machinery, of which automobile is consumer durable, special and general machinery are industrial 
durable, and electric-machine includes both), three industrial materials and fuel (non-ferrous metal product, steel product, and petroleum product) and one non-durable (apparel), in total eight commodities.

Position of eight commodities and the structure by category of inventory investment

Next table exhibits the total inventory investment of individual commodities and all industries first in the values (unit: billion yen) and share by category to the total value, for 2008Q4 and 2009Q1 respectively. In several cases the share by category was negative.

For example, in special and general machinery which are industrial durables shares of goods-in-process inventory investment were high, and particularly in 2009Q1 when inventory investment drastically decreased its shares were overwhelming $(72.2 \%$ and 98.2\%). In contrast, in apparel (consumer non-durable) the share of distribution inventory investment was predominant (109.9\% and $82.9 \%)$.

\begin{tabular}{|c|c|c|c|c|c|c|c|c|c|c|}
\hline & \multicolumn{3}{|l|}{ 2008Q4 } & & & \multirow[t]{2}{*}{ 2009Q1 } & & & \multirow[b]{3}{*}{ rdistribution } & \multirow[b]{3}{*}{ rraw } \\
\hline & & \multicolumn{2}{|c|}{ share to rtotal $(\%)$} & & & & \multicolumn{2}{|c|}{ share to rtotal (\%) } & & \\
\hline & rtotal(value) & rfinal & rprocess & rdistribution & rraw & rtotal(value) & rfinal & rprocess & & \\
\hline apparel & 48.7 & 25.1 & -5.3 & 109.9 & -29.4 & -213.5 & 7.8 & 5.2 & 82.9 & 4.1 \\
\hline petroleum & 435.1 & -26.7 & -5.4 & 30.2 & 101.9 & 402.8 & 4.1 & 2.1 & 44.7 & 49.1 \\
\hline steel & 54.0 & -139.6 & 46.7 & 55.4 & 137.6 & -221.6 & 62.5 & 16.3 & 8.0 & 13.2 \\
\hline non-ferros metal & 189.6 & -5.1 & 21.7 & 25.3 & 58.2 & 74.6 & 23.7 & -23.9 & 93.2 & 6.8 \\
\hline general machinery & 94.5 & 41.8 & 48.9 & 9.2 & 0.0 & -176.9 & 14.9 & 72.2 & 12.9 & 0.0 \\
\hline special machinery & 207.8 & 35.9 & 51.7 & 12.4 & 0.0 & -197.3 & -16.4 & 98.2 & 18.2 & 0.0 \\
\hline electric-machine & 555.9 & 12.7 & 26.1 & 61.2 & 0.0 & -1292.8 & 18.6 & 50.6 & 30.7 & 0.0 \\
\hline automobile & 553.2 & 2.3 & 32.4 & 65.2 & 0.0 & -837.1 & 42.0 & 30.1 & 27.8 & 0.0 \\
\hline all inudstries & $3,215.9$ & 1.1 & 22.6 & 50.0 & 26.4 & $-4,278.1$ & 23.4 & 55.6 & 22.6 & -1.5 \\
\hline
\end{tabular}

The next table, for total-, goods-in-process-, and distribution inventory investment, exhibits the share (\%) of each commodity and their sum total to the all industries inventory investment value in two focused quarters, respectively. In all cases, the sum total of eight commodity's shares exceeded $50 \%$. The shares of electric-machine and automobile were remarkably high.

The $2^{\text {nd }}$ and $3^{\text {rd }}$ columns show the share of goods-in-process- and distribution inventory investment to the total inventory investment. The share of the former in 2008Q4 was $22.6 \%$, and in 2009Q1 55.6\%.

\begin{tabular}{|c|c|c|c|c|c|c|c|c|c|c|c|}
\hline & & & & & & & & & & unit: \% & \\
\hline & & 8 commodities' share & & & & non-ferros & general & special & eletric- & & \\
\hline & & in all industries & apparel & petroleum & steel & metal & machinery & machinery & machine & automobile & total \\
\hline \multirow[t]{2}{*}{ rtotal } & 2008.Q4 & 100.0 & 1.5 & 13.5 & 1.7 & 5.9 & 2.9 & 6.5 & 17.3 & 17.2 & 66.5 \\
\hline & 2009.Q1 & 100.0 & 5.0 & -9.4 & 5.2 & -1.7 & 4.1 & 4.6 & 30.2 & 19.6 & 57.5 \\
\hline \multirow[t]{2}{*}{ rprocess } & 2008.Q4 & 22.6 & -0.4 & -3.3 & 3.5 & 5.7 & 6.4 & 14.8 & 20.0 & 24.7 & 71.4 \\
\hline & 2009.Q1 & 55.6 & 0.5 & -0.4 & 1.5 & 0.7 & 5.4 & 8.1 & 27.5 & 10.6 & 54.0 \\
\hline \multirow[t]{2}{*}{ rdistribution } & 2008.Q4 & 50.0 & 3.3 & 8.2 & 1.9 & 3.0 & 0.5 & 1.6 & 21.2 & 22.5 & 62.1 \\
\hline & 2009.Q1 & 22.6 & 18.3 & -18.6 & 1.8 & -7.2 & 2.4 & 3.7 & 41.1 & $24.1^{\circ}$ & 65.6 \\
\hline
\end{tabular}

[7-2]. Automobile, and Electric-machine 
In sections [7-2] [7-5] I study the inventory investment in eight commodities by commodity and by inventory category in the order corresponding to automobile and electronic-machine ([7-2]), special machinery and general machinery ([7-3], non-ferrous metal-, steel-, and petroleum product [7-4]), and apparel ([7-5]).

As shown below, both the composition ratio (shares) by category and fluctuation patterns of inventory investment varies a great deal depending on commodity. It is hard to select commodities that typically represent inventory investment composition and its fluctuation pattern, and my selection may not be exempt from blame that it is leading to an oversimplification. In any case, as a result both of the large shares in all industries inventory investment and of their wild fluctuations, four commodities I study in [7-2] and [7-3] represent and move in tandem with the all industries inventory investment behavior and fluctuation patterns we studied in previous sections.

[7-2-1]. automobile

\section{Quarterly inventory investment}

Four figures exhibit the quarterly inventory investment in automobile (unit: billion yen), in total and by category, 2003 2010. The first figure exhibits the total and all four categories, then, three figures each for rfinal, rprocess, and rdistribution with rtotal, omitting rraw which is consistently 0 .

All three categories move in tandem with the total inventory investment. Over the whole period, the influence of goods-in-process inventory was the largest, but for the period after Lehman Shock that of distribution inventory became overwhelming. The distribution inventory investment consistently reported a positive value from 2007 to the 2008Q4, and then recorded a negative value for 6 quarters since 2009Q1 and a big positive value in $2010 \mathrm{Q} 3$.

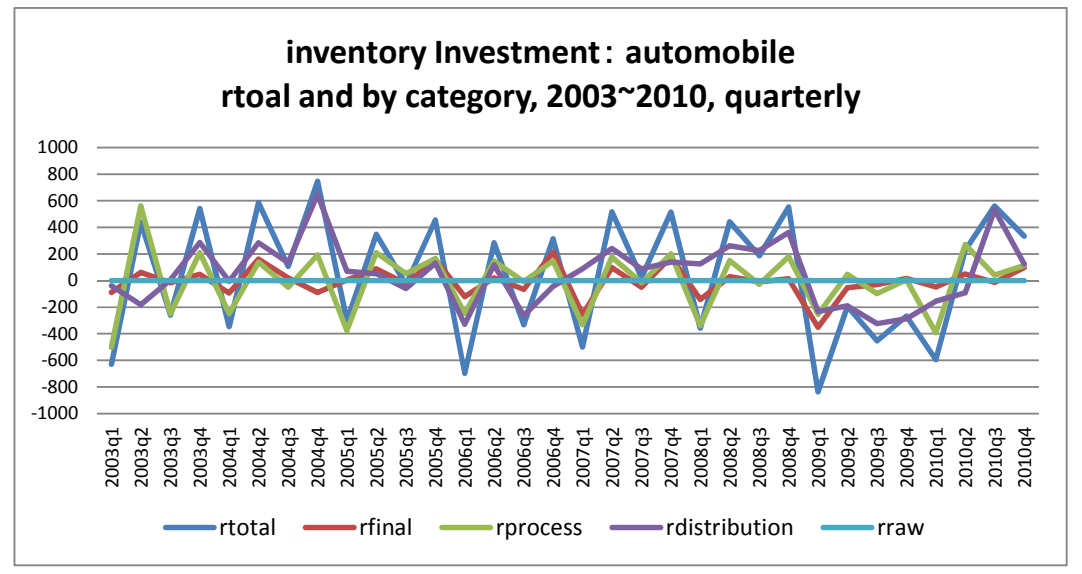



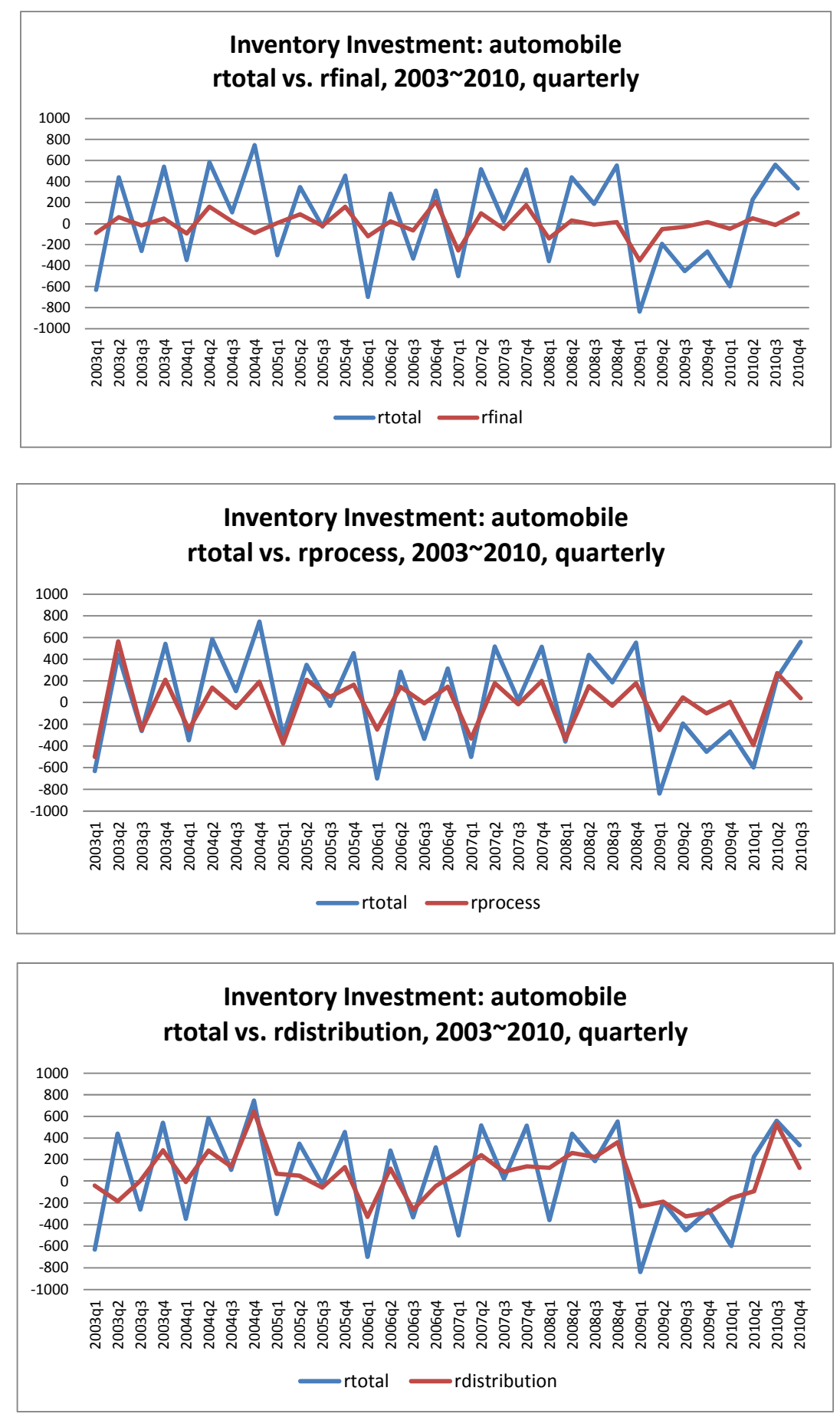

Annual inventory investment: 1994 2010

In annual automobile inventory investment estimates, 1994 2010, the influence of distribution inventory was overwhelming over the entire period. In contrast, that of the goods-in-process inventory, in quarterly estimates more than comparable to the distribution inventory, became dramatically small. 
Both in quarterly- and annual estimates the influence of product inventory investment was extremely low-profile.

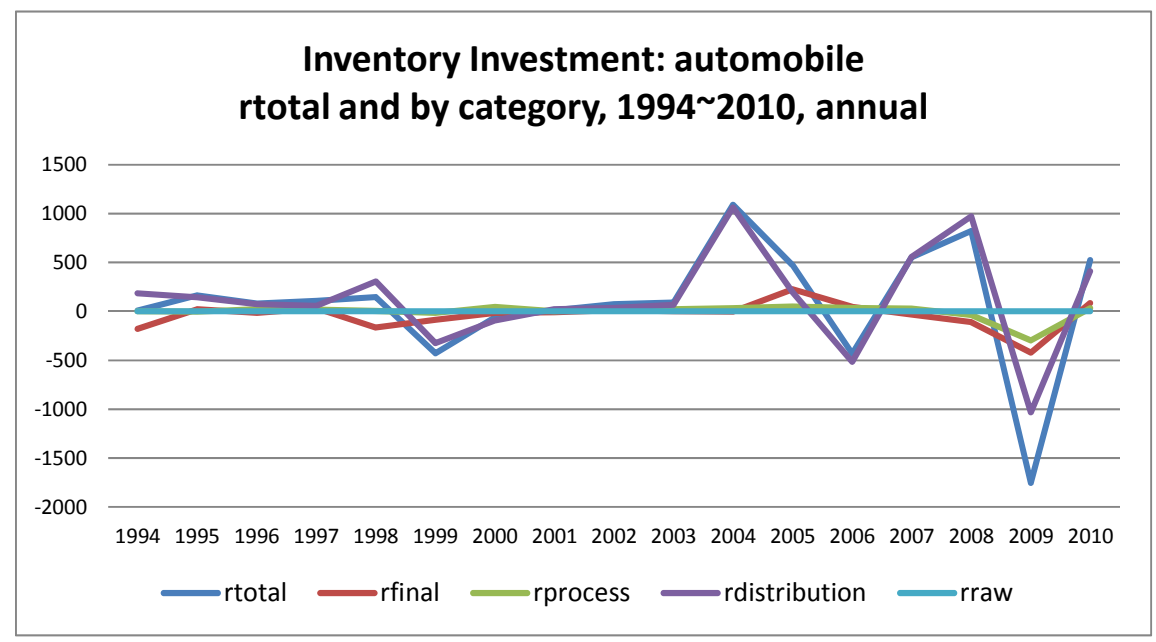

[7-2-2]. Electric-machine

Quarterly inventory investment

Also in electric-machine rraw was almost always 0 (although before 2003 it was not exactly 0 ).

Both in quarterly- and annual estimates, the fluctuation pattern of electric-machine inventory investment in many aspects are similar to that of automobile. In quarterly estimates all three categories move in tandem with the total inventory investment. Over the whole period, the influence of goods-in-process inventory was the largest, but after 2006, 2006 2007 in particular, that of the distribution inventory became overwhelming.

Unlike the case of automobile, nowhere we find the distribution inventory investment recorded either a positive or negative value continuously over a year. We find no noticeable change in its fluctuation pattern before and after the Lehman Shock. Rfinal consistently fluctuated little. 

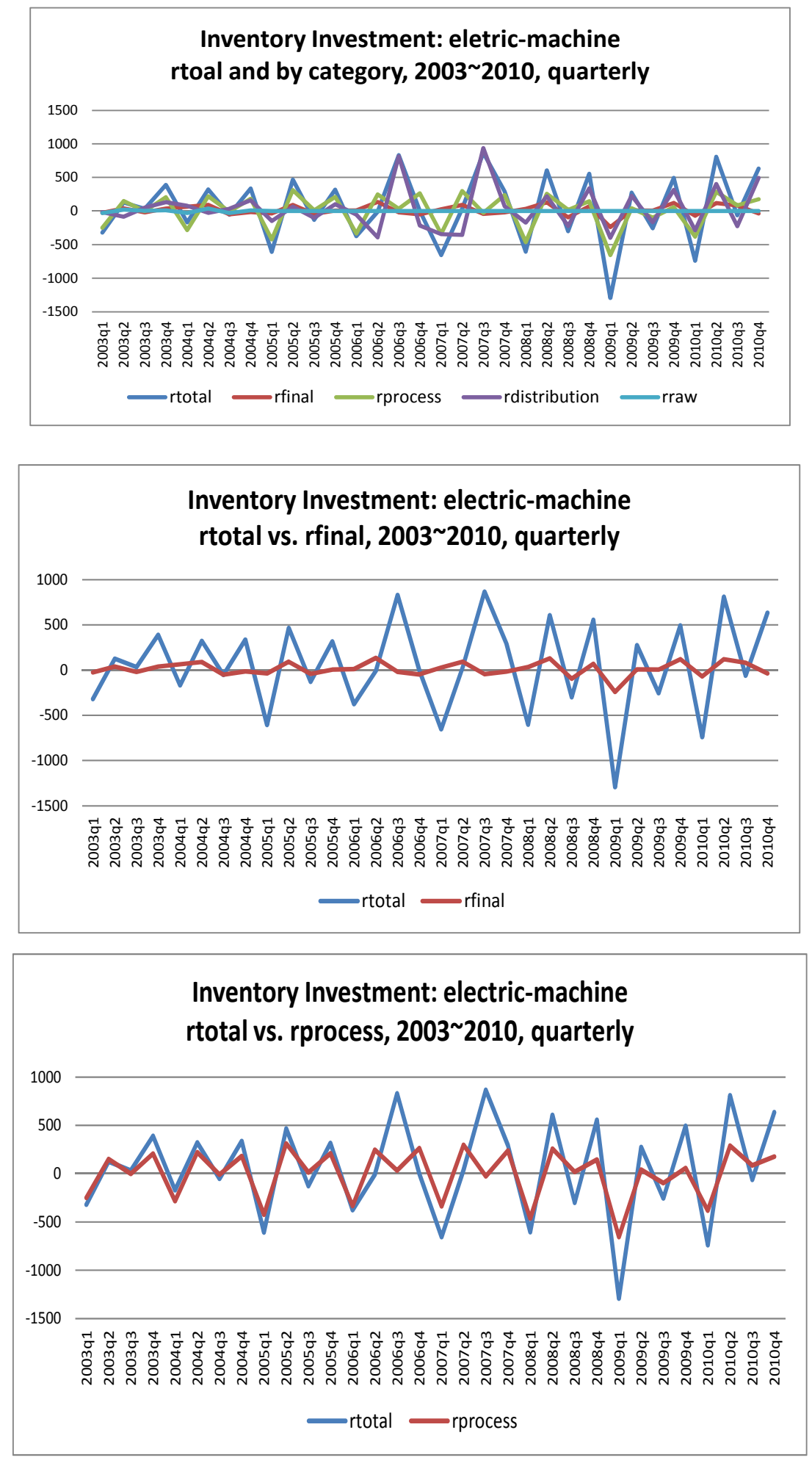


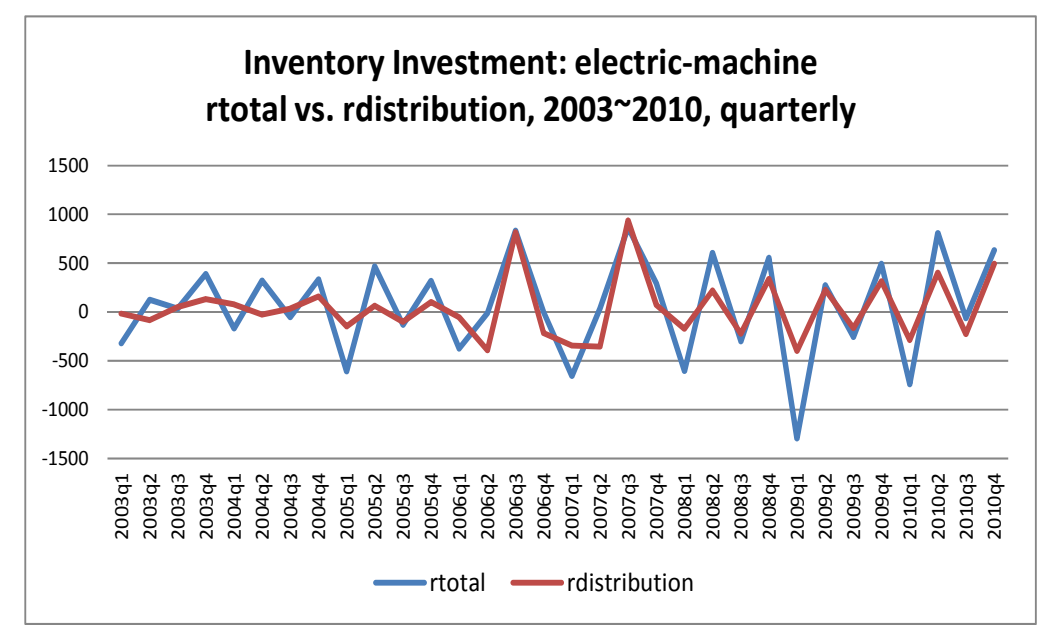

Annual inventory investment: 1994 2010

The influence of rprocess on rtotal, which was big in quarterly estimates, was big also in annual electric-machine inventory investment estimates. The drastic decline in 2009 (big negative value) is particularly noteworthy. The influence of rdistribution, whose influence was as big as rprocess in quarterly estimates, was also big in annual estimates.

The content of "electric-machine" changes radically and rapidly. Partly for this reason, no clear explanation is available for the dramatic decline in electric-machine rprocess in 2009. My guess is that the contribution of the decrease in values due to fair value adjustments of goods-in-process inventory stock. As shown above, both rtotal and rprocess recorded a big negative value in 2009 Q1.

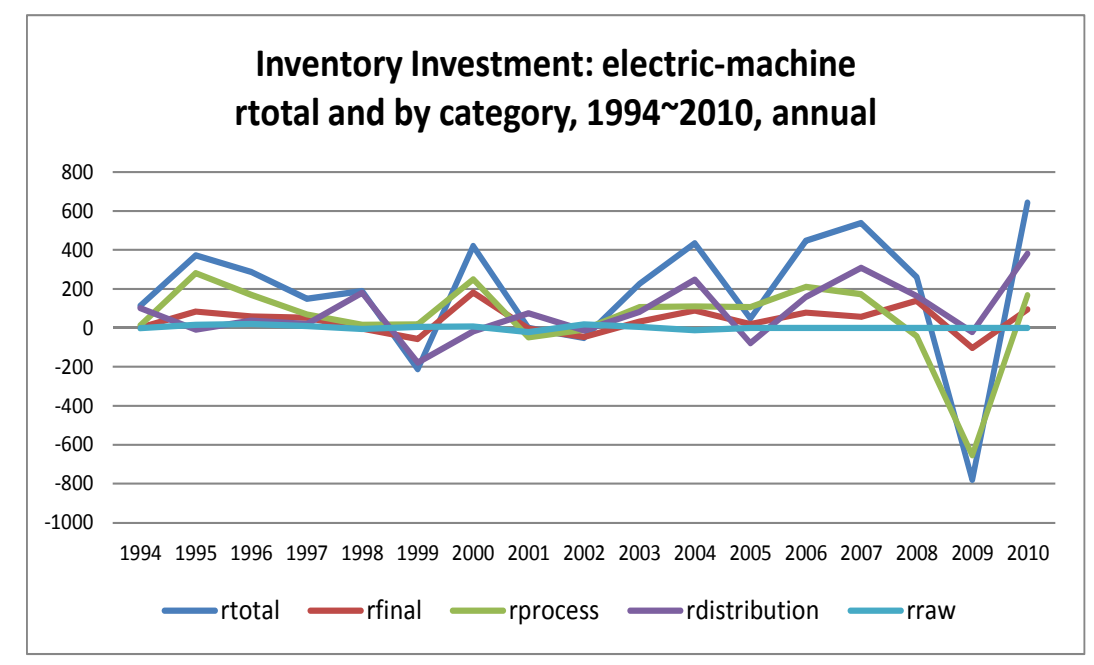

[7-3]. Special machinery and general machinery 
For two reasons, I include special machinery and general machinery, both for industrial equipment, in eight commodities. First, in all industries quarterly estimates the rprocess fluctuation dominates the rtotal fluctuation, but in annual estimates its influence almost disappears. For investigating the details of rprocess, as representatives of commodities with a big share in all industries rprocess I choose them. Second, the dramatic collapse in overall economic activity after the Lehman Shock, deteriorating the economic prospect, rapidly decreased the demand for equipment investment goods. Supposing this influence most prominently, I choose them as representatives of equipment investment related commodities.

They share many characteristics. General machinery records a drastic decline in inventory investment around 2000, which is not found in special machinery.

[7-3-1]. Special machinery

\section{Quarterly inventory investment}

Quarterly rraw was consistently 0 also in special machinery.

The share of rprocess to rtotal was consistently overwhelming. Although the share was small, the rfinal moved in tandem with rtotal. For five quarters running since 2009Q1 rtotal and rprocess recorded big negative values. The share of rdistribution was consistently small.

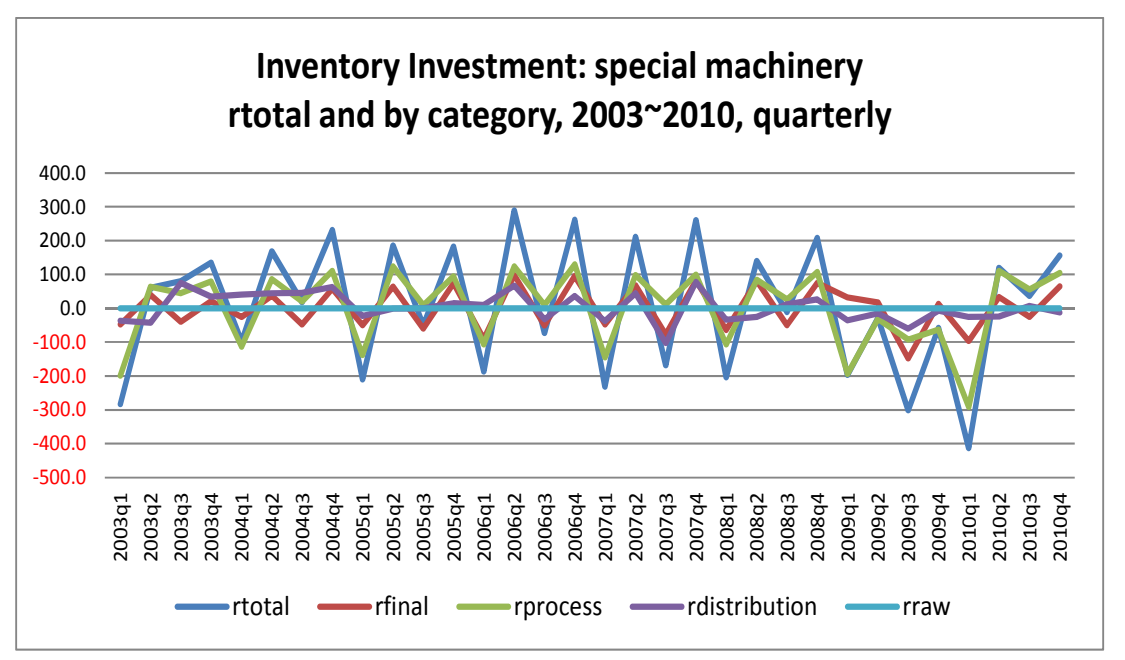



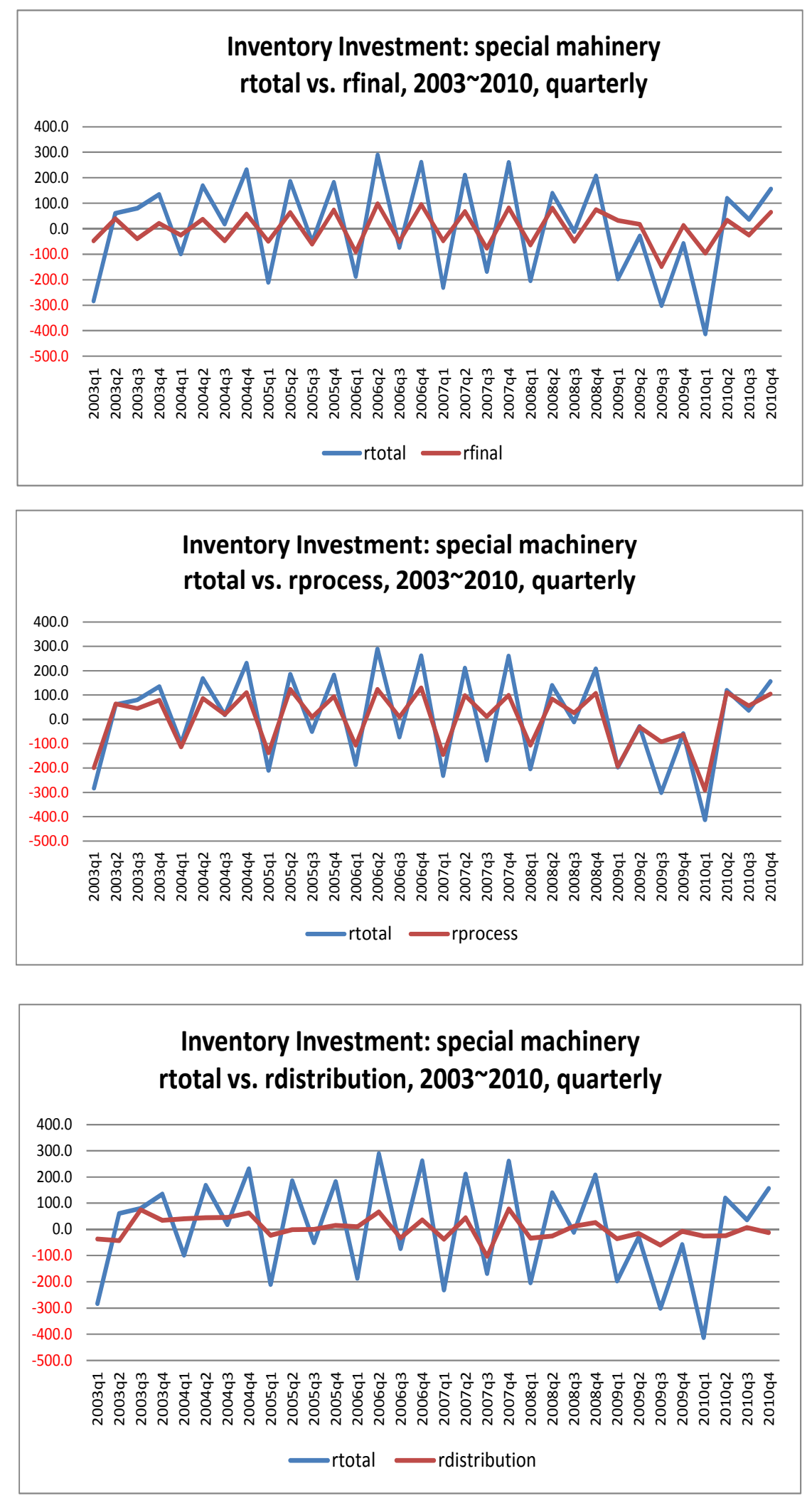

$\underline{\text { Annual inventory investment: 1994 2010 }}$ 
The influence of rprocess on rtotal, which was overwhelming in quarterly estimates, was remarkably smaller in annual special machinery inventory investment estimates. In contrast, rdistribution, whose share was extremely small in quarterly estimates, increased the share in annual estimates. Nonetheless, in dramatic rtotal decline in 2009, the share of rprocess was dominant.

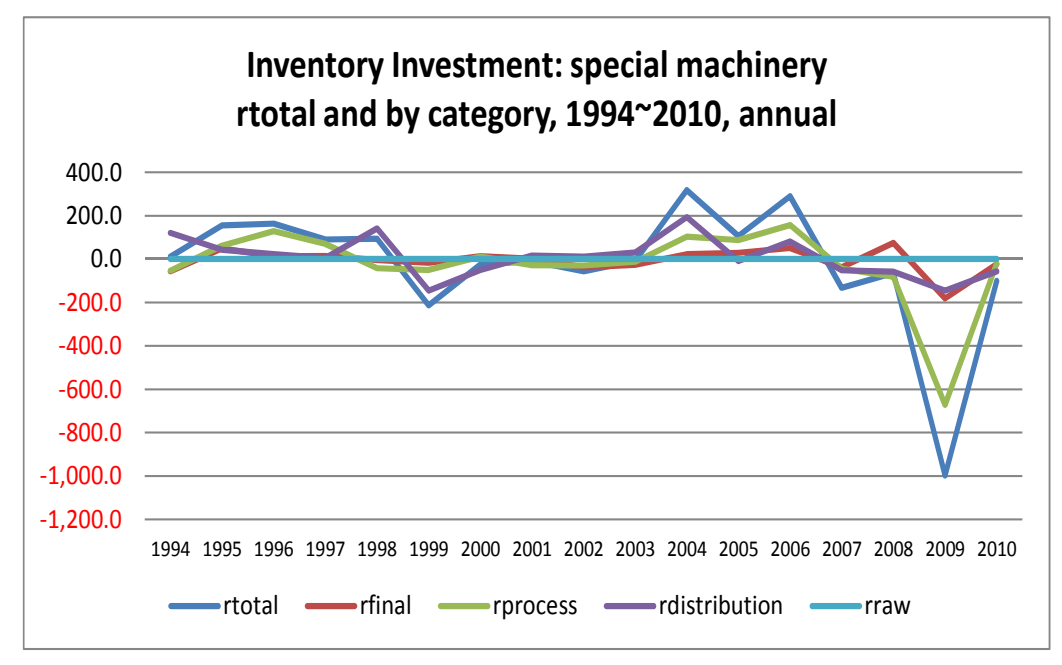

[7-3-2]. General machinery

\section{Quarterly inventory investment}

As in special machinery, quarterly rraw was consistently 0 also in general machinery.

Also like special machinery, the share of rprocess to rtotal in general machinery was consistently overwhelming, and, although the share was small, the rfinal moved in tandem with rtotal. Also like special machinery, for five quarters running since 2009Q1 rtotal recorded big negative values, and rprocess moved similarly. The preceding 2008Q4 did not report a positive value larger than the previous the $4^{\text {th }}$ quarter average value. Again like special machinery, the share of rdistribution was consistently small.

Here also we observe in rtotal and rprocess clearly regular seasonal fluctuations, particularly sharp decline in the $1^{\text {st }}$ quarter. Though the size much smaller, we observe similar seasonal fluctuations in rfinal. 

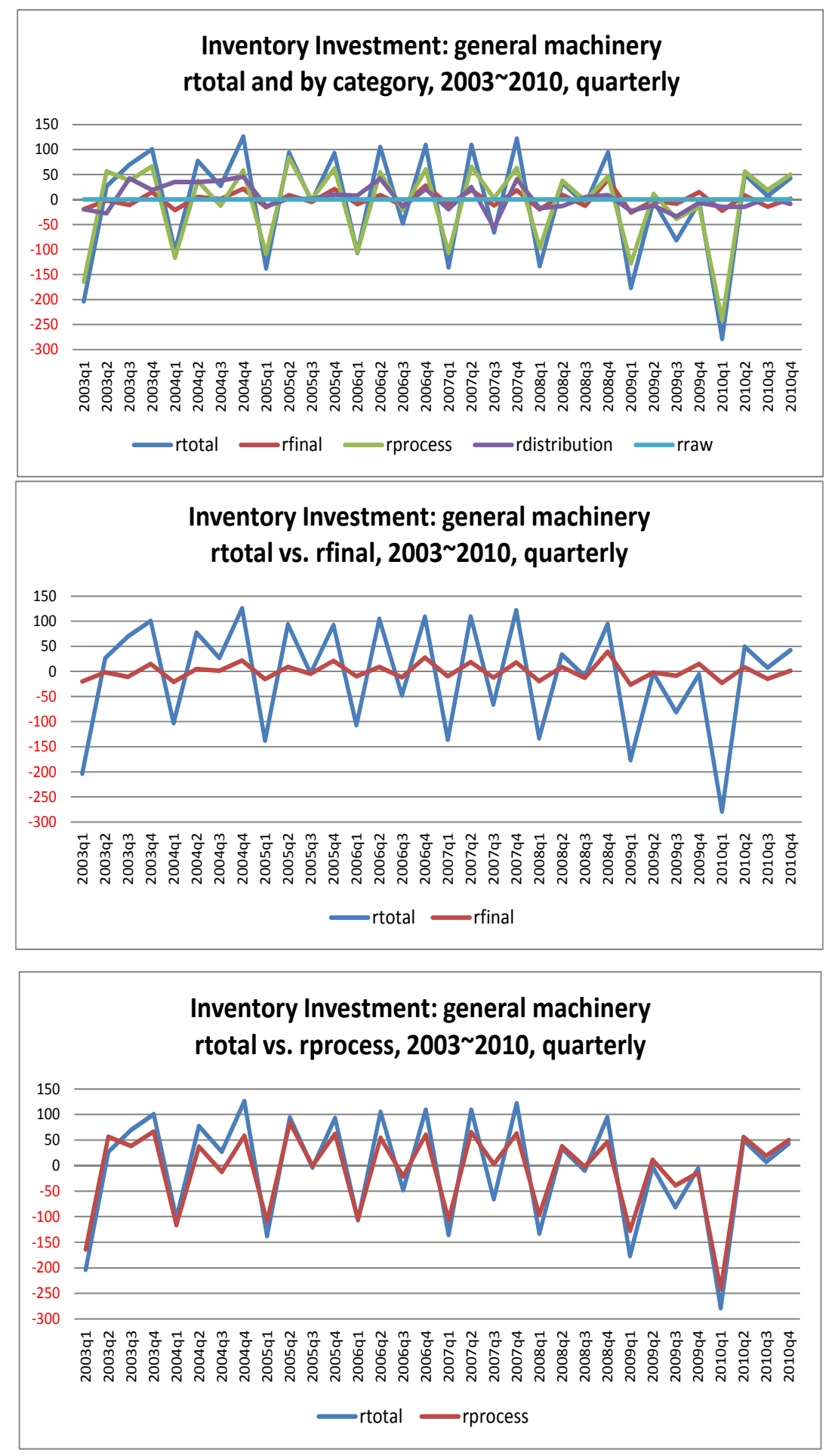


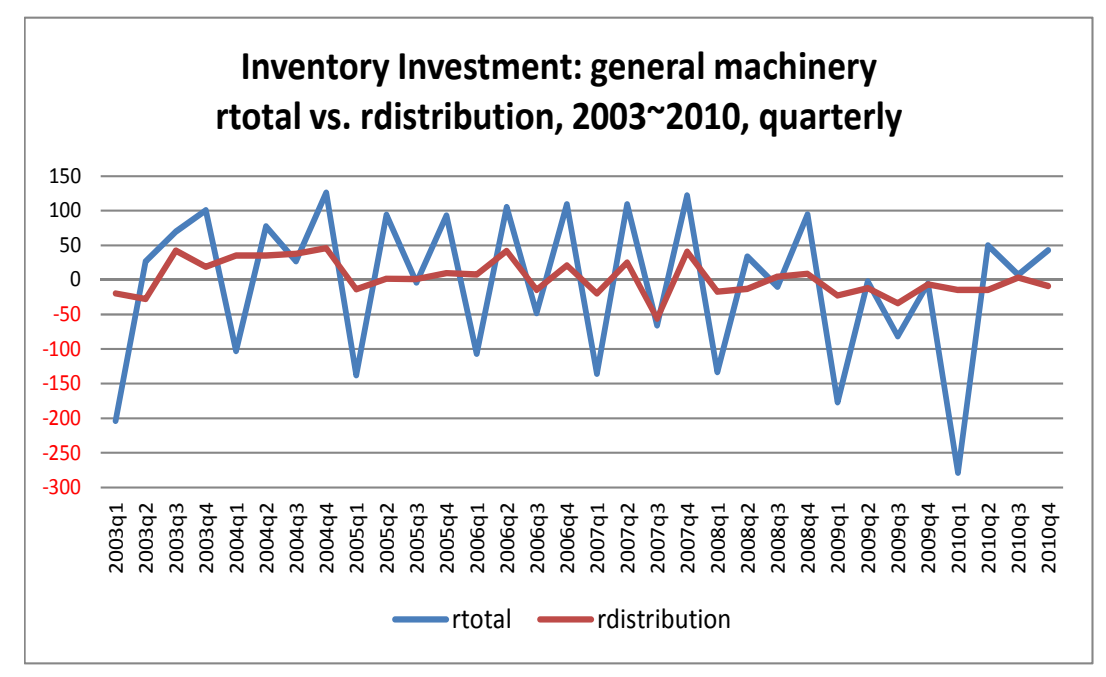

Annual inventory investment: 1994 2010

With the exception of years around 2000 and 2009, the influence of rprocess on rtotal, which was overwhelming in quarterly estimates, was remarkably small in annual general machinery inventory investment estimates. In contrast, rdistribution, whose share was extremely small in quarterly estimates, increased the share in annual estimates.

In years around 2000 and 2009 when rtotal recorded extremely big negative values, the share of rprocess was overwhelming. In 1998 and 2004 when rtotal increased (though not so remarkably), the share of rdistribution was dominant.

Four years' continued big negative values after the accumulation in 1998 are more striking than the decline after the Lehman Shock. As shown above, in special machinery we observe no such remarkable decline after 2008 like in general machinery.

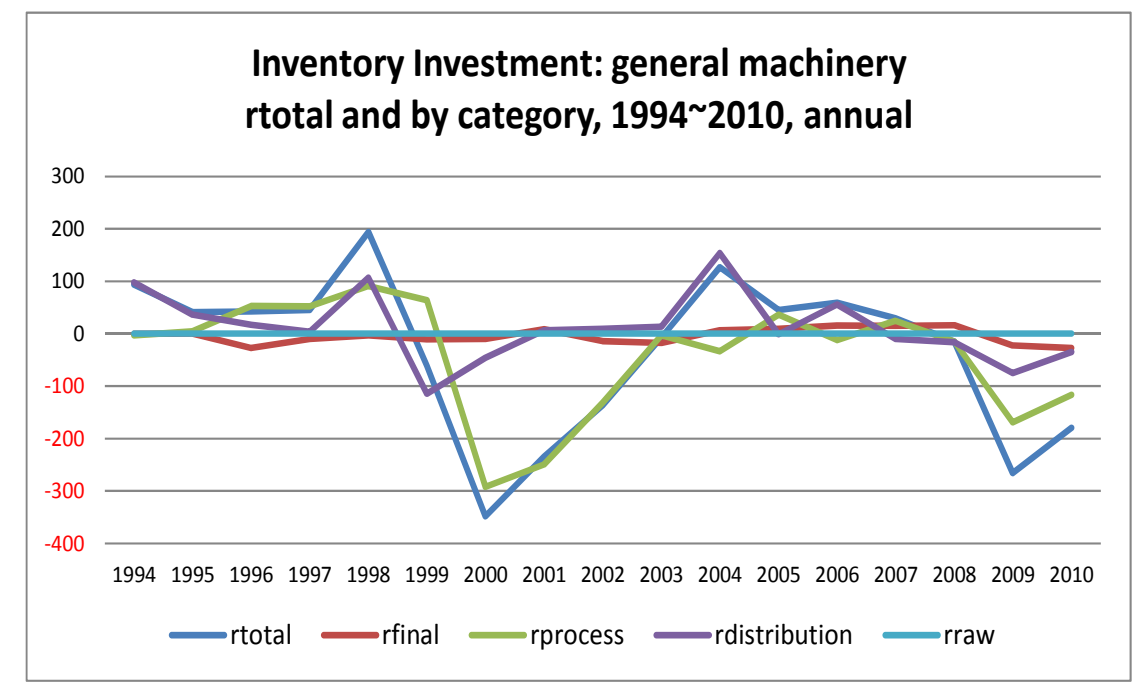


[7-4]. Non-ferrous metal-, steel-, and petroleum product

Section [7-4] studies Non-ferrous metal-, steel-, and petroleum product, which are raw materials, fuel or intermediate products. In contrast with the four commodities studied in [7-2] and [7-3], both in quarterly- and annual estimates of those three, the share of rprocess was the smallest, rdistribution and rraw becoming much higher. This applies also to apparel studied in [7-5].

[7-4-1]. Non-ferrous metal product

\section{Quarterly inventory investment}

Together with petroleum product, non-ferrous metal product may be ideal in that the big rtotal increase in 2008Q4 after the Lehman Shock is consistent with the expectation and image of dramatic inventory accumulation as a consequence of unexpected demand collapse and the subsequent adjustment process. However, comparing with electric-machine and automobile, their rtotal's weights to the all industries rtotal were small. When the rtotal increased after the Lehman Shock, first rraw increased and then rdistribution followed. The same sequence applied to the start of adjustment process that followed. The same pattern is observed in petroleum product.

Over the whole period, the influence of rdistribution was dominant, and that of rraw followed. The period after Lehman Shock was exceptional, when first rraw increased sharply and then rdistribution followed. This pattern applies also to petroleum product.

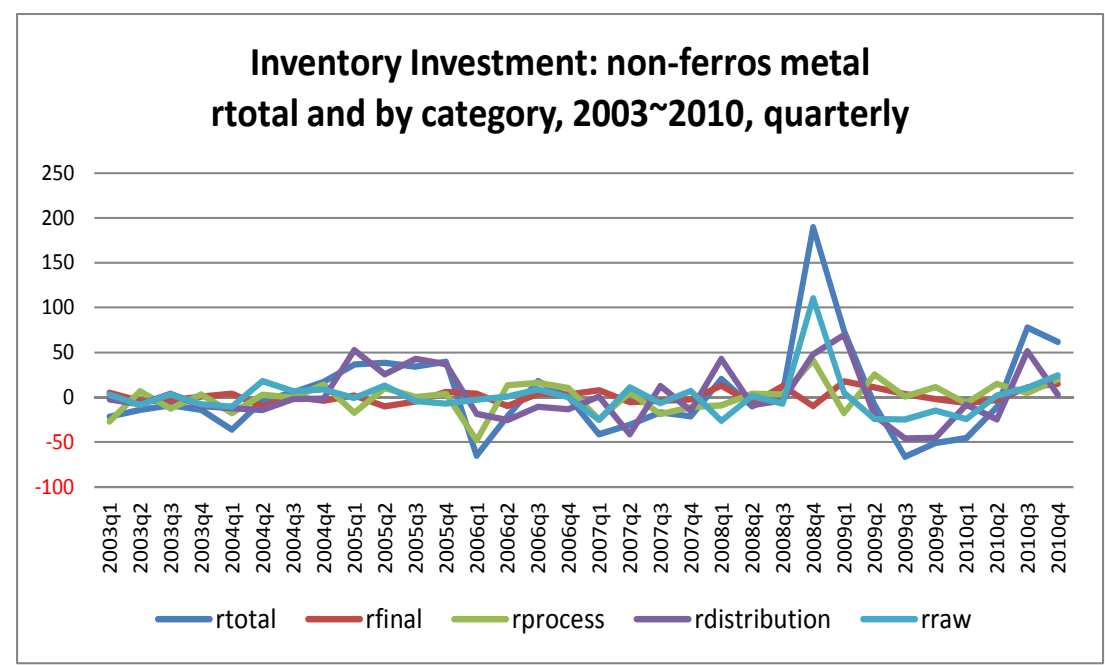



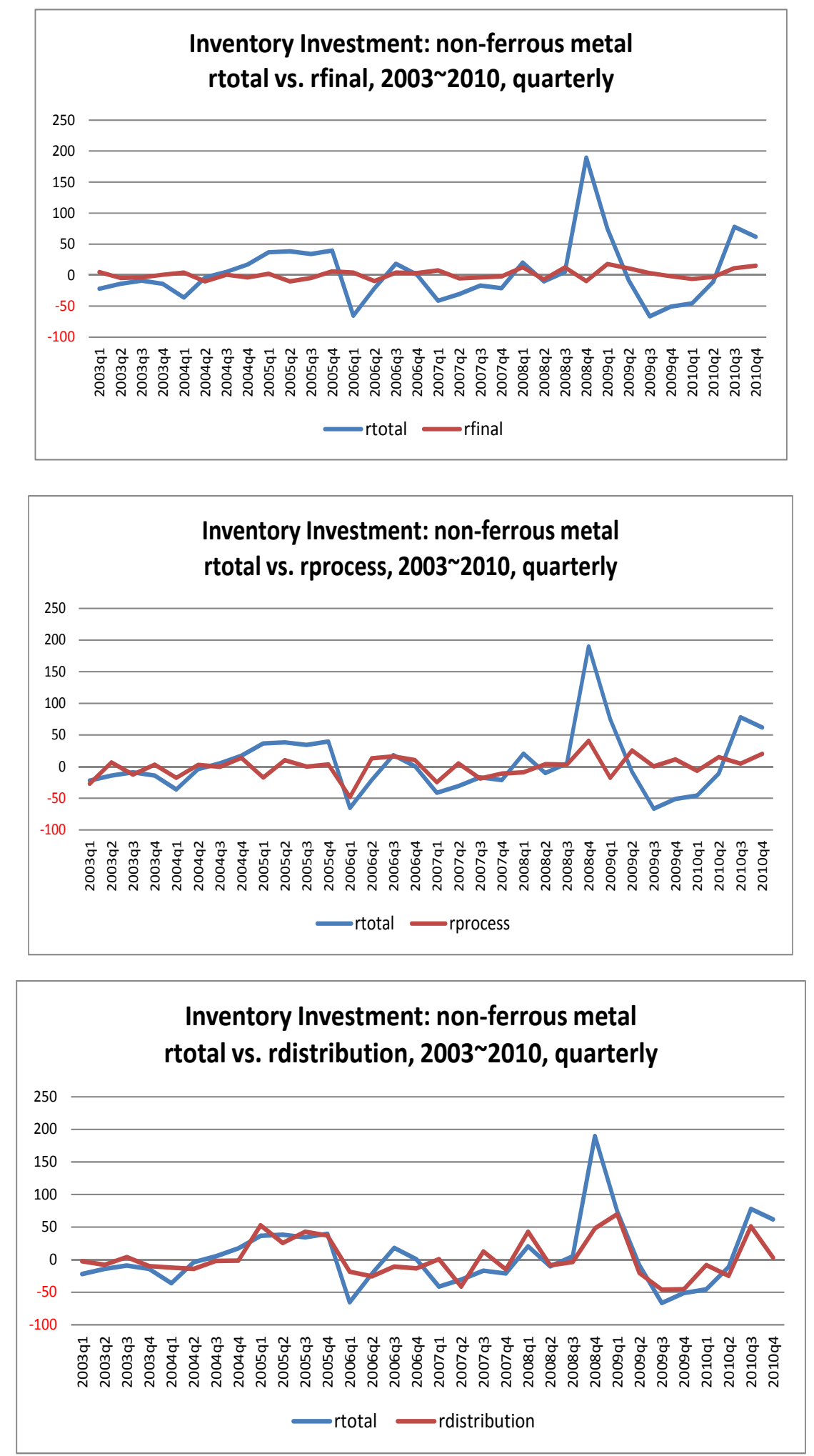


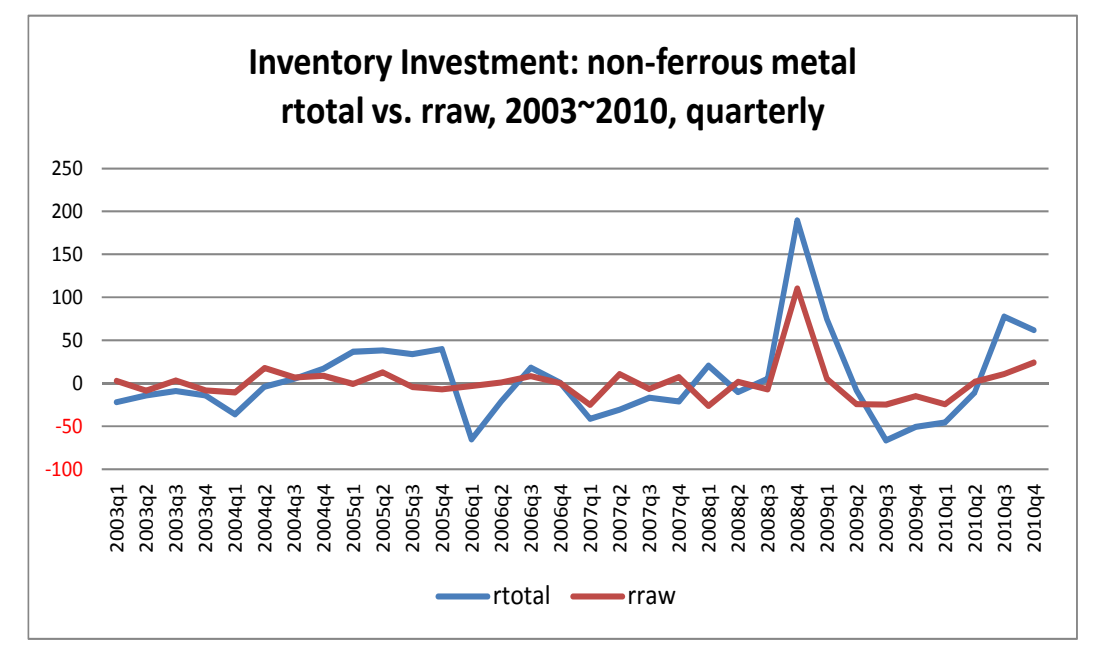

Annual inventory investment: 1994 2010

Here the influence of rdistribution is overwhelming, and next comes rraw by a large margin.

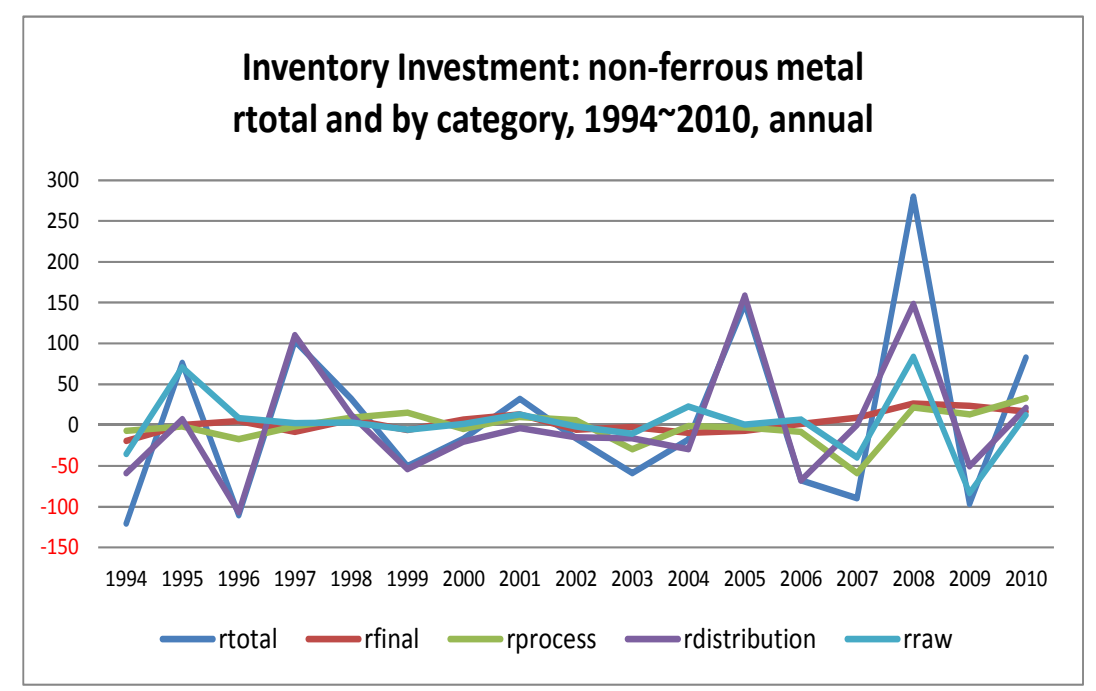

[7-4-2]. Steel product

Quarterly inventory investment

Like non-ferrous metal- and petroleum product, steel product is for industrial material and intermediate product. Here we do not find two observations commonly found in four commodities including automobile studied in [7-2] and [7-3]: (1) the influence of rprocess was overwhelming; (2) rraw was consistently 0.

Quarterly inventory investment of steel product is different from that of non-ferrous metal- and petroleum product in that all four inventory category had fairly big share, respectively. 
Both in all industries and in many commodities we commonly observe that rtotal radically decline in the $1^{\text {st }}$ quarters, where most inventory categories, particularly rprocess, move in tandem with rtotal. This applies also to steel product.

The size of fluctuations in rprocess obviously decreased since 2006, in contrast that of rraw and rdistribution increased.

In four commodities including automobile studied in [7-2] and [7-3] rtotal recorded big negative values for several quarters running since 2009Q1. However, in steel product, as before, rtotal recorded a big negative value in 2009Q1 and positive value in the next quarter. In that sense, the Lehman Shock period was not special for steel product. Neither is the preceding 2008Q4 when rtotal increased.

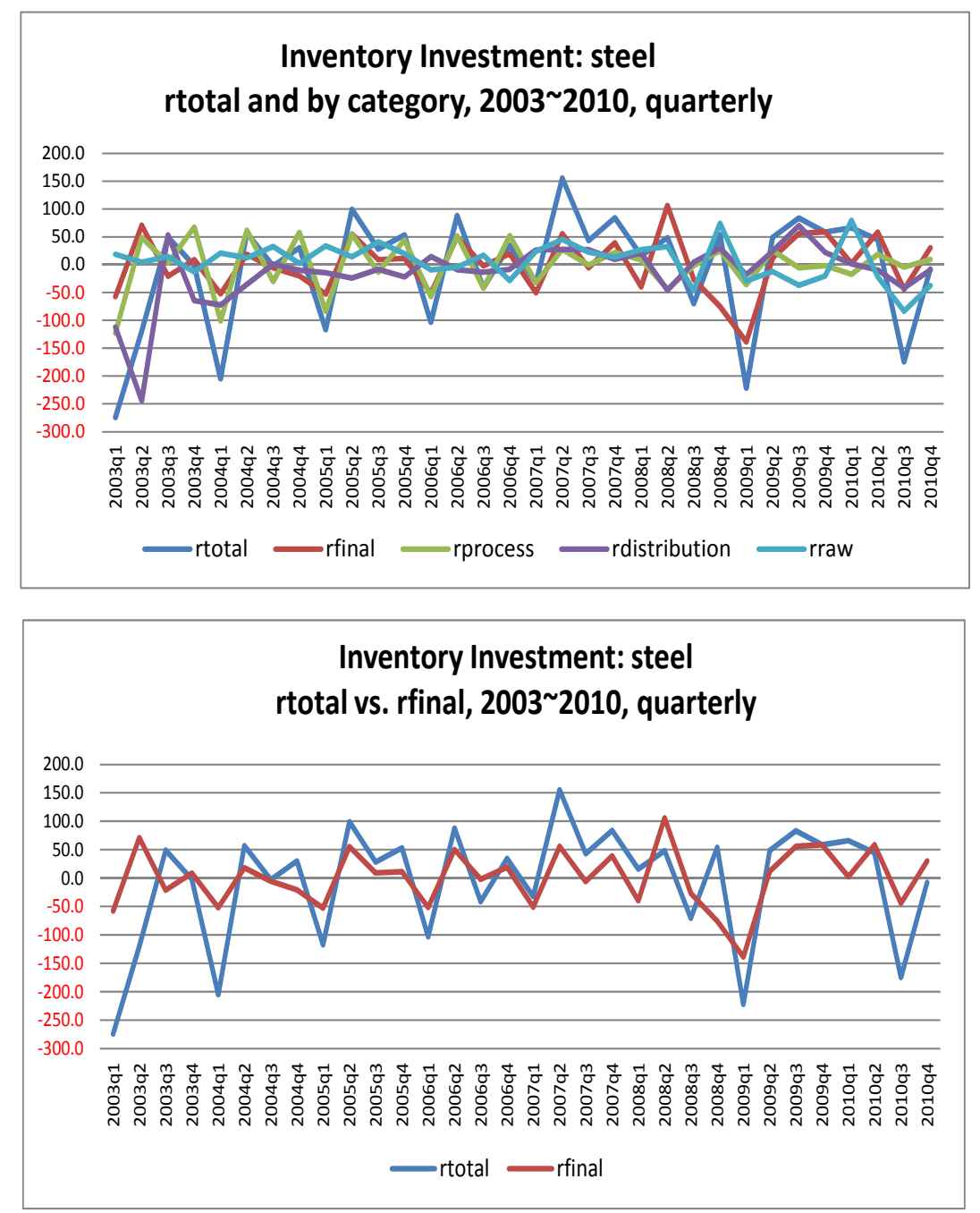



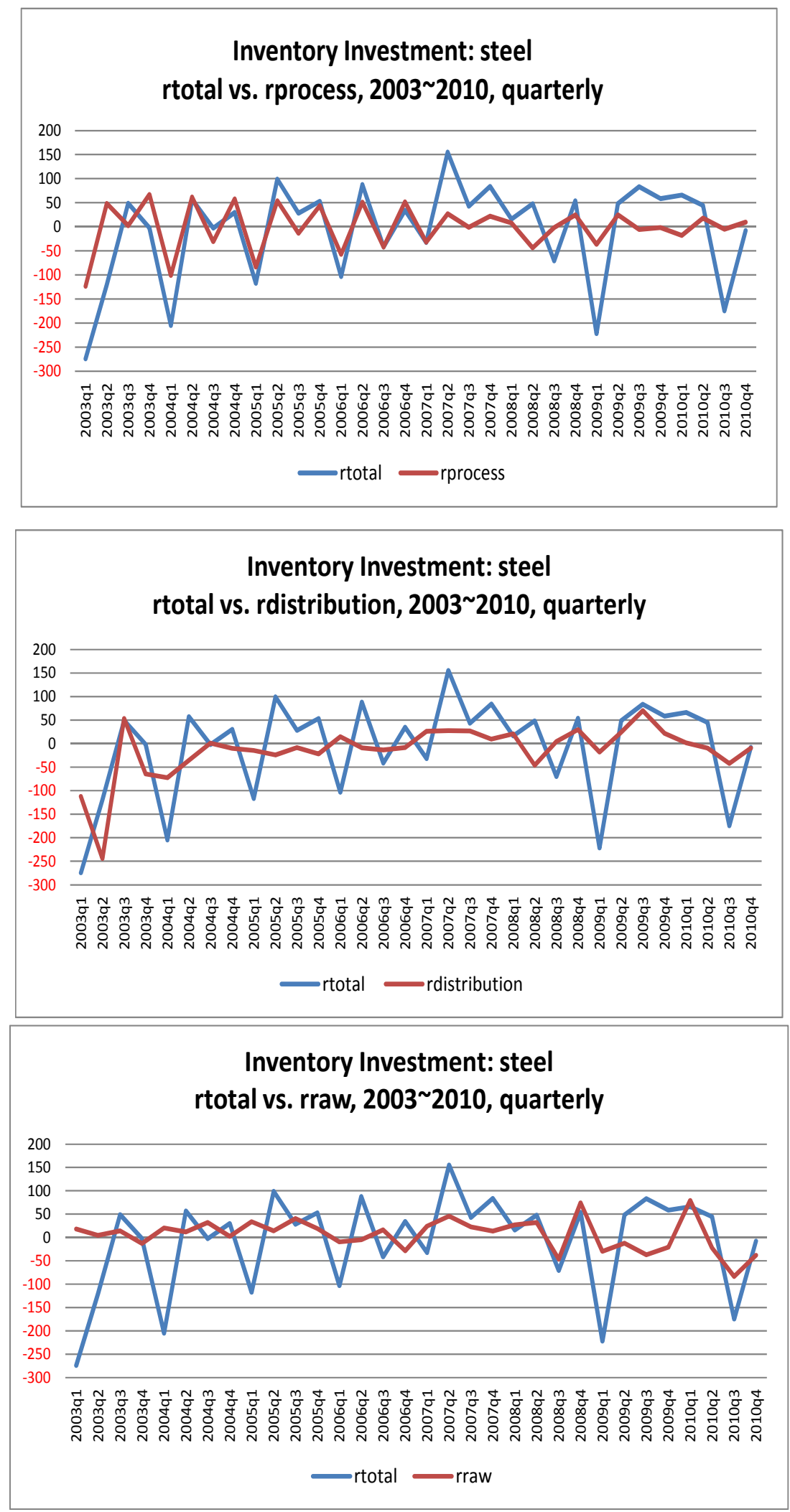

Annual inventory investment: 1994 2010 
Also in steel product, annual inventory investment is significantly different from quarterly inventory investment.

Before around 2004, the influence of annual rdistribution overwhelmed the annual rtotal. Since then, rraw also increased the share. Rprocess whose share is large in quarterly estimates is small in annual estimates, and rdistribution whose share is small in quarterly estimates increases in annual estimates.

In was in 2007 (not in 2008) when rtotal increased, where rdistribution and rraw increased.

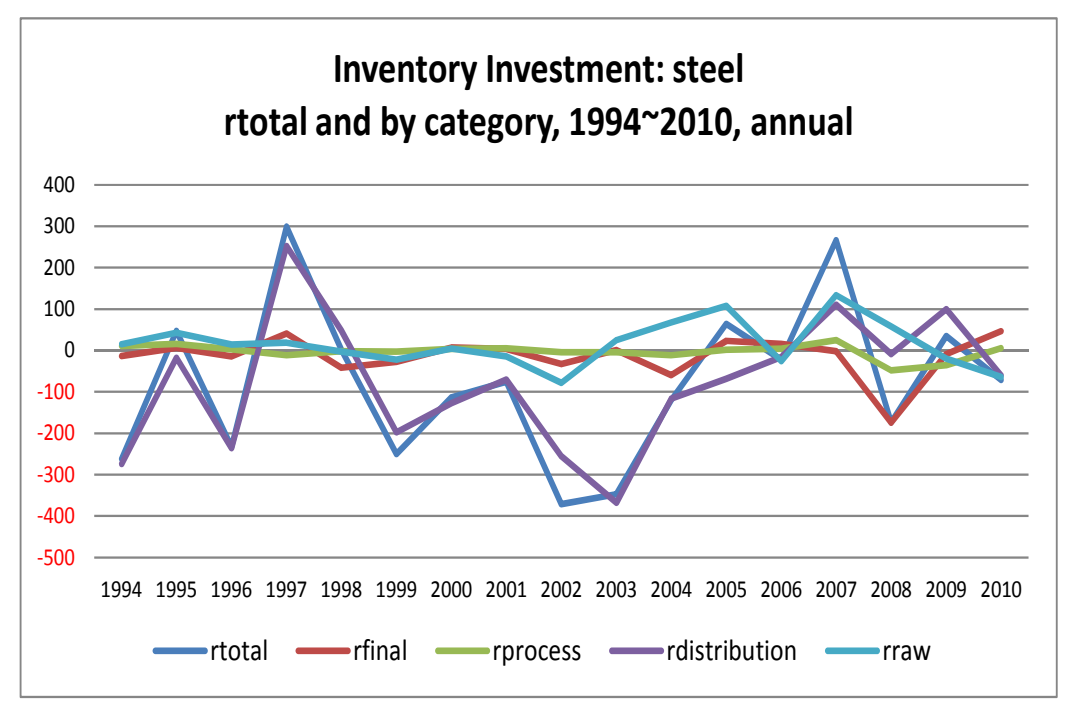

[7-4-3]. Petroleum product

\section{Quarterly inventory investment}

Like non-ferrous metal- and steel product, petroleum product is for industrial material, fuel and intermediate product. Here we do not find observations commonly found in four commodities including automobile studied in [7-2] and [7-3], either.

Both in all industries and in many commodities we commonly observe that rtotal radically decline in the $1^{\text {st }}$ quarters, where most inventory categories, particularly rprocess, move in tandem with rtotal. This does not apply to petroleum product.

What is conspicuous in rtotal in petroleum product is a dramatic increase both in 2008Q4 and 2009Q1, and remarkable negative values for three quarters running since 2009Q3. Both primarily reflected the fluctuations of rdistribution and rraw, although their shares changed radically across quarters. The influence of rprocess during this period was the smallest. 

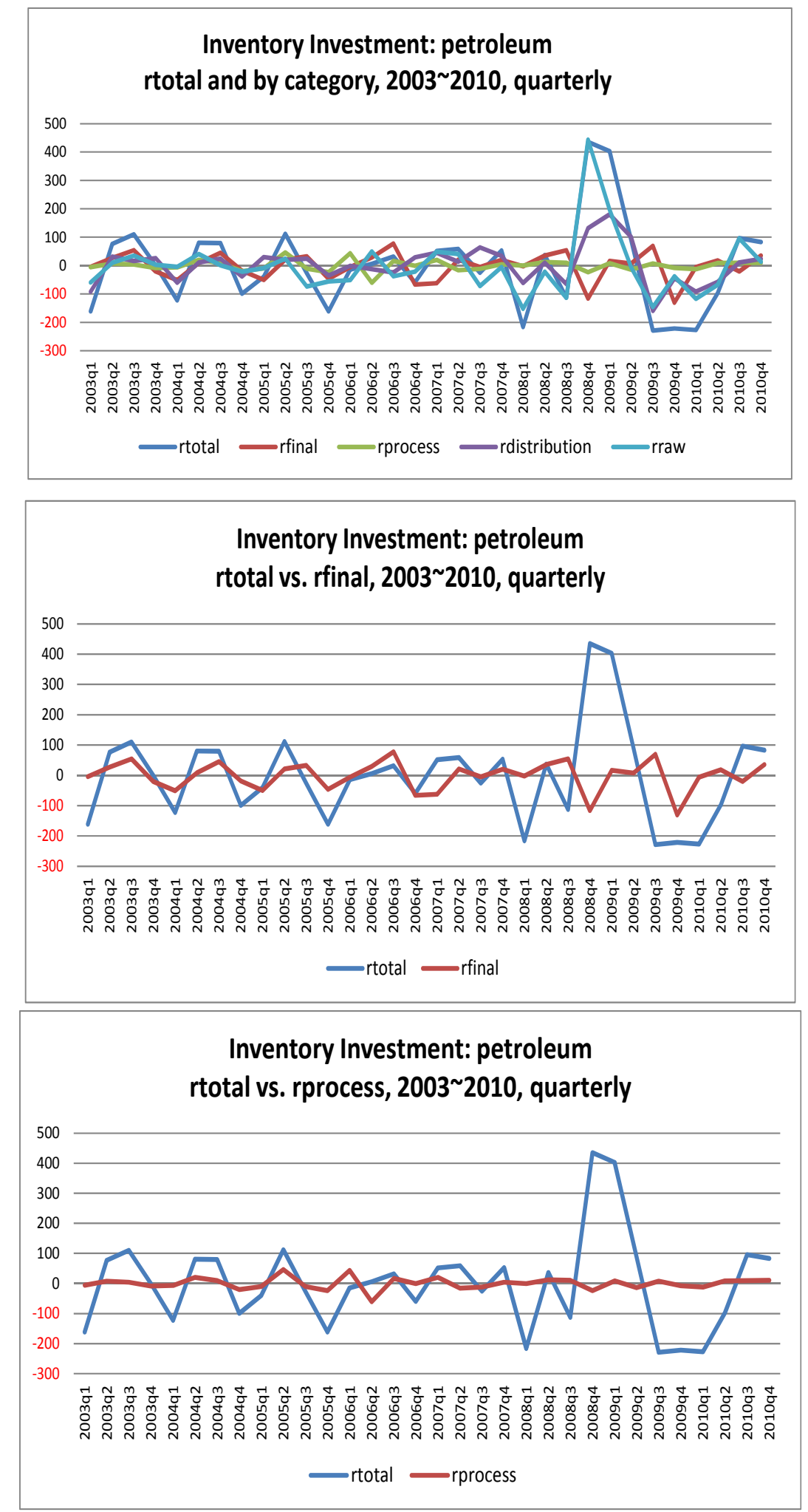

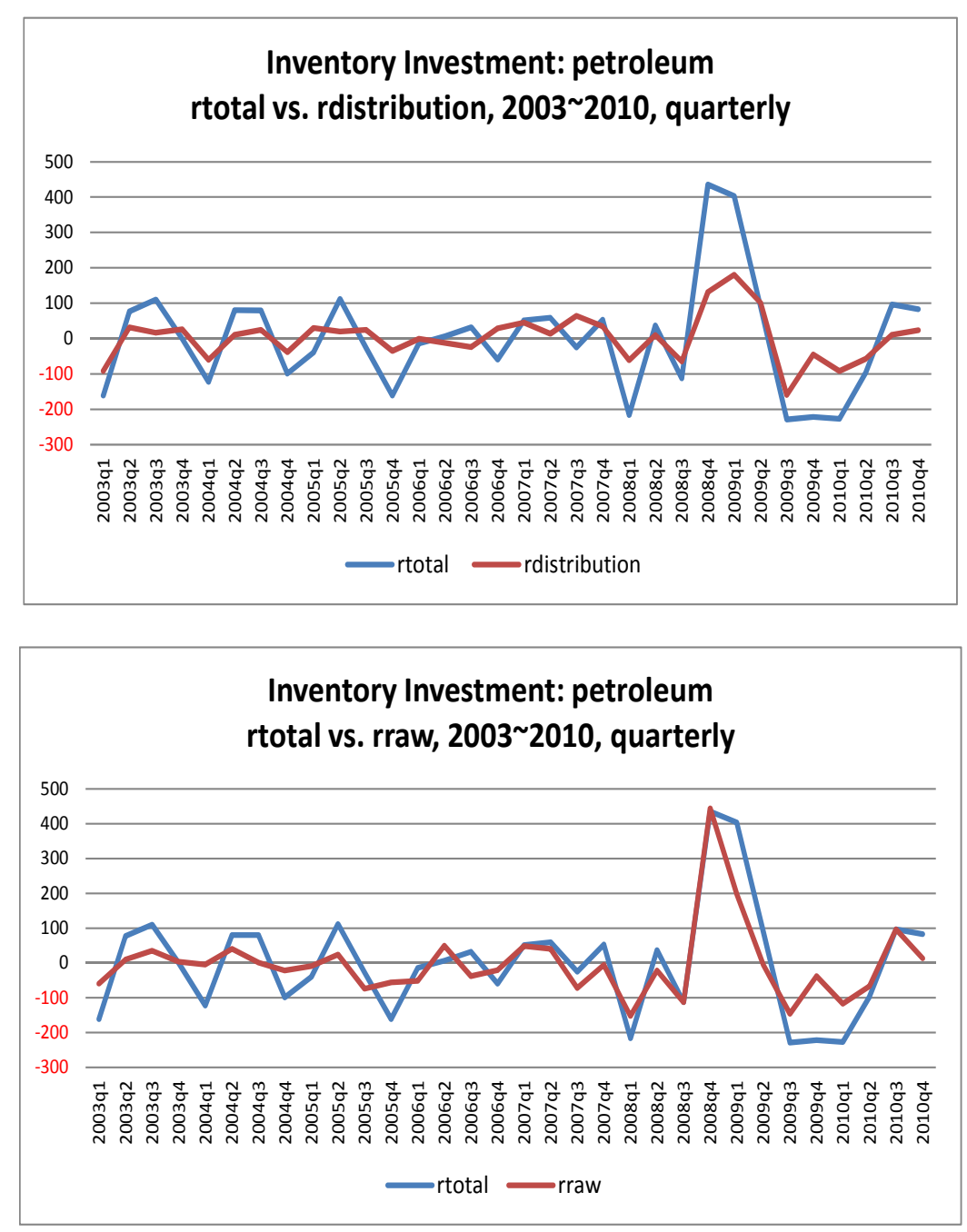

Annual inventory investment: 1994 2010

In petroleum product, annual inventory investment is not significantly different from quarterly inventory investment.

Either in increase or decrease, the fluctuation in rdistribution decisively influenced rtotal. During the period after 2007, rdistribution increased first and rraw followed. In 2008 rdistribution decreased, but rraw increased, leaving rtotal at a high level. In 2009, both rraw and rtotal decreased dramatically, and rdistribution increased a little. 


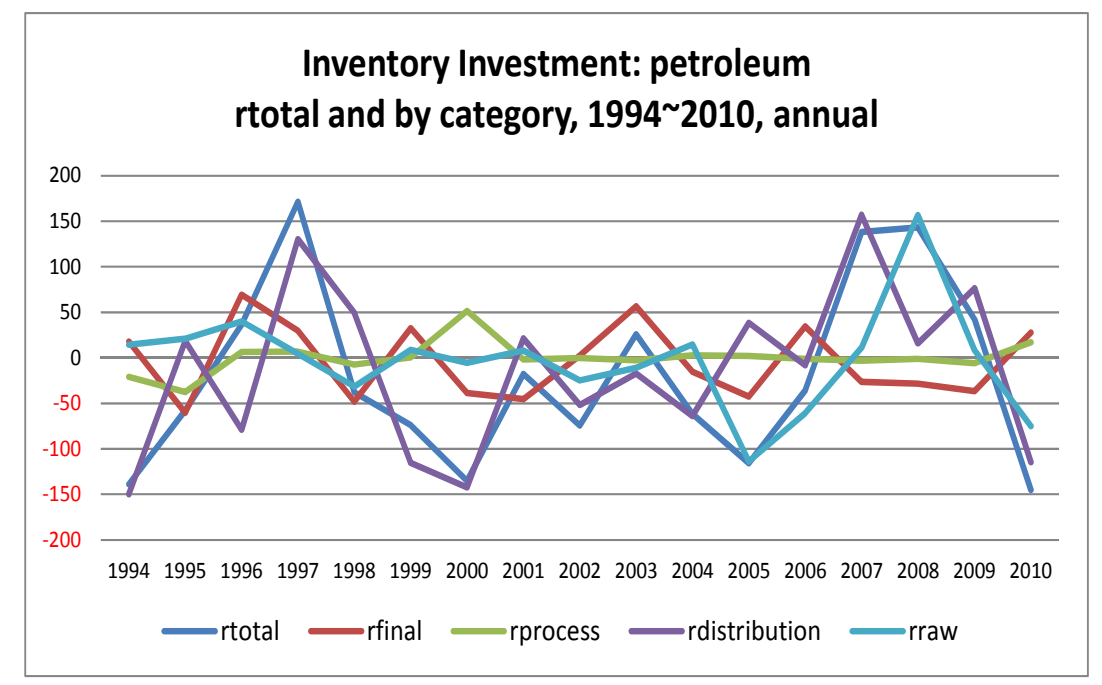

[7-5]. Apparel

Section [7-5] studies apparel as a representative of non-durable consumer product.

\section{Quarterly inventory investment}

Also in apparel we find the observation common to many commodities that rtotal sharply decline in the $1^{\text {st }}$ quarters. In the $1^{\text {st }}$ quarters all the four inventory categories report negative values in chorus, of which the influence of rdistribution is overwhelming. As in many commodities, they record big positive values both in the $2^{\text {nd }}$ and $4^{\text {th }}$ quarters, and intermediate values in the $3^{\text {rd }}$ quarters.

Presumably reflecting an obvious downward trend in nominal sales consistently observed during the period under study, we observe a consistent downward trend in rtotal, which is more clearly found in annual inventory investment. 

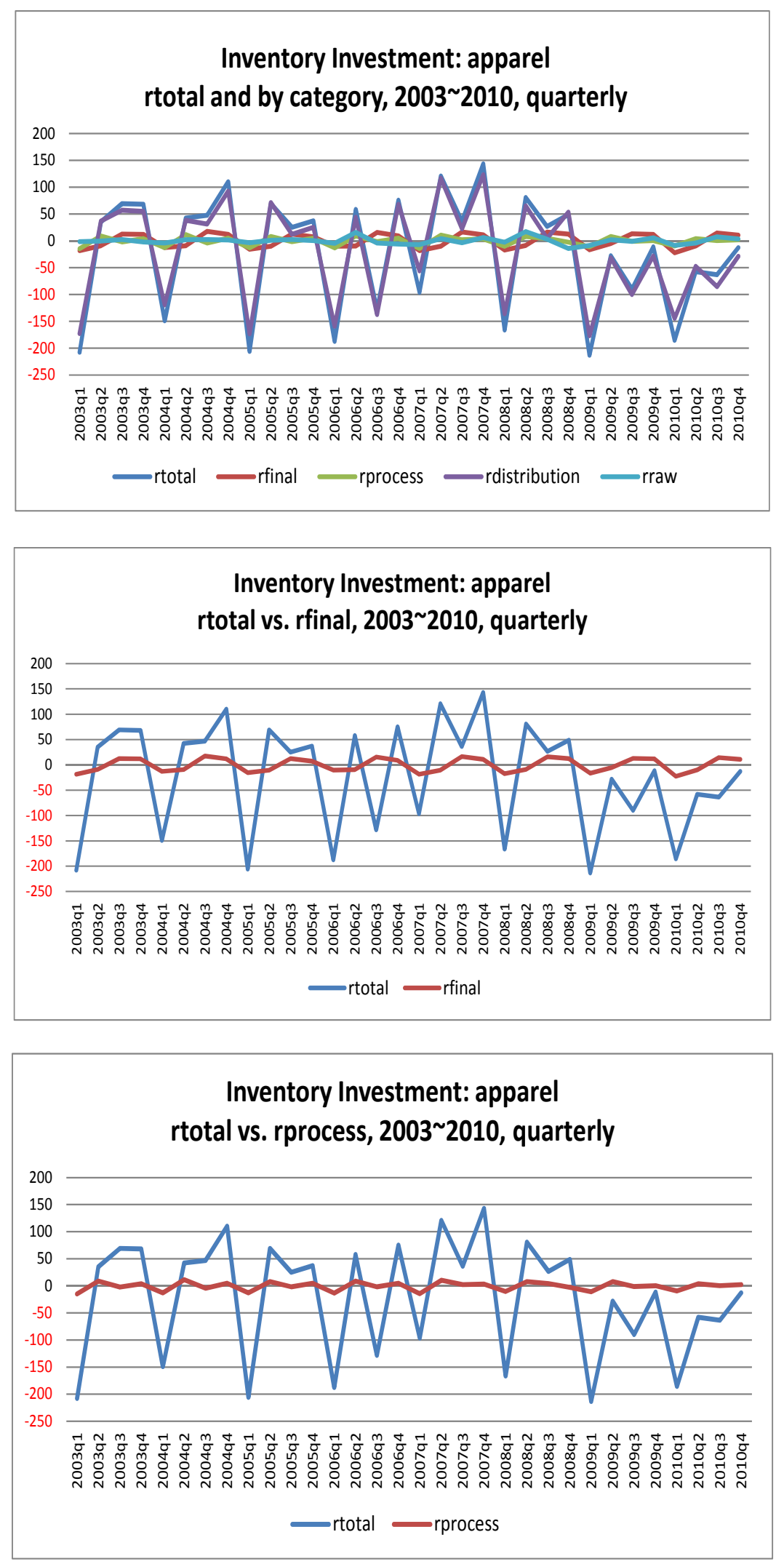

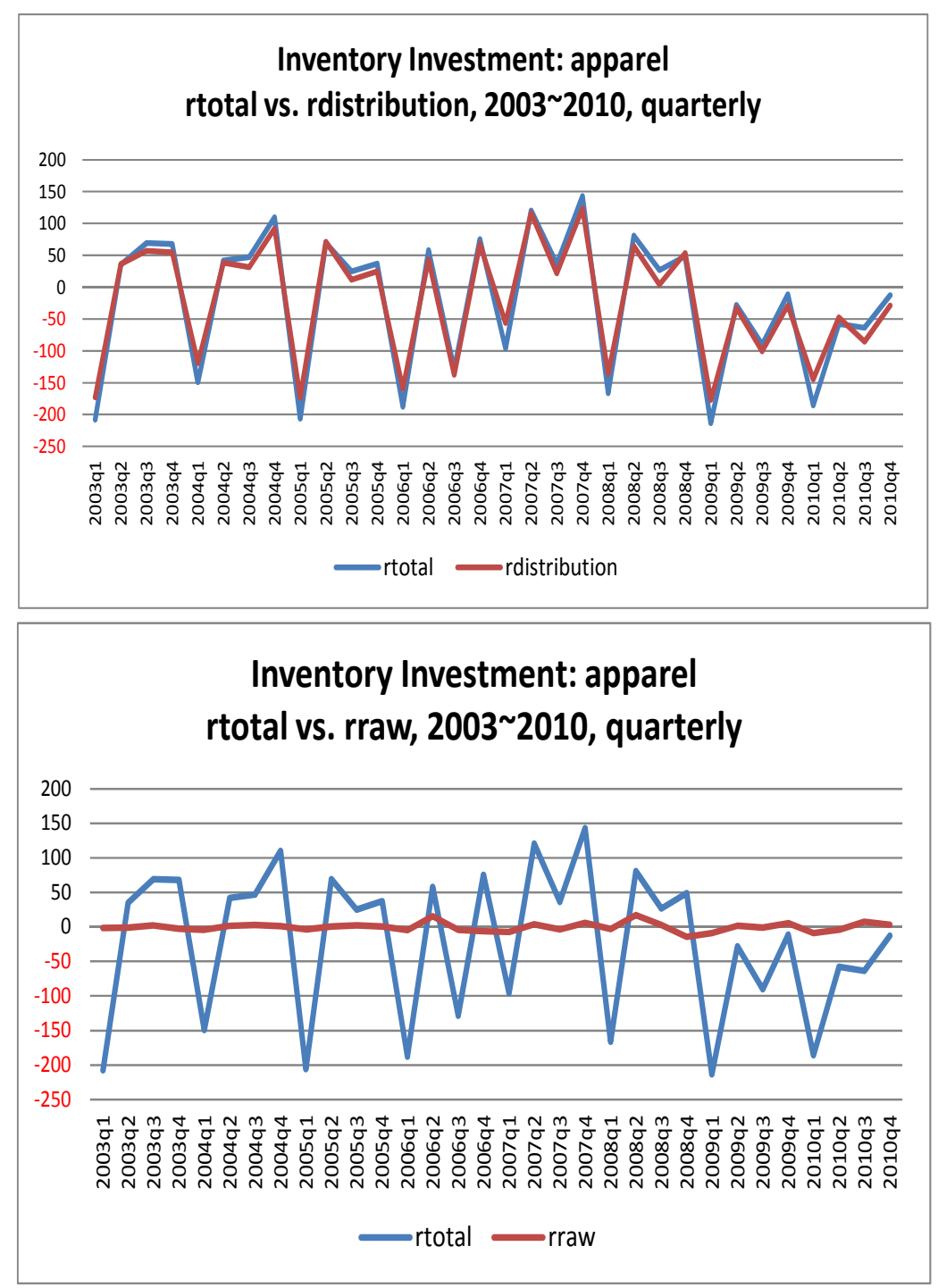

Annual inventory investment: 1994 2010

In apparel, annual inventory investment is not significantly different from quarterly inventory investment. Reflecting an obvious consistent downward trend in nominal sales, both rtotal and inventory investment by category almost always recorded negative values, where the influence of rdistribution was overwhelming. 


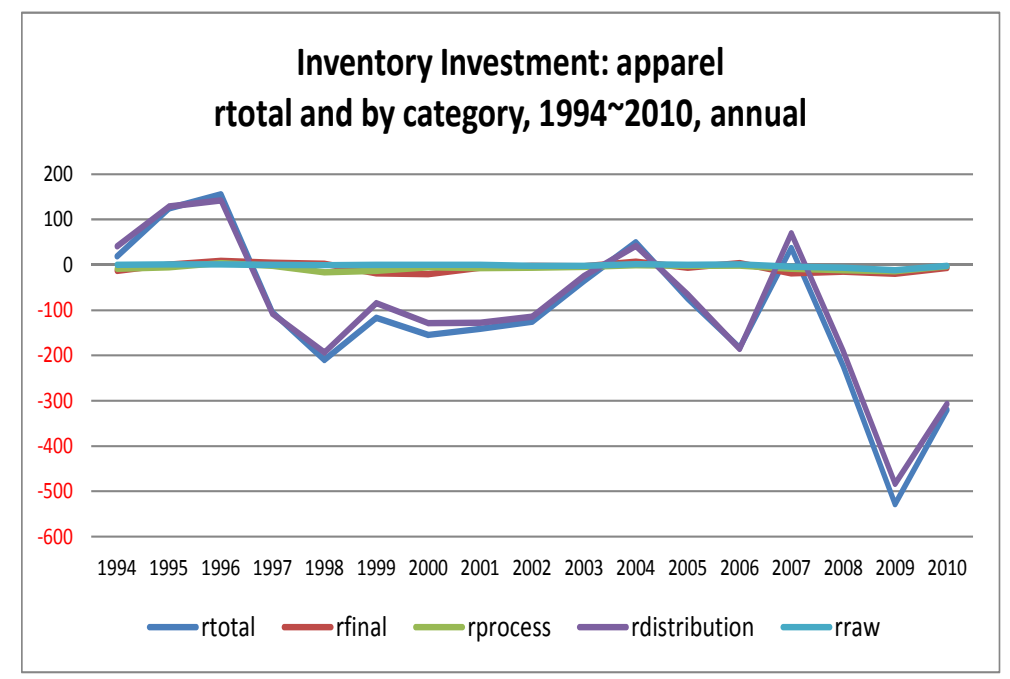




\section{[8] "Inventory Stock Adjustment” Process}

[8-1]. Introduction, and All Industries Inventory Investment

Section [8] investigates the "inventory stock adjustment" processes, shifting the focus of the study from individual quarters and years to their sequences for "stock adjustment". The focus of the investigations are the details of inventory accumulation due to the dramatic demand decline after the Lehman Shock and the subsequent stock adjustment process, that is fluctuations in inventory by category and the time course of adjustment process including the length of adjustment time.

Inventory investment in each time unit (for example, quarter) is the difference in value of inventory stock at the end of period and that at its beginning, that is, the net increase in inventory stock value. The accumulation of inventory stock and its subsequent adjustment process is the variation in inventory stock value. For the whole picture of inventory investment and its fluctuations, studying inventory investment in individual quarters is insufficient, and it is essential to focus on "accumulation process" over sequence of time units (quarters or years). In accordance with the result of the study in previous sections, Section [8] focus on the accumulation- and adjustment processes.

Either with quarterly- or annual estimates, previous sections studied the inventory investment focusing on individual unit periods. However, whether or not depending on a long-term program, it is not unusual to accumulate or reduce inventory stock continuously over several unit periods, as the conventional wisdom argues. It is implausible to assume that rtotal or inventory investment by category at quarter $\mathrm{t}$ is independent of the ones at quarter $\mathrm{t}-1$ or $\mathrm{t}+1$ (and more distant quarters).

This study investigates the inventory investment fluctuations that occurred as a consequence of an exogenous shock (an unexpected event) and its subsequent adjustment process, focusing on the period around Lehman Shock, for which it is more appropriate to take sequences of unit periods as a basic examination object. The conventional wisdom argues that during the period around Lehman Shock, the Japanese economy suffered from an unexpected severe economic downturn with dramatic demand collapse over several quarters. Upon this, many business people and researchers with longstanding interest in inventory fluctuations should have thought and expected that in various areas of the economy inventory stock had accumulated in an enormous scale over several quarters and then its adjustment process had followed for another several quarters. For examining the accuracy and validity of this 
expectation along the conventional wisdom, as part of detailed study of inventory fluctuations, we have to take sequences of adjustment period as basic examination unit.

Section [8] investigates the accumulation and its subsequent adjustment process in all industries and eight commodities studied in [7], focusing on the period around Lehman Shock. In addition, for comparison, on the subset of those commodities I examine carry the same study over the period of "Financial Crisis" 41 after the fall of 1997, on which I confirm that the conclusion drawn from the study of the Lehman Shock period is neither special nor idiosyncratic.

Previous discussions up to [7] show that, with the exception of petroleum- and non-ferrous metal product, even during the period after Lehman Shock in most commodities no notable increase in inventory investment was observed. This holds also in all industries inventory investment. The implication of this observation that rarely remarkable inventory stock accumulation was observed even as a consequence of an unexpected dramatic demand decline is important. In most commodities we observe remarkable decline in rtotal in 2009Q1 and after, and many commodities recorded negative rtotal value for several quarters running. ${ }^{42}$

It was rdistribution and rraw that increased rtotal in an exceptional move in petroleum- and non-ferrous metal product during the period after Lehman Shock. In all industries rprocess overwhelmed the fluctuations of rtotal, but in these two commodities the share of rprocess was small and their fluctuations low-profile. In special- and general machinery where the share of rprocess was dominant and in automobile and electric machine whose weights in all industries rprocess were high, rarely do we find notable increase in rtotal after the Lehman Shock, and we find notable decrease in rprocess in the following quarters.

Note that 2008Q4 when rtotal increased remarkable in some commodities is the $4^{\text {th }}$ quarter when rtotal remarkably increases as part of regular seasonal

41 In November 1997 "Financial Crisis" suddenly grew apparent in Japan. It was on 22 November 1997 that Yamaichi Securities gave up the idea of self-resuscitation, on which many Japanese clearly remember the apologizing press conference by the newly appointed president. On November 3 Sanyo Securities filed a bankruptcy-reorganization plan, on 17th Hokkaido Takushoku Bank announced that, giving up the idea of self-resuscitation, it transferred business to Hokuyo Bank, and on $26^{\text {th }}$ of the same month Tokuyo City Bank gave up the idea of self-resuscitation on which the Finance Minister and the Bank of Japan Chairman released statements. For more details, see Miwa [2008, pp.6 8].

42 "If not for the adjustment of accumulated inventory stock, what caused this dramatic rtotal decline and its continuation?" emerges to readers as a new puzzle. It is not an agenda of this study, however. By association, see the Appendix (Section [12]) of this paper. 
fluctuations, and that 2009Q1 when rtotal recorded a dramatic decline in almost all commodities is the $1^{\text {st }}$ quarter when rtotal drastically decreases, reporting a large negative value.

\section{All industries accumulated inventory investment values}

Before the study by commodity in [8-2], I show below two figures on all industries accumulated inventory investment values, taking 2008Q3 and 1997Q3 as the starting point T. For the details of those figures, including the choice of $\mathrm{T}$, see the discussion on the petroleum product accumulated inventory investment values in [8-2].

As shown in detail in [8-3] concerning automobile, the fluctuation patterns observed in automobile accumulated inventory investment values are basically common to such commodities as electric-machine, specific- and general machinery, and also all industries. For example, I find neither notable accumulation in inventory stock after the Lehman Shock nor its ex-post adjustment process. In quarterly estimates the influence of rprocess is dominant in rtotal fluctuations, but in the trend and long-run fluctuations in rtotal rdistribution becomes important.

\section{Period around the Lehman Shock}

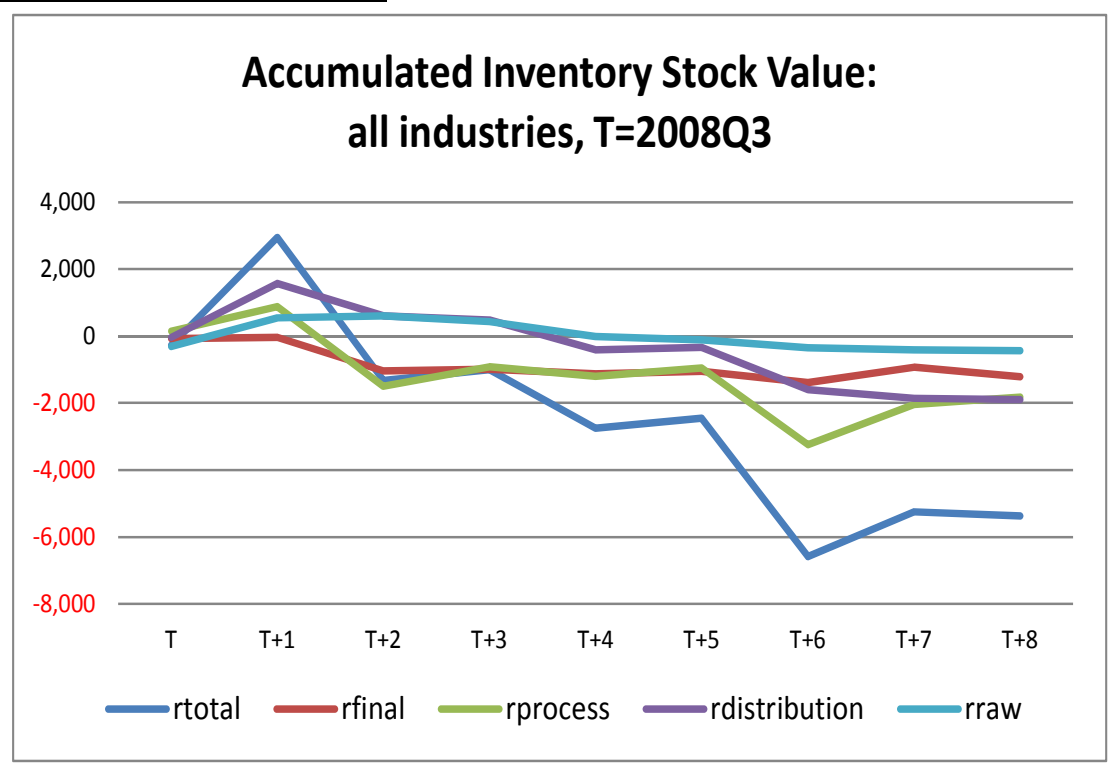

The increase in inventory stock in 2008Q4 $(\mathrm{T}+1)$, just after the Lehman Shock, was rather small, and most accumulated inventory stock values turn to negative in 2009Q1 (T+2) and recording larger negative values in the following quarters. No inventory stock reduction to be regarded as an adjustment process for the accumulated inventory stock due to the Shock. 


\section{Period around the "Financial Crisis"}

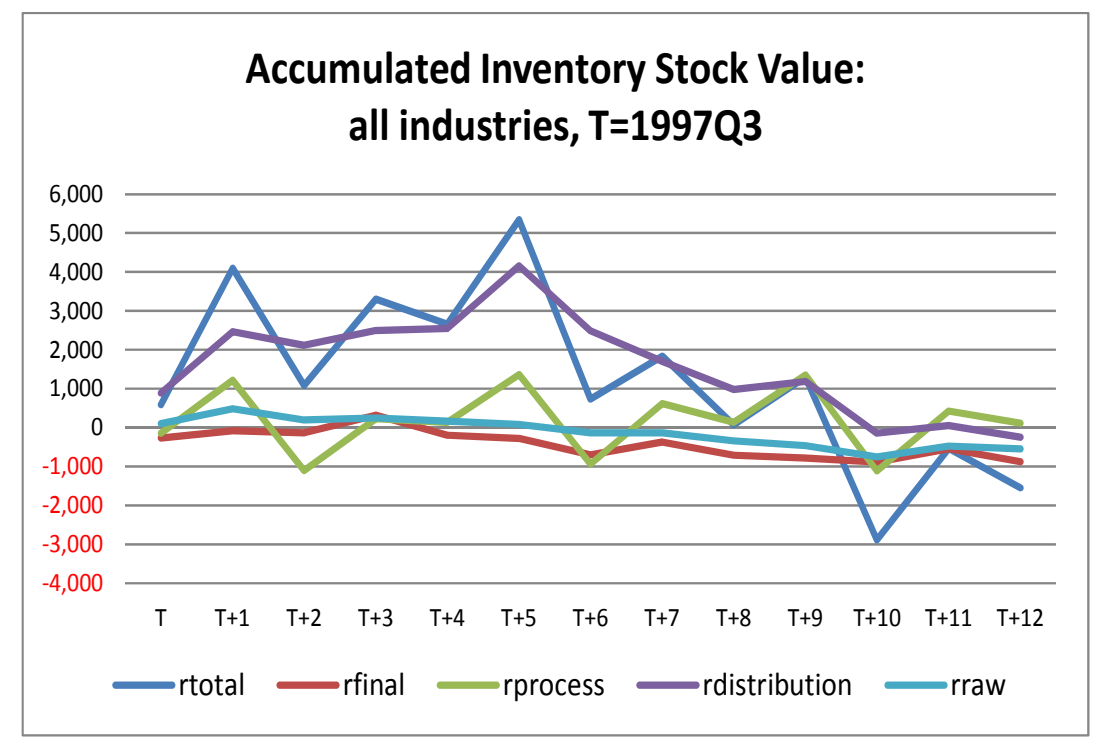

During the period around the "Financial Crisis" the peak of all industries accumulated inventory stock, primarily due to rdistribution, was 1998Q4 $(\mathrm{T}+5)$, where the difference of its value from that at $\mathrm{T}=0$ was 3 trillion yen in rdistribution and 4 trillion yen in rtotal. These values correspond to $2 \sim 3 \%$ of 180 trillion yen, nominal quarterly shipment value of the time, or 2 or 3 days nominal shipment value.

Rtotal returned in 1999Q1 $(\mathrm{T}+6)$ to the start level, and rdistribution in 1999Q3 $(\mathrm{T}+8)$.

[8-2]. Petroleum-, Non-ferrous Metal-, and Steel Product

[8-2] studies petroleum- and non-ferrous metal product where rtotal increased remarkably during the Lehman Shock period, together with steel product.

[Petroleum product]

Period around the Lehman Shock

Supposing to be a framework for the other commodities, I present here detailed study of petroleum product.

During the period around Lehman Shock, inventory stock in petroleum product, particularly distribution inventory, accumulated dramatically.

In the quarterly GDP inventory investment estimates by commodity, rraw is the net increase in values of petroleum product stock firms hold as industrial raw materials and fuel, which does not include crude oil held by oil manufacturers. Here, focus is placed upon the petroleum product accumulated by purchasers as raw material 
and fuel and its subsequent "stock adjustment process".

As the data is available till the end of 2010, in some cases figure ends before $\mathrm{T}+8$. For focusing on the adjustment process, I present 4 figures beginning with 2008Q3 2009Q2, respectively, that show 4 inventory investments by category and rtotal.

First, I present a table of quarterly petroleum inventor investment values by category and rtotal, together with nominal shipment value (not the accumulated values, unit: billion yen), and then four figures on accumulated values.

\begin{tabular}{|l|r|r|r|r|r|r|}
\hline & & & & \multicolumn{3}{|c|}{ petroleum product } \\
\hline $2008 \mathrm{q} 1$ & nsales & \multicolumn{1}{|c|}{ rtotal } & \multicolumn{1}{c|}{ rfinal } & rprocess & rdistribution & \multicolumn{1}{c|}{ rraw } \\
\hline $2008 \mathrm{q} 2$ & $5,472.2$ & -216.2 & -2.5 & -0.3 & -61.1 & -152.2 \\
\hline $2008 \mathrm{q} 3$ & $5,383.9$ & 36.8 & 35.6 & 12.5 & 10.1 & -21.5 \\
\hline $2008 \mathrm{q} 4$ & $6,338.5$ & -112.6 & 54.4 & 10.4 & -64.4 & -113.1 \\
\hline $2009 \mathrm{q} 1$ & $4,549.9$ & 435.1 & -116.0 & -23.6 & 131.3 & 443.4 \\
\hline $2009 \mathrm{q} 2$ & $3,662.0$ & 402.8 & 16.4 & 8.4 & 180.1 & 197.9 \\
\hline $2009 \mathrm{q} 3$ & $3,536.2$ & 89.0 & 7.6 & -14.2 & 101.5 & -5.8 \\
\hline $2009 \mathrm{q} 4$ & $4,174.3$ & -228.6 & 69.7 & 7.7 & -159.9 & -146.2 \\
\hline $2010 \mathrm{q} 1$ & $4,423.3$ & -221.3 & -130.4 & -7.9 & -45.4 & -37.5 \\
\hline $2010 \mathrm{q} 2$ & $4,693.4$ & -226.9 & -5.6 & -12.4 & -91.5 & -117.5 \\
\hline $2010 \mathrm{q} 3$ & $4,451.5$ & -97.3 & 18.4 & 9.1 & -57.8 & -67.1 \\
\hline $2010 \mathrm{q} 4$ & $4,617.8$ & 96.1 & -20.3 & 10.0 & 10.6 & 95.8 \\
\hline
\end{tabular}

Rtotal increased prominently in 2008Q4, where increase in rraw was overwhelming, followed by rdistribution, rprocess and rfinal recording negative values. Rtotal recorded a big positive value also in 2009Q1 where rraw decreased to less than the half and rdistribution increased instead, rprocess and rfinal remaining stable. In 2009Q2 only rdistribution recorded a fairly big value. From 2009Q1 2009Q4 rtotal recorded big negative values, where both rdistribution and rraw recorded big negative values, and in 2009Q4 rfinal also recorded a big negative value.

The first figure start with the values of 2008Q3 ( $\mathrm{T}=2008 \mathrm{Q} 3$ ).

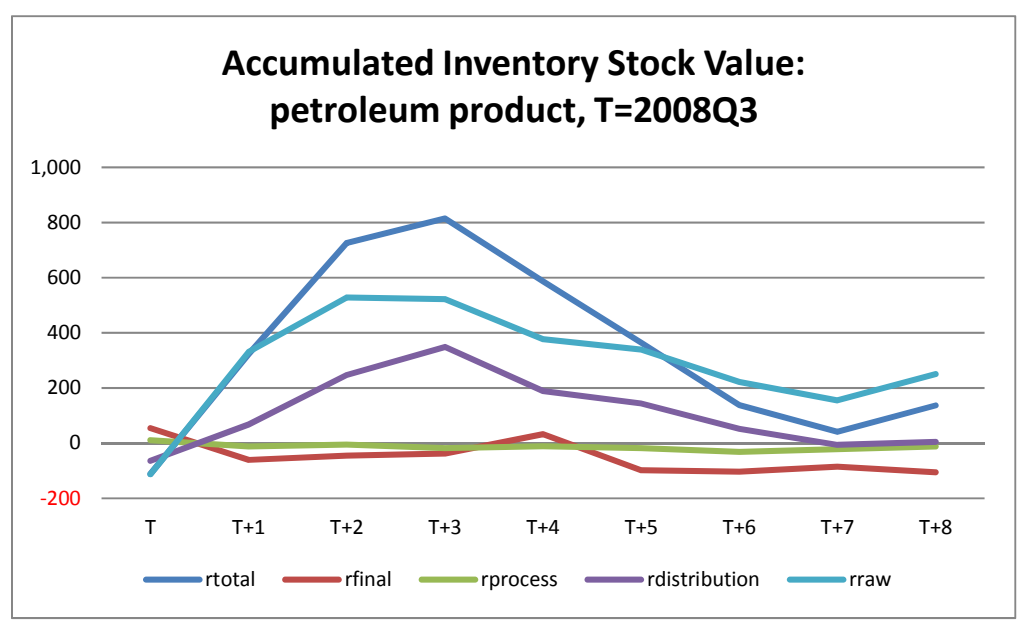



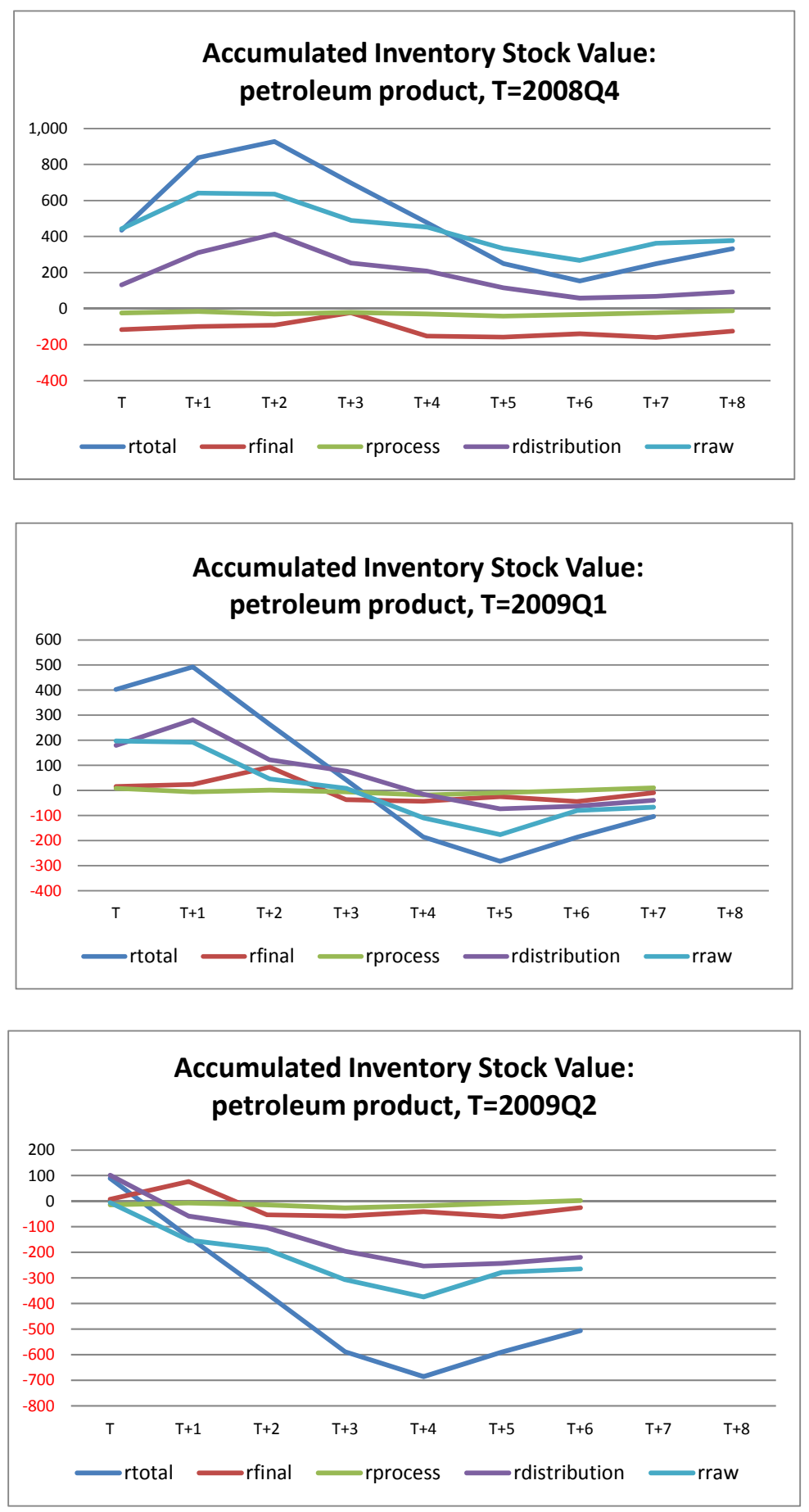

Although the estimates I use unchanged, the level of accumulated inventory investment values greatly differ depending on the choice of $T$, the starting point, with which readers receive different impressions. Like the figures on all industries accumulated values in [8-1], in [8-2] [8-5] I show, for the period after Lehman Shock figures on T=2008Q3, and for the "Financial Crisis" on T=1997Q3.

Readers might be interested in how many months' or days' shipment 
correspond to the additionally accumulated inventory investment stock values. Here I focus on the difference between the cumulative inventory investment values and the 2008Q3 values. This difference in rtotal at 2009Q1 $(\mathrm{T}+2)$ and 2009Q2 are 600 billion yen and 910 billion yen. As shown in the above table, nominal shipment in 2008Q4 was 4.5 trillion yen, of which 910 billion yen corresponds to $20 \%$, that is, 18 days' shipment. 43

In petroleum product, the influence of rraw was the largest on the rtotal fluctuations, and that of rdistribution the second, rather than rprocess that has overwhelming influence in many commodities. It took one and half years for the inventory stock level to return to the start level.

Because it was an unexpected event with profound influence, the dramatic demand decrease in Japan after the Lehman Shock was an extremely exceptional situation that was anticipated to cause dramatic accumulation of inventory stock. In addition, together with non-ferrous metal product, petroleum product is exceptional in that inventory stock accumulation during this period was conspicuous. In such an exceptional case, that is, exceptional commodity and time, the accumulated inventory stock increase corresponds to mere 18 days' shipment value.

\section{Period around the "Financial Crisis"}

Upon the previous conclusion about the period around Lehman Shock, readers may wonder: How about the other period? Maybe it was not so much unexpected as the Lehman Shock, but the situation during the period of "Financial Crisis" in 1997 1999 must be still of great interest to many readers.

The collapse of Yamaichi Securities occurred in November 1997, at the end of 1997Q4. Even before this event observers were worrying about the coming depression, and therefore the beginning of "confusion" and "adjustment process" may be a little earlier. Because of this, I show a corresponding table for 1997 2002, and a figure of accumulated inventory investment stock value over 12 quarters (3 years) from 1997Q3.

Compared to the period after Lehman Shock, either of the inventory accumulation or its subsequent adjustment process is very unimpressive.

43 Real shipment value data is unavailable, and instead I use the nominal shipment value data. For this, 18 days may be slightly overvalued. 
petroleum product

\begin{tabular}{|l|r|r|r|r|r|r|}
\hline & nsales & rtotal & rfinal & rprocess & rdistribution & rraw \\
\hline $1997 q 1$ & $3,059.2$ & -198.3 & 6.2 & 17.5 & -99.6 & -122.4 \\
\hline $1997 q 2$ & $2,814.6$ & 1.4 & -15.1 & -25.2 & 51.1 & -9.3 \\
\hline $1997 q 3$ & $2,940.3$ & 288.0 & 45.1 & 17.2 & 143.1 & 82.6 \\
\hline $1997 q 4$ & $3,096.9$ & 80.4 & -6.3 & -2.6 & 35.7 & 53.6 \\
\hline $1998 q 1$ & $2,856.6$ & -224.1 & -46.4 & -9.2 & -109.3 & -59.2 \\
\hline $1998 q 2$ & $2,453.0$ & 15.2 & -10.8 & 1.9 & -30.5 & 54.6 \\
\hline $1998 q 3$ & $2,636.9$ & 112.3 & 61.9 & 14.5 & 13.4 & 22.5 \\
\hline $1998 q 4$ & $2,762.1$ & 58.5 & -53.1 & -14.7 & 176.0 & -49.7 \\
\hline $1999 q 1$ & $2,429.6$ & -61.6 & -16.0 & 16.8 & -108.8 & 46.3 \\
\hline $1999 q 2$ & $2,328.5$ & 125.4 & 40.5 & 0.1 & -12.9 & 97.8 \\
\hline $1999 q 4$ & $2,663.4$ & -108.1 & 7.3 & -11.4 & -5.4 & -98.6 \\
\hline $2000 q 1$ & $2,947.2$ & -29.8 & 0.5 & -5.0 & 11.6 & -36.8 \\
\hline $2000 q 2$ & $2,901.0$ & 44.7 & 5.7 & 70.9 & -86.2 & 54.3 \\
\hline $2000 q 3$ & $2,740.0$ & -61.0 & -13.1 & -8.0 & -42.2 & 2.4 \\
\hline $2000 q 4$ & $3,099.7$ & 61.4 & -4.3 & 45.4 & 43.9 & -23.6 \\
\hline $2001 q 1$ & $3,241.6$ & -180.4 & -26.9 & -56.8 & -57.9 & -38.7 \\
\hline $2001 q 2$ & $3,164.7$ & -111.6 & -10.1 & 15.2 & -67.5 & -49.3 \\
\hline $2001 q 3$ & $3,009.1$ & 169.3 & 5.4 & 8.9 & 118.9 & 36.1 \\
\hline $2001 q 4$ & $3,133.3$ & -20.6 & 34.6 & 23.1 & -99.5 & 21.1 \\
\hline $2002 q 1$ & $3,109.5$ & -54.9 & -75.5 & -49.2 & 69.6 & 0.1 \\
\hline $2002 q 2$ & $2,967.3$ & 136.3 & 41.9 & 3.8 & 24.9 & 65.7 \\
\hline $2002 q 3$ & $2,918.3$ & -1.4 & -14.0 & 37.3 & -12.5 & -12.3 \\
\hline $2002 q 4$ & $3,142.3$ & -82.3 & -3.3 & -29.8 & -20.4 & -28.9 \\
\hline & $3,322.6$ & -126.8 & -22.0 & -11.6 & -43.7 & -49.5 \\
\hline
\end{tabular}

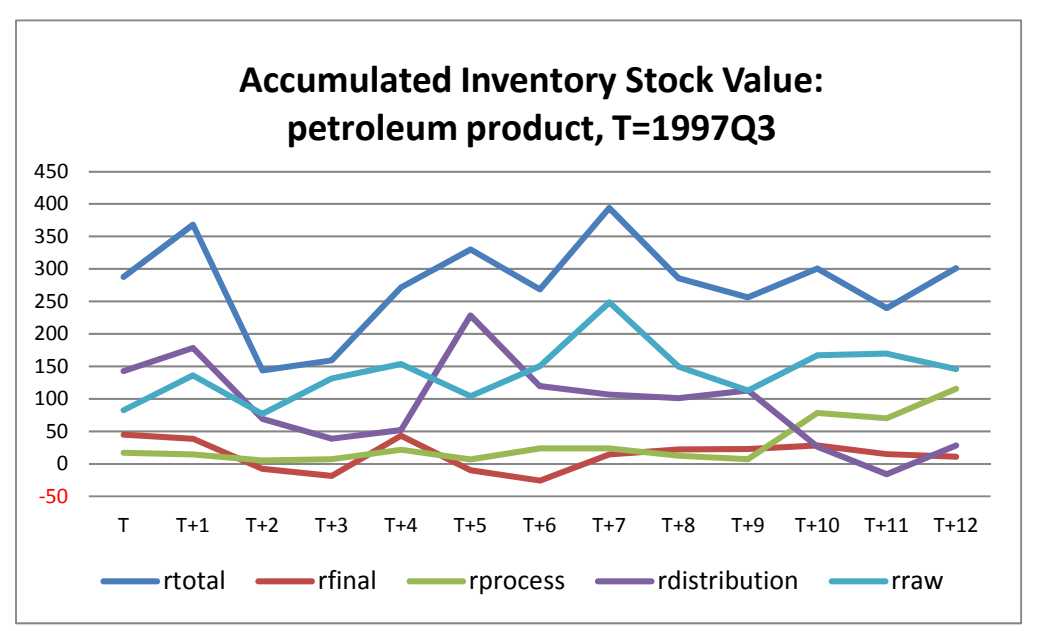

[Non-ferrous metal product]

Period around the Lehman Shock 


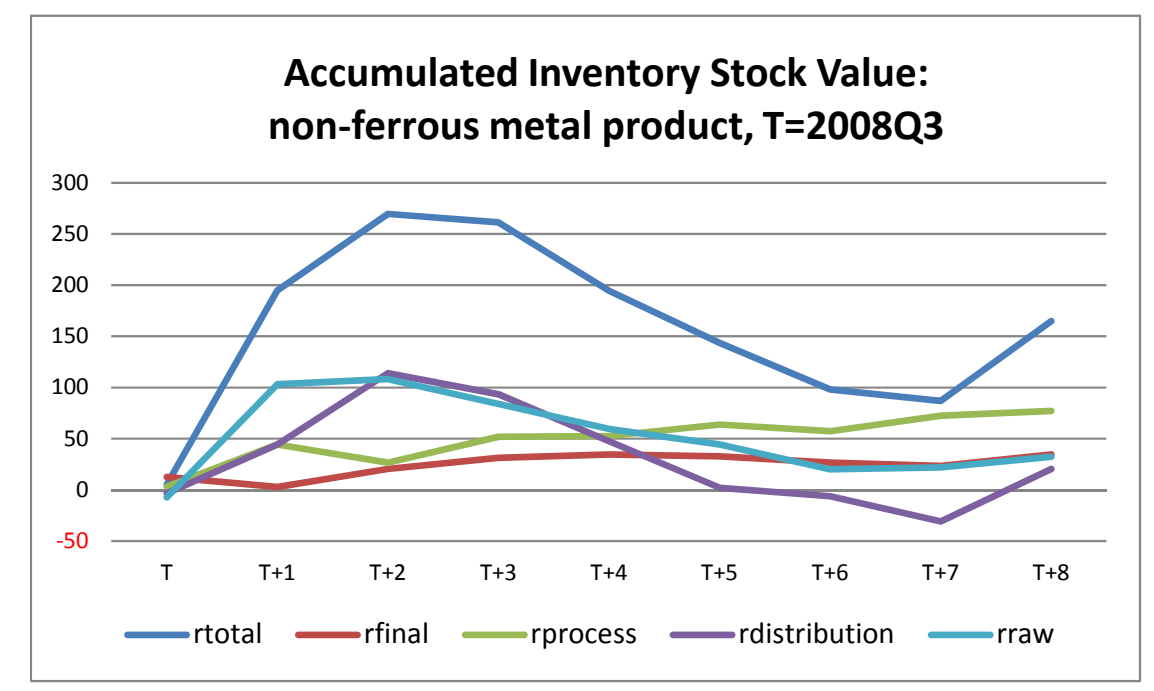

270 billion yen, the accumulated inventory investment value at the peak after the Lehman Shock (at 2009Q1, T+2) corresponds to 30\% of 900 billion yen, the quarterly nominal shipment of the time, or 27 days' shipment, of which rraw and rdistribution occupied 100 billion yen, respectively.

Like petroleum product, at $\mathrm{T}+1$ rraw increased remarkably and at $\mathrm{T}+2$ rdistribution followed. It took one and half years for the inventory stock to return to the start level, too.

Period around the "Financial Crisis"

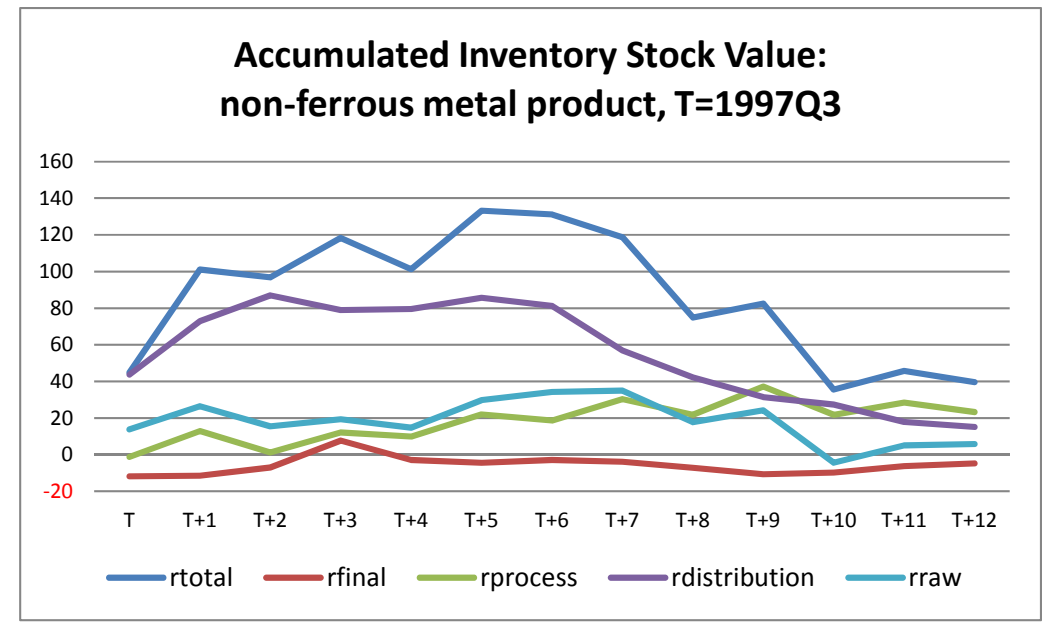

130 billion yen, the accumulated inventory investment value at the peak during this period (at 1998Q4, $\mathrm{T}+5$ ) corresponds to $37 \%$ of 350 billion yen, the quarterly nominal shipment of the time, or 34 days' shipment, where the influence of rdistribution was overwhelming. ${ }^{44}$ It took two and half years for the inventory stock to return to the

44 If the process started from 40 billion yen at $\mathrm{T}$, the difference reduces to 100 billion yen, corresponding to 28 days' shipment. 
start level.

[Steel product]

Period around the Lehman Shock

As shown in [7], during this period we find no remarkable increase in steel product inventory investment, which suggests that there was no need for inventory adjustment. The remarkable reduction in rtotal in 2008Q4 $(\mathrm{T}+1)$ and 2009Q1, where the influence of rfinal was overwhelming, should not be part of "adjustment" process.

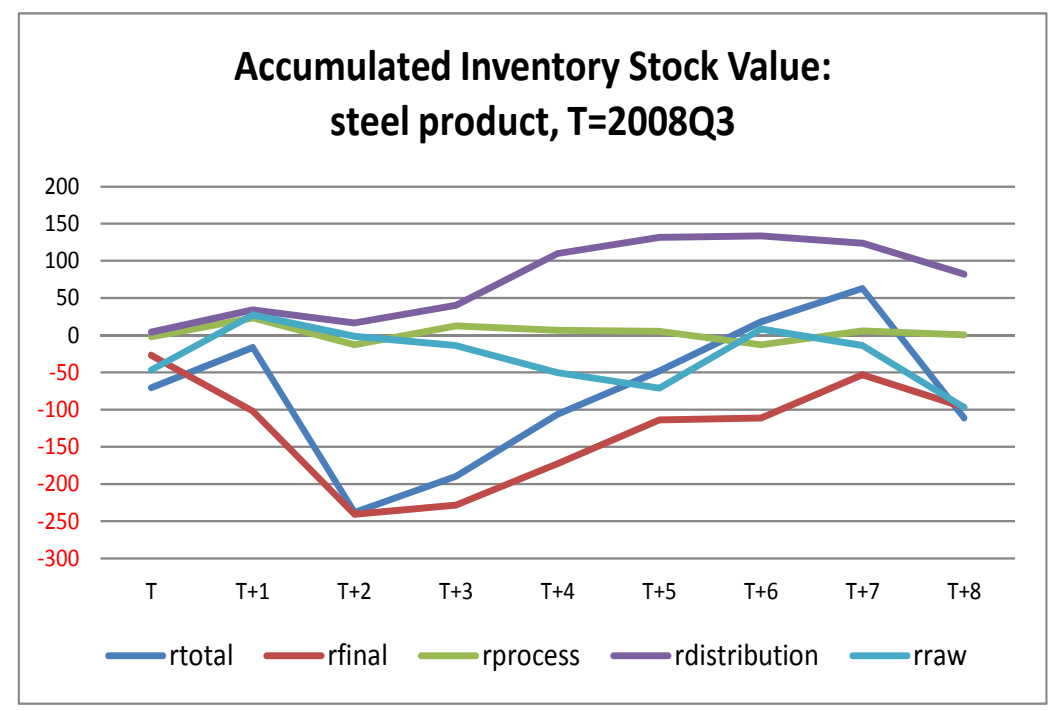

-200 billion yen, the accumulated inventory reduction value at the peak during this period (at 2009Q1, T+2) corresponds to $4 \%$ of 5 trillion yen, the quarterly nominal shipment of the time, or 4 days' shipment.

\section{Period around the "Financial Crisis"}

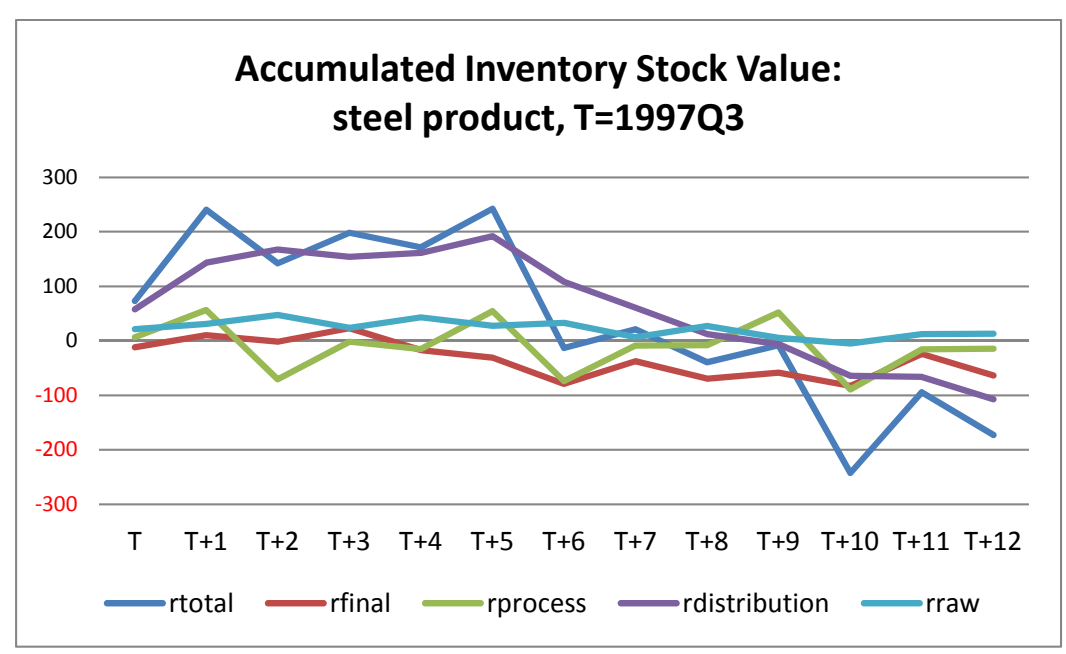


200 billion yen, the accumulated inventory investment value at the peak during this period (at 1998Q4, $\mathrm{T}+5$ ) corresponds to $6 \%$ of 3.5 trillion yen, the quarterly nominal shipment of the time, or 6 days' shipment, where the influence of rdistribution was overwhelming. It took two years for the inventory stock to return to the start level.

\section{[8-3]. Automobile and Electric-Machine}

[8-3] studies automobile and electric-machine. As shown in [7], in either commodity the influence of rprocess is overwhelming in quarterly inventory investment fluctuations, but rdistribution in annual fluctuations. Accumulated inventory investment values illustrate those points more clearly.

As we see below, most observations about the fluctuations in automobile inventory investment are commonly observed in electric-machine, specific- and general machinery, and also all industries.

\section{[Automobile]}

\section{Period around the Lehman Shock}

Quite often automobile has been in the news in Japan, including the drastic export decline after the Lehman Shock.

In automobile, however, after the Lehman Shock, we observe some increase in rdistribution, but almost no increase either in rfinal or rprocess. The accumulated total inventory stock in 2008Q4 was completely dissolved in the next quarter, 2009Q1, and long-lasting inventory stock reduction continued in the following quarters. It is unreasonable to see it as stock adjustment process.

It was in $2009 \mathrm{Q} 2(\mathrm{~T}+2)$ when the distribution stock returned to the start level. After this, the decreasing trend continued for a long time, dominating the long-run inventory investment trend in rtotal.

500 billion yen, the initial accumulated total inventory investment value, corresponds to $5 \%$ of 10 trillion yen, the quarterly shipment of the time, or 5 days' shipment. 2 trillion yen, the stock value decrease from the peak to the bottom (at the 3 quarters later, $\mathrm{T}+6$ ) corresponds to 20 days' shipment. 


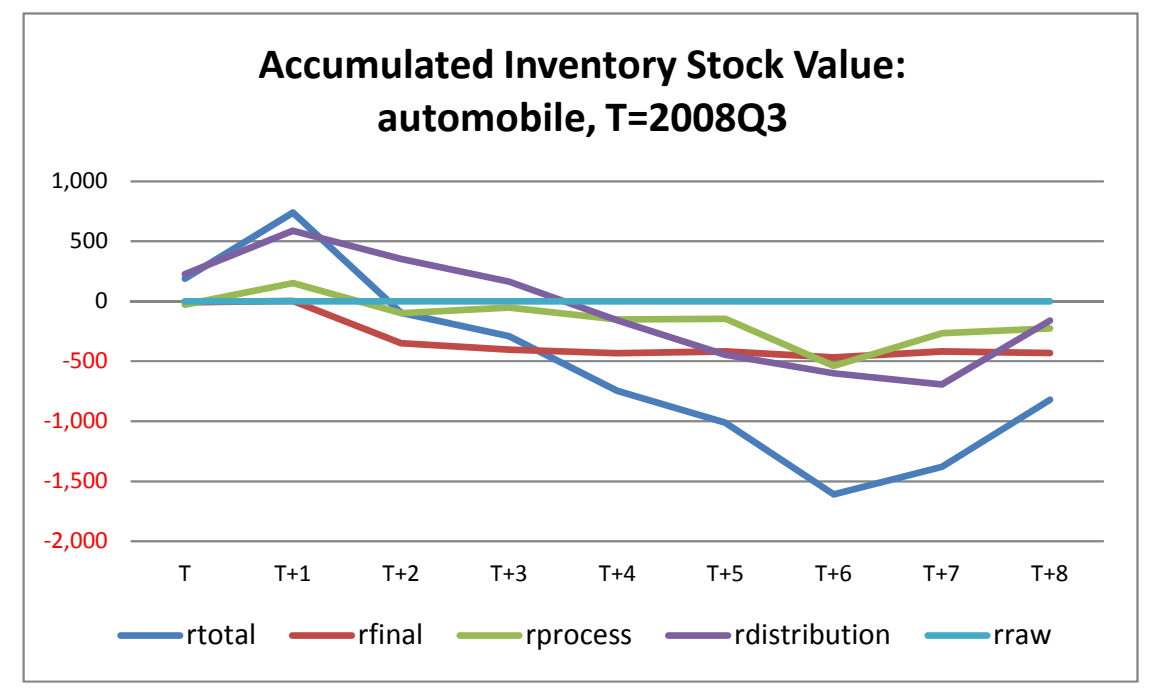

Period after the "Financial Crisis"

During the period after the "Financial Crisis" since 1997Q3, we observe wild rise and fall in accumulated inventory stock, where the influence of rprocess was overwhelming. After the peak at 1998Q4 $(\mathrm{T}+5)$, however, we find a clear decreasing trend in total inventory stock value, where rfinal and rdistribution were dominant.

500 billion yen, increase in total inventory stock value between 1998Q1 T+2) and 1998Q4 where rdistribution was dominant, corresponds to $10 \%$ of 10 trillion yen, the quarterly shipment of the time, or 9 days' shipment.

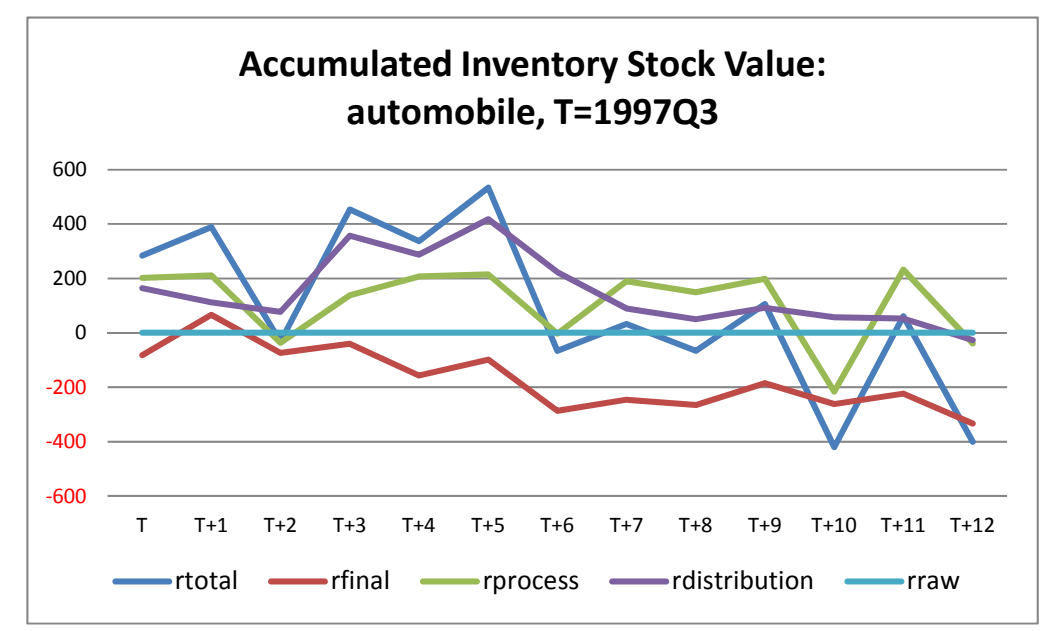

This increase in inventory stock value of 500 billion yen was accumulated between 1998Q1 and 1998Q4, the period the difference becomes the largest, that is, from the bottom quarter to the peak quarter in above mentioned regular seasonal fluctuation. In the next quarter, rtotal was -500 billion yen, decreasing the accumulated value to less than 0. If we assume the average of rtotal in 1997Q1 and 1998Q1 (and also 1999Q1) as the additional value along the regular seasonal fluctuations, this 500 billion 
yen dissolves (disappears) almost completely.

The influence of rprocess is overwhelming in quarterly regular seasonal fluctuations in rtotal. Its influence decreases remarkably in long-run trend in rtotal fluctuations, however. ${ }^{45}$

Either during the period around Lehman Shock or around the "Financial Crisis", the peak period of inventory stock accumulation was reached at the $4^{\text {th }}$ quarter, when quarterly inventory investment regularly records a big positive value, much larger than the annual average. Focusing also on drastic rtotal decline in the $1^{\text {st }}$ quarter as part of regular seasonal fluctuation, above observations raise serious doubts on the following conventional wisdom: (1) Those shocks or unexpected big events result in a huge inventory stock accumulation, for the resolution of which a long-run adjustment process is necessary; (2) this kind of inventory fluctuation is a major cause of macro-economic fluctuations. Obviously, however, as consequence of those shocks we find no notable increase in inventory stock, and therefore no need for adjustment.

[Electric-machine]

The accumulated electric-machine inventory stock value reveals almost the same features as in automobile.

\section{Period around the Lehman Shock}

The increase in total inventory stock in 2008Q4 was small, and the accumulated value in 2009Q1 recorded a large negative value both in total inventory and inventory by any category, and remained negative for the following quarters. Rprocess and rdistribution were dominant in the repeated quarterly fluctuations.

What we find is miles away from the expectation of the conventional wisdom: Unexpected situation after the Lehman Shock results in a huge inventory stock accumulation, for the resolution of which long-run adjustment process followed.

45 I will not repeat below, but readers should note that this point applies to almost all commodities with the exception of petroleum- and non-ferrous metal product and apparel, and also to all industries. 


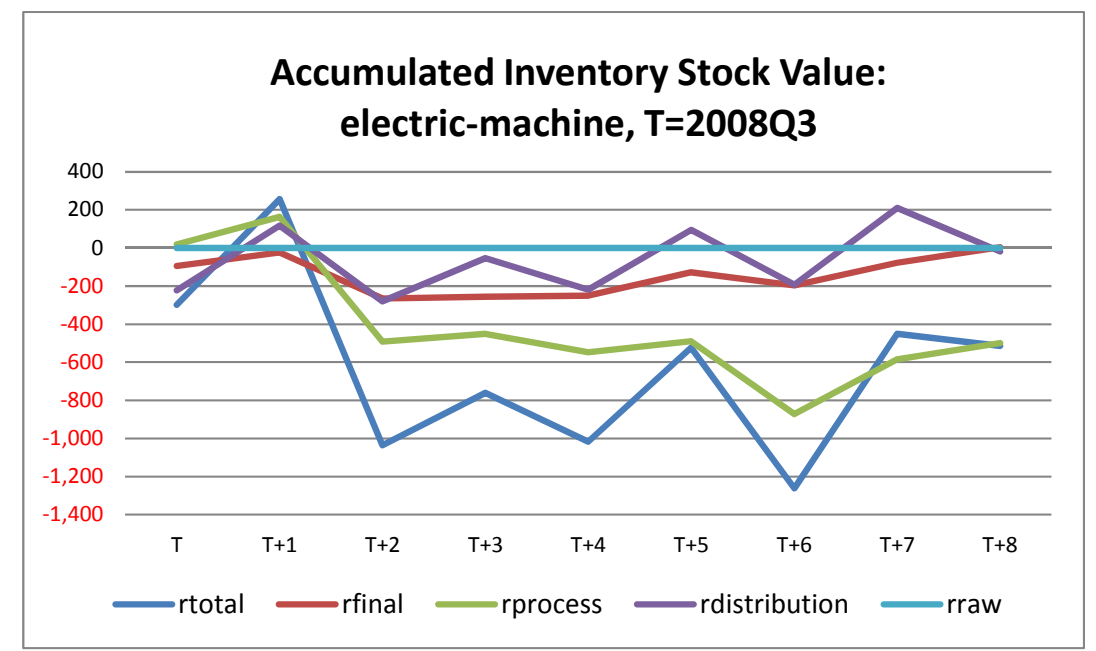

Period after the "Financial Crisis"

The fluctuation pattern of the accumulated electric-machine inventory stock value since 1997Q3 is almost the same as that of automobile, and the above comment on automobile applies here almost at it is.

400 billion yen, the difference in accumulated inventory stock value between 1998Q1 of the bottom and 1998Q4 of the peak, corresponds to 4\% of 9 trillion yen, the shipment value of the time, or 4 days' shipment. On this point, the above comment on automobile applies as well.

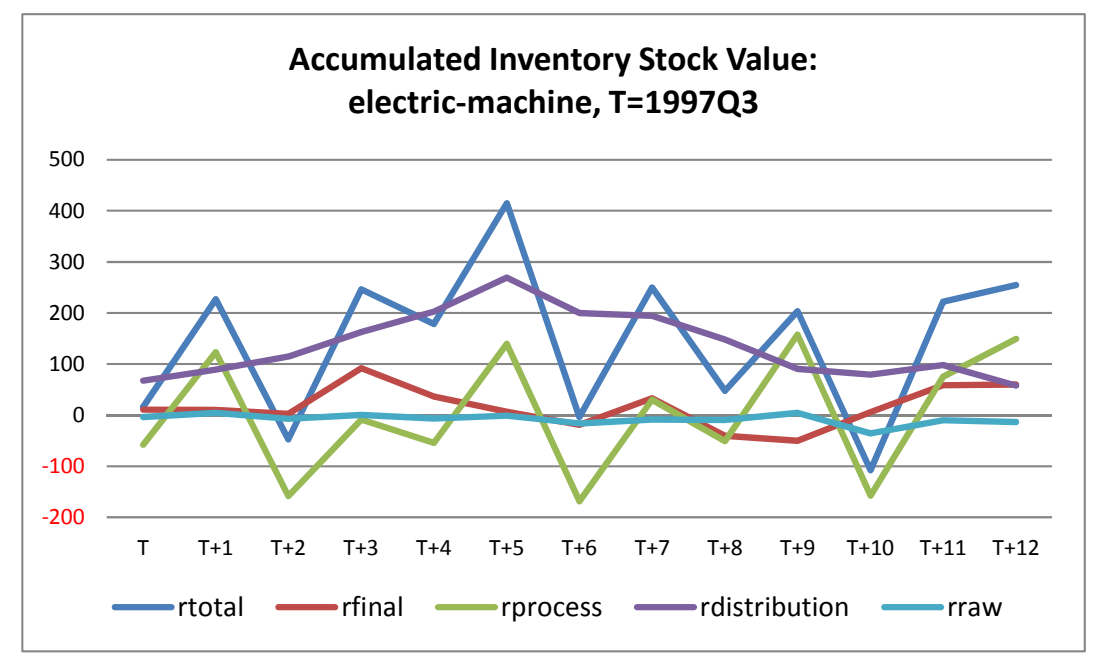

[8-4]. Special- and General Machinery

[8-4] studies special- and general machinery. Both of their accumulated inventory stock values reveal almost the same features as automobile. 
In both the influence of rprocess was overwhelming in quarterly rtotal fluctuations. For the long-run trend and fluctuations, however, the influence of rdistribution was dominant, which was evident particularly during the period around Lehman Shock. In special machinery accumulated inventory stock decreased continuously since 1999Q1. In contrast, in general machinery, due to remarkable rprocess increase toward 1999Q4, realization of its decreasing trend retarded.

\section{[Special Machinery]}

Period around the Lehman Shock

During the period around Lehman Shock, special- and general machinery reveal almost the same movement in accumulated inventory stock value.

During this period I find no remarkable difference between special- and general machinery in fluctuation pattern of accumulated inventory stock values: neither its remarkable increase just after the Shock nor the adjustment process. We observe a decreasing trend in inventory stock.

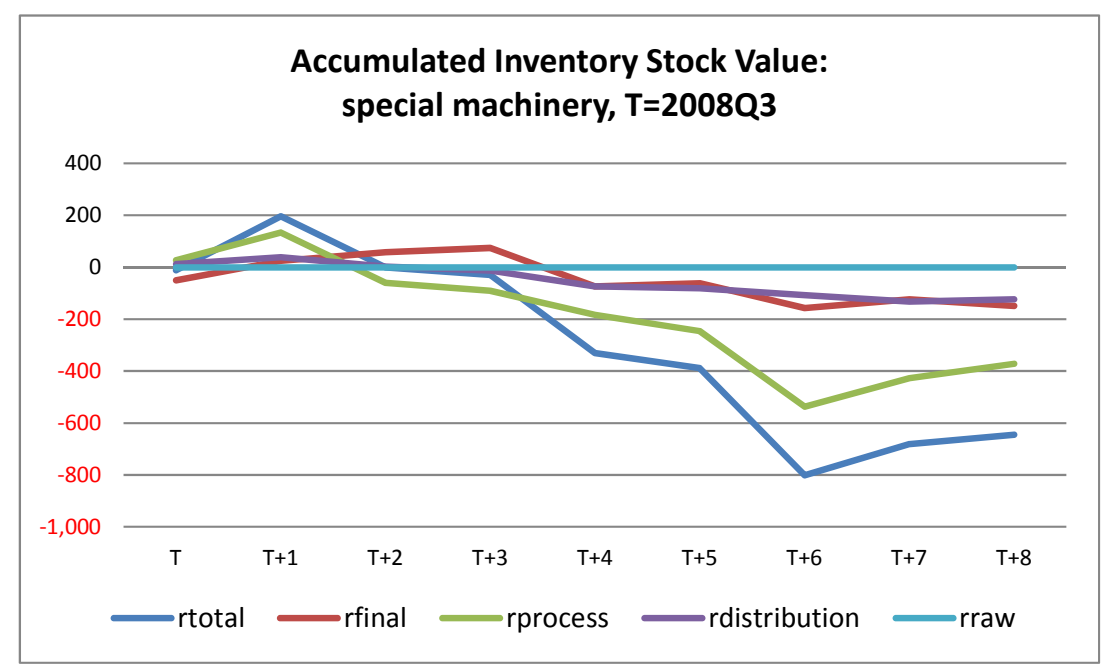

\section{Period around the "Financial Crisis"}

200 billion yen, the difference in accumulated inventory stock value between 1998Q1 and 1998Q4, corresponds to 7\% of 3 trillion yen, the quarterly nominal shipment of the time, or 6 days' shipment, which almost completely disappeared in the next 1999Q1. 


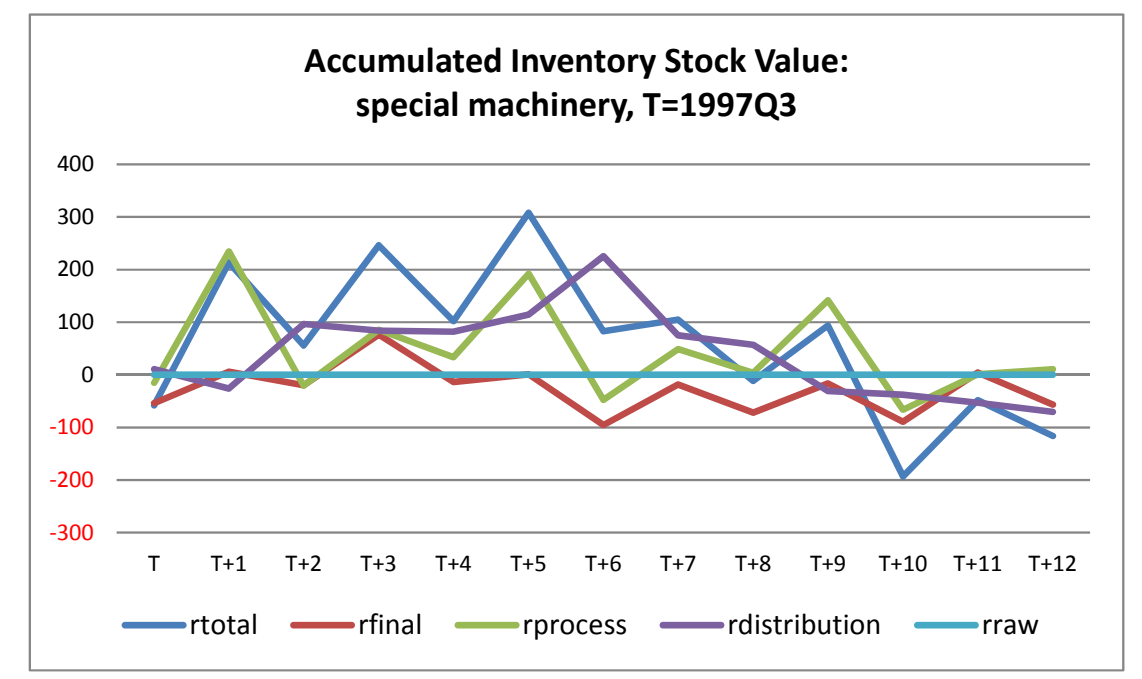

[General machinery]

Period around the Lehman Shock

Previous comment on special machinery almost completely applies to general machinery.

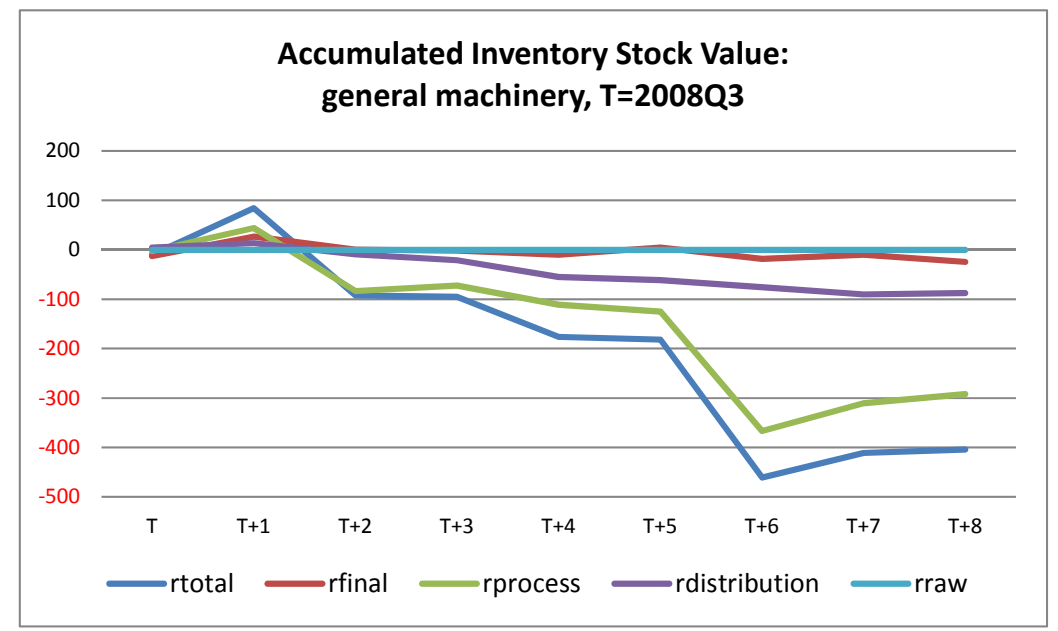

Period around the "Financial Crisis"

300 billion yen, the difference in accumulated inventory stock value between 1998Q1 and 1998Q4, corresponds to 1/7 of 2 trillion yen, the quarterly nominal shipment of the time, or 13 days' shipment, half of which disappeared in the next 1999Q1, and completely disappeared in 2001Q1. 


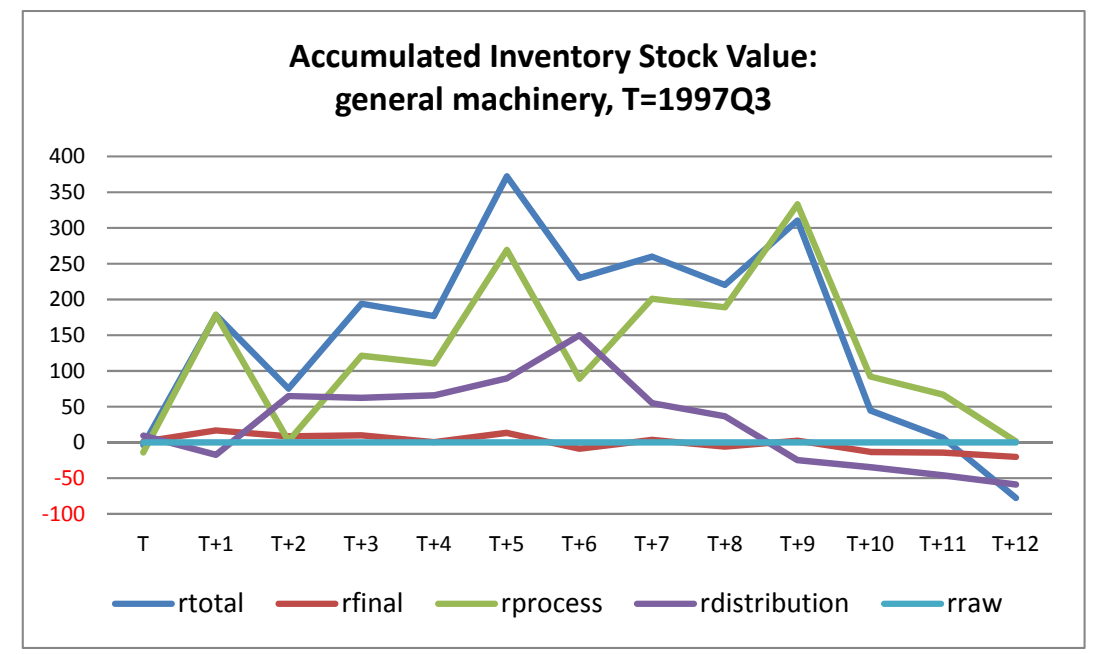

[8-5]. Apparel

In apparel, non-durable consumption goods, in either period we find little increase in rtotal. Particularly during the period around Lehman Shock, rtotal decreased monotonically. In either period, the influence of rdistribution overwhelmed the fluctuations in rtotal, and other inventory investments by category remained consistently around 0 .

Period around the Lehman Shock

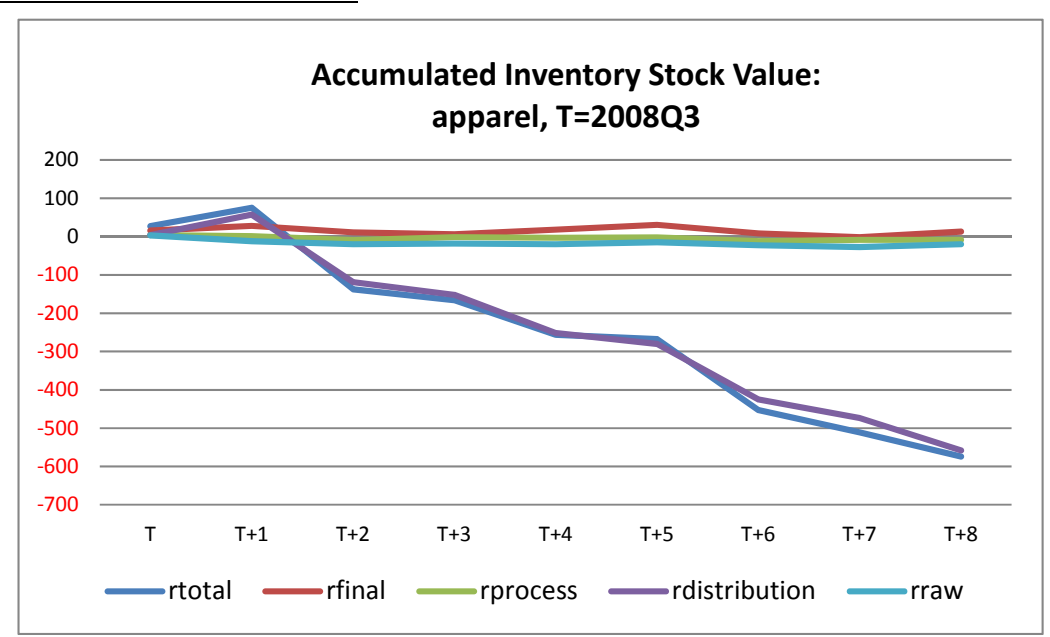

Period around the "Financial Crisis" 


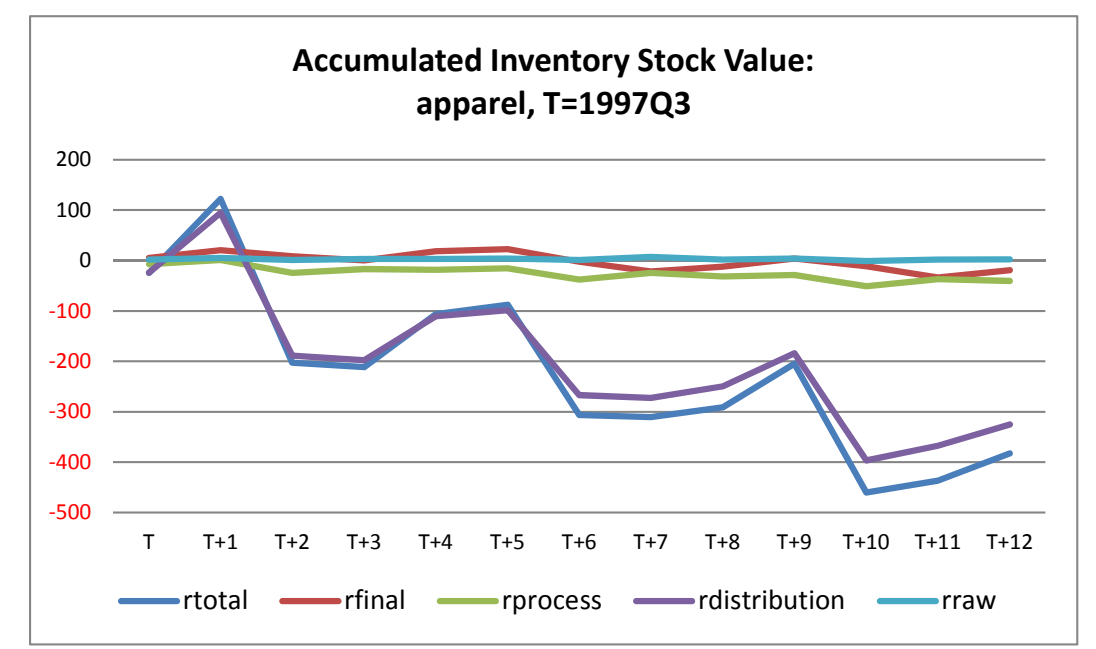

[9] Consequence of Exogenous Shock and Inventory Stock Adjustment Process:

Summary and Supplements

Section [9] first summarizes the studies in [7] and [8] on the consequence of exogenous shocks, focusing on the period around Lehman Shock, and inventory investment on the following adjustment process, and next presents supplementary materials for supporting the conclusions. Following the summary in [9-1], as in [6] for [4] and [5], [9-2] confirms that we reach the same conclusions with inventory data from Corporate Enterprise Quarterly Statistics. Assuming a question, "Is it really possible to deliver a prompt response to 'unexpected event' like a dramatic demand decline after Lehman Shock, and did firms actually deliver it?", [9-3] presents empirical data, both from METI's Indices of Industrial Production Forecast and BOJ's "annual projections" from Tankan (Short-term Economic Survey of Enterprises in Japan), that support the view of firms' prompt response.

[9-1] Summary

Sections [7] and [8] studied the second issue of this research: Investigation of corporate inventory investment behavior, focusing on the consequence of an exogenous shock, unexpected situation for most economic agents involved, and its adjustment process. As an exogenous shock for investigation, I focus on the dramatic demand decline both at home and abroad after Lehman Shock, events occurred after the bankruptcy of Lehman Brothers Co. in mid-September 2008. For comparison, I placed focus also on the decline in domestic economic activity and confusion during the period called "the Financial 
Crisis" since the end of 1997.

Most researches on quarterly inventory investment fluctuations uses long-term time-series inventory data from quarterly SNA (GDP) statistics. ${ }^{46}$ As the second research issue of investigating the reality of inventory investment behavior in the light of cause-and-effect relationship, [7] and [8] focused on the period after Lehman Shock. As shown in [2], drastic shipment decline both at home and abroad after the Lehman Shock was so rapid and drastic that for most economic agents involved it was an unexpected situation. For this reason, the inventory stock accumulation since 2008Q4 (or increase in inventory investment after 2008Q4) has been commonly expected to be the most enormous and serious scenario assumable. Also it has been expected that the subsequent investment adjustment process was the most serious and clearly observable, both in the depth and duration of adjustment process.

From examinations in [7] and [8] I drew five conclusions that are beyond expectation and shocking to many readers.

(1) Either in inventory investment in 2008Q4 or in accumulated inventory stock increase since 2008Q4, the size of inventory investment increase, expected to be serious as a consequence of a rapid and drastic exogenous shock, was small, if any.

(2) Primarily because there appeared little accumulation of inventory stock with the shock that would need for adjustment, I find in subsequent quarters no phenomena to be regarded as an "inventory stock adjustment" process. Over a long period after Lehman Shock, we observe a long-lasting massive decline both in production and shipment, during which in many areas (or commodities) inventory investment continually recorded negative values.

(3) Above points (1) and (2) commonly apply to many commodities, particularly to those with wild fluctuations in quarterly GDP inventory investment statistics.

(4) Above points (1) and (2) commonly apply particularly to goods-in-process inventory investment whose influence has been overwhelming in many commodities' quarterly GDP inventory investment fluctuations.

(5) In some commodities like petroleum product, we observe phenomena different from (1) and (2). However, both the depth and duration of adjustment process fell far short of observers' expectation, which is not remarkable enough to influence the all industries inventory investment, particularly its fluctuations. In those commodities, it was distribution- and raw material stock rather than product- and goods-in-process stock that was accumulated after the Shock.

46 For example, Kashyap et al [1994] that studied the influence of restrictive monetary policy during the 1981 1982 recession is exceptional. 
The rapid and drastic shipment decline both at home and abroad after the Lehman Shock was an unexpected event for many economic agents involved. The inventory stock accumulation since $2008 \mathrm{Q} 4$ has been commonly expected to be the most enormous and serious scenario assumable both in its size and the duration of subsequent inventory adjustment process. Above conclusions (1) (5) raise strong doubts about the validity of the conventional explanation that exogenous shocks like unexpected events are a primary cause of observed wild fluctuations in quarterly GDP inventory investment data. ${ }^{47}$

It is a conventional wisdom about inventory investment fluctuations that unexpected events are the primary cause of wild fluctuations in inventory investment for which long-lasting adjustment process is unavoidable. This view has activated researches on inventory investment fluctuations, to which many macro-economists have been attracted. This view, particularly emphasizing the slow adjustment speed, has worked with the argument: "The adjustment speed of the market is much slower than the textbook economics assumes. The government should actively intervene into the market for appropriately deal with macro-economic fluctuations due to inventory fluctuations and its adjustment, for example." The conclusions of this research raise fundamental doubts also on this kind of view.

Above conclusions drawn from the study of the Japanese economy during the period around Lehman Shock also apply to the period of the "Financial Crisis" since the end of 1997. Concerning the Japanese economy in this period, harmful effects on the whole economy of the collapses of major financial institutions that actually occurred and related disquiet and confusion in the overall financial system have attracted tremendous interest. The period of the "Financial Crisis" in Japan elapsed without enforcing effective policies, from the study of which I drew the same conclusions. They would have serious implications to the evaluation of government countermeasures adopted in countries represented by the US during the period around the Lehman Shock.

Following Sections [4] and [5], in Section [6] I suggested: in investigating the reality of inventory investment and the fluctuations generating mechanisms where promptness is inessential, we should switch focus from the quarterly GDP estimates to

47 For example, Feldstein and Auerbach [1976, p.362] wrote: “[E]conomists have been interested in the sales-forecast error as a source of unanticipated inventory accumulation at least since the publication in 1941 of Metzler's theoretical study of inventory cycle." Economists addressing the causes and mechanism for inventory investment fluctuations are to face a new challenge of excluding from the list of leading candidates of causes unexpected events like the dramatic demand decline in Japan during the period around Lehman Shock. 
the annual SNA estimates, and make active use of micro-based source statistics like IIP and Corporate Enterprise Statistics. The goods-in-process inventory investment (rprocess), overwhelming in wild fluctuations, particularly its regular seasonal fluctuations, of quarterly inventory investment (rtotal) reported little remarkable variations during the period after Lehman Shock. In some commodities with notable inventory accumulation it was distribution- and raw material inventory investment that dominated the rtotal fluctuations. In this point, the studies in [7] and [8] support the suggestion of [6] that raised doubts on the conventional view to emphasize the inventory investment estimates in quarterly GDP statistics, focusing on its wild fluctuations.

\section{[9-2]. Materials from Corporate Enterprise Quarterly Statistics Inventory Data}

As shown in [6], Corporate Enterprise Quarterly Statistics (CEQS) plays a critical role in obtaining the quarterly inventory investment estimates. The inventory investment, the net increase in inventory stock, in quarterly GDP statistics is estimated by commodity from business accounting inventory stock data.

Remarkable regular seasonal fluctuations are observed both in inventory stock- and its variation values from CEQS published by industry, which summarize the reports from corporations. [9-2] shows that the basic conclusion summarized in [9-1] also holds in study with inventory data from CEQS. On the relationship between the inventory investment estimates (commodity-based) of quarterly GDP statistics and the inventory data (firm-industry based) of CEQS, see the above explanation in [6]

\section{Inventory investment in the manufacturing sector,}

\section{and wholesaling- and retailing sector}

The two figures for inventory investment in the manufacturing sector, shown above in [6], in 2008Q4 the level of inventory investment, either in total inventory or inventory by category, was nearly 0 , lower than the previous $4^{\text {th }}$ quarter average and also rather lower than the preceding 2008Q3. Simply, in 2008Q4 we observe no inventory stock accumulation. In 2009Q1, both in total inventory and inventory by category, inventory investment recorded a big negative value. The size of the decline from the preceding quarter was remarkably larger than the previous $1^{\text {st }}$ quarter average. The inventory investment in the next quarter, 2009Q2, was nearly 0. By any standard, we find no notable phenomena to be regarded as vast inventory stock accumulation and subsequent inventory adjustment process expected as consequences 
of unexpected rapid and drastic shipment reduction as an exogenous shock. This point is clear also from the subsequent figures on accumulated inventory stock values by quarter. Inventory investment in each 2008 quarter was lower than that of corresponding 2007 quarter, and the value was still lower in 2009 quarter than in 2008 with the only exception of the $4^{\text {th }}$ quarter that is slightly higher.

The same conclusion holds for the inventory investment in the manufacturing sector under the "Financial Crisis" since 1997Q4.

From the study of inventory investment in the wholesaling- and retailing sector, bearing in mind the comparison with distribution inventory investment in quarterly GDP statistics, we draw the same conclusion. Both in wholesaling- and retailing sector, in 2008Q4 inventory investment were nearly 0, rather lower than the other $4^{\text {th }}$ quarter levels. In 2009Q1 inventory investment in wholesaling sector was remarkably lower than the other $1^{\text {st }}$ quarter levels, which returned to 0 in the next 2009Q2. In retailing sector in 2009Q1 inventory investment was slightly below 0, and reported a big negative value in 2009Q2, and a big positive value in 2009Q3. In either sector, we find no notable phenomena to be regarded as vast inventory stock accumulation and subsequent inventory adjustment process.

The same conclusion holds for the inventory investment both in wholesalingand retailing sector under the "Financial Crisis" since 1997Q4.

\section{Inventory investment by industry}

I report here the result of the study, using CEQS data, of five industries: petroleum- and coal product manufacturing, steel, industrial machinery manufacturing, automobile and automotive parts manufacturing, and construction. CEQS studies the inventory investment by firms in all size categories, that is, the whole industry. I use the CEQS data till 2012Q3 (unit: million yen).

\section{Petroleum- and Coal Product Manufacturing}



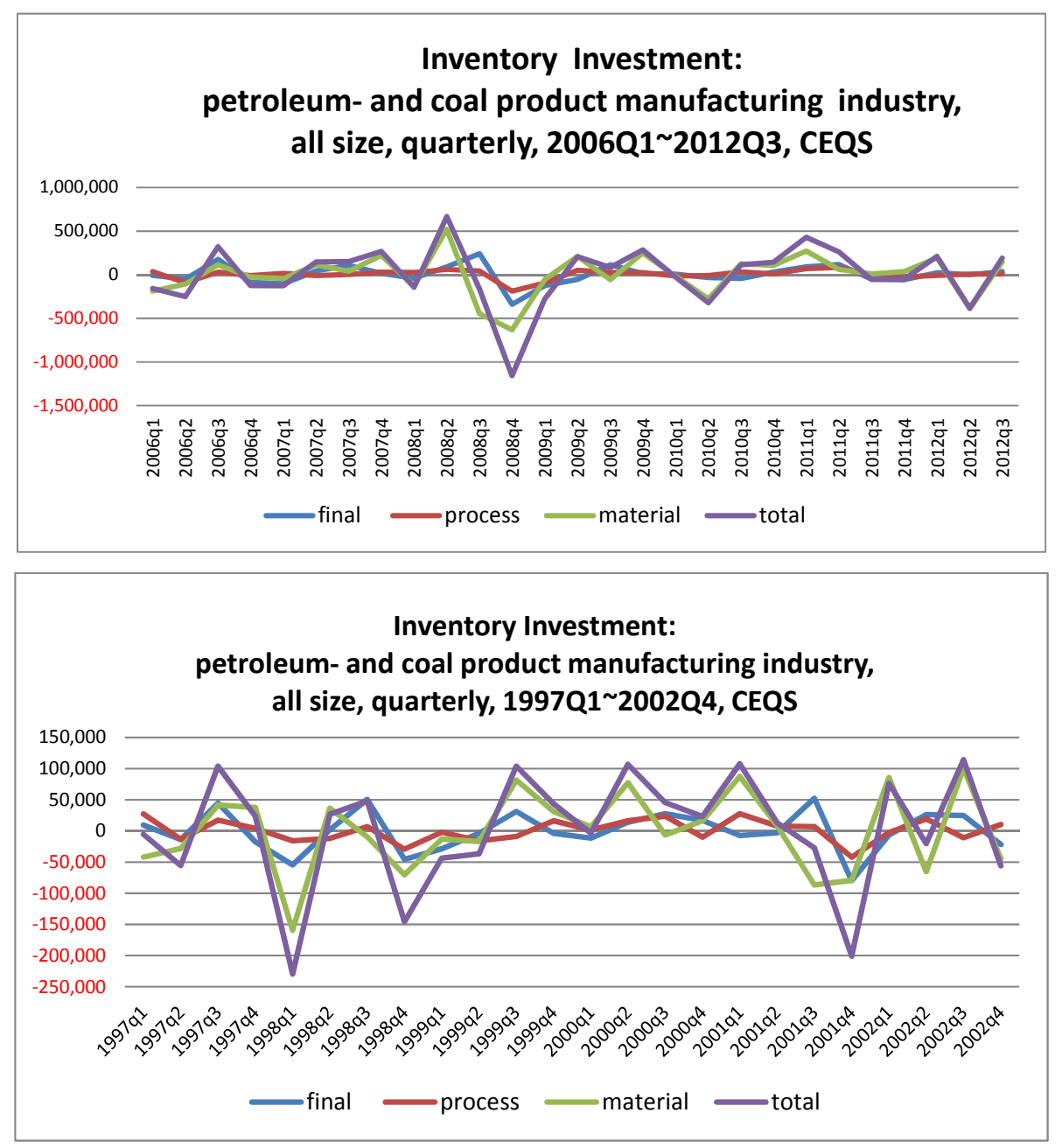

In petroleum- and coal product manufacturing industry, raw material inventory occupied more than $40 \%$ of the total inventory stock, and product- and goods-in-process stocks $30 \%$ and $20 \%$, respectively. The ratio of inventory stock to the total assets had been more than $10 \%$, which began to rise since mid-2000, reaching $25 \%$ recently.

Inventory stock value rose from 10 trillion yen to 25 trillion yen recently. Inventory investment in 2008Q4 (not in 2009Q1) recorded -1 trillion yen, corresponding to $4 \%$ of inventory stock, and -250 billion yen in $1998 \mathrm{Q} 1$ corresponds to $2.5 \%$.

Before the year of 2000 fairly clear regular seasonal fluctuations were observed, which, however, are not recently. Particularly, a big negative value in 2008Q4 is striking.

Accumulation of inventory stock since 2008Q4, its expected peak quarter, and subsequent stock adjustment were observed. The same applies to the period of "Financial Crisis" since 1997Q4.

Including 2011Q2, just after the Great East Japan Earthquake, in any shock 
periods we find no notable inventory accumulation.

$\underline{\text { Steel Manufacturing }}$
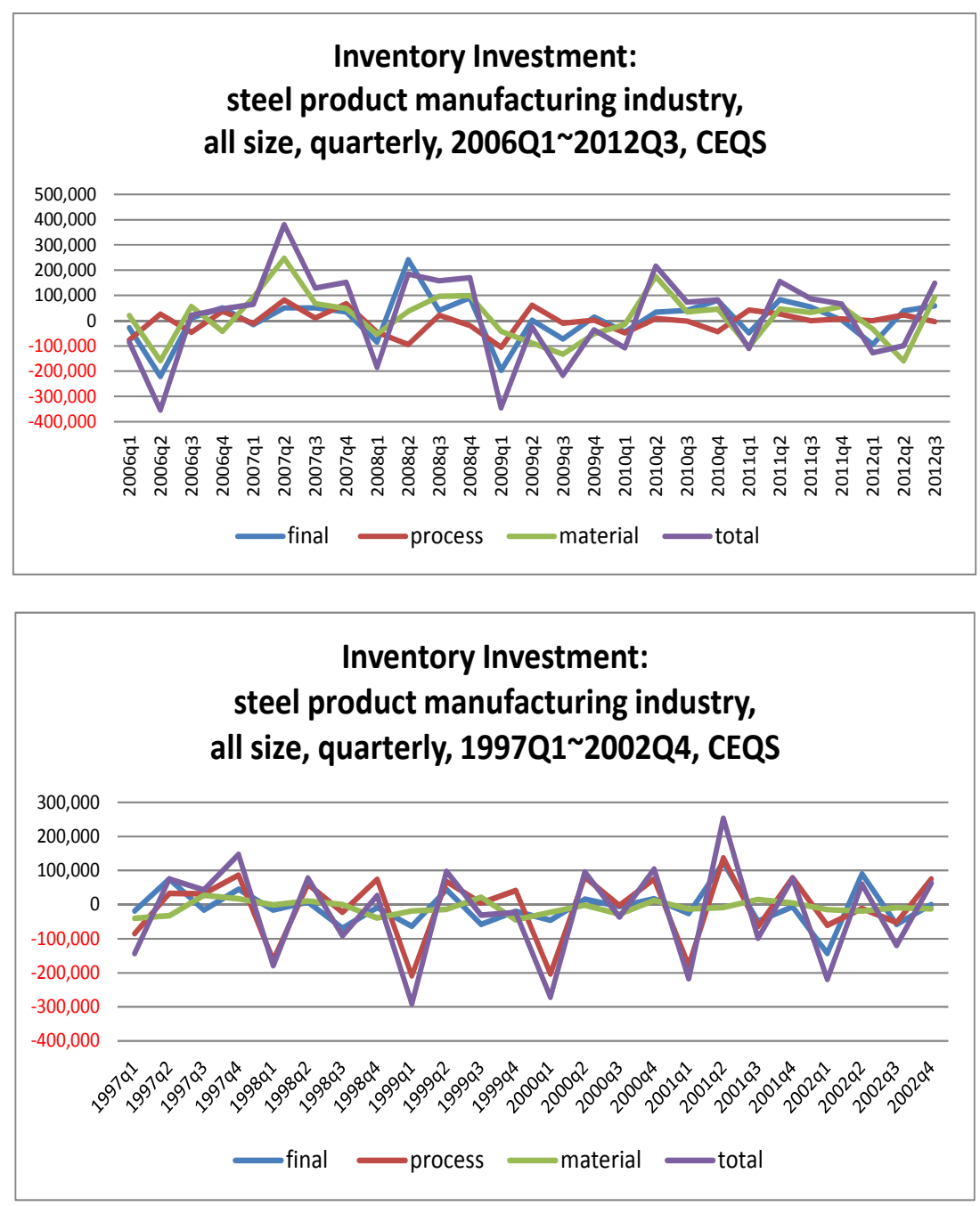

In steel manufacturing industry, raw material inventory had occupied $35 \%$ of the total inventory stock, which rose to more than mid- $40 \%$ level recently. Product inventory occupied more than 30\%, and goods-in-process inventory decreased from more than $30 \%$ to less than $20 \%$. The ratio of inventory stock to the total assets had been more than $10 \%$, which began to rise since mid-2000, reaching $15 \%$ recently.

Inventory stock value decreased from 3 trillion yen to 2 trillion yen, and again increased to more than 3 trillion yen recently. Inventory investment in 2009Q1 recorded -300 billion yen, corresponding to 10\% of inventory stock, and -300 billion yen in 1998Q1 corresponds to $15 \%$.

Before the year of 2000 we observe fairly clear regular seasonal fluctuations, but after that we find some disarray in regularity. 
Inventory investment in 2008Q4 was not particularly large, whose absolute value was by far smaller than that of corresponding negative value in 2009Q1. During the period around Lehman Shock neither notable inventory stock accumulation nor subsequent stock adjustment process was observed. The same applies to the period of "Financial Crisis" since 1997Q4.

Including 2011Q2, just after the Great East Japan Earthquake, in any shock periods we find no notable inventory accumulation.

\section{Industrial Machinery Manufacturing}

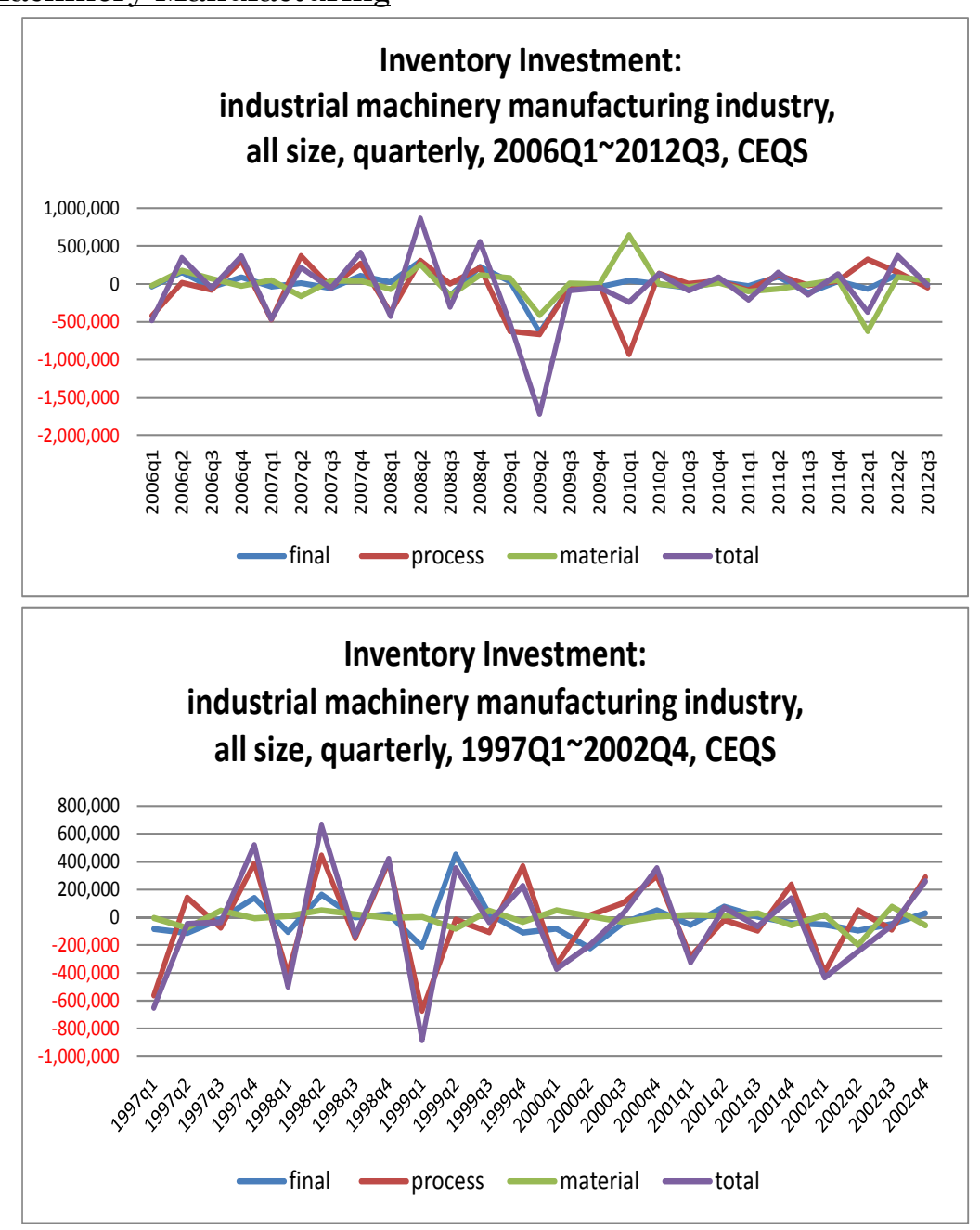

In industrial machinery manufacturing industry, goods-in-process inventory consistently occupied more than 50\% of the total inventory stock, although after 2010 it decreased to mid-30\%, returning to the former level recently. The share of product inventory decreased from more than $30 \%$ to more than $20 \%$ and again rose to $25 \%$ recently. That of raw material inventory remained stable at less than $20 \%$, with the exception of less than $40 \%$ in $2010-2011$. The ratio of inventory stock to the total assets 
has been more than $10 \%$.

Inventory stock value underwent a lot of changes between 3 trillion yen and 6 trillion yen. Inventory investment in 2009Q2 recorded -1.7 trillion yen, which corresponds to 30\% of 6 trillion yen, inventory stock value of 2008Q4 (previous peak). -910 billion yen in 1999 Q 1 corresponds to $20 \%$ of the inventory stock value at the same period.

We observe a regular seasonal fluctuation consistently, although sometimes fluctuation range changes remarkably. Fluctuation range does not necessarily expand during shock periods.

No remarkable inventory investment increase in 2008Q4 was observed, and it recorded a large negative value in 2009Q1. Neither during the period around Lehman Shock nor around the "Financial Crisis" we find remarkable inventory stock accumulation or subsequent stock adjustment process. No such phenomenon was observed after the Great East Japan Earthquake.

Automobile and Automotive Parts Manufacturing

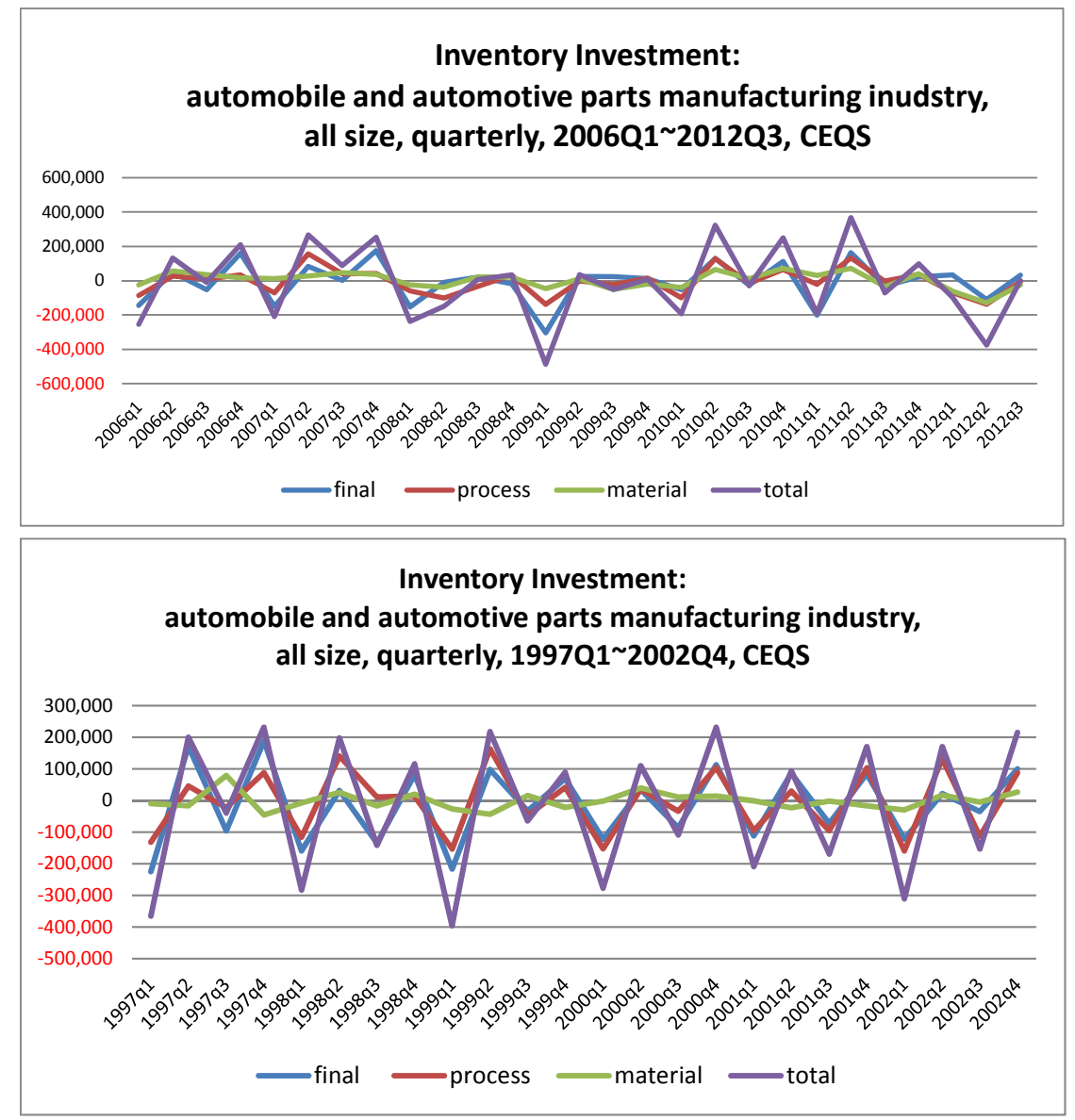

In automobile and automotive parts manufacturing industry, the share of 
goods-in-process inventory to the total inventory stock rose around 2000 from mid-30\% to more than $40 \%$, and remained less than $40 \%$ since then. The share of product inventory decreased gradually from less than 50\%, and since 2000 remained stable at $40 \%$. That of raw material inventory rose from less than $20 \%$ to more than $20 \%$ in mid-2000, further rising to less than $30 \%$. The ratio of inventory stock to the total assets decreased from $7 \sim 8 \%$ to $5 \%$ and became stable.

Inventory stock value consistently reports 25 trillion yen, of which 500 billion yen, the absolute value of inventory investment both in 2007Q2 and 2009Q1, corresponds to $2 \%$, and 400 billion yen, its maximum absolute value during the period around 2000 , less than $2 \%$.

We consistently observe a regular seasonal fluctuation with stable fluctuation range.

We observe no remarkable inventory investment increase in 2008Q4, but its big negative value in 2009Q1. Neither during the period around Lehman Shock nor around the "Financial Crisis" we find remarkable inventory stock accumulation or subsequent stock adjustment process. No such phenomenon was observed after the Great East Japan Earthquake.

\section{$\underline{\text { Construction }^{48}}$}

48 In CEQS the inventory stock value of construction industry was slightly less than 40 trillion yen in the first half of 1990s, which has decreased to the recent level of its one-third. In SNA, therefore in quarterly GDP estimates, construction (commodity number: 59) consistently records 0 for total inventory investment, and therefore goods-in-process inventory investment. In SNA, inventory investment value is estimated through commodity-flow method as changes in inventory stock value, and goods-in-process stock in construction industry, like still-in-construction buildings, are mostly included in fixed capital formation. As mentioned in [6] the inventory stock value of all manufacturing industry in the first half of 1990 in CEQS was 40 trillion yen, almost equivalent to that of construction industry of the time. 

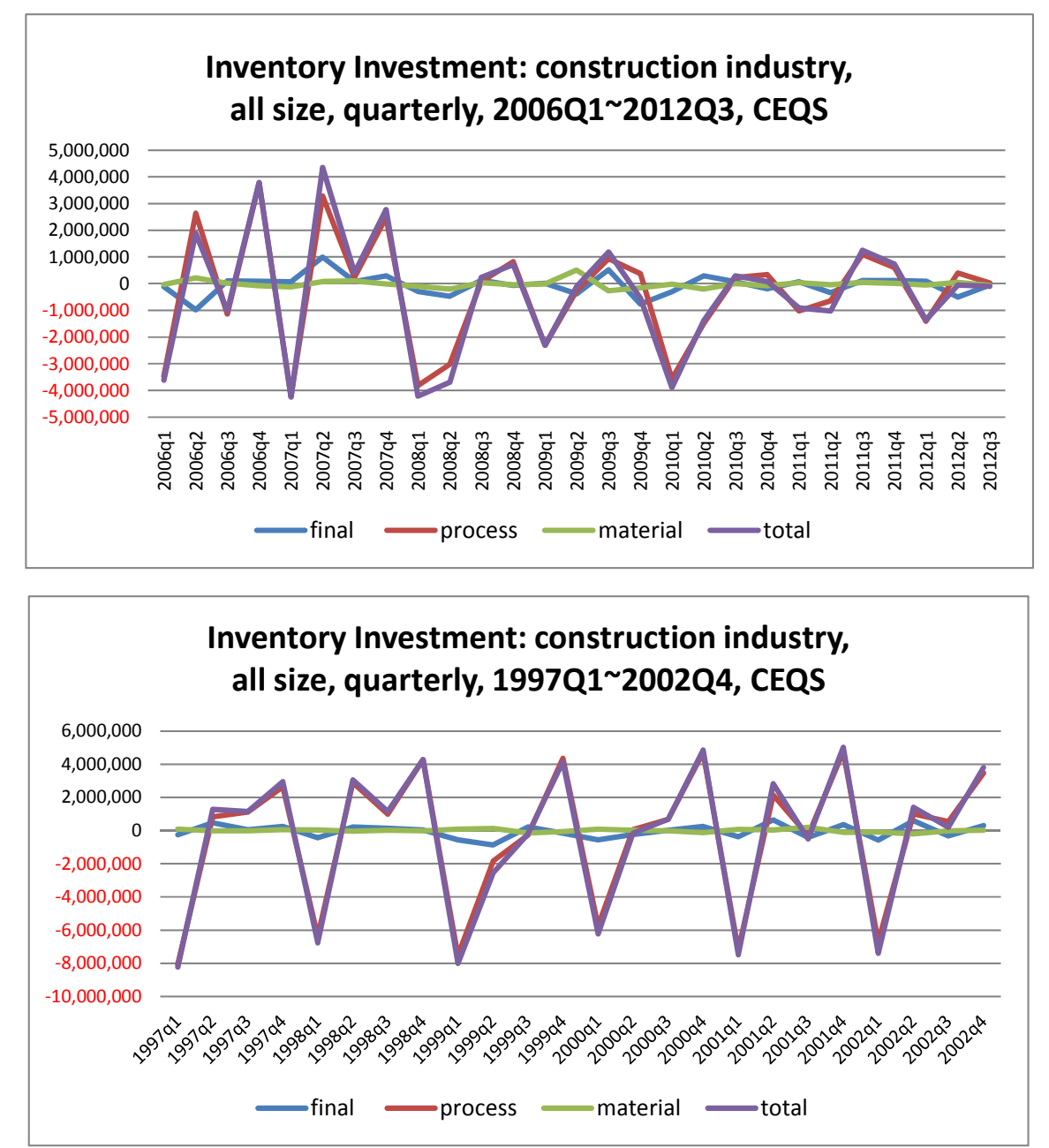

In construction industry, goods-in-process inventory occupied $80 \%$ of the total inventory stock, and raw material inventory $16 \sim 17 \%$. The ratio of inventory stock to the total assets has consistently decreased from $30 \%$ to the recent value of $15 \%$.

8 trillion yen, the maximum absolute value of inventory investment in the second half of the 1990s, corresponds to $25 \%$ of more than 30 trillion yen, the inventory stock value of the time. Although in the second half of the 2000s the maximum absolute value decreased to 4 trillion yen, the ratio did not decrease as the inventory stock value became less than 15 trillion yen.

As a whole we observe a consistent and clear declining trend in inventory stock value, on which we observe an M-shaped regular seasonal fluctuation. The decline trend became more impressive since 2008.

We observe no remarkable inventory investment increase in 2008Q4, but its big negative value in 2009Q1. Neither during the period around Lehman Shock nor around the "Financial Crisis" we find remarkable inventory stock accumulation or subsequent stock adjustment process. No such phenomenon was observed after the 
Great East Japan Earthquake.

[9-3]. METI's Indices of Industrial Production Forecast and BOJ's Tankan Annual Projections

Sections [7] and [8] studied Japanese firm's inventory investment behavior, focusing on the consequence of exogenous shocks and subsequent stock adjustment process, like the Japanese economy under an unexpected situation with rapid and drastic demand decline after the Lehman Shock. The conclusions of the study raise serious questions on the validity of the leading view that exogenous shocks like unexpected situations are effective explanation for observed wild fluctuations in quarterly inventory investment.

Readers would be surprised at the conclusions, together both with the previous conclusions about regular seasonal fluctuation in quarterly GDP statistics summarized in [6] and the observation from Indices of Industrial Production reported in [2] that monthly indices of shipment and production behave in unison. Some would be confronted with following puzzle: "How long will it take for producers to recognize such a sudden demand decline, to determine countermeasures upon managerial judgment drawn from newly collected information about its size and duration, and coordinating actions both with sections inside the firm and with contracting partners? It must take a fairly long time to effectively enforce appropriate countermeasures in production. How such prompt responses are feasible? Is it actually possible to enforce them effectively?" 49

As reference materials for studying this puzzle, [9-3] reports the investigation results of METI's (Ministry of Economy, Trade, and Industry) Indices of Industrial Production Forecast and BOJ's (Bank of Japan) Tankan (Short-term Economic Survey of Enterprises in Japan) "annual projections", focusing on the revision process in production- or business plans during the period after shocks.

Indices of Industrial Production Forecast surveys 195 commodities from Manufacturing Industry Production Forecasting Survey. It is a monthly survey of firms selected from large producers in decreasing order of production volume to the cumulative total of $80 \%$ in each commodity under survey. At the end of every month it surveys the actual production of previous month, the production plan for the present month, and the production plan for the next month, whose deadline is the $10^{\text {th }}$ of the present month, and the response rate $100 \% .{ }^{50}$

49 Some readers may wonder: "The basic assumption that it was an unexpected situation is further away from the mark?"

50 For more details, see the METI's Homepage. 
I report here two figures on the whole manufacturing sector, for $2008 \sim$ Nov. 2011.

The first shows the actual production (hereafter, Actual), production plan for the present month (Present), and production plan for the next month (Next) of each month. For example, on the vertical direction on 200901 (January 2009) readers find three values: Next reported on 10 December 2008, Present reported on 10 January 2009, and Actual reported on 10 February 2009.

Until February 2009 when production decreased drastically, Present was slightly higher than Actual, and Next higher than Present, in some cases more than 10\% higher. Even after Actual reversing a downward trend, it took a month for Present to reverse the trend, and more for Next. ${ }^{51}$

Two points are particularly important. First, Two indices of production plan (Present and Next) began to decrease immediately when the actual production index (Actual) began to decrease. Second, along such a rapid and drastic production decrease process, three production indices did not significantly deviate. Those points suggest that production plans are appropriately formulated and flexibly revised even on monthly base.

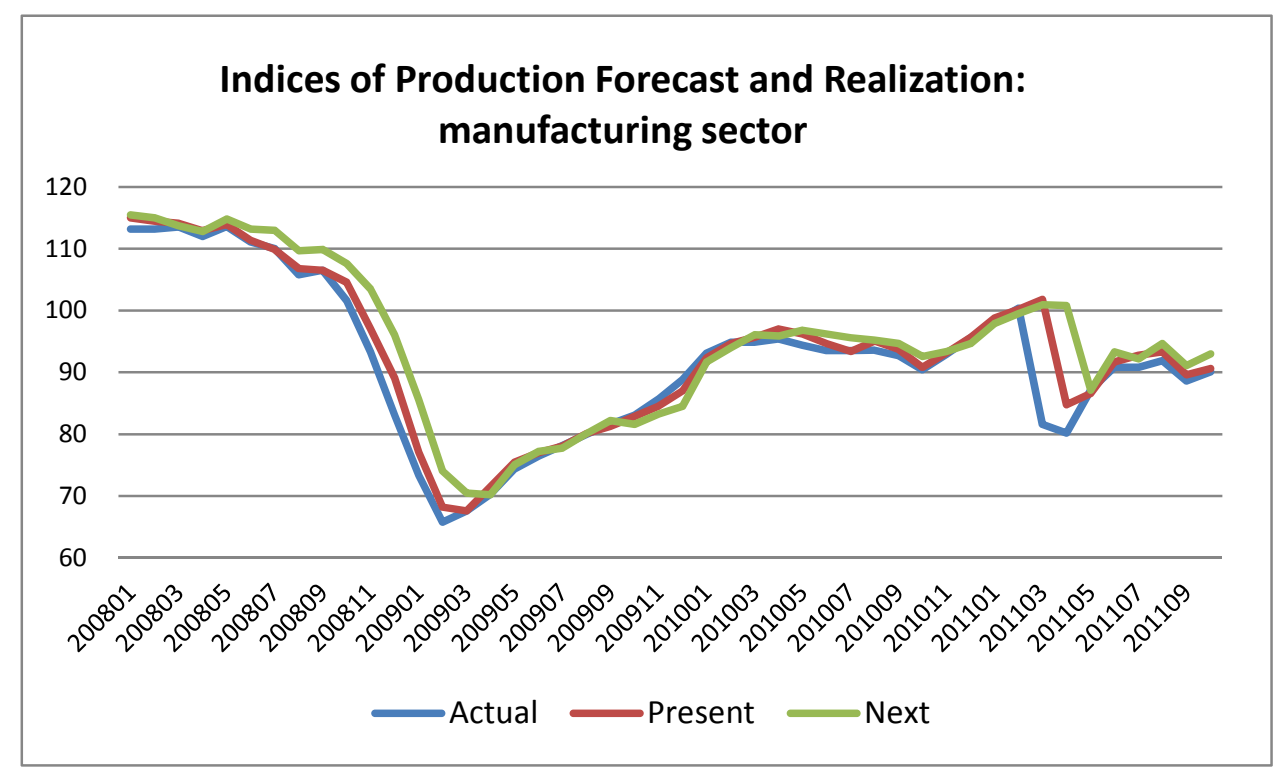

The next figure illustrates the degree of attainment of Next, for which I obtained three indices: rate of forecast revision $(\mathrm{RFR})=($ Present-Next $) / \mathrm{Next} * 100$, degree of attainment $(\mathrm{DA})=($ Actual - Present $) / \mathrm{Next} * 100$, and degree of attainment 2

51 With the Earthquake in March 2011, production decreased drastically particularly in March and April, the influence of which is reflected in Present and Next in one or two months later. 
$($ DA2 $)=($ Actual - Next $) /$ Next*100 $(=$ RFR+DA $)$.

During the period after Lehman Shock, DA reported -7\%, the largest absolute value, in January 2009, and DA2 reported -15\% in March 2009 when DA -3\%. Not only during the period of drastic demand decrease but also after the reversion of declining trend, all the indices recorded negative values, that is, Present and Next remained below Actual. Moreover, Next was revised to more pessimistic Present, which was still optimistic than Actual. In this sense, production plans are flexibly revised even on monthly base, but not sufficiently accurate.

The absolute values of those indices after the Great East Japan Earthquake exceeded the maximum absolute values after the Lehman Shock.

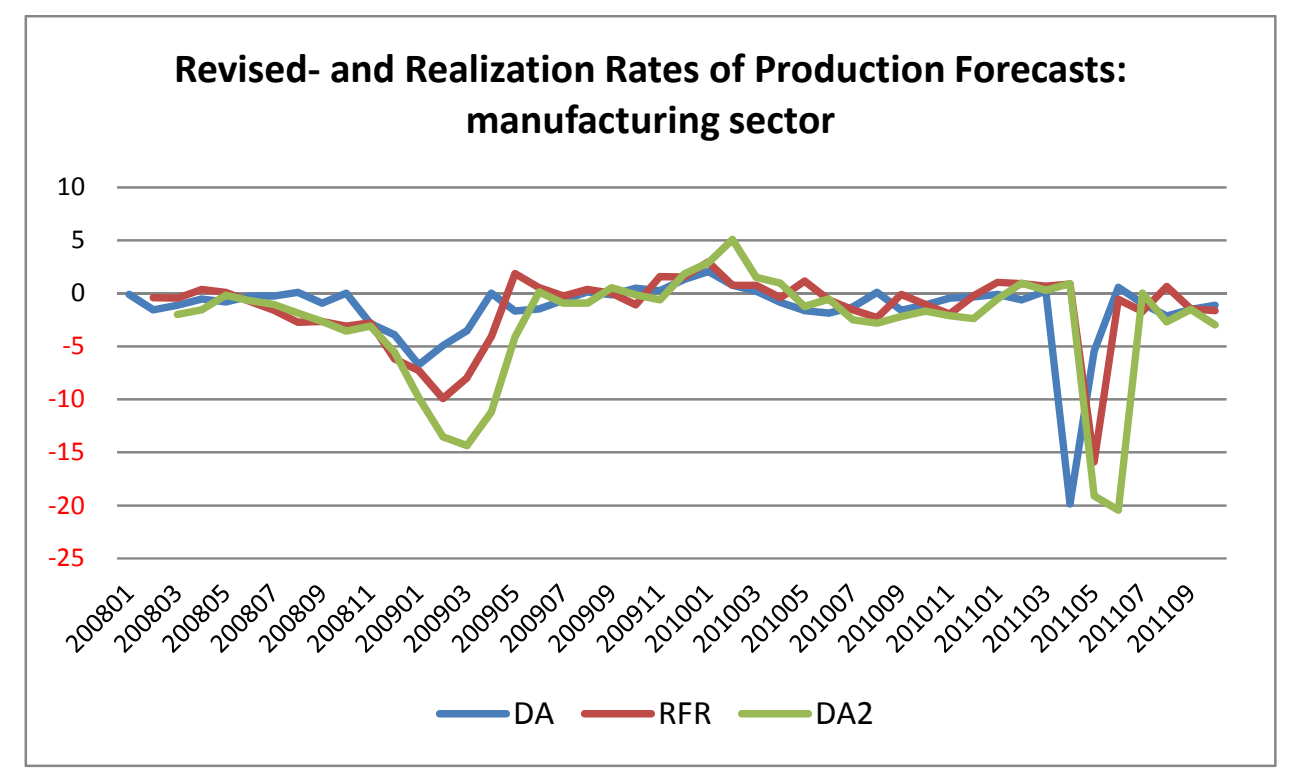

Next, I report from the study of BOJ's Tankan "annual projections". BOJ's

Tankan is a quarterly survey on more than 10,000 firms, conducted in June, September, December and March of the next year, of which "annual projections" is a part. I use here annual sales projections, for which, dividing a year (actually fiscal year beginning in April) into two periods, from April to September ( $1^{\text {st }}$ half year) and from October to next year's March (2nd half year), it surveys production plans (projections) six times in total. For example, on the sales projections for the $1^{\text {st }}$ half year of FY(fiscal year)2008, it surveys in March, June, September, December of 2008 and March and June of 2009. The March survey is conducted in February and March, and called the March issue.

Here I focus on the 4,500 firms in the manufacturing sector. Firms are divided into 3 categories by the size of paid-in capital: large firms with more than 1 billion yen, medium sized firms with 100 million- 1billion yen, and small firms with 20 million- 100 million yen. For each three category and all firms, I create indices for 
change in sales projections or actual sales on year-over-year basis (\%). 52

Two points are of our primary concern: At what time sales projections are revised in such a turbulent period as the Lehman Shock?; and is there any difference by firm size in the timing and revision range?

Next figure shows the result focusing on the $2^{\text {nd }}$ half of FY2008 which is the only place we find notable revision during the period around Lehman Shock.

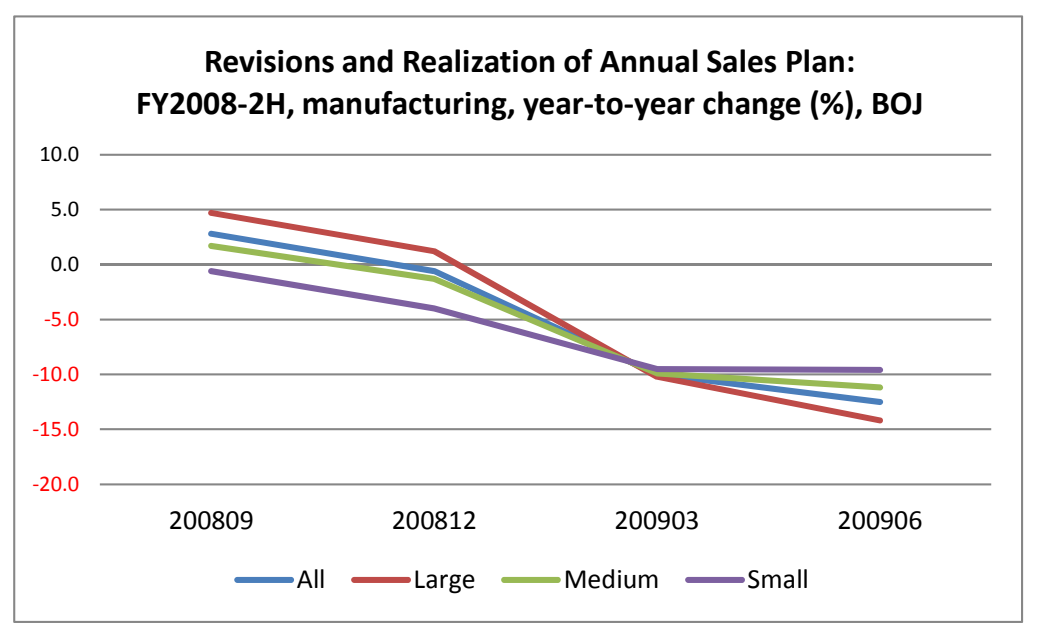

Annual sales projections for the $2^{\text {nd }}$ half of FY2008 began to drastically decrease in December survey, accelerated in the March (of 2009, the end of the fiscal year) survey, and further revised downward in June survey. Comparison with the above mentioned monthly Indices of Industrial Production, it tells that projection revision developed in parallel with actual production. Indices by firms size tells that in smaller firms the rate of production decline was smaller and the start of projection revision earlier. ${ }^{53}$

[10]. Implications

Quarterly SNA inventory statistics, both in estimating process and substance, is diverse across countries

Using Japanese data, this study investigates the inventory investment of Japanese firms and industries and related observations. Obviously, the conclusions are involved directly in the Japanese phenomena during the period under study. Nonetheless, the content and conclusions of this study would have important implications in multiple research issues in many countries outside Japan, including

52 For more information, see FAQ Explanations on BOJ's Homepage.

53 Note that Indices of Industrial Production and Indices of Production Forecast are commodity-based, and BOJ's Tankan is firm-based. 
inventory investment related statistics and phenomena, the relationship between inventory investment- and macroeconomic fluctuations, and the effectiveness of monetary policy.

The statistics generation, both in the choice in estimation method and in the content, is subjected to various restrictions, particularly that of the source statistics availability including the timing of their availability. The quarterly GDP inventory investment estimates in Japan, the principal examination object of this study, is no exception. Particularly, in countries other than Japan, quarterly SNA statistics produced in response to strong demand emphasizing promptness, including "changes in inventories" or inventory investment, seem to be estimated under constraints stricter than Japan. Either in or outside Japan, inventory investment estimates and researches using them have rarely been closely examined, focusing even on the biases and tics they might include, through tracing back to source statistics and their uses.

OECD [2012, p.14] explains that only eleven OECD countries utilize enterprise surveys in estimating "changes in inventories", only part of which are allowed to use both monthly- and quarterly statistics as the situation demands, like in Japan where together with Census of Manufacturers (annual) as the basic framework, quarterly statistics like Corporate Enterprise Quarterly Statistics and monthly Indices of Industrial Production (IIP) based on Current Survey of Production are all available. For example, seven countries "derive total stock change as a residual by deducting all other components of final expenditure from total GDP". Therefore, OECD offers a caution: "If applied uncritically, all errors in other estimates accumulate in the estimate for changes in inventories." 54

Now many readers are careful enough not to rivet their eyes on the relationship between wild fluctuations in quarterly SNA inventory investment data and macroeconomic fluctuations, without careful examination of accurate correspondence and deviations between various statistics like "inventory investment estimates" and the reality of inventory stock or inventory investment behavior. ${ }^{55}$

For inventory investment data estimation, Japan is an ideal OECD country,

54 For more details, see Table 7. Change in Inventories: Summary of sources used (pp.31-32). OECD [2012] is the current version of the document first published in 1979. 55 They would argue: We have to carefully check the accuracy in correspondence of the results therefore the objects of the study to its original targets and objectives, concerning the researches based on problem setting like "Is inventory fluctuation pro-cyclical or counter-cyclical?" or "How long is the cycle duration? Isn't the inventory cycle a synthetic form of multiple cycles with different wavelengths?" Many inventory cycle studies use a long-term quarterly time series data, primarily paying attention to the correlation validity. Obviously, correlation is different from causality. 
with generous source statistics availability. ${ }^{56}$ I do not argue that the conclusions of this research, drawn from the Japanese quarterly GDP inventory statistics, directly apply to studies in other countries. I do not argue that a similar situation or more serious situations are present (and left unnoticed and untouched) in many countries, either. I believe, however, many readers recognize that they will stimulate the interest both in the study of inventory data in other countries focusing on its estimation process and source statistics, and in the great variety of inventory investment. It is my hope that pretty soon comparative investigation over relevant information from many countries becomes feasible.

This research investigated both the inventory investment behavior of Japanese firms and related statistics, covering multiple areas such as estimation methods and actual content of statistics, notes and restrictions in its use, and use of related studies. The conclusions raise important issues including those for reexamination of previous studies and reconstruction of relevant statistics, from the problem setting for inventory investment research to the examination and use of their results. A proposal of this research mentioned in [9-1] suggests a future direction: In investigating the reality of inventory investment and the fluctuations generating mechanisms where promptness is inessential, we should switch focus from the quarterly GDP estimates to the annual SNA estimates, and make active use of micro-based source statistics like IIP and Corporate Enterprise Statistics.

\section{diverse content of inventory stock and inventory investment}

Both the study of Japanese quarterly GDP inventory investment estimates and the investigation of the consequence and subsequent inventory stock adjustment in Japan expected to occur in response to a large exogenous shock after the Lehman Shock raise strong doubts at least concerning Japan on the validity of assumption that inventory investment fluctuation is a major cause of macroeconomic fluctuation. This conclusion has important implications both for the evaluation of previous studies on inventory investment and its fluctuation and for the direction of relevant future studies.

The intensity and magnitude of fluctuations in quarterly GDP inventory investment estimates has not accurately reflected the actual inventory investment fluctuation. Instead, it has vastly overstated the actual fluctuations, and moreover both

56 Readers still sympathizing with the conventional view of the Japanese economy that has had a strong preference to emphasize its special and idiosyncratic features might overlook the conclusions with smile, arguing that "it must be a part of its idiosyncrasy." For readers who feel at odds with the conventional view of the Japanese economy or are interested in another view, see Miwa and Ramseyer [2006]. 
the direction of included deviations and its degrees are unclear. Focusing on this, many researchers would recognize that the importance of investigation on inventory investment behavior and its fluctuation primarily based on quarterly SNA inventory statistics would decrease significantly. At least, growing interest would be directed to the substance of related statistics and the search for alternative sources of appropriate information. 57

Fluctuation in goods-in-process inventory investment is dominant in wild fluctuation in quarterly GDP inventory investment statistics, which disappears in annual GDP inventory investment statistics almost completely. In annual statistics, the influence of goods-in-process inventory investment radically decreases, and instead that of distribution- and raw material inventory investment become dominant. When researchers switch the focus of examination from quarterly- to annual estimates, both the basic image of inventory investment and the study objectives will accordingly change, switching the focus of attention from goods-in-process- (and product-) to distribution- and raw material inventory investment.

Raw material inventory stock in SNA statistics is not the value of raw material stock held by manufacturers of the commodity in question, but the value of stock of commodity in question held as raw material inventory stock by its users. ${ }^{58}$ For this reason, either for distribution- or raw material inventory stock, enterprise surveys on production and inventory focusing on manufacturers which are widely used in many countries, such as Census of Manufacturers and Indices of Industrial Production in Japan and Survey of Current Business in the U.S., cannot be directly used.

For example, Feldstein and Auerbach [1976] investigated "the behavior of inventories in durable-manufacturing industries, the most volatile components of business inventories", focusing on "the real value both of finished-goods inventories and of the inventories of purchased materials and goods in process" (p.352). On this research

57 In many countries, like in Japan, overwhelmingly strong demand for quick supply of quarterly SNA statistics including inventory investment estimates might have a powerful effect on the statistics-making process. It seems a good choice not to excessively emphasize the association with the quick (or preliminary) estimates at the time of obtaining quarterly final (revised) estimates, and also to make effort in improving the accuracy in quick estimates. Unless placing special emphasis on the prompt report, researchers should take the annual estimates as basic materials, and in using quarterly estimates strongly keep in mind that they are the products under extremely severe constraints including the availability of source statistics.

58 For example, raw material inventory stock of steel product in SNA statistics is not the raw material inventory stock of iron-ore and coal held by steel manufacturers but steel product held by automobile manufacturers and construction companies as material stock for their economic activities. 
design, in addition to above mentioned issue of choice in the materials and focus of study, from observations in Japan after the Lehman Shock this paper raises a question about the validity of assumed judgment that inventory investment in durable-manufacturing industries is "the most volatile components of business inventories". 59

\section{further implications...}

Together with the conclusion that the quarterly GDP estimates overemphasize the inventory investment fluctuations, the study of exogenous shocks, focusing on the situation after Lehman Shock, on the inventory stock accumulation as a consequence and subsequent adjustment process have important implications on multiple fronts. What follows is a part.

The conclusions have an impact of the basic understanding and studies on the market function and its "imperfections". A leading theory argues: Unexpected shocks and errors in prediction result in vast amount and value of inventory stock accumulation, for which long-term adjustment process follow; these processes has been a major cause of wild macroeconomic fluctuations. The conclusion of this study raises a serious doubt to this theory, suggesting that it overemphasizes the "imperfections" in the market's supply-demand adjustment function. ${ }^{60}$

This study of inventory investment and related statistics might have a big impact on the debates over the effectiveness of monetary policy, including the one over "financial accelerator". The Fall 1995 issue of Journal of Economic Perspectives featured articles on Monetary Transmission Mechanism. Following Introduction (Mishkin, 1995) and Taylor [1995], Bernanke et al [1995, p.27] write at the opening: "Most economists would agree that, at least in the short run, monetary policy can significantly influence the course of the real economy. ... There is far less agreement, however, about exactly how monetary policy exerts its influence: the same research that has established that changes in monetary policy are eventually followed by changes in output is largely silent about what happens in the interim. To a great extent, empirical

59 Although the importance and the researchers' interest might decrease, as a research topic the significance of inventory investment behavior studies, and as its part estimation of inventory investment function, will not disappear. On this point, see Section [12] of this paper.

60 At the opening of "Price Adjustment in the Long Run" in "Chapter 16. Money and Business Cycles II: Sticky Prices and Nominal Wage Rates", Barro[2008, p.397] writes: "Our analysis of the new Keynesian model applies in the short run, when we do not allow for adjustments in the prices, $\mathrm{P}(j)$, set by each firm $j$. In the longer run, the prices adjust, and these adjustments tend to undo the real effects from a change in the nominal quantity of money, M." The conclusion of this study gives an answer to a familiar question: "How long is 'the long run'?" 
analysis of the effects of monetary policy has treated the monetary transmission mechanism itself as a 'black box.".

From the long-term debate over various issues, I focus on the following point on "financial accelerator". ${ }^{61}$ Blinder and Maccini [1991, p.82] points: "[L]ittle influence of real interest rates on inventory investment can be found empirically.” To this, Kashyap et al [1994], examining the inventory investment behaviors in the US manufacturing sector during 1981-1982 recession, refute that monetary policy had effect through effect on inventory investment by small businesses. This argument, by way of researches including Gertler and Gilchrist [1994], developed to Bernanke et al [1996, 1999]. The latter, "The Financial Accelerator in a Quantitative Business Cycle Framework" in Handbook of Macroeconomics, Volume 1, declares at the opening (p.1343)62: "The principal objective ... is to show that credit-market imperfections can be incorporated into standard macroeconomic models in a relatively straightforward yet rigorous way".

Bernanke et al [1996] write at the opening: "The 'small shocks, large cycles' puzzle motivates our paper" (p.1), and argue that "credit-market imperfections", exerting serious impact discriminatorily on small businesses, have grave impact on inventory investment behavior, particularly of small businesses. They continue: "We refer to the amplification of initial shocks brought about by changes in credit-market conditions as the financial accelerator."

The "imperfections" and constraints in financial market have been debated actively, using such various expressions as credit-market imperfections, liquidity constraint, and financing-constraint. However, little has been achieved empirically in related studies, many readers recognizing the problems "largely unsolved"(Blanchard, 2009, p.216). ${ }^{63}$

61 About "the monetary transmission mechanism: the process through which monetary policy decisions are transmitted into changes in real GDP and inflation", Taylor [1995, p.11] in the same issue writes at the opening: "There are, of course, many different views of the monetary transmission mechanism. These views differ in the emphasis they place on money, credit, interest rates, exchange rates, asset prices or the role of commercial banks and other financial institutions." On the situation after the Lehman Shock, he comments (pp.41-42): "In the recent crisis, many have viewed the reduction in credit flows as more systemic than the interest rate changes because certain credit markets did freeze up, but there is still little empirical evidence supporting this view." 62 This article begins: "The canonical real business cycle model and the textbook Keynesian IS-LM model differ in many fundamental ways. However, these two standard frameworks for macroeconomic analysis do share one strong implication: Except for the term structure of real interest rates, which, together with expectations of future payouts, determines real asset prices, in these models conditions in financial and credit markets do not affect the real economy."

63 For more details on this point, see Miwa [2013, pp.205-6, notes 6, 7]. The argument 
Even if a leading argument on credit-market imperfections is theoretically valid, the empirical conclusions of this research raise strong doubts on the effectiveness of financial accelerator theory. ${ }^{64}$

\section{[11]. Conclusion}

Knowledge is not like a stock or ore, sitting there waiting to be mined. It is an extremely heterogeneous assortment of information in continuous flux. Only a small part of it is of any use to someone at a particular point of time, and it takes effort and resources to access, retrieve, and adapt it to one's own use. ... A major aspect of learning is that the unknown keeps expanding as we learn. This should be looked at positively. It is much better this way --- especially for those of us who are engaged in research" (Griliches, 1994, pp.16, 18).

The above commentary of Professor Zvi Griliches, from his presidential address to the American Economic Association, entitled "Productivity, R\&D, and the Data Constraints", in January 1994, applies directly to macro-economic fluctuations, inventory investment, firm behavior, and the market functions.

Readers may have a negative image with this research, strongly impressed by examining critically and raising grave and destructive questions to the conventional wisdom about the macro-economic fluctuations, particularly inventory investment fluctuations, inventory investment, firm behavior, and the market functions. Nonetheless, not a few readers would strongly recognize the importance of the liberation from the restraint and spell of wrong conventional wisdom, I believe.

For more than half a century, inventory investment has attracted wide

since Kashyap et al [1994] emphasizing the credit-market imperfections assumes that small businesses under severe constraints on the access to capital markets like CP market are particularly vulnerable to restrictive monetary policy. Using firm-level-data on Japanese business firm's financing behavior, Miwa [2012] draws three conclusions: (1) The ratio of bank borrowings to total assets has been in every firm size category by far lower than the conventional wisdom assumes; (2) Particularly the ratio further decreased remarkably since the 2000 s under the "quantity easing zero-interest rate" monetary policy; (3) The ratio has been the lower, the smaller the firm size category. For example, recently in the smallest firm size category with paid-in capital from 10 million yen to 20 million yen, the share of small businesses with zero short-term borrowing from financial institutions is at the level of two thirds. For the reality in detail of small business financing that has been emphasized to be under severe financing constraints, see Miwa [2011].

64 Also on the cause of the rapid world trade contraction after Lehman Shock, often called the Great Trade Collapse, a leading view emphasize the role of inventories. 
attention of macroeconomists as a major cause of short-term macroeconomic fluctuations. Studies of past quarterly data often conclude that too high or too low inventory stock took on average 8 or 12 quarters for adjustment, and repeatedly the processes and mechanisms involved have become the focus of many major studies. Emphasizing the long-lasting adjustment process for resolving accumulated inventory stock (in fact of not so big size), many conclude that "the market adjustment does not work so quickly as many economists assume, and its supply-demand adjustment is not so effective and efficient." Yet microeconomists and business people familiar with corporate behavior have frequently expressed misgivings about the enterprise.

Going into the data estimation process and source statistics, this research investigated the quarterly SNA (GDP) inventory investment statistics on which most inventory studies primarily depend. From two perspectives this research investigated for 1994-2010 the inventory investment statistics and inventory investment behavior in Japanese industries, the conclusions of which raise grave doubts on the leading view of inventory investment research.

Even among OECD countries, quarterly SNA inventory investment statistics varies widely both its availability and the substance in estimation method and source statistics, which also varies at different periods. In addition, like the two quick estimates and two final estimates in Japan, often there are more than one set of quarterly SNA estimates. For this reason, in this paper I focus on the $1^{\text {st }}$ final estimates of Japan during the period after adopting 93SNA, and hope for comparable study results on other countries.

Japan during this period is an ideal OECD country for quarterly SNA inventory investment statistics, with generous source statistics availability and well-established estimation method. For this research I am allowed to use estimates both by commodity and by inventory category that are obtained as intermediate product for quarterly SNA inventory investment estimates. In addition, in Japan various inventory-investment-related information is available as complimentary materials.

A leading basic view of inventory investment that it fluctuates wildly is widely accepted, which forms the common basis for research on inventory investment behavior. The first subject of the study is the examination, going into the data estimation process and source statistics, of inventory investment statistics, focusing on the causes of fluctuations. The conclusion of the first study subject raises a grave doubt on the validity of this basic view: A dominant portion of wild fluctuation we observe in quarterly GDP inventory investment statistics is due to its estimation process and source statistics, and at least in Japan the quarterly GDP inventory investment 
statistics does not accurately report the reality of inventory investment behavior. From this, I conclude: In investigating the reality of inventory investment and the fluctuations generating mechanisms where promptness is inessential, we should switch focus from the quarterly GDP estimates to the annual SNA estimates, and make active use of micro-based source statistics like IIP and Corporate Enterprise Statistics.

The conclusion of the first study subject raises a strong doubt on the validity of a leading basic view of inventory investment behavior. As the second study subject, I examine the validity of this basic view through a detailed case study. Focusing on the Japanese economy during the period after Lehman Shock in the fall of 2008, I closely investigated the inventory stock accumulation and subsequent inventory stock adjustment process the leading view strongly expected to occur in response to a rapid and drastic demand decline, an unexpected exogenous shock. Even in such a situation where the most serious consequence must have occurred, little inventory stock accumulation was observed in many industries and the industry as a whole, and no remarkable fluctuations to be regarded as its adjustment process was found, either. Those results also raise serious doubts on the leading basic view of inventory investment that it fluctuates wildly. This conclusion is consistent both with an alternative view of inventory investment as part of rational corporate behavior and with observations drawn from micro-based source statistics.

The conclusions of this research, drawn from the Japanese quarterly GDP inventory statistics, will stimulate the interest both in the study of inventory data in other countries focusing on its estimation process and source statistics, and in the great variety of inventory investment. At the same time, the conclusions pose a serious doubt on the validity of the basic view of inventory investment that it wildly fluctuates, leading to its re-examination. The conclusions pose a grave implication not only for re-evaluation of the literature in inventory investment variations but also for other research topics in macroeconomics like monetary transmission mechanisms including "financial accelerator" theory. "This should be looked at positively. It is much better this way --- especially for those of us who are engaged in research" (Griliches).

[12]. (Appendix): Inventory Investment Decision-making Process, Inventory Investment Function, and Data Availability Constraint

With wild fluctuations, particularly with huge share of fluctuations in GDP in contrast to a tiny fraction of its size in GDP, quarterly SNA (GDP) inventory investment statistics has attracted wide attention among economists and business people as a 
major cause of violent macroeconomic fluctuations. The conclusions of this research, that fluctuations in quarterly SNA inventory investment statistics has not appropriately and accurately corresponded to the reality of inventory investment and that inventory stock accumulation and its subsequent stock adjustment due to exogenous shocks and prediction failures have been significantly smaller than the conventional wisdom assumes, will decrease not only in Japan but also all over the world the interest in studies on the reality of inventory investment fluctuations and mechanisms involved. The research direction and objectives might experience a major change as well.

Notwithstanding, interest on the inventory investment decision-making mechanism, and on specification and estimation of inventory investment function will never disappear. It is indispensable to constructing econometric macro-models.

Although not within the agenda of this research, for reference materials for those future challenges, in [12] I record related points I found on the way of this research, at the end illustrating a risk of neglecting the influence of regular seasonal fluctuations I emphasized.

\section{Whose inventory and what category of inventory?}

There is a wide range of variations in inventory, inventory stock, or inventory investment. Even if it may be useful for simplicity, it will incur a tremendous cost to assume that the same mechanism for all inventory and study the decision making mechanism in representative inventory investment behavior formulation. I might be more serious in inventory investment function than in equipment investment function.

Either for annual- or quarterly SNA (GDP) statistics, inventory investment value is estimated, by four categories of raw material-, goods-in-process-, product-, and distribution inventory, respectively, with different method and from different source statistics. ${ }^{65}$ In addition, principal decision-making agent of inventory investment varies greatly, by industry and commodity, by time period, and by inventory investment category. Facing a considerable diversity in inventory, both specifying and estimating the inventory investment function must proceed with difficulty. Neglecting the diversity will be risky and incur a huge cost.

The influence of goods-in-process inventory investment fluctuations is overwhelming in quarterly GDP inventory investment statistics, which almost entirely

65 The estimation method adopted in the US seems basically not to be different. For the US method on inventory estimation, see p.7-6 of GDP estimation manual of URL (http://www.bea.gov/national/pdf/NIPAhandbookch7.pdf). As in Japan it is estimated by 4 categories. 
disappears in annual statistics. In annual statistics, the fluctuations in total inventory investment by themselves decrease remarkably, where distribution- and raw material inventory become dominant. Distribution inventory primarily held by distribution firms and goods-in-process by manufacturers are basically different in decision-making firms and also in decision-making mechanisms. ${ }^{66}$

\section{Who makes decisions? How interests of firms are coordinated?}

Researcher will face a tough challenge of how to deal with the cooperation- and rivalry relations among firms involved.

No one would deny the basic framework to analyze the inventory investment and its fluctuations as part of optimizing behavior of rational decision-making agents. However, each industry is composed of multi-stages (manufacturing- and distribution process, respectively, is usually multistage), and also is mutually interdependent and works closely with neighboring industries. Even under severe constraints of data availability, many researchers feel odd as excessively simplified assumption about a basic choice to explain inventory investment fluctuations (in macro-data) as a consequence of specific agents' (quite often, an agent's) optimizing behavior.

For example, many manufacturers of automobile, auto parts, raw material, and production equipment, together with many distributors, transportation-, and finance companies, participate in the automobile production-distribution process. Suppose the total automobile inventory investment optimization problem. Who plays the leading role in this optimization decision making? How it is enforced, coordinating the interests of participants involved? Typically an auto parts manufacturer trade with multiple automobile manufacturers. The same holds for trades between auto parts- and materials manufacturers, and automobile manufacturers and production equipment manufacturers. An automobile dealer does not always trade with an automobile manufacturer.

Obviously, it incurs a huge cost for an automobile manufacturer to enforce its "optimization policy" to pursue its own maximum profit, neglecting the interests of auto parts- and materials manufacturers and distributors. Even if an automobile manufacturer tries its best in coordinating the interests of various firms included, its

66 Ramey and West [1999, p.887] make a short comment, entitling "3.4. Whose inventories?": "Indeed, a large fraction of the inventory literature focuses on manufacturers' finished goods inventories, often in six two-digit industries that are known as 'production to stock'. To some, in fact, the model is not a particularly attractive one for studying any other types of inventories [e.g., Blinder and Maccini (1991)]." 
decision on such a vastly complicated problem like the one of centralized planned economy will not be blessedly accepted by most participants. The one finally reached will be significantly different from the solution of a single agent's optimization problem.

This research used the quarterly GDP inventory investment statistics by 4 inventory categories and by 91 commodities, with which I could focus on some aspects of the interdependent relations on the production-distribution process. As part of the results, I find that the influence of goods-in-process inventory is overwhelming in quarterly inventory investment statistics, while that of distribution stock is dominant in annual statistics. Notwithstanding, no effective measure to investigate such following issues are not available, yet: Who are the leading decision makers?; How the interests of firms involved are coordinated?; and What actually occur on the spot? For an effective challenge in studying the inventory investment decision making mechanisms and in specifying and estimating inventory investment function, researchers need to prepare themselves for the possibility of encountering and struggling with those difficulties.

\section{A tragic comedy?: consequence of neglecting regular seasonal fluctuation}

Last of all, I illustrate a picture, a situation like a tragic comedy that will result as a consequence of neglecting regular seasonal fluctuations. Suppose that a researcher estimates an inventory investment function on the basis of a view that inventory stock level is adjusted so as to maintain a constant ratio of shipment value (or inventory stock works closely with shipment value).

Next figure shows the all industries' quarter-over-quarter change in nominal shipment value (diffnsales: real shipment value is unavailable), from Q1 to Q4 separately. We find a similar kind of regular seasonal fluctuations like in inventory investment shown above in [5]. 


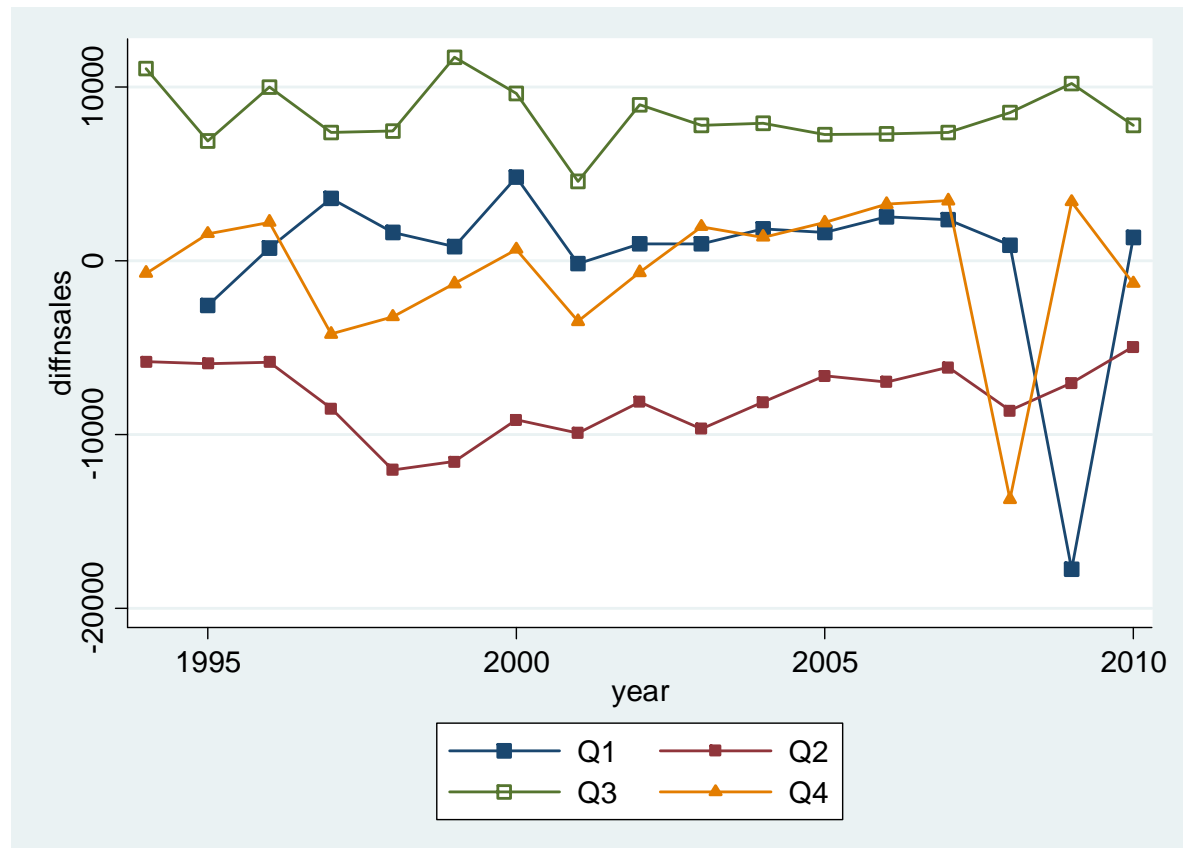

Note the relative positions of each quarter's line, which is different from the inventory investment's lines. The brown line almost always at the bottom indicates the Q2 estimates, the green line on the top the Q3, the blue line and the khaki line both at the middle the Q1 and Q4, respectively. With the exception of the values in 2008Q4 and 2009Q1, the relative positions remain extremely stable, implying that there is a clear and stable regular seasonal fluctuation.

Suppose calculate the coefficients of correlation between diffnsales and rtotal, including lagged variables, neglecting the existence of regular seasonal fluctuations. Due to strong influence of regular seasonal fluctuations, we expect to find statistically significant coefficients, with sign reversals depending on the choice in lag-structure.

Next three figures shows the scattered diagrams for rtotal on the vertical axis and diffnsales on the horizontal axis, and the first figure for no-lags, the second for -1 lag for diffnsales (L.diffnsales), and the third for +1 lag for diffnsales (F.diffnsales). Readers who argue the forward-looking behavior of firms might be satisfied with the result of the third figure. 


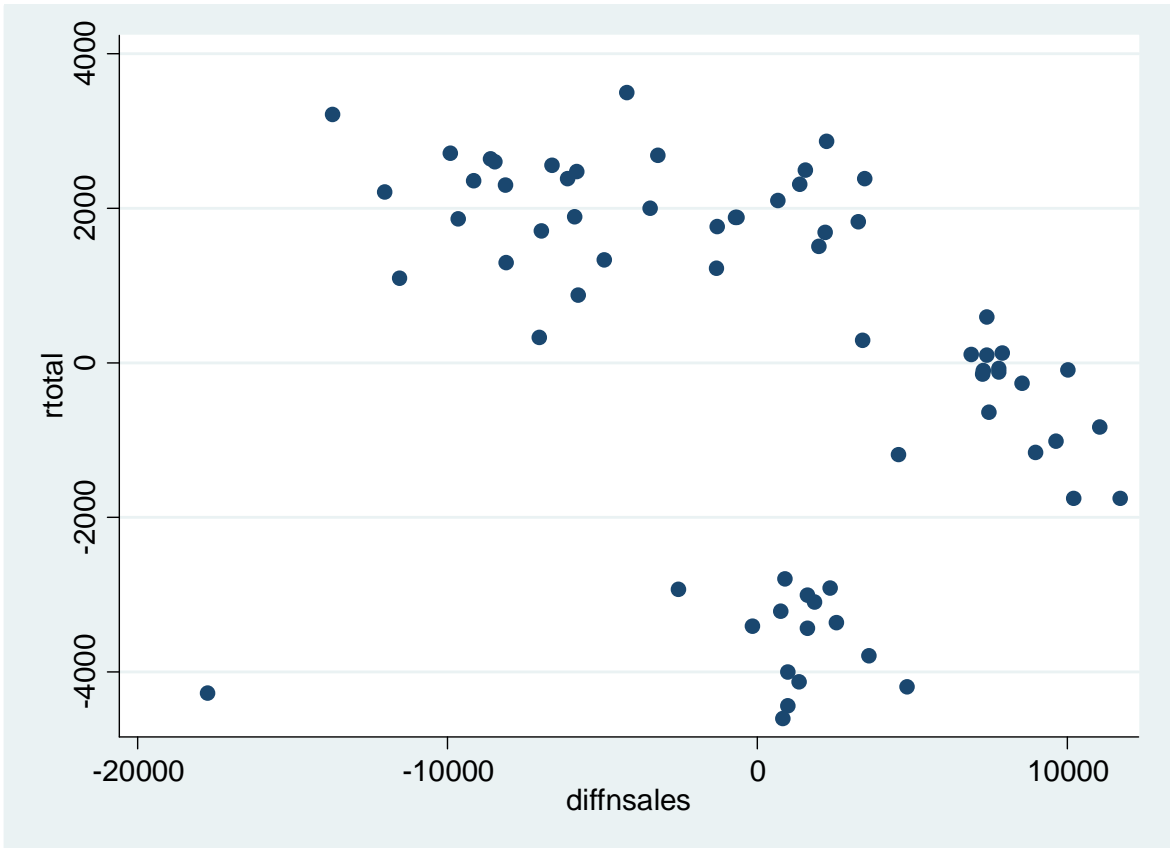

As expected, with diffnsales we find a negative correlation. The correlation coefficient is $\rho=-0.3621$.

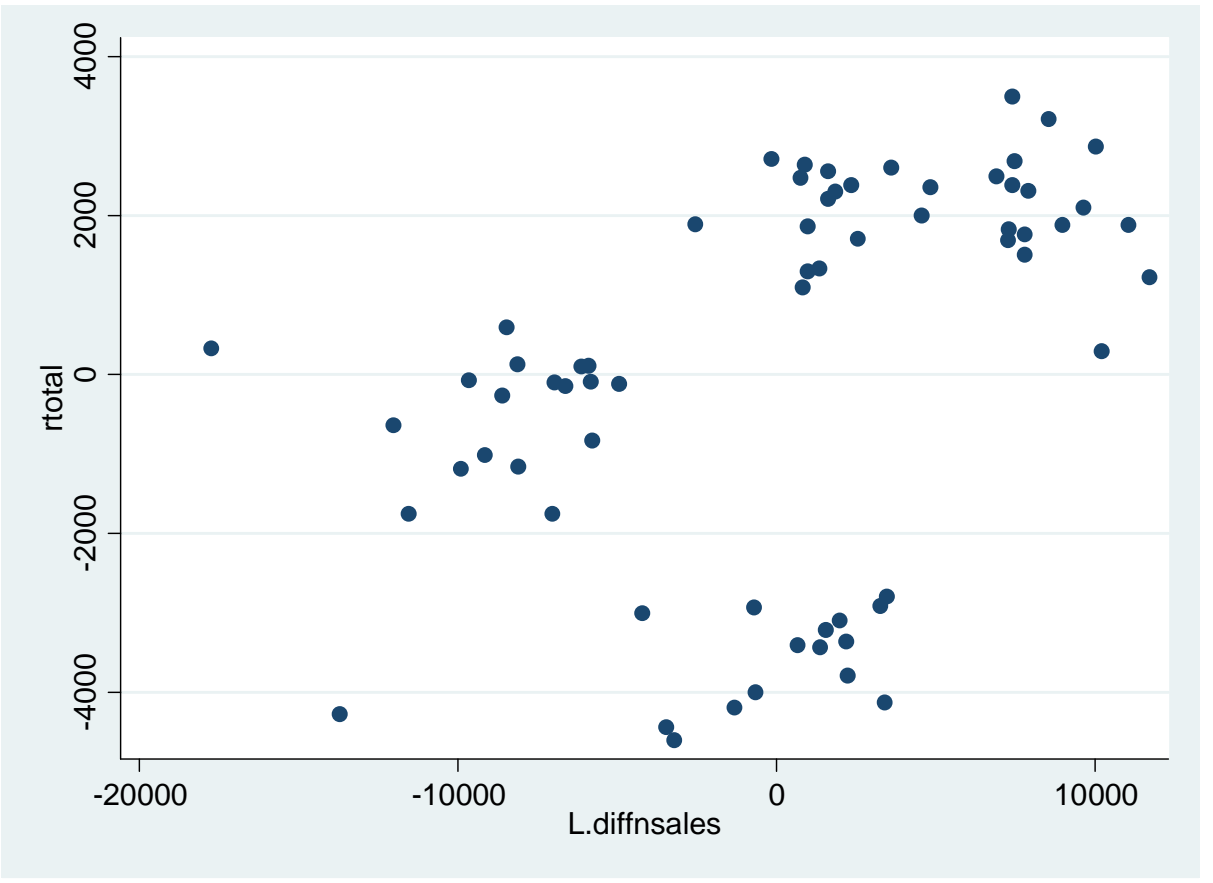

As expected, with L.diffnsales we find a positive correlation. The correlation coefficient is $\rho=0.4206$. Some readers might think that firms tend to replenish inventory stock with one quarter lag. 


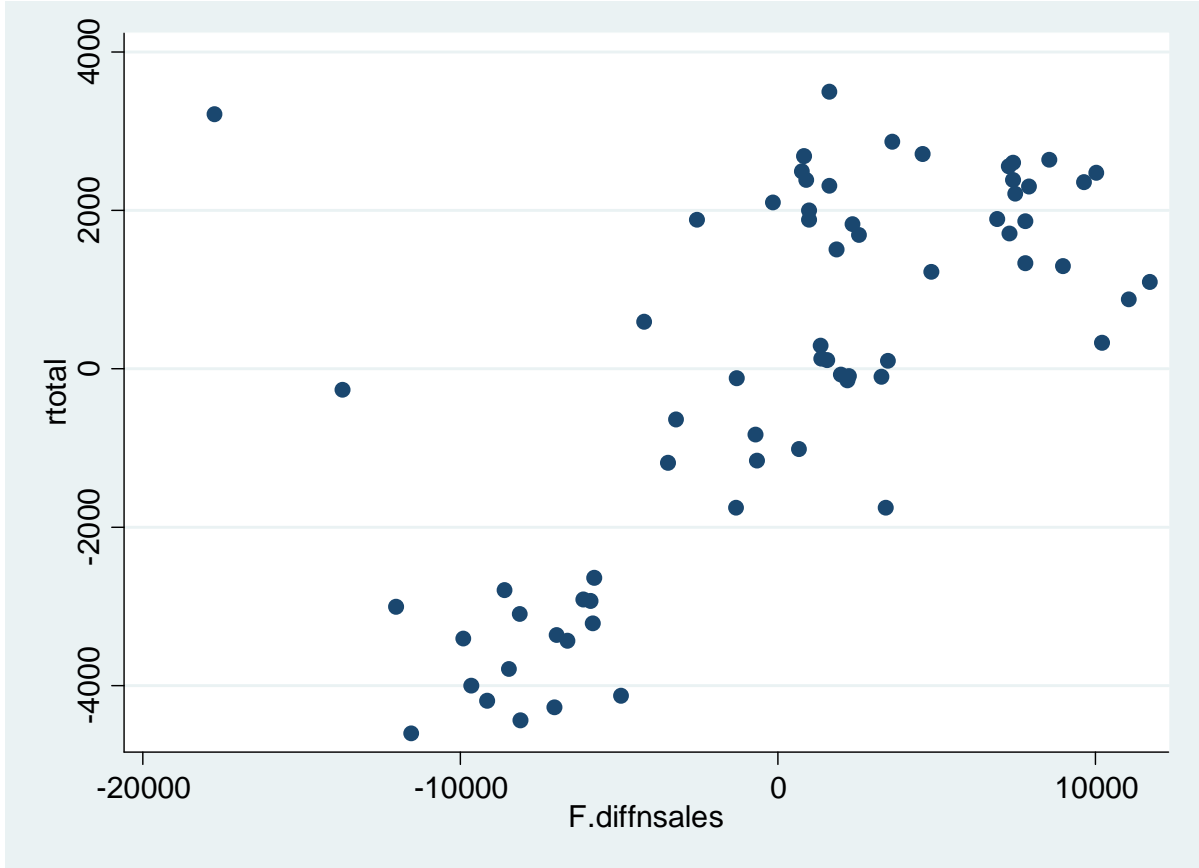

Among the 3 cases, the correlation coefficient is the highest in this case with F.diffnsales, with positive sign, $\rho=0.6799$. Some readers who argue the forward-looking behavior of firms might be very much satisfied with the result. The t-value of the regression coefficient in a simple regression is 7.48 , and adj. $\mathrm{R}^{2}=0.4541$.

Replacing the vertical axis variable to Rrtotal (revised rtotal), three correlation coefficients become $-0.0991,0.1869$, and 0.0937. As expected, all coefficients are statistically insignificant.

Next figure shows the all industries revised quarter-over-quarter change in nominal shipment value, Rdiffnsales, from Q1 to Q4. Rdiffnsales is obtained by subtracting its average quarterly value from estimates in each quarter, as in [5]. 


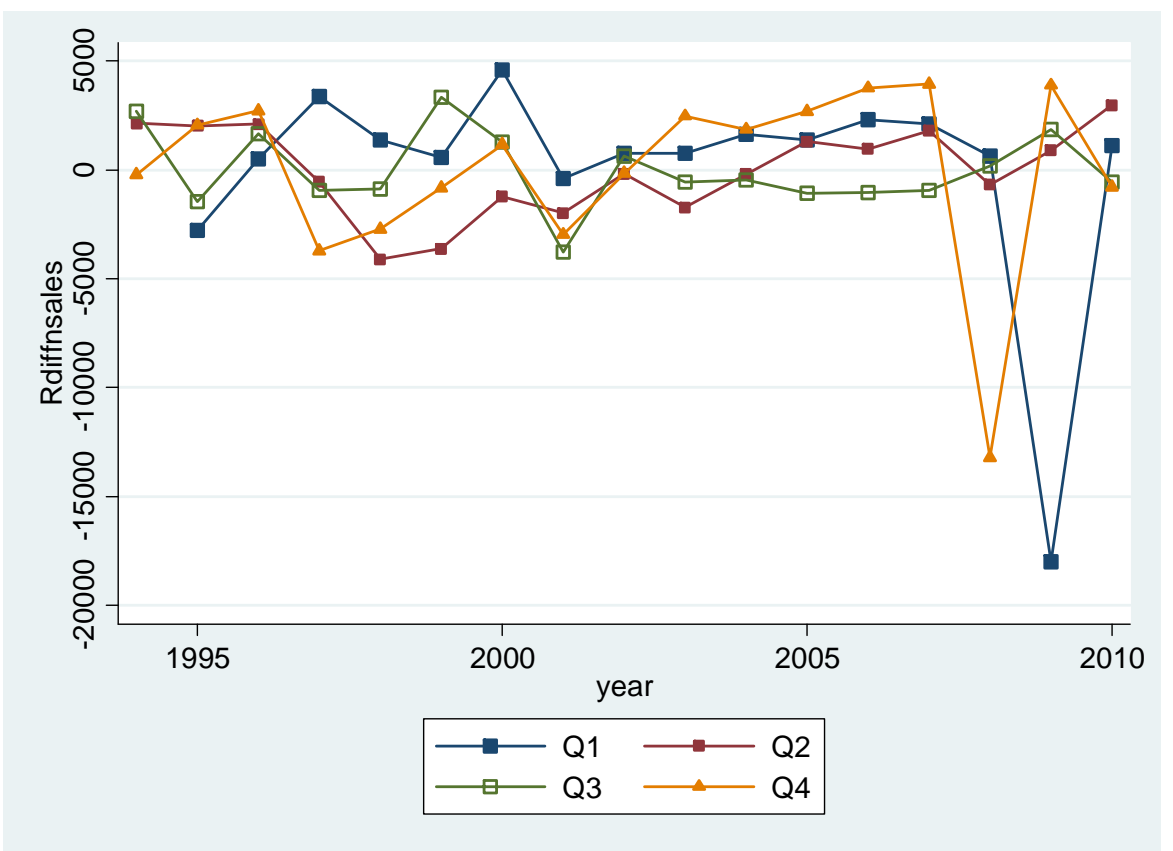

Three correlation coefficients between rtotal (as in the first three cases) and Rdiffnsales with lag of $0,-1$, and +1 are $-0.0550,0.0961,-0.0528$, respectively. As expected, all coefficients are statistically insignificant.

Last of all, three correlation coefficients between Rrtotal and Rdiffnsales with lag of $0,-1$, and +1 are $-0.1943,0.3644,-0.1853$, respectively. Now the second one with -1 lag is statistically significant, with positive sign. Replacing lags $(-1,+1)$ with $(-2,+2)$, the absolute values to the correlation coefficients increase to 0.3709 and -0.2319 , respectively.

Nobody hopes to see this kind of study report to appear, particularly emphasizing the first three cases, I believe.

\section{Reference:}

Abramovitz, Moses [1950] Inventories and Business Cycles, National Bureau of Economic Research.

Baldwin, Richard. ed. [2009] Great Trade Collapse: Causes, Consequences and Prospects, A VoxEU.org Publications: Geneva (CEPR).

Barro, Robert J. [2008] Macroeconomics: A Modern Approach, Thomson South-Western. Bernanke, Ben S. [1993] "Credit and the Macroeconomy," Federal Reserve Bank of New York Quarterly Review, XVIII, pp.50-70.

Bernanke, Ben S. and Mark Gertler, "Inside the Black Box: The Credit Channel of Monetary Policy Transmission", 9-4, Autumn.

Bernanke, Ben S., Mark Gertler, and Simon Gilchrist [1996] "The Financial 
Acceleration and the Flight to Quality", Review of Economics and Statistics, Feb. pp.1 15.

Bernanke, Ben S., Mark Gertler, and Simon Gilchrist [1999] "The Financial Accelerator in a Quantitative Business Cycle Framework," J. B. Taylor and M. Woodford eds., Handbook of Macroeconomics, Volume 1, pp.1341-1393, Elsevier Science B.V.

Blanchard, Olivier [2009] "The State of Macro", Annual Review of Economics, 1, pp.209-28.

Blinder, Alan S. and Louis J. Maccini [1991] "Taking Stock: A Critical Assessment of Recent Research on Inventories," Journal of Economic Perspectives, 5-1, Winter, pp.73-96.

Feldstein, Martin and Alan Auerbach [1976] "Inventory Behavior in Durable-Goods Manufacturing: The Target-Adjustment Model”, Brooking Papers in Economic Activity, 2, pp.351-86.

Gertler, Mark and Simon Gilchrist [1994] "Monetary Policy, Business cycles, and the behavior of small manufacturing firms" QJE, pp.309-340

Griliches, Zvi [1994] "Productivity, R\&D, and the Data Constraints," American Economic Review, 84-1, pp.1-23.

Kashyap, Anil, Owen A. Lamont, and Jeremy C. Stein [1994] "Credit conditions and the cyclical behavior of inventories," QJE, August, pp.565-592

Kunitomo, Naoto [2001] "Use of Seasonal Adjustment Method X-12-ARIMA (2000) Case of Corporate Enterprise Statistics" Keizaigaku ronshu (The Journal of Economics of the University of Tokyo), 67-3, pp.2-29 (in Japanese).

Kunitomo, Naoto [2006] "Commentary: Seasonal Adjustment Methods" in Minotani, Nawata, and Wago eds. Handbook of Econometrics, pp.452-466, Asakura-shoten (in Japanese).

Metzler Lloyd A. [1941] "The Nature and Stability of Inventory Cycles," Review of Economic Statistics, vol.23, August.

Mishkin, Frederic S. [1995] "Symposium on the Monetary Transmission Mechanism," Journal of Economic Perspectives", 9-4, Autumn.

Miwa, Yoshiro [2011] "The Financing Behavior by Small Firms, and Small-firm Loans by Banks,” Keizaigaku ronshu (The Journal of Economics of the University of Tokyo), 77-1, pp.22-84 (in Japanese).

Miwa, Yoshiro [2012] "Are Japanese Firms Becoming More Independent from Their Banks? Evidence from the Firm-Level Data of the 'Corporate Enterprise Quarterly Statistics, 1994-2009", Public Policy Review (Ministry of Finance, 
Japan), 8-4, October.

Miwa, Yoshiro [2013] "How Strongly Do 'Financing Constraints' Affect Firm Behavior? Japanese Corporate Investment since the Mid-1980s", Public Policy Review (Ministry of Finance, Japan), 9-1, January.

Miwa, Yoshiro and J. Mark Ramseyer [2006] The Fable of the Keiretsu: Urban Legends of the Japanese Economy, The University of Chicago Press.

CAO (Cabinet Office, Government of Japan, Economic and Social Research Institute, Department of National Accounts) [2012] "Estimation Manuals for Quarterly GDP Quick Estimates, $5^{\text {th }}$ edition” (revised in July 2006, in Japanese) (http://www.esri.cao.go.jp/jp/sna/data/reference1/h12/pdf/honbun.pdf)

OECD[2012] "An Overview of Country Practices" in Quarterly National Accounts: $A$ report on the sources and methods used by OECD Member Countries, OECD. http://www.oecd.org/std/nationalaccounts/1919562.pdf

Ramey, Valerie A. and Kenneth D. West [1999] "Inventories," J. B. Taylor and M. Woodford eds., Handbook of Macroeconomics, Volume 1, pp.863-923, Elsevier Science B.V.

Romer, David [2012] Advanced Macroeconomics, McGraw-Hill.

Taylor, John B. [1995] “The Monetary Transmission Mechanism”, Journal of Economic Perspectives, 9-4, Autumn, pp.11-26.

Taylor, John B. [2009] "Defining Systemic Risk Operationally", Kenneth E. Scott, George P. Schultz, and John B. Taylor eds. Ending Government Bailouts: As we know them, Hoover Institution Press.

Wen, Yi [2005] "Understanding the inventory cycle," Journal of Monetary Economics, 52, pp.1533-1555.

Wen, Yi [2011] "Input and Output Inventory Dynamics", American Economic Journal: Macroeconomics, 3 (October), pp.181-212. 